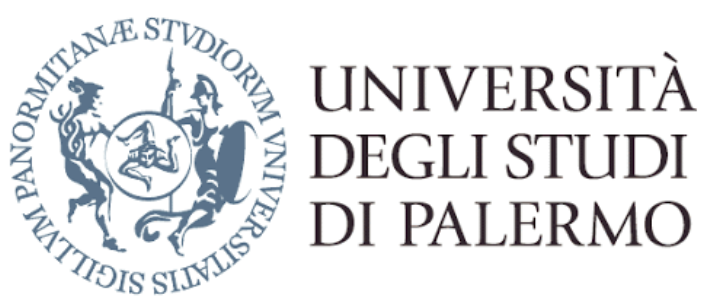

Dottorato in

Mediterranean Biodiversity.

Dipartimento di

Scienze Agrarie Alimentari e Forestali.

AGR 13

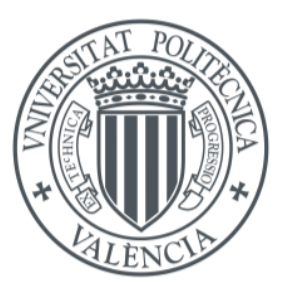

UNIVERSITAT POLITĖCNICA DE VALÈNCIA

Doctorado en

Recursos y Tecnologías Agrícolas

Instituto

Agroforestal Mediterráneo

Sanidad Vegetal y Recursos Naturales

Valorization of Citrus spp. Cultivars cultivated in Sicily for the industrial use of citrus derivatives and

in particular for potential alternative uses of essential oils for the enhancement of the island's citrus production

$\mathrm{PhD}$ STUDENT

Antonino Ioppolo

TUTOR

Prof. Eristanna Palazzolo

CO TUTOR

Prof. Filippo Saiano
COORDINATOR

Prof. Maria Antonietta Germanà

CO TUTOR

Prof. Mercedes Verdeguer Sancho

CO TUTOR

Prof. Carmina Reig Valor

CYCLE XXXII

OCTOBER 2020 



\section{Abstract: Valorization of Citrus spp. cultivars cultivated in Sicily for the industrial use of citrus derivatives andin particular for potential alternative uses of essential oils for the enhancement of the island's citrus production.}

In this doctoral thesis are discussed a series of scientific issues regarding citrus fruits production and processing, species of particular relevance in Sicily and in the Mediterranean area.

Objectives and research activities addressed in this thesis were agreed with the citrus industry "EuroFood" and financed by the research project "PON industrial Ph.D. - a.a. 2016/2017".

The research project was targeted to study the traceability and sustainability of citrus production, and to find new applications to the by-products and waste products of citrus industry with the objective of appreciate and enhance the Sicilian citrus industry.

The following topics are addressed and developed in this thesis:

- Characterization of the bioactive compounds present in essential oils (EOs) and in the hydrolate of different citrus species.

- Monitoring of the effect of controlled water stress on the production of EOs in leaves and flowers of Citrus sinensis (L.) Osbeck cv. 'Sanguinelli' and Citrus $\times$ clementina cv. 'Clemenules';

-Test the phytotoxic effects of citrus EOs on four important weed species in the Mediterranean area, two monocotyledon (Echinochloa crus-galli (L.) P.Beauv. and Avena fatua L.) and two dicotyledon (Amaranthus retroflexus L., and Portulaca oleracea L.) by different experiments in vitro and in greenhouse conditions;

-Evaluation of the effect as natural biostimulants of wastewaters from citrus processing industry by its application on soil microbial community;

-Quantification of rare earth elements in lemon fruits from different geographical areas for its possible use as geochemical tracers applied to lemon production.

Different Citrus EOs have been characterized in this study and it has been verified that the oils produced by the pruning waste could be used for the extraction of EOs with high yields. In addition, nutraceutical and pharmacological substances have been found in the orange industrial hydrolates. 
Industrial lemon EO showed good potential when testing its herbicidal activity. Lemon EO represents a good basis for the development of herbicides of natural origin, biodegradable and eco-friendly.

Thanks to the application of water stress after the winter vegetative restart, a conclusion found was that water stress increased the diameter of the fruit and it was observed that the effects of stress were not immediate on citrus trees, but were evident after some time.

The study of the application of lemon, orange and mandarin hydrolates in the soil, as irrigation water provided the effects on stable and labile soil $\mathrm{C}$ pools, on biomass and microbial activity and on main microbial groups. Overall, hydrolates can play a role in sustainable agriculture because when added to a soil, they improve soil quality and fertility.

The Rare Earth Element model could be used as a tool to connect lemon production to the soil where they were produced, for a possible geographical characterization and a direct link between the production and the territory or soil.

The results obtained were very interesting because:

- they provided the means for sustainable agriculture;

- they increased the value of the by-products and waste products of the citrus industry;

- they proposed applications for the citrus production and transformation cycle being more sustainable;

- they could valorize the Sicilian lemons by linking them to their production area.

These results could have practical repercussions in the production cycle of citrus fruits and give a boost to the Sicilian citrus fruit sector. 


\section{Riassunto: Valorizzazione di cultivar di Citrus spp. coltivate in Sicilia ai fini di una utilizzazione industriale dei derivati agrumari ed in particolare di potenziali usi alternativi degli oli essenziali per un potenziamento delle produzioni agrumicole isolane.}

In questa tesi di dottorato vengono affrontate una serie di tematiche scientifiche riguardanti la produzione e la lavorazione degli agrumi, specie di particolare rilevanza in Sicilia e nell'area mediterranea.

Gli obiettivi e le attività di ricerca affrontate in questa tesi sono stati concordati con l'industria agrumaria "EuroFood" e finanziati dal progetto di ricerca "PON industrial Ph.D. - a.a. 2016/2017". Il progetto di ricerca è stato finalizzato allo studio della tracciabilità e sostenibilità della produzione agrumicola, e della ricerca di nuove applicazioni dei sottoprodotti e dei prodotti di scarto dell'industria agrumaria con l'obiettivo di valorizzarli, per dare un valore aggiunto l'industria agrumaria siciliana.

Gli argomenti affrontati e sviluppati in questa tesi sono:

- Caratterizzazione dei composti bioattivi presenti negli oli essenziali (OE) e nell'idrolato di diverse specie di agrumi.

- Monitoraggio dell'effetto dello stress idrico controllato sulla produzione di OE in foglie e fiori di Citrus sinensis (L.) Osbeck cv. "Sanguinelli" e Citrus $\times$ clementina cv. "Clemenules";

-Testare gli effetti allelopatici degli OE di agrumi, su quattro specie importanti di piante infestanti nell'area mediterranea; due monocotiledoni (Echinochloa crus-galli (L.) P.Beauv. e Avena fatua L.) e due dicotiledoni (Amaranthus retroflexus L. e Portulaca oleracea L.) tramite esperimenti in vitro e in vivo;

-Valutazione dell'effetto sulla comunità microbica del suolo come biostimolanti naturali,delle acque reflue dell'industria di trasformazione degli agrumi mediante la sua applicazione come acque irrigue;

-Quantificazione degli elementi che compongono le terre rare nei frutti di limone, provenienti da diverse aree geografiche, per il loro possibile utilizzo come traccianti geochimici applicati alla produzione dei limoni.

In questo studio sono stati caratterizzati diversi OE di agrumi ed è stato verificato che gli oli prodotti dagli scarti di potatura potrebbero essere utilizzati per l'estrazione di OE con alte rese. 
Inoltre, negli idrolati industriali di arancia sono state trovate sostanze nutraceutiche e farmacologiche.

L'olio essenziale di limone industriale ha mostrato un buon potenziale durante i test della sua attività erbicida. OE di limone rappresenta una buona base per lo sviluppo di erbicidi di origine naturale, biodegradabili ed eco-compatibili. Grazie all'applicazione dello stress idrico controllato dopo la ripresa vegetativa invernale, si è concluso che lo stress ha aumentato il diametro del frutto e si è osservato che gli effetti non erano immediati sugli agrumi, ma erano evidenti dopo un po' di tempo. Lo studio dell'applicazione degli idrolati di limone, arancia e mandarino nel suolo, come acqua di irrigazione, ha fornito gli effetti: sulla quantità di C del suolo stabile e labile e della biomassa; sull'attività microbica e sui principali gruppi microbici. Nel complesso, gli idrolati possono svolgere un ruolo nell'agricoltura sostenibile perché quando aggiunti a un suolo ne migliorano la qualità e la fertilità.

Il modello delle terre rare potrebbe essere utilizzato come strumento per collegare la produzione di limoni al territorio dove sono stati prodotti, per una possibile caratterizzazione geografica e un collegamento diretto tra la produzione e il territorio o suolo.

I risultati ottenuti sono stati molto interessanti perché:

- hanno fornito i mezzi per un'agricoltura sostenibile;

- hanno aumentato il valore dei sottoprodotti e dei prodotti di scarto dell'industria agrumaria;

- hanno proposto applicazioni per il ciclo di produzione e trasformazione degli agrumi più sostenibili;

- potrebbero valorizzare i limoni siciliani legandoli alla loro zona di produzione.

Questi risultati potrebbero avere ripercussioni pratiche nel ciclo produttivo degli agrumi e dare una spinta al settore degli agrumi siciliani. 


\section{Resumen: Valorización de cultivares de Citrus spp. cultivados en Sicilia con el propósito de hacer un uso industrial de los derivados de los cítricos y, en particular, de posibles usos alternativos de los aceites esenciales para potenciar la producción citrícola de la isla.}

En esta Tesis Doctoral se discuten una serie de cuestiones científicas relacionadas con a la producción y el procesamiento de algunas especies de cítricos de especial relevancia en Sicilia y en el área mediterránea.

Los objetivos, acordados previamente con la industria de cítricos "EuroFood" y financiados por el proyecto de investigación "PON Industrial Ph.D. - a.a. 2016/2017", se centran en estudiar la trazabilidad y sostenibilidad de la producción de algunas especies de cítricos, así como encontrar nuevas aplicaciones a los subproductos y productos de desecho de la industria, con el fin de mejorar su rentabilidad. Por lo tanto, los temas que se desarrollarán serán los siguientes: -Caracterización de los compuestos bioactivos presentes en aceites esenciales (AE) y en el hidrolato de diferentes especies de cítricos.

- Seguimiento del efecto del estrés hídrico controlado sobre la producción de AE en hojas y flores del cv. Sanguinelli de Citrus sinensis y del cv. Clemenules de Citrus $\times$ clementina;

- Estudio de los efectos fitotóxicos de los AE en cuatro especies arvenses importantes en el área mediterránea, dos monocotiledóneas (Echinochloa crus-galli (L.) P.Beauv. y Avena fatua L.) y dos dicotiledóneas (Amaranthus retroflexus L. y Portulaca oleracea L.) mediante experimentos in vitro e in vivo;

- Estudio del efecto bioestimulantes de las aguas residuales de la industria procesadora de cítricos sobre la comunidad microbiana del suelo;

-Cuantificación de elementos de tierras raras en frutos de limón cultivados en diferentes áreas geográficas, para su posible uso como trazador geoquímico.

Los principales resultados obtenidos son la caracterización de diferentes $\mathrm{AE}$, de los cuales los producidos por los residuos de la poda podrían ser utilizados como método de extracción de nuevos AE con alto rendimiento. También se han encontrado sustancias nutracéuticas y farmacológicas en los hidrolatos industriales de naranja.

Por otra parte, el AE industrial de limón mostró un buen potencial como agente herbicida, siendo, por tanto, de gran interés en la fabricación de herbicidas de origen natural, biodegradables y ecológicos. 
La aplicación del estrés hídrico controlado después del reposo invernal y, por tanto, en el momento de la brotación incrementó el diámetro final del fruto. La respuesta en el árbol no fue inmediata.

La aplicación de hidrolatos de limón, naranja y mandarina al suelo junto al agua de riego, potenció los depósitos de C contribuyendo a aumentar la biomasa y mejoró la actividad microbiana. Estos resultados ponen de manifiesto el papel que los hidrolatos pueden desempeñar en la agricultura sostenible mejorando la fertilidad del suelo.

Finalmente, el modelo de Elementos de Tierras Raras podría utilizarse como una herramienta de conexión entre la producción de limón y el suelo del que proviene, contribuyendo, de esta manera, a su caracterización geográfica.

En resumen, los resultados obtenidos en esta TD contribuyen a impulsar el sector cítrico siciliano ya que:

- proporcionan medios para una agricultura sostenible;

- aumentan el valor de los subproductos y residuos de la industria;

- proponen aplicaciones para que el ciclo de producción y transformación sea más rentable;

- revalorizan los limones sicilianos vinculándolos a su zona de producción. 


\section{Resum: Valorització de cultivars de Citrus spp. cultivats a Sicília amb el propòsit d'un ús industrial de derivats dels cítrics i, en particular, de possibles usos alternatius dels olis essencials per a potenciar la producció citrícola de l'illa.}

En esta Tesi Doctoral es discutixen una sèrie de qüestions científiques relacionades amb la producció i el processament d'algunes espècies de cítrics d'especial rellevància a Sicília i a l'àrea mediterrània. Els objectius, acordats prèviament amb la indústria de cítrics "EuroFood" i finançats pel projecte d'investigació "PON Industrial Ph.D. - a.a. 2016/2017", es centren en estudiar la traçabilitat i sostenibilitat de la producció d'algunes espècies de cítrics, així com de trobar noves aplicacions als subproductes i productes de rebuig de la indústria, amb el fi de millorar la seua rentabilitat. Per tant, els temes que es desenvoluparan seran els següents:

-caracterització dels compostos bioactius presents en els olis essencials $(\mathrm{OE})$ i en el l'hidrolato de diferents espècies de cítrics.

- Seguiment de l'efecte de l'estrés hídric controlat en la producció d'OE en fulles i flors del cv. Sanguinelli de Citrus sinensis i del cv. Clemenules de Citrus $\times$ clementina;

- Estudi dels efectes fitotòxicos dels $\mathrm{OE}$ de cítrics en quatre espècies arvenses importants en l'àrea mediterrània, dos monocotiledònies (Echinochloa crus-galli (L.) P.Beauv. i Avena fàtua L.) i dos dicotiledònies (Amaranthus retroflexus L. i Portulaca oleracea L.) per mitjà de diferents experiments in vitro i in vivo;

- Estudi de l'efecte bioestimulant de les aigües residuals de la indústria processadora de cítrics sobre la comunitat microbiana del sòl;

-Quantificació d'elements de terres rares en fruits de llima cultivats en diferents àrees geogràfiques, per al seu possible ús com a traçador geoquímic.

Els principals resultats obtinguts són la caracterització de diferents $\mathrm{OE}$, dels quals els produïts pels residus de la poda podrien ser utilitzats com a mètode d'extracció de nous $\mathrm{OE}$ amb alt rendiment. També s'han trobat substàncies nutracéutiques i farmacològiques en els hidrolats industrials de taronja. D'altra banda, l'OE industrial de llima va mostrar un bon potencial com a agent herbicida, sent, per tant, de gran interés en la fabricació d'herbicides d'origen natural, biodegradables i ecològics. L'aplicació de l'estrés hídric controlat després del repòs hivernal i, per tant, en el moment de la brotació va incrementar el diàmetre final del fruit. La resposta en l'arbre no va ser immediata. L'aplicació de hidrolats de llima, taronja i mandarina al sòl amb 
l'aigua de reg, va augmentar els depòsits de carbó (C) contribuint a augmentar la biomassa i va millorar l'activitat microbiana.

Aquests resultats posen de manifest el paper dels hidrolats en l'agricultura sostenible millorant, d'aquesta manera, la fertilitat del sòl. Finalment, el model d'Elements de Terres Rares podria utilitzar-se com una ferramenta d'enllaç entre la producció de llima i el sòl del què prové, contribuint, d'esta manera, a la seua caracterització geogràfica.

En resum, els resultats obtinguts en esta TD contribueixen a impulsar el sector cítric sicilià ja que:

- proporcionen mitjans per a una agricultura sostenible;

- augmenten el valor dels subproductes i residus de la indústria;

- proposen aplicacions perquè el cicle de producció i transformació siga de més rendabilitat;

- revaloritzen les llimes d'origen sicilià vinculant-les a la seua zona de producció. 
Index

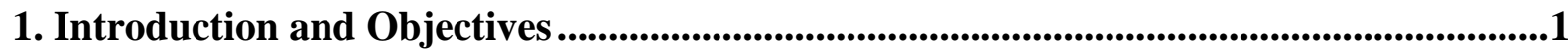

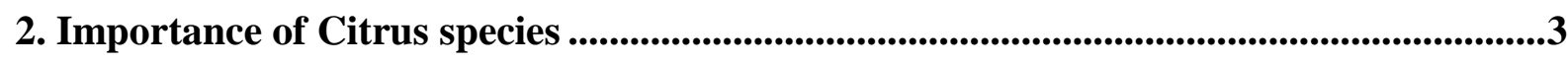

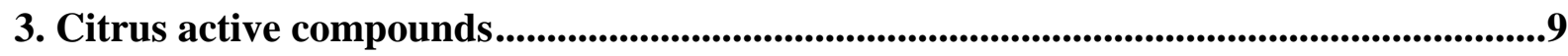

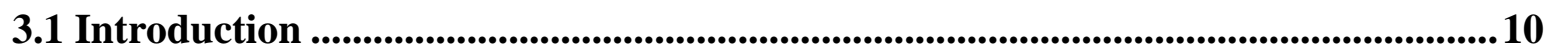

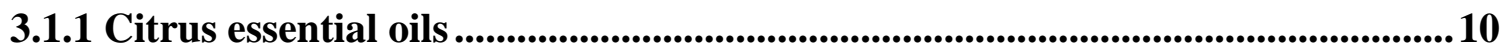

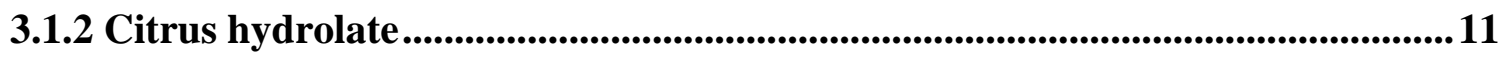

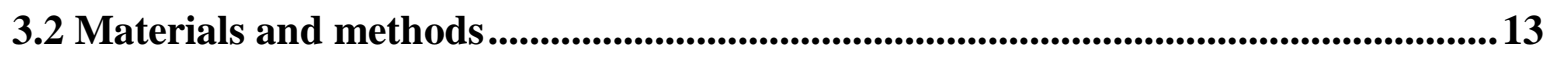

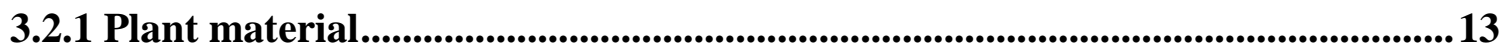

3.2.2 Citrus essential oil extracts ......................................................................14

-Industrial method (FMC Technology) ......................................................14

-Laboratory method (Clevenger Apparatus) .................................................................16

3.2.3 Gas Chromatography-Mass Spectrometry (GC/MS) analysis of EOs and hydrolates............................................................................................................. 17

-Sample preparation .................................................................................................17

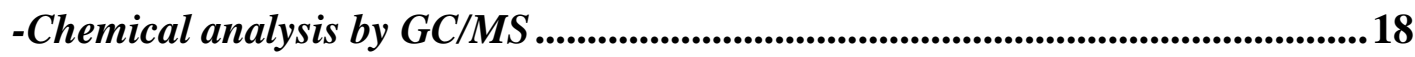

3.2.4 Liquid chromatography (LC ) analysis. ................................................................ 19

-HPLC-DAD analysis ........................................................................ 19

-LC-MS/MS Q-Tof Analysis .......................................................................19

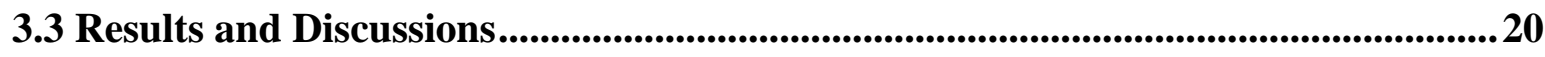

3.3.1 EOs extracted EOs extracted from fruits WN e ZB by different methods FMC and Clevenger Apparatus......................................................................................................2 20

-Orange EOs

-Lemon EOs.................................................................................................................... 20

3.3.2 EOs from the commercial lemon orchard of the year $2018 / 2019$....................23

3.3.3 GC/MS analysis of Industrial Hydrolates ..............................................................29 
3.3.4 LC/MS Q-TOF analysis of Industrial Hydrolate by Citrus sinensis

4. Effect of controlled water stress of Citrus $\times$ clementina cv. Clemenules and Citrus

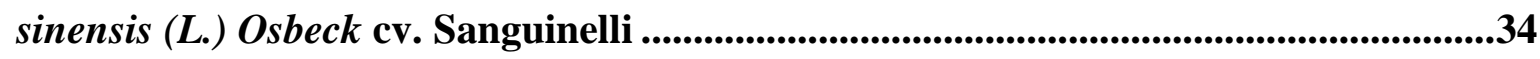

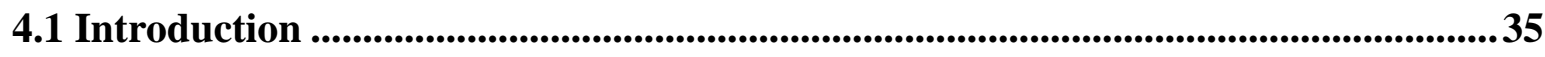

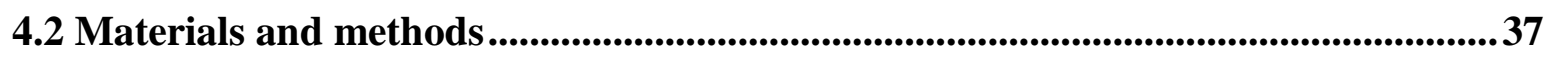

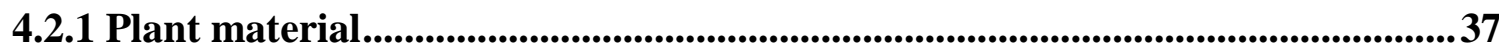

4.2.2 Measurement of the water potential of the trees ...........................................37

4.2.3 EOs extraction and characterization ............................................................ 37

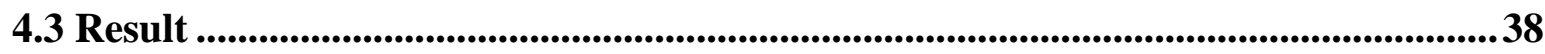

4.3.1 Clemenules EOs

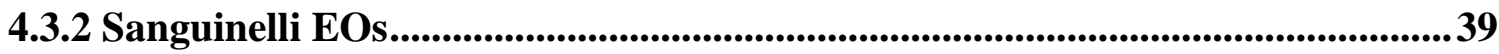

4.3.4 Effects of water stress on shoots production .............................................................. 41

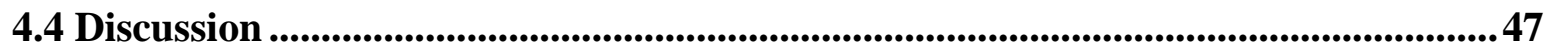

5.Allelopathic effect of citrus essential oils on weed species ............................................48

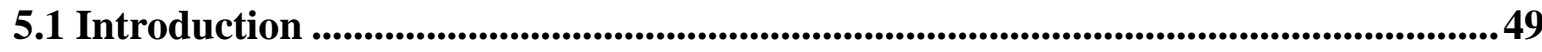

5.2 Materials and Methods ...............................................................................................551

5.2.1 Plant material...........................................................................................51

5.2.2 In vitro allelopathic activity test of essential oils ...............................................51

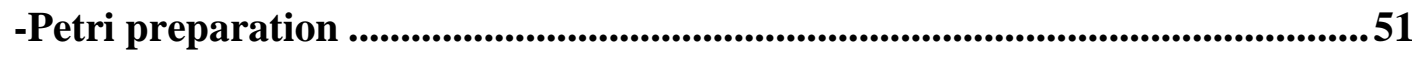

-EO application .........................................................................................................5 51

- Germination chamber condition ...................................................................................51

- Allelopathic activity monitoring ..................................................................................552

5.2.3 In vivo allelopathic activity test of essential oil..........................................52

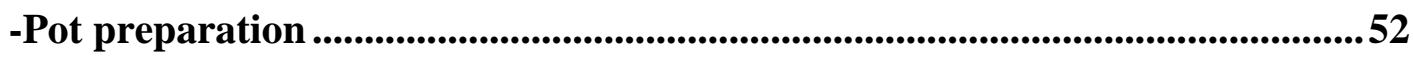

- Plants preparation ...................................................................................................................5 53 


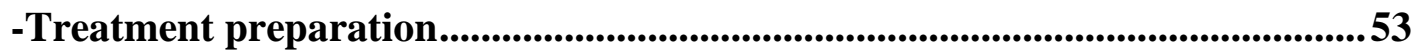

-Greenhouse environmental conditions .........................................................54

- Allelopathic activity in vivo measurement ..................................................55

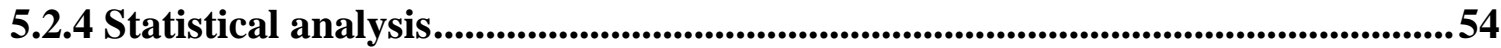

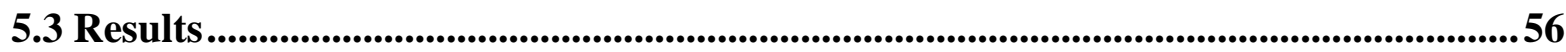

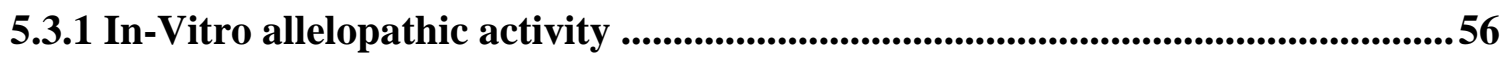

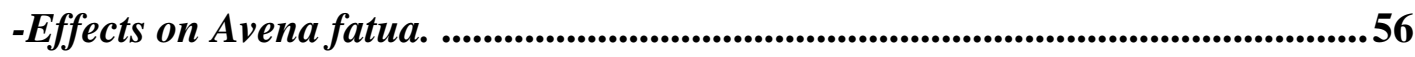

-Effect on Amaranthus retroflexus ...............................................................58

-Effect on Echinochloa crus-galli ......................................................................59

-Effect on Portulaca oleracea ............................................................................62 62

5.3.2 In-Vivo allelopathic activity of different LI treatment ..................................64

-Effect on A. fatua ...........................................................................................64

-Effects of EOs on A. retroflexus ..........................................................65

-Effect on Echinochloa crus-galli ...............................................................6 67

-Effect on Portulaca oleracea ..................................................................69

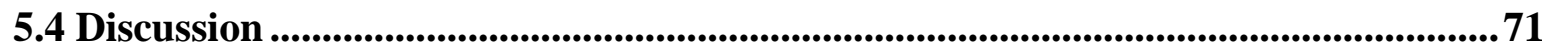

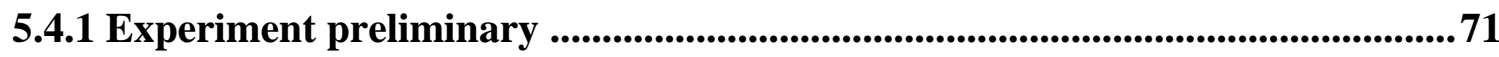

5.4.2 In vitro weed germination test.................................................................................... 71

5.4.3 Possible chemical compounds of citrus EOs with allelopathic activity............ 72

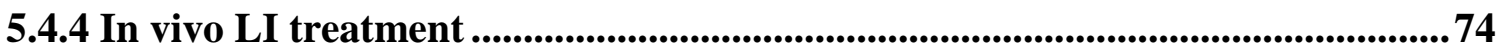

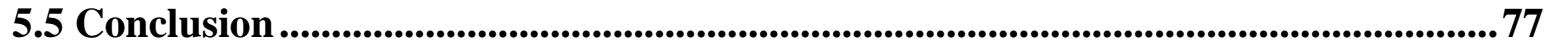

6 Wastewaters from citrus processing industry as natural biostimulants for soil microbial

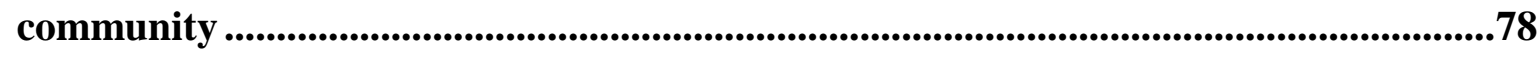

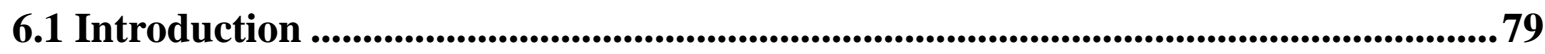

6.2 Materials and methods.............................................................................................................81 
6.2.1 Citrus wastewaters ...............................................................................................................81

6.2.2 Experimental set-up ..........................................................................................................82

6.2.3 Soil analyses .........................................................................................................................88

6.2.4 Statistical analyses .............................................................................................................83

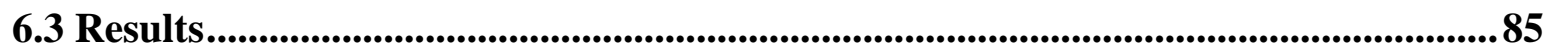

6.3.1Chemical composition of CWWs .......................................................................................85

6.3.2 Effect of CWWs on soil total organic carbon and $\mathrm{pH}$..............................................85

6.3.3 Effects of LWW on biochemical soil properties and microbial groups.............85

6.3.4 Effects of OWW on biochemical soil properties and microbial groups ............86

6.3.5 Effects of TWW on biochemical soil properties and microbial groups.............87

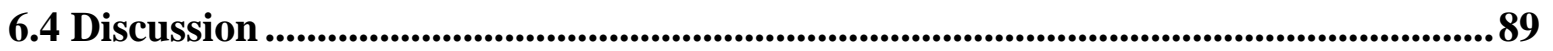

6.5 Conclusions ……...........................................................................................................................93

7 Geochemical traceability applied to lemon production. ...........................................................107

1 Introduction ................................................................................................................................................... 108

7.2 Materials and methods..............................................................................................110

7.2.1 Chemicals ...................................................................................................................................110

7.2.2. Plant material and sampling.......................................................................................110

7.2.3 Sample preparation ................................................................................................................110

7.2.4 ICP-MS analyses................................................................................................................111

7.2.5 Data representation ...........................................................................................................112

7.4 Discussion .............................................................................................................................................113

7.4.1 REE concentration in soil, fruit and juice..............................................................113

7.4.2Effect of REE absorption by cultivar ............................................................................113

7.4.3 Soil...................................................................................................................................................... 113

7.4.4 Fruit and juice...........................................................................................................................116 


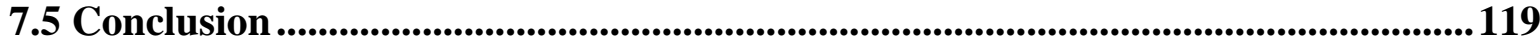

8. Conclusions ....................................................................................................................123

9. References..............................................................................................................................127 


\section{Abbreviation Index}

AI

AU

BAME

CFC

CFS

CLC

CLS

CT

CTR

Cv.

CWW

DTPA

DW

EO

E

E. A

FAME

FAO

FMC

GC-MS

GC-FID

ICP-MS

INT

JBT

HPLC-

HREE

LC

LREE

LI

LSD
Essential oil extracted from orange fruit peels by industrial method Essential oil extracted from orange fruit peels by Clevenger apparatus Bacterial Acid Methyl Ester

Clementina Flower Control

Clementina Flower Stress

Clementina Leaves Control

Clementina Leaves Stress

Catania

Control Treatment

Cultivar

Citrus Waste Water

Diethylenetriamine pentaacetato

Dry Weight

Essential oil

Hexane

Ethyl acetate

Fatty Acid Methyl Ester

Food and Agricultural Organization

Food Machinery Corporation

Gas Chromatography-Mass Spectrometry

Gas Chromatography- Flame Ionization Detector, Inductively Coupled Plasma -Mass Spectrometry

Interdonato

John Bean Technologies

DAD Hight Performance Liquid Chromatography -Diode Array Detector

Hight Rare Earth Element

Liquid Chromatography

Light Rare Earth Element

Essential oil extracted from lemon fruit peels by industrial method Least Significant Difference 
LU Essential oil extracted from lemon fruit peels by Clevenger apparatus

LWW Lemon Waste Water

ME Messina

MBC Microbial Biomass Carbon

MTC Mandarin Tadivo of Ciaculli

NA Napoli

NOB Nobiletin

OWW Orange Waste Water

PA Palermo

PGI Protected Geographical Indication

PLFA Phospholipid Fatty Acids

PMA Polymethylacrylate

PMF Poly-Metossi-Flavone

Q-TOF-MS Quadrupole-Time of Flight- Mass Spectrometry

REE Rare Earth Element

RG Siracusa

RI Retention Index

SLC Sangunelli Leaves Controntrol

SLS Sangunelli Leaves Stress

TN Total Nitrogen

TOC Total Organic Carbon

TP Trapani

TWW Tangerin Waste Water

UCC Upper Continental Crust

WHC Water Holding Capacity

WN Washington Navel

WW Waste Water

ZB Zagara Bianca 


\section{Table Index}

Table 3_1. Different EOs samples. 13

Table 3_2. Percentage of the volatile components of lemon and orange essential. 23

Table 3_3. Percentage yields of essential oils collected from a commercial lemon orchard in $2018 / 2019.24$

Table 3_4. Composition of essential oils extracted from ZB and INT fruits. 27

Table 3_5. Composition of essential oils from ZB e INT leaves. 28

Table 3_6. Percentage of the volatile components of industrial hydrolates from lemon (LI), orange $(A I)$ and tangerine $(M I)$. 31

Table 3_7. Percentage of different substances present in Orange Industrial Hydrolate 32 Table 4_1. Percentages of the Citrus $\times$ clementina $c v$. Clemenules essential oils components.

Table 4_2. Percentage of Citrus sinensis (L.) Osbeck cv. Sanguinelli essential oils components. Values lower than $0.07 \%$ was denoted as traces $(t)$.

Table 5_S1. Transplant, treatment and explant dates are reported. Average, maximum and minimum temperature and HR in the greenhouse during, each experiment are reported

Table 5_la and 5_1b. Effects of citrus EOs on A. fatua hypocotyl length (5_1a) and germination (5_1b).

Table 5_2a and 5_2b. Effect of citrus EOs on A. fatua seedling length (5_2a) and root length (5_2b).

Table 5_3a and 5_3b. Effects of citrus EOs on A. retroflexus hypocotyl length (5_3a) and germination (5_3b).

Table 5_4a and 5_4b. Effect of citrus EOs on A. retroflexsus seedling length (5_4a) and root length (5_4b).

Table 5_5a and 5_5b. Effects of citrus EOs on E. crus-galli hypocotyl length (5_5a) and germination (5_5b).

Table 5_6a and 5_6b. Effect of citrus EOs on E. crus-galli seedling length (5_6a) and root length (5_6b). 
Table 5_7a and 5_7b. Effects of citrus EOs on P. oleracea hypocotyl length (5_7a) and germination $\left(5 \_7 b\right)$.

Table 5_8a and 5_8b. Effect of citrus EOs on P. oleracea seedling length (5_8a) and root length (5_8b).

Table 5_9a and 5_9b. Effect of different LI treatment on A. fatua. Efficacy (5_9a) and Plant length (5_9b).

Table 5_10a and 5_10b. Effect of different LI treatments on A. fatua root length (5_10a) and aerial part length (5_10b).

Table 5_11a and 5_11b. Effect of different LI treatment on A. fatua on fresh (5_11a) and dry weight (5_11b).

Table 5_12a and 5_12b. Effect of different LI treatment on A. retroflexus. Efficacy (5_12a) and Plant length (5_12b).

Table 5_13a and 5_13b. Effect of different LI treatments on A. retroflexus root length (5_13a) and aerial part length (5_13b).

Table 5_14a and 5_14b. Effect of different LI treatment on A. retroflexus on fresh (5_14a) and dry weight (5_14b).

Table 5_15a and 5_15b. Effect of different LI treatment on E. crus-galli. Efficacy (5_15a) and Plant length (5_15b).

68

Table 5_16a 16b. Effect of different LI treatments on E. crus-galli root length (5_16a) and aerial part length (5_16b).

Table 5_17a and 5_17b. Effect of different LI treatment on E. crus-galli on fresh (5_17a) and dry weight (5_17b).

Table 5_18a and 5_18b. Effect of different LI treatment on P. oleracea. Efficacy (5_18a) and Plant length (5_18b).

Table 5_19a and 5_19b. Effect of different LI treatments on P. oleracea root length (5_19a) and aerial part length (5_19b).

Table 5_20a and 5_20b. Effect of different LI treatment on P. oleracea on fresh (5_20a) and dry weight (5_20b). 70

Table 6_1. Main chemical properties of lemon, orange and tangerine wastewaters. $\quad 94$

Table 6_2. F values obtained following two-way ANOVA performed on soil parameters. 94 
Table 6_3. Metabolic and microbial quotients determined 7, 28 and 56 days after the addition of lemon, orange and tangerine wastewaters. 96

Table 6_4. Main microbial groups (nmol FAs $g^{-1}$ dry soil) determined 7, 28 and 56 days after the addition of lemon, orange and tangerine wastewaters. 98

Table 6_S1. Volumes of lemon, orange and tangerine wastewaters and distilled water (H2O), and grams of total $C$ and $N$ added per $\mathrm{kg}$ of dry soil.

Table 6_S2. Total organic carbon (TOC; $\mathrm{g} \mathrm{kg-1)} \mathrm{determined} \mathrm{1,} \mathrm{7,} 28$ and 56 days after the addition of lemon, orange and tangerine wastewaters.

Table 7_1. Average amounts in nanomoles $* \mathrm{Kg}^{-1}$ and standard error of REE in citrus fields soil samples regrouped for Geographic area.

Table 7_2. Average amounts in nanomoles $* \mathrm{Kg}^{-1}$ and standard error of REE in citrus fruit samples regrouped for Geographic area.

Table 7_3. Average amounts in nanomoles $* \mathrm{Kg}^{-1}$ and standard error of REE in citrus juice samples regrouped for Geographic area. 


\section{Figure index}

Figure 2_1. Production of citrus worldwide in thousands of tons (FAO 2017). 6

Figure 2_2. Types of citrus fruit produced in the world in thousands of tons (FAO 2017). 7

Figure 2_3. Citrus fruit processed by industry in the world in thousands of tons (FAO 2017). 7

Figure 2_4. Cross section of orange fruit. $\quad 8$

Figure 3_1. FMC juice extractor. Load of the calibrated fruits inside the cups. 15

Figure 3_2. (A) EO extraction from lemon peels with Clevenger Apparatus. (B) Detail of lemon EO extracted.

Figure 4_1. Effect of controlled water stress on Clemenules type of shoots. 42

Figure 4_2. Effect of controlled water stress on Sanguinelli type of shoots. 43

Figure 4_3. Controlled water stress effect on Sanguinelli buds differentiation. $\quad 43$

Figure 4_4. Controlled water stress effect on Clemenules fruit number. 44

Figure 4_5. Controlled water stress effect on Clemenules fruit diameter. 45

Figure 4_6. Controlled water stress effect on Sanguinelli number of fruits. 45

Figure 4_ 7. Controlled water stress effect on Sanguinelli fruit diameter. 46

Figure 5_1. A. retroflexus plantlet (a) before treatment and (b) one hour after treatment. 76

Figure 5_2. Whitening of the leaf tissues 24 hours after treatment in (a), A.retroflexus (b) P. oleracea, (c) E. crus-galli and (d) one week after treatment application in A. fatua. 76

Figure 6_1. Soil reaction determined after 2 hours, and 1, 3, 7, 21, 28, 56 days since the addition of lemon, orange and tangerine wastewaters. 100

Figure 6_2. Biochemical soil variables determined after 7, 28 and 56 days since the addition of lemon wastewaters. 101

Figure 6_3. Microbial respiration rate and parameters to addition lemon wastewater. 102

Figure 6_4. Biochemical soil variables determined after 7, 28 and 56 days since the addition

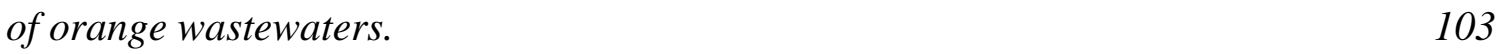

Figure 6_5. Microbial respiration rate and parameters to addition orange wastewater. 104 Figure 6_6. Biochemical soil variables determined after 7, 28 and 56 days since the addition of tangerine wastewaters.

105

Figure 6_7. Microbial respiration rate and parameters to addition tangerine wastewater. 106 Figure 7 _ 1. S[HREE]UCC vs $\sum[L R E E] U C C$ relations for all soils of citrus field. 
Figure 7_2. UCC-normalized REE patterns of soil sample of citrus field.

Figure 7_3. $\sum[H R E E] U C C$ vs $\sum[L R E E] U C C$ relations for lemon fruit grouped for origin area.

117

Figure 7_4. Soil-normalized REE patterns of fruit sample of different origin area. 117

Figure 7_5. $\sum[H R E E] U C C$ vs $\sum[L R E E] U C C$ relations for lemon juice grouped for origin area.

118

Figure 7_6. Soil-normalized REE patterns of juice sample of different origin area. 118

Figure 8_1. Preparation of ice-cream made with chocolate, Pantelleria capers and lemon Essential Oils.

125

Figure 8_2. Innovation award won at the Sherbeth Festival 2017.

126 

1. Introduction and Objectives 
Citrus fruits have a significant economic impact and are an important contribution to the human diet. In the last decades as opposed to the world market, Italian citrus fruit cultivation, especially Sicilian, has had remarkable deceptions due to globalization and the importation of low quality foreign goods, which very often are sold as Italian. The strong point of our production is that thanks to the favourable climate excellent products of excellent quality are obtained with few phytochemical treatments with the possibility of having even the edible peel, which is denied in many fruits imported from abroad. Therefore, it becomes important for the consumer to be sure of the origin of the product. Furthermore, it is fundamental to rework the entire production cycle from cultivation to transformation, to make it more sustainable.

The common objectives of this thesis in agreement with the citrus industry "EuroFood" and the research project "PON industrial P.h.D - a.a. 2016/2017" are traceability, sustainability, enhancement, and use of the by-products and waste products of the citrus industry.

The secondary product par excellence in the citrus industry is the essential oil (EO), which very often due to the high quantities produced in the world has a low cost. Tangerine oil is an exception, which is very appreciated and has high values.

This thesis aimed to evaluate the composition of EOs in different periods of commercial recollection during the year (Chapter 3) and alternative uses of EOs especially lemon and orange EOs. Abiotic stress has been applied to clementine and orange plants to see the effect on the composition of EOs in (Chapter 4).

Allelopathic activity of EOs on weeds was studied in (Chapter 5); the inhibition of pathogenic fungi and the microbial activity were tested and their possible use for the production of flavoured foods was evaluated. The products that the industry often considers waste, and therefore are treated as waste, first of all, are a cost for the company, but if not well treated, they can become pollution for the environment. One objective of our work developed in (Chapter 6) is to reuse the water coming from the extraction of EOs knowing that it contains bioactive substances characterized in (Chapter 3), which, applied correctly, can favour soil microorganisms.

Today traceability is very important for the final consumer and food safety. The objective of this thesis is to evaluate the direct link that exists between soil and the final product through geochemical tracers. This issue is addressed in (Chapter 7).

All the works and results obtained are discussed later. 
2. Importance of Citrus species 
The Citrus genus belonging to the Rutaceae family has species which are among the most important fruit crops in the world, and it also contains a large variety of species used for ornamental purposes. Generally, citrus plants are small evergreen trees or shrubs, their distinguishing feature is that they have flowers, leaves and fruits that produce a strong perfume, highly appreciated for consumers. The perfume is due to the EOs that the plant synthesizes. The composition of the EOs from the different organs of the plant differs, also the EOs composition varies within the species, and depends on both the cultivar and the time of harvest as we could see later.

The origin of the citrus fruits is identified with a history full of controversies and very interesting legends. In the past, there was much confusion regarding the classification of the genus Citrus. This confusion over time and thanks to the advent of new technologies that support new research is by no means resolved over the years. Groups of researchers believe that citrus fruits originated in the subtropical and tropical areas of Asia, particularly in parts of Southeast Asia including China, India and the Malay Archipelago (Bartholomew and Sinclair, 1952; Sinclair, 1961; Scora, 1975; Ranganna et al., 1983, Ramana et al., 1981; Gmitter and $\mathrm{Hu}$ 1990).

According to ancient Chinese manuscripts, the first documented reference concerning citrus fruits was during the reign of Ta Yu (between 2205 and 2197 BC) when mandarins and pummelos were considered of high value being offered for the imperial court (Webber, 1967; Nagy and Attaway 1980).

Hali Yen - Chih in 1.179 AD, wrote the oldest monograph of Citrus and most likely the first, he described and named 27 varieties of the sweet-sour orange-mandarin group in his Chii $\mathrm{Lu}$ (Scora, 1975). Some commercial species such as oranges, mandarins and lemons were originally thought to come up from Southeast Asia, however recent research claims that the true origins of citrus fruits are Australia, New Caledonia (off Eastern Australia) and New Guinea (Anitei, 2007).

The diffusion of citrus fruits from the regions of origin has been very slow. It is believed that in northern Africa and southern Europe citriculture was introduced towards the end of the first millennium by the advent of the Arabs who were good farmers. Subsequently after the discovery of America, thanks to Spanish and Portuguese explorers from Europe, citrus fruits spread in the new world (Scora, 1975). The first crops appeared for the first time in Florida and California around 1655 and 1769, respectively. From then on, the processing and global trade of citrus fruits have increased significantly, making citrus fruits one of the most important fruits in the world (Ramana et al, 1981). 
The citrus fruits best known for their commercial importance are sweet-oranges (Citrus sinensis (L.) Osbeck), lemons (Citrus limon (L.) Osbeck), limes (Citrus aurantiifolia (Christm.) Swingle), grapefruit (Citrus paradisi Macfad) and tangerines (Citrus reticulata Blanco). Citrus fruits are grown in over 140 countries around the world (Figure 2_1); most of the crops are located on both bands around the equator that includes tropical and subtropical areas at $35^{\circ} \mathrm{N}$ and $35^{\circ} \mathrm{S}$ latitudes (Ramana et al., 1981). Annual world citrus production has grown strongly in the past half century, from around 30 million tons in the late 1960s (FAO, 1967) to a total production of over 125 million tons in 2016 (FAO, 2017), with oranges that contribute over 65\% of world citrus production (Figure 2_2) (FAO, 2017).). The introduction after the Second World War of the frozen concentrated orange did the juice retains its organoleptic properties, at the same time that transportation costs and losses due to storage diseases were minimized; moreover, thanks to recognized health properties, these products have spread widely with a nutritional and economic impact (Ting, 1980). This led to the growth of the processing industries. According to the FAO database, world citrus production destined for processing in 2016 was 23.5 million tons (FAO, 2017). The top ten countries that process citrus fruits every year are Brazil, the United States, Mexico, Argentina, China, Spain, South Africa, Italy, Costa Rica and Turkey (FAO, 2017). Of the total of processed citrus fruits, about $80 \%$ are oranges (FAO, 2017) and correspond to about $30 \%$ of the fresh product, followed by lemon with $10 \%$ which corresponds to $15 \%$ of fresh production (Figure 2_3) (FAO, 2017). As previously mentioned, the citrus fruits generally used for processing are sweet orange, mandarin, grapefruit, lemon and lime. The fruit of citrus is a berry and is called hesperidium, the shape and size are different according to the species. The shape of the fruit for most oranges tends to be round or oblong in the case of some cultivars, their diameter can vary from 5.7 to $9.5 \mathrm{~cm}$. While they assume a flat spherical shape mandarin and grapefruit, respectively their radius varies from 5 to $9.5 \mathrm{~cm}$ and from 9.5 to $14.5 \mathrm{~cm}$. Lemon and lime are usually oblong. Their diameter varies respectively for lemons from 4.4 to $6.4 \mathrm{~cm}$; and limes from 3.8 to $5 \mathrm{~cm}$ (Ranganna et al., 1983).

Generally, citrus fruits have tight and well cohesive skin with the fruit, except for most of the mandarins, that have a loose skin character that has been maintained and improved over time because it is pleasant to the consumer (easy-peel). The external part of the citrus fruits is the peel or zest, which is composed from the outside towards the inside by epidermis, flavedo where inside we find the oil glands, and albedo (Figure 2_4 ). 


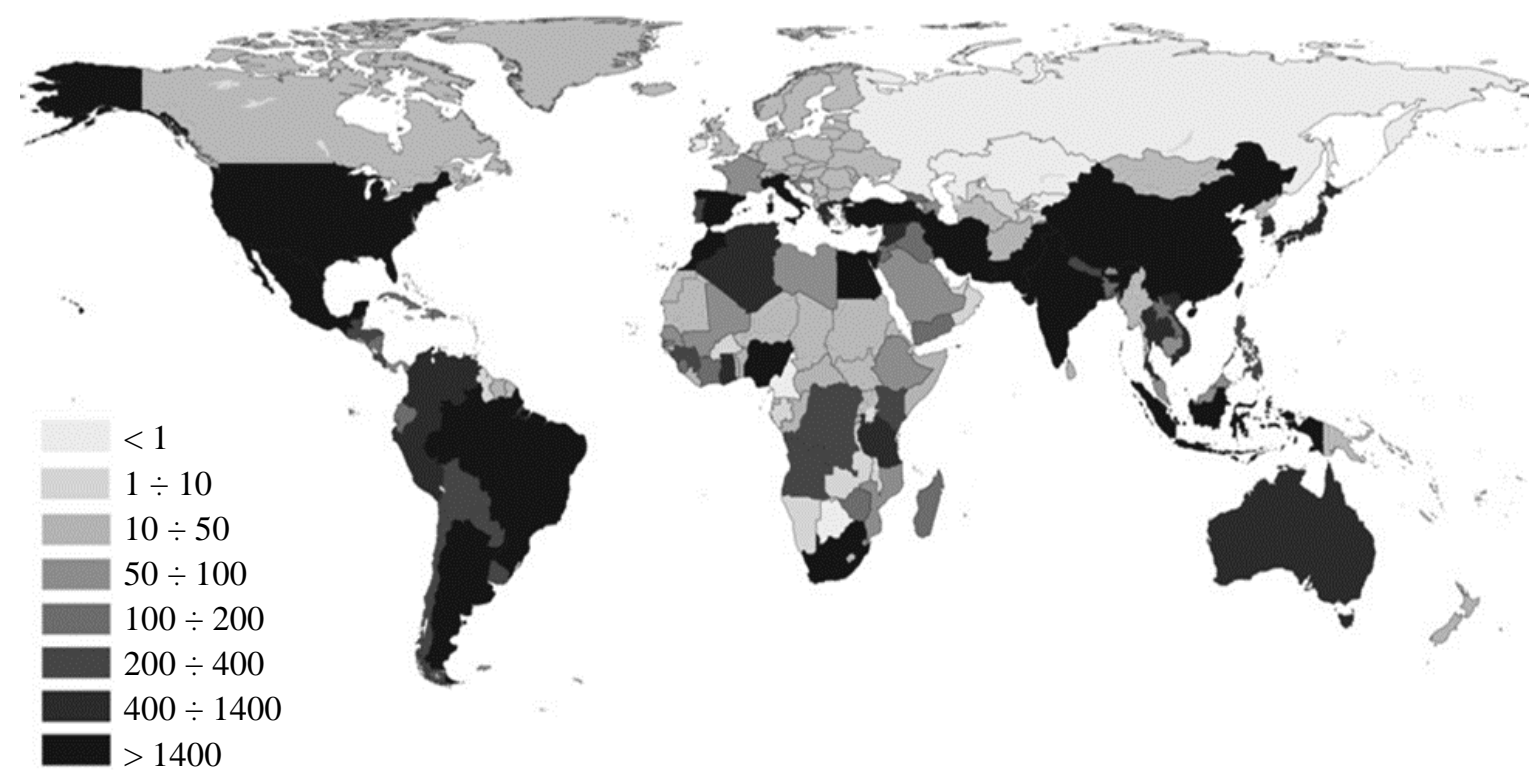

Figure 2_1. Production of citrus worldwide in thousands of tons (FAO 2017).

The epidermis is made up of one or more layers of cells and coated with wax, to form a compact parenchyma. The flavedo, in the subepidermal region, contains chromoplasts that give the fruit the characteristic colour of each variety that varies from green, yellow, orange to the red typical of red oranges; also, we find the numerous oil bags filled with aromatic EOs. Under the oil glands, the flavedo merges with the albedo (mesocarp), which depending on the species or variety, varies in thickness. In commercial cultivars with genetic improvement, this thickness in some fruits has been reduced to a minimum over the years. Between the flavedo and the segments, there is the albedo. Albedo is a tissue made up of layers of parenchymatous cells rich in glycosides (flavanones), bitter principles, pectin, pectic enzymes, and has a spongy appearance (Figure 2_4).

The wire-shaped vascular bundles of the albedo form a network parallel to the axis of the fruit along the outside of the segments. These are rich in peroxidase. In the ripe fruit, the pulp is made up of segments (carpels), about ten in number, distributed around the central axis of the fruit. Each segment is surrounded by a thin wall (carpellar membrane called a septum) which is a tissue of epidermal origin with a cuticular surface. 


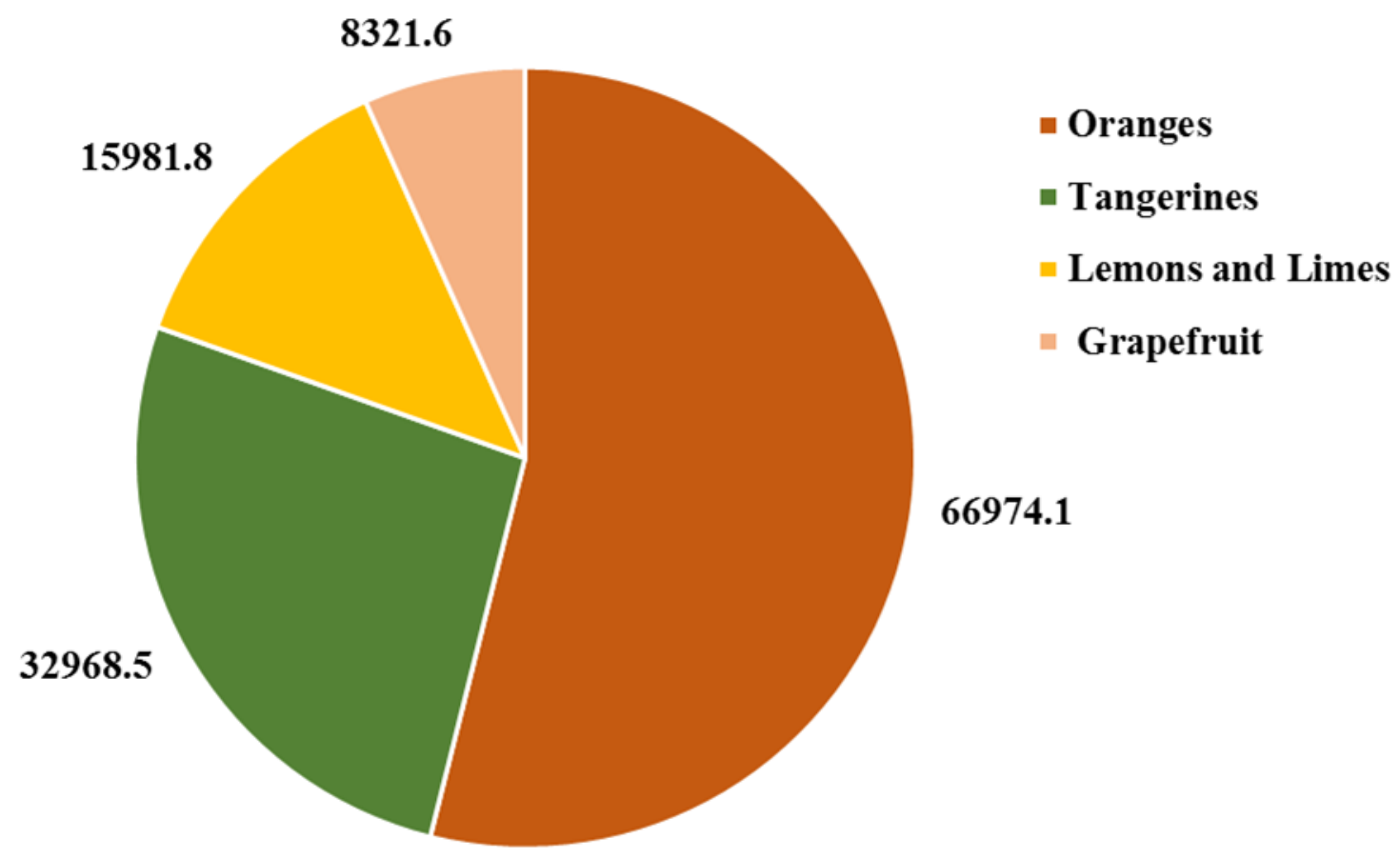

Figure 2_ 2. Types of citrus fruit produced in the world in thousands of tons (FAO 2017).

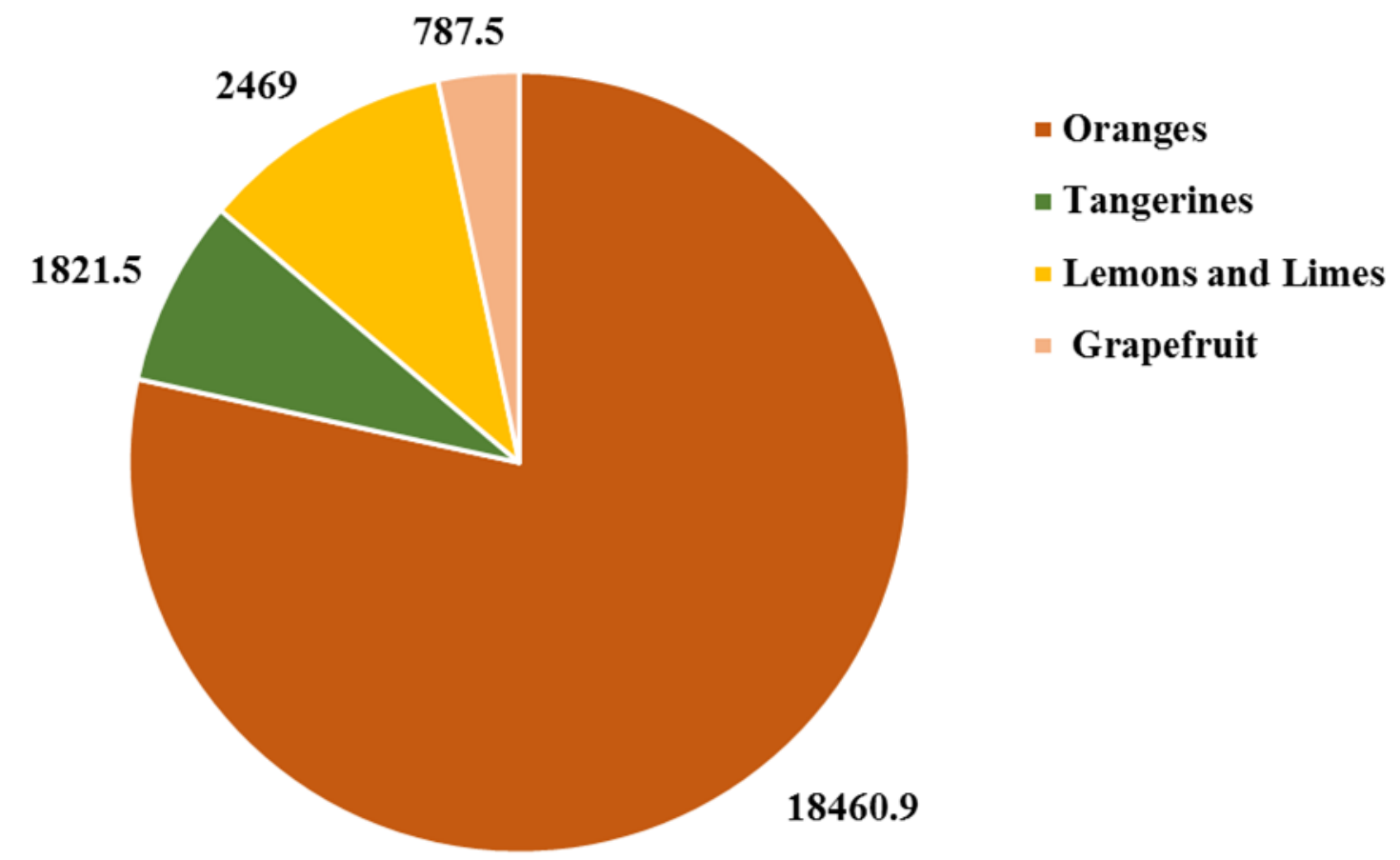

Figure 2_3. Citrus fruit processed by industry in the world in thousands of tons (FAO 2017).

When the fruit ripens, the juice is contained in very compacted vesicles, which fill the segments and are attached to the walls with small hair-like papillae. The juice bags are characterized by the presence of large vacuoles which contain sugars and organic acids which, together with the water, make up the juice. Furthermore, the seeds when present are 
contained within the segments and are attached to the walls through a placenta (Ranganna et al., 1983; Agusti, 2003; Vacante and Calabrese 2009)

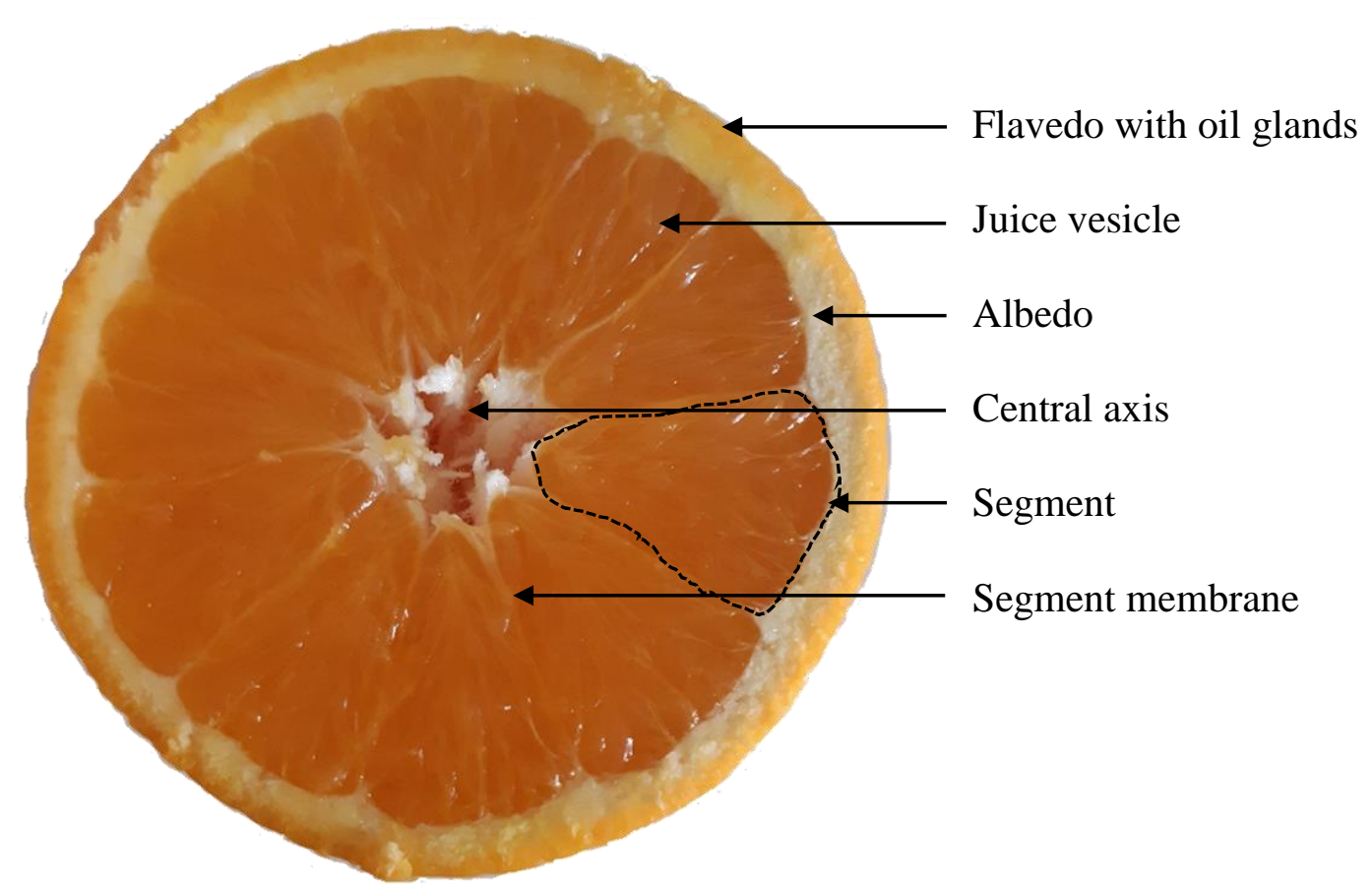

Figure 2_4. Cross section of orange fruit. 
3. Citrus active compounds 


\subsection{Introduction}

\subsubsection{Citrus essential oils}

EOs are highly studied natural products. Also called volatile or ethereal oils, (Guenther 1948, Palazzolo et al., 2013) are highly aromatic oily substances produced by different parts of the plant (flowers, buds, seeds, leaves, twigs, bark, herbs, wood, fruits and roots) as secondary metabolites.

EOs are very complex natural mixtures of lipophilic substances, as terpenoids, aromatic compounds, oxides, ethers, alcohols, esters, aldehydes and ketones, that can contain about 20-100 components at different concentrations. In citrus EOs, usually, two or three compounds are the main components (Limonene, $\beta$-Pinene, $\gamma$-Terpinene) which reach quite high concentrations (20-90\%) and determine their biological properties (Dugo and Mondello, 2010). In general, approximately 3000 EO have been investigated, of these 300 have commercial importance and are used for the pharmaceutical, agronomic, food, health, cosmetic and perfume industries (Palazzolo et al., 2013). Citrus EOs have characteristic odours, which depend on the species, or on the part of the plant in which they are produced (fruits, leaves, flowers). These odours are due to the presence of volatile compounds that characterize the aroma given off or volatile fraction. The volatile fraction of citrus EOs depending on the species can vary between $85 \%$ in lime oils and $99 \%$ in some sweet orange oils (Giacomo and Mincione 1994).

In nature, EOs play very important roles such as plant protection, antibacterial, antifungal, insecticide, allelopathic. In some cases, EOs act as insect attractors to promote pollination or seed dispersal. Thanks to their bactericidal and fungicidal properties, they are used as alternatives to synthetic products (Carson and Riley, 2003, Palazzolo et al., 2013). The major components of citrus EOs are Limonene, $\alpha$-Pinene, $\beta$-Pinene, $\gamma$-Terpinene, Myrcene, Geranial and Neral. Their percentages are highly variable depending on the species.

The EO with the greatest quantity of Limonene is that of bitter orange, which contains 96.5\%. The mandarin EO contains $5.24 \%$ of $\alpha$-Pinene. Lime EO contains $28.44 \%$ of $\beta$ Pinene and $5.30 \%$ of Neral. Lemon EO contains $12.05 \% \gamma$-Terpinene and $4.16 \%$ Geranial. Grapefruit EO contains the highest amount of Myrcene 6.9\% (Dugo and Mondello, 2010). 


\subsubsection{Citrus hydrolate}

The citrus fruit processing requires large amounts of drinking water for washing fruits and equipment, and for extracting EOs and juices, etc. In Italy, citrus fruits are widely cultivated and processed in the southern part (Zema et al., 2012), particularly in the Sicily region.

Navarro et al., 2008 estimated that a citrus factory that processes $25 \mathrm{t} / \mathrm{h}$ of lemon produces over 10 million litres of wastewater per day. This quantification conflicts with a survey conducted in a typical citrus fruit industry in Sicily that transforms 60,000 t / year. The quantity of wastewater produced is about 1 to 1 (water to fruit) concerning the quantity of fruit processed. Of these, $11 \%$ is hydrolate.

Hydrolates derive from the process of industrial extraction of EOs by cold pressing of citrus peels. In the EO extraction process, the water utilized in this process was often been treated as waste (Lin et al., 2011). In a comparative study on the composition of forty-four hydrolates and their EOs was evidenced that the bioactivity of hydrolates is not always the same as that of the EOs and the concentration of the major component was extremely low as compared with that of the EO (Inouye et al., 2009).

The citrus fruit wastewater to which hydrolate belongs is rich in organic matter and suspended solids. They have a high content of EOs and acidity ( $\mathrm{pH}<3$ ) (Zema et al., 2012). They also contain low amounts of nitrogen, phosphorus and traces of other microelements. However, thanks to their composition, the hydrolates could be reused instead of being, a problem and a cost for disposal of the same, charged to the company.

The reliability of the purification, the efficiency and the sustainability of the activated sludge plants, commonly used for the purification of the citrus processing wastewater, are conditioned negatively by some characteristics of the wastewater: qualitative and quantitative variability, high acidity, lack of nutrients and high EO content (Lane, 1983). Furthermore, the activated sludge purification process of citrus wastewater requires a lot of energy (Cheng et al., 2012).

There are no studies on the composition of hydrolates produced by the citrus industry with cold press extraction. There are very few studies regarding the composition of the hydrolates extracted with Clevenger apparatus from orange blossom which over the centuries has traditionally been used in the Mediterranean area in foods to flavour cakes and drinks, but also as a medicine and for skincare (Bellakhdar, 1997; Hmamouchi, 1999; Jeannot et al., 2005). A highly studied hydrolate is that of rose flowers and volatile compounds such as citronellol, nerol, geraniol and linalool have been found in rose water (Baydar and Göktürk, 
2005; Baydar et al., 2007; Mostafavi and Afzali; 2009; Koksal et al., 2015). The compounds listed above are also present in citrus EOs, so it is assumed that they would be also present in our hydrolates. The studies and composition will be discussed later. 


\subsection{Materials and methods}

\subsubsection{Plant material}

The plant material to extract the EO was sampled from various experimental fields at different times, depending on the cultivars of species from which they were extracted. The different EOs samples were reported in table 3_1.

The EO of orange cv. Washington Navel (WN) was extracted from the fruits collected in January 2017, from the experimental citrus field of the University of Palermo. While the EOs from fruits and leaves of lemons Zagara Bianca (ZB) and Interdonato (INT) were obtained from samples collected from the field of Petrosino (TP) in three different periods of the year: September 2018, January 2019 and May 2019 in correspondence with the three harvest periods. From the same field fruits of $\mathrm{ZB}$ were collected in large quantities in February 2017, to develop out the phytotoxicity tests.

\begin{tabular}{|c|c|c|c|c|c|c|}
\hline $\begin{array}{c}\text { EO } \\
\text { Samples }\end{array}$ & Type & cv. & Year & $\begin{array}{c}\text { Harvest } \\
\text { period }\end{array}$ & $\begin{array}{l}\text { Method of } \\
\text { extraction }\end{array}$ & $\begin{array}{c}\text { Typical } \\
\text { name }\end{array}$ \\
\hline LI & Fruits & $\mathrm{ZB}$ & 2017 & February & Industrial & Invernale \\
\hline AI & $"$ & WN & $"$ & $"$ & $"$ & Brasiliano \\
\hline MI & $"$ & MTC & & $"$ & $"$ & Tardivo \\
\hline LU & $"$ & $\mathrm{ZB}$ & $"$ & " & Hydro distillation & Invernale \\
\hline AU & $* \prime$ & $\mathrm{WN}$ & $"$ & $"$ & $"$ & Brasiliano \\
\hline S1 & Leaves & $\mathrm{ZB}$ & 2018 & September & $"$ & \\
\hline $\mathrm{S} 2$ & $"$ & INT & $"$ & " & $"$ & \\
\hline S3 & Fruits & $\mathrm{ZB}$ & $"$ & $"$ & $"$ & Verdello \\
\hline S4 & $"$ & $"$ & $"$ & $"$ & $"$ & Primo Fiore \\
\hline S5 & $"$ & INT & $"$ & $"$ & $"$ & Limone Fino \\
\hline G6 & Leaves & $\mathrm{ZB}$ & 2019 & January & $"$ & \\
\hline G7 & $"$ & INT & $"$ & $"$ & $"$ & \\
\hline G8 & Fruits & $\mathrm{ZB}$ & $"$ & $"$ & $"$ & Invernale \\
\hline G9 & $"$ & INT & $"$ & $"$ & $"$ & Bastardone \\
\hline M10 & Leaves & $\mathrm{ZB}$ & $"$ & May & $"$ & \\
\hline M11 & $"$ & INT & $"$ & $"$ & $"$ & \\
\hline M12 & Fruits & $\mathrm{ZB}$ & $"$ & $"$ & $"$ & Bianchetto \\
\hline
\end{tabular}

Table 3_1. Different EOs samples. It is reported type of plant material, cultivar, year and period of harvest, method of extraction and typical name of fruit production. * These fruits were recollected from the experimental field from the University of Palermo.

The industrial EOs and hydrolates used came from EuroFood citrus industry, where EOs extracted from the fruit of orange cv. (WN), lemon cv. (ZB), and mandarin cv. 'Tadivo' of 'Ciaculli' (MTC.) from winter productions in February 2017, coming from different areas of Sicily of which the exact origin was not known, except the ZB that was from the field listed above. 


\subsubsection{Citrus essential oil extracts}

\section{-Industrial method (FMC Technology)}

The typical process of a Sicilian citrus industry consists in receiving fresh fruit from citrus groves, short temporary storage of the fruits, subsequent washing, calibration and elimination of unsuitable ones, extraction and finishing of the juice, heat treatment, packaging and conservation of the finished. The main product of the citrus industry is juice. The juice can be marketed fresh sold in bottles or brick or is concentrated and sold to the food industries for the production of juices or others. Concentrated juice has many advantages: the concentrate is easy to store, it is more compact, therefore easier and less expensive to transport, but above all, it maintains its original organoleptic characteristics. The fruits are generally received mixed with limited quantities of leaves and stems that can disturb the transport equipment. To avoid this, they are treated with leaf removers. Subsequently, the fruits are brushed employing rotating brushes and washed under splashes of water to remove waxes, microbiological contamination and residual phytosanitary products. The washed fruits pass on belts where those unsuitable for processing are manually removed and are then automatically classified by size. Calibration is important for the machine which extracts juice and EOs. Juice and EOs can be recovered with different extraction systems or technologies; the most popular is that of FMC Technology (Food Machinery Corporation) (today JBT "John Bean Technologies" Foodtech), in-line extractors. Calibration is essential for the FMC system so that there is correct machine operation, maximum system performance and the highest quality juice is obtained. The principal characteristic of the FMC system is that is the unique machinery able to process fruits without preliminary cutting fruits in two halves.

The in-line FMC juice extractor (Figure 3_1) processes 3 to 8 pieces of fruit per cycle; the upper cups, mounted on a bar, move up and down through a cam transmission system, while the lower cups are fixed. All the cups are made of "fingers" that cross when the upper cups go down to the lower cups.

The extractors have a hopper of channels in which the calibrated fruit arrives through an inclined feeding belt; the cam system throws fruit into lower cups and upper cups begin to drop. In this way, the fruits begin to be pressed against the circular knives that remain on the bottom of the lower cups and held above the filter tubes, which function as juice prefinishers. The descending action cuts a thorn of peel and when the "fingers" cross the entire internal part of the fruit is forced downwards through the filter tube; the juice passes into the juice collector. The peel never meets the juice. 
The pressure of the upper cup and a limiter in the non-perforated lower part of the orifice tube, force the juice to flow through the perforated part of the filter tube in the juice collector, which is completely closed. At the same time, the filter moves upwards, pressing the segments and forcing the residual juice to exit through the filter; pulp, seeds and rags are ejected from the lower end of the orifice tube. The extraction cycle is complete when the orifice tube is at the same height as the top end of the filter tube. The squeezed juice is collected in the filter tube and then transported to the juice processing equipment. With the "In-Line" extractors, the juice yield and quality are very good.

Besides, the in-line extractors recover the EO at the same time as the squeezing. The "finger" of the cup cuts the peel into strips and presses it causing the outflow of the EO. A spray of water collects EO and emulsion is formed. This emulsion is collected in a screw conveyor and goes to a finisher to remove suspended solids. Emulsion reaches the centrifugal separators, where is divided into EO and wastewater (hydrolates). At the end of this phase, the EOs and hydrolates are sampled. The EOs were stored in a refrigerator at $4{ }^{\circ} \mathrm{C}$ in $125 \mathrm{ml}$ glass bottles, while the hydrolates were stored in polymethylacrylate (PMA) bottles from 11 to $-18^{\circ} \mathrm{C}$. EOs and hydrolates are rich in bioactive substances that will be studied within the thesis. In conclusion, with FMC systems, the fruits are separated into four flows: juice, peels, cores and oil emulsion.

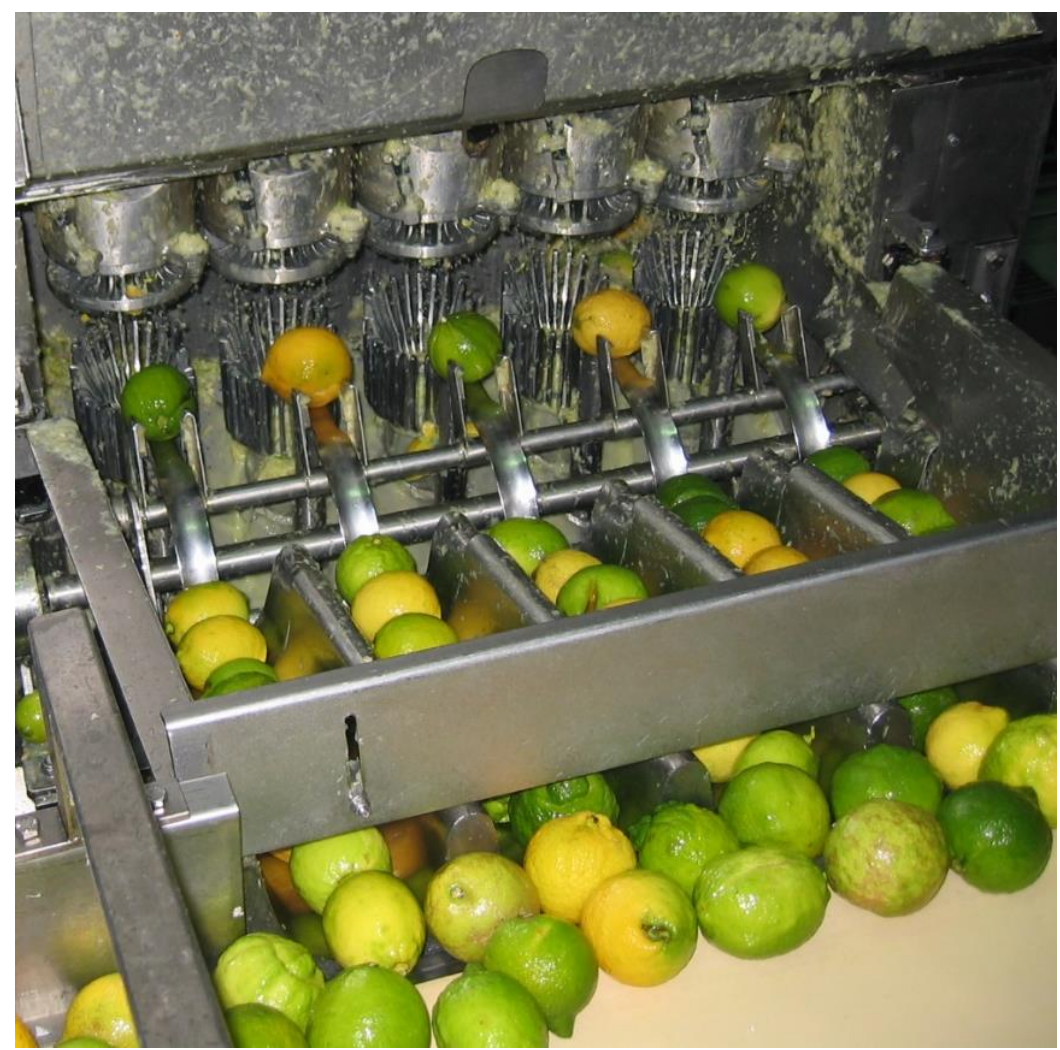

Figure 3_1. FMC juice extractor. Load of the calibrated fruits inside the cups. 


\section{-Laboratory method (Clevenger Apparatus)}

The hydro-distillation process through Clevenger apparatus (Figure 3_2) is one of the most used for the production of EOs.

The components of the EOs are almost completely immiscible in the liquid state in water, often thermolabile and have boiling temperatures between 150 and $250^{\circ} \mathrm{C}$. The plant material, in direct contact with water, is subjected to temperatures around $100{ }^{\circ} \mathrm{C}$. In this process, water is believed to perform a triple function: hot water softens the material and penetrates inside, facilitating the release of soluble components. The water vapour by condensing on the surface of the material provides the latent heat of vaporization to the volatile components and contributes strongly to the total pressure thanks to its vapour pressure. After the condensation of the steam, the EO and the water return to be immiscible and can be easily separated. This process can induce changes by rearrangement of thermolabile compounds. Furthermore, the presence of water can induce the partial hydrolysis of some compounds and solubilize the compounds having non-negligible solubility in water. Extractions were performed according to the European Pharmacopoeia (European Pharmacopoeia, 1975).

After peeling the fruits, $200 \mathrm{~g}$ of peels were placed in 31 glass flasks; 21 of distilled water was added. The hydro-distillation process was then started using a Clevenger type apparatus. The extraction process lasted 3 hours (until no more EO was obtained). For each cultivar or species, the extraction of EO from the fruit peels was carried out at least three times. The EOs were collected, dried under anhydrous sodium sulphate (Na2SO4) and stored in vials, at $4{ }^{\circ} \mathrm{C}$, for analysis and subsequent use. The extraction water (hydrolate) was recovered. The plant material was removed by filtration with sieves having a $5 \mathrm{~mm}$ mesh. The hydrolates were stored at $-18^{\circ}$ in PMA containers. For EOs obtained from leaves and flowers from the water stress experiment, the procedure used was the same described above for all EOs but, as the sample quantities were smaller, the extractions were made in 21 flasks, adding 11 of distilled water and the hydrolate was thrown away. 




Figure 3_2. (A) EO extraction from lemon peels with Clevenger Apparatus. (B) Detail of lemon EO extracted.

\subsubsection{Gas Chromatography-Mass Spectrometry (GC/MS) analysis of EOs and hydrolates}

\section{-Sample preparation}

For GC/MS analysis of all EOs, $20 \mu \mathrm{L}$ of each one were placed in vials of $1.5 \mathrm{ml}$ and $1 \mathrm{~mL}$ of hexane was added. For GC/MS analysis of the industrial hydrolates, $20 \mathrm{ml}$ of each one were placed in $50 \mathrm{ml}$ falcon containers together with $5 \mathrm{ml}$ of hexane. The falcons were stirred for 2 hours at a speed of $70 \mathrm{rpm}$ per minute. Subsequently, the falcons were centrifuged at $3000 \mathrm{rpm}$ for 5 minutes. From the falcon, $1.5 \mathrm{ml}$ of extract in hexane was recovered and placed in the vials. The vials were stored at $4{ }^{\circ} \mathrm{C}$ for subsequent analysis. Furthermore, this procedure was also performed by replacing the hexane with ethyl acetate. The extractions in hexane and ethyl acetate were performed for all industrial hydrolate samples. For GC/MS analysis of hydrolate obtained from lemon ZB peels by Clevenger 
Apparatus, a $200 \mathrm{~mL}$ sample was placed in a $300 \mathrm{ml}$ flask together with $20 \mathrm{ml}$ of hexane. The flask was capped and stirred for 2 hours at a speed of $70 \mathrm{rpm}$. Subsequently, the emulsion was placed in a separating funnel and left to rest for an hour so that the hexane separated from the aqueous phase. The aqueous phase was removed manually. The remaining hexane extract was dried under anhydrous sodium sulphate (Na2SO4) in a $50 \mathrm{ml}$ emery flask. To remove part of hexane from the extract, the flask was placed in the rotavapor at a temperature of $50{ }^{\circ} \mathrm{C}$. When the volume had decreased to about $1 \mathrm{ml}$, the extract was recovered and placed in the vials. The same process was also performed by replacing hexane with ethyl acetate. The vials were stored at $4{ }^{\circ} \mathrm{C}$ for subsequent analysis.

\section{-Chemical analysis by GC/MS}

An Agilent 6890 gas chromatograph instrument equipped with the mass spectrometer detector Agilent 5975 B was used for the chromatographic analyses. A fused silica capillary column SLB5MS (length $30 \mathrm{~m}$, internal diameter $0.25 \mathrm{~mm}, 0.25 \mu \mathrm{m}$ film thickness of silphenylene polymer equivalent in polarity to $5 / 95 \%$ poly-diphenyl/dimethylsiloxane phase) from Supelco, Italy, was the stationary phase. The injector in splitless mode had a temperature of $250^{\circ} \mathrm{C}$. Experimental chromatographic conditions were as follows: Helium carrier gas at $1 \mathrm{ml} / \mathrm{min}$; oven temperature program: $5 \mathrm{~min}$ isotherm at $40^{\circ} \mathrm{C}$ followed by a linear temperature increase of $4^{\circ} \mathrm{C}$ min- 1 up to $200^{\circ} \mathrm{C}$ held for $2 \mathrm{~min}$. MS scan conditions were: electronic impact (EI) as ionization technique, at $70 \mathrm{eV}$, source temperature $230^{\circ} \mathrm{C}$, interface temperature $280^{\circ} \mathrm{C}$, mass scan range $33-350 \mathrm{~m} / \mathrm{z} .1 \mu \mathrm{L}$ of any sample was injected. For quantitative results, each sample was analyzed in GC-FID with the same instrumental conditions of GC-MS chromatograph as above reported. The FID detector was set at $250^{\circ} \mathrm{C}$ and $1 \mu \mathrm{L}$ of the neat product was injected. The response factor in GC-FID analysis was considered equal to 1 and three replicates of each sample were made. The internal standard was undecane. Identification of the individual components was based (i) on comparison of their GC retention indices (RI), determined relative to the retention time of a series of $n$ alkanes with linear interpolation, (ii) on computer matching with mass spectral libraries (NIST 05) and (iii) comparison with spectra of authentic samples or literature data (Adams, 2007). 


\subsubsection{Liquid chromatography (LC ) analysis}

Samples preparation of (HPLC-DAD and LC-MS/MS Q-Tof) analysis.

Samples preparation took place with the same method previously used for the preparation of both Clevenger and industrial hydrolates for the GC-MS analysis. The only difference was to remove the extracting agent and replace it with $0.5 \mathrm{ml}$ of methanol.

\section{-HPLC-DAD analysis}

Sample of $20 \mu \mathrm{L}$ was analyzed using an Agilent HPLC system (quaternary pump G1311A), coupled with a photodiode array detector (DAD) (Series G13115D) and an autosampler (Series G1329A), managed by the Agilent software. An Agilent Eclipse XBDC18 column $(150 \times 4.6 \mathrm{~mm}$ i.d. with particle size $5 \mu \mathrm{m})$ was used.

G1311A quaternary pump was used to mix the mobile phase to avoid pressure fluctuations due to mixing methanol in water. All solvents were HPLC grade. The optimal separation was achieved with a binary mobile phase gradient, at a flow of $0.5 \mathrm{~mL} / \mathrm{min}$, with a column temperature of $30{ }^{\circ} \mathrm{C}$ and an injection volume of 20 microliters. The gradient solvents were water/formic acid (99/1) at $\mathrm{pH} 3.0$ (A) and acetonitrile (B). The gradient elution program was as follows: $0-15 \mathrm{~min}, 10-25 \% \mathrm{~B}, 15-20 \mathrm{~min}, 25-30 \% \mathrm{~B}$ and the flow rate was $0.5 \mathrm{ml} / \mathrm{min}$. The chromatograms were recorded at $280 \mathrm{~nm}$.

\section{-LC-MS/MS Q-Tof Analysis}

An aliquot of industrial hydrolate was subjected to HPLC-Q-Tof analysis with an Agilent G6540B MS Q-TOF, used in full scan mode in a range, from m/z 150-1500 Da, at a scan time of 2 spectra/s. Dual Electrospray Ionization (ESI) fragmenter was used at $2600 \mathrm{~V}$ in negative mode. The other source parameters were set as follows: source offset, $300 \mathrm{~V}$; desolvation temperature, $300{ }^{\circ} \mathrm{C}$, the flow of nitrogen $8 \mathrm{~L} / \mathrm{min}$, fragmenter $75 \mathrm{~V}$. The separation of the sample was carried out on a Zorbax Eclipse Plus Acquity C18 (2.0 x $150 \mathrm{~mm}, 3 \mu$ ). The column temperature was kept at $30^{\circ} \mathrm{C}$. An aliquot of $25 \mu \mathrm{L}$ was injected into HPLC-QTOF at a flow of $0.5 \mathrm{~mL} / \mathrm{min}$. Linear gradient elution, A $(0.1 \%$ formic acid in water) and B (acetonitrile) was applied with the following gradient: 5\% B for $5 \mathrm{~min}$, successively linearly increased to $15 \%$ of $\mathrm{B}$ within 10 minutes, then the composition was kept constant for another 5 minutes. Solvent B was then increased to $30 \%$ in 5 minutes and kept constant for another 10 minutes. Finally, in 7 minutes the mixture composition was brought back to the initial one (B 5\%). Nitrogen was used as nebulizing gas and helium as the collision gas. 


\subsection{Results and Discussions}

\subsubsection{EOs extracted EOs extracted from fruits WN e ZB by different methods FMC and Clevenger Apparatus.}

The chemical composition of the oils is reported in Table 3_2.

\section{-Orange EOs}

In the orange EO (AU) extracted with Clevenger Apparatus of the WN peel, 38 different compounds $(98.94 \%)$ were identified. The compounds were divided into the following phytochemical groups: monoterpene hydrocarbons $(94.72 \%)$, oxygenated components $(3.84 \%)$, sesquiterpene hydrocarbons $(0.31 \%)$ and oxygenated sesquiterpenes $(0.07 \%)$. The major component identified was Limonene 89.92\% (monoterpene hydrocarbon) followed by myrcene $2.73 \%$. The rest of the compounds were found in quantities below $1 \%$.

In the industrial orange EO (AI), 23 different compounds $(99.10 \%)$ were identified. The compounds were divided into four phytochemical groups: monoterpene hydrocarbons (94.38\%), oxygenated components, (3.69\%), sesquiterpene hydrocarbons $(0.76 \%)$ and oxygenated sesquiterpenes $(0.27 \%)$. In the monoterpene hydrocarbons group, the major component was Limonene (89.17\%) followed by myrcene (3.47\%) and $\alpha$-Pinene $1.51 \%$. The rest of the compounds were below $1 \%$.

\section{-Lemon EOs}

In the lemon EO (LU) extracted with Clevenger Apparatus of the ZB peel, 57 different compounds $(99.51 \%)$ were identified. The compounds were divided into phytochemical groups: monoterpene hydrocarbons (80.82\%), oxygenated components (16.33\%), sesquiterpene hydrocarbons $(2.31 \%)$ and oxygenated sesquiterpenes $(0.05 \%)$.

The main compounds were found to be monoterpenes. The major components identified from the monoterpene hydrocarbon fraction were Limonene (53.19\%), $\beta$-Pinene (11.71\%), $\gamma$-Terpinene (10.0\%), $\alpha$-Pinene $(2.11 \%)$ and Myrcene $(2.01 \%)$. In the oxygenated components, the main compounds were Geranial (3.09\%), followed by (Z)-Citral (2.09\%). In the industrial lemon EO (LI), 38 different compounds $(98.40 \%)$ were identified. The compounds were divided in phytochemical groups: monoterpene hydrocarbons $(86.08 \%)$, oxygenated components (7.91\%), sesquiterpene hydrocarbons (4.14\%) and oxygenated sesquiterpenes $(0.28 \%)$. The main compounds were monoterpenes. In the monoterpene hydrocarbons group, the major components identified were Limonene (54.31\%), $\beta$-Pinene (12.08\%), $\gamma$-terpinene (11.87\%), myrcene (2.55\%) and $\alpha$-Pinene $(2.42 \%)$. 
In oxygenated components, the main compounds were geranial $(2.70 \%)$, followed by Zcitral $(1.71 \%)$ and neryl acetate $(1.19 \%)$. The $\beta$-bisabolene $(1.74 \%)$ was the major component of the sesquiterpene hydrocarbons fraction, followed by (E)- $\alpha$-bergamotene $(1.20 \%)$ and E-caryophyllene $(0.71 \%)$. In the EOs analyzed, Limonene was the main component. According to Dugo and Mondello (2010) Limonene is a major component of Citrus species. Limonene was mostly present in the orange EOs. $\beta$-Pinene was present in large quantities in lemon EOs while in orange EOs it was missing. $\gamma$-Terpinene was also present in high quantities in the lemon EOs but in the orange EOs, it was present in low quantities. Monoterpene hydrocarbons were the main fraction, accounting for almost $95 \%$ in both EOs (AU; AI); while in lemon EOs, the concentration of this group was lower than in the orange EOs. For the other groups that constituted the orange EOs, there were no differences in the quantitative composition. Instead, in the qualitative composition of the orange EOs eight more compounds were identified in the group of the oxygenated components of the AU EO compared with AI. Furthermore, the amount of oxygenated components present in lemon EOs was higher than that of orange EOs. The quantity of oxygenated components in LU was $8.4 \%$ higher than in LI. Furthermore, in LU EO within the oxygenated components group, seventeen more compounds were identified than in LI EO.

From the results obtained, we can say that extraction with Clevenger apparatus (Hydrodistillation) compared to industrial cold extraction favours the formation of the compounds of the oxygenated components group, which is coincident with the results found by Ferhat et al. (2007).

\begin{tabular}{lccccc}
\hline & & \multicolumn{4}{c}{ Abundance \% } \\
\cline { 3 - 6 } Compounds & RI & A U & AI & LU & LI \\
\hline Monoterpene Hydrocarbons & & $\mathbf{9 4 . 7 2}$ & $\mathbf{9 4 . 3 8}$ & $\mathbf{8 0 . 8 2}$ & $\mathbf{8 6 . 0 8}$ \\
Tricyclene & 926 & 0.02 & & & \\
$\alpha$-Thujene & 931 & & & 0.52 & 0.84 \\
$\alpha$-Pinene & 939 & 0.36 & 1.51 & 2.11 & 2.42 \\
Camphene & 953 & & & 0.09 & 0.11 \\
Sabinene & 976 & 0.57 & & & \\
$\beta$-Pinene & 980 & & & 11.71 & 12.08 \\
Myrcene & 991 & 2.73 & 3.47 & 2.01 & 2.55 \\
$\alpha$-Phellandrene & 1004 & 0.11 & & 0.06 & 0.10 \\
$\delta$-3-Carene & 1011 & 0.20 & & & \\
$\alpha$-Terpinene & 1018 & 0.11 & & 0.27 & 0.47 \\
Limonene & 1031 & 89.92 & 89.17 & 53.19 & 54.31 \\
(Z)- $\beta-O c i m e n e$ & 1040 & & & 0.03 & 0.15 \\
(E)- $\beta$-Ocimene & 1050 & 0.08 & 0.09 & 0.08 & 0.24
\end{tabular}




\begin{tabular}{|c|c|c|c|c|c|}
\hline$\gamma$-Terpinene & 1062 & 0.27 & 0.06 & 10.00 & 11.87 \\
\hline Terpinolene & 1086 & & 0.09 & 0.75 & 0.90 \\
\hline p-Mentha-2,4(8)-diene & 1086 & 0.36 & & & \\
\hline$\alpha$-Terpinolene & 1088 & & & 0.02 & 0.05 \\
\hline Oxygenated compounds & & 3.84 & 3.69 & 16.33 & 7.91 \\
\hline Octanal & 1005 & & 0.88 & 0.19 & 0.17 \\
\hline Linalol oxide & 1078 & & & 0.02 & 0.06 \\
\hline Octanol & 1080 & 0.81 & & 0.06 & \\
\hline Linaly formate & 1088 & & & 0.73 & 0.22 \\
\hline Linalool & 1098 & 0.56 & 0.87 & & \\
\hline Nonanal & 1098 & 0.04 & 0.13 & 0.39 & 0.20 \\
\hline Fenchol exo & 1112 & & & 0.02 & \\
\hline Sabinaketone & 1117 & & & 0.11 & \\
\hline Limonene oxide & 1139 & & & 0.17 & \\
\hline Verbenol & 1140 & & & 0.20 & \\
\hline$\delta$-Camphor & 1142 & & & 0.03 & \\
\hline (E)- $\beta$-Terpineol & 1144 & 0.03 & & & \\
\hline Isopulegol & 1145 & & & 0.11 & \\
\hline Citronellal & 1153 & & 0.18 & 0.36 & 0.24 \\
\hline Isoborneol & 1158 & & & 0.05 & \\
\hline Borneol & 1165 & 0.05 & & & \\
\hline Phellandren-8-ol & 1166 & & & 0.10 & \\
\hline 1-Nonanol & 1173 & 0.74 & & & \\
\hline Terpinen-4-ol & 1177 & 0.03 & & 1.35 & 0.13 \\
\hline Isocitral & 1185 & 0.36 & & 1.86 & \\
\hline$\alpha$-Terpineol & 1189 & 0.40 & 0.15 & & \\
\hline Myrtenol & 1194 & & & 0.08 & \\
\hline Decanal & 1209 & 0.04 & 0.88 & 0.12 & 0.12 \\
\hline Nerol o (E)-Geraniol & 1228 & 0.21 & & 1.23 & 0.09 \\
\hline Thymol,Methyl Ether & 1235 & & & 0.06 & 0.07 \\
\hline (Z)-Citral & 1237 & & & 2.09 & 1.71 \\
\hline Neral & 1240 & & 0.18 & & \\
\hline Piperitone & 1252 & & & 0.04 & \\
\hline Geraniol & 1255 & 0.14 & & 1.31 & \\
\hline Geranial & 1270 & & 0.32 & 3.09 & 2.70 \\
\hline Citral & 1270 & 0.24 & & & \\
\hline Peryllaldheyde & 1271 & 0.04 & & & \\
\hline$\gamma$-Terpin-7-ol & 1287 & & 0.08 & & \\
\hline Limonene-10-ol & 1289 & & & 0.04 & \\
\hline Perilla alcohol & 1295 & & & 0.05 & \\
\hline Carvacrol & 1298 & & & 0.05 & \\
\hline Undecanal & 1306 & 0.06 & & 0.08 & 0.05 \\
\hline Carvometil Acetate & 1351 & & & 0.14 & 0.10 \\
\hline Neryl acetate & 1365 & 0.02 & & 1.27 & 1.19 \\
\hline Geranyl acetate & 1380 & & & 0.91 & 0.86 \\
\hline Methyl methanthranilate & 1402 & 0.06 & & & \\
\hline Geranyl propionate & 1477 & & & 0.03 & \\
\hline Sesquiterpene Hydrocarbons & & 0.31 & 0.76 & 2.30 & 4.14 \\
\hline$\delta$-Elemene & 1340 & 0.02 & & & \\
\hline$\alpha$-Cubebene & 1351 & & & 0.04 & \\
\hline
\end{tabular}




\begin{tabular}{llllll}
$\alpha$-Copaene & 1376 & & 0.08 & & \\
$\beta$-Cubebene & 1390 & & 0.11 & & \\
$\beta$-Elemene & 1391 & 0.05 & & & \\
(E) Cariophyllene & 1418 & 0.03 & & 0.37 & 0.71 \\
$\alpha$-Santalene & 1420 & & & 0.04 & \\
$\beta$-Cedrene & 1422 & & 0.10 & & \\
$($ E)- $\alpha$-Bergamotene & 1434 & & 0.08 & 0.63 & 1.20 \\
$\alpha$-Humulene & 1453 & 0.02 & & 0.04 & 0.05 \\
$\beta$-Santalene & 1460 & & & 0.07 & 0.15 \\
$\gamma$-Muurolene & 1476 & 0.13 & & & \\
Valencene & 1490 & & 0.27 & & \\
$\alpha-$ Selinene & 1494 & 0.02 & & & \\
(Z)- $\alpha$-Bisabolene & 1503 & & & 0.04 & 0.06 \\
(E,E)- $\alpha$-Farnesene & 1508 & & & 0.10 & \\
$\alpha-$-Selinene 7-epi- & 1517 & 0.03 & & & 0.15 \\
$\beta$-Bisabolene & 1520 & & & 0.94 & 1.75 \\
$\delta$-Cadinene & 1524 & & 0.12 & & \\
(E) $\alpha$-Bisabolene & 1530 & & & 0.03 & 0.05 \\
Oxygenated sesquiterpenes & & $\mathbf{0 . 0 7}$ & $\mathbf{0 . 2 7}$ & $\mathbf{0 . 0 5}$ & $\mathbf{0 . 2 8}$ \\
Campherenol & 1654 & & & 0.05 & 0.08 \\
$\beta$-Sinensal & 1696 & 0.03 & 0.18 & & \\
$\alpha$-Sinensal & 1752 & 0.03 & 0.09 & & \\
Nootkatone & 1800 & 0.02 & & & 0.20 \\
Limetin o Citropten & 1992 & & & & $\mathbf{9 8 . 4 0}$ \\
Identified compounds & & $\mathbf{9 8 . 9 4}$ & $\mathbf{9 9 . 1 0}$ & $\mathbf{9 9 . 5 1}$ & \\
\hline
\end{tabular}

Table 3_2.Percentage of the volatile components of lemon $(L U, L I)$ and orange $(A U, A I)$ essential oils obtained by different extraction processes and identified by GC/MS analysis.

\subsubsection{EOs from the commercial lemon orchard of the year 2018/2019}

Lemon species of ZB and INT cultivars were studied in the year 2018/2019. The lemon, especially the ZB cultivar, is a typical flourishing species: the same plant shows fruits and flowers at the same time in different stages of phenological development and the different types of fruits correspond to different blooms (Amenta et al., 2015). The fruits and leaves were collected during the commercial maturity periods of these cultivars, which were September, January and May. Each commercial production of each cultivar had a typical name reported in table $3 \_1$.

The EO yields $(\mathrm{R})$ are reported in table $3 \_3$ and were calculated using the formula:

$\mathrm{R}=\mathrm{V} / \mathrm{M} * 100$.

$\mathrm{V}$ in $(\mathrm{mL})$ is the volume of the EOs obtained by Clevenger Apparatus;

$\mathrm{M}$ in $\mathrm{g}$ is the fresh weight of the leaves or whole fruits.

The highest yield of EO was found in ZB leaves collected in May (M10, 0.49\%), also ZB leaves sampled in September possessed a similar yield (S1, 0.46\%), while in ZB leaves 
sampled in January the yield was lower $(\mathrm{G} 6,0.32 \%)$ (Table 3_3). The leaves of INT showed also the maximum yield of EO in the sample collected in May (M11, 0.38\%), while the samples collected in January and September presented similar yields (S2 and G7, 0.21\%). The yield in fruits ranged from 0.15 (ZB fruits from May and September) to 0.11 (INT fruits from September and January). The higher yield of EO from leaves was obtained in May in both lemon cultivars. This study is interesting for the use of lemon pruning waste because the lemon in Sicily is pruned in May.

\begin{tabular}{cc}
\hline Samples & EO R $(\boldsymbol{\%})$ \\
\hline S1 & 0.46 \\
S2 & 0.21 \\
S3 & 0.12 \\
S4 & 0.15 \\
S5 & 0.11 \\
G6 & 0.32 \\
G7 & 0.21 \\
G8 & 0.15 \\
G9 & 0.11 \\
M10 & 0.49 \\
M11 & 0.38 \\
M12 & 0.15 \\
\hline
\end{tabular}

Table 3_3. Percentage yields of essential oils collected from a commercial lemon orchard in 2018/2019.

The EO yield of the fruits was influenced mainly by the cultivar and not by the time of harvest because the same EO yield was obtained from almost all the lemon productions of the same cultivar, except for the fruit Verdello simple (S3) which presented a lower yield as compared with other fructifications of the ZB cultivar. A reason for this lower content could be the thinner peel that characterizes the Verdello fruits assuming it has a lower content of EO than the other fruits. Considering the yield data of EOs obtained of any production, the ZB cultivar was more productive than the INT cultivar.

The chemical composition of EOs from fruits is reported in Table 3_4 and from leaves in Table 3_5.

A total of 108 compounds (Table 3_4) were identified in the six EOs of fruit peel: 26 in S3, 18 in S4, 16 in G8, 16 in S5 and 17 in GEN9. The total recovery was 100\% for S5, 99.1\% for $\mathrm{G} 9,98.51 \%$ for $\mathrm{M} 12,98.5 \%$ for $\mathrm{S} 4$ and $97.89 \%$ for $\mathrm{G} 8$.

All EOs were dominated by a high content of monoterpene hydrocarbons: $95.70 \%$ in S5, $94.76 \%$ in $\mathrm{G} 9,92.38 \%$ in M12, $91.88 \%$ in G8, $90.88 \%$ in S3 and $89.03 \%$ in S4. Oxygenated 
monoterpenes also characterized lemon fruit EOs: represented $9.47 \%$ in $\mathrm{S} 4,6.96 \%$ in $\mathrm{S} 3$, $5.85 \%$ in $\mathrm{M} 12,5.66 \%$ in $\mathrm{G} 8,4.03 \%$ in $\mathrm{S} 5$ and $3.51 \%$ in G9. Moreover, sesquiterpene hydrocarbons was a group present in some EOs in small quantities: $0.87 \%$ in G9, $0.35 \%$ in G8, $0.28 \%$ in M12 and $0.27 \%$ in S5. The main compounds of the EOs were Limonene, $\alpha$ Pinene and $\gamma$-terpinene. Limonene was the compound most present in all lemon fruit EOs and it was amounted: $84.18 \%$ in $\mathrm{S} 5,79.49 \%$ in $\mathrm{S} 3,78.3 \%$ in $\mathrm{S} 4,76.94 \%$ in $\mathrm{G} 9,73.29 \%$ in G8 and $67.02 \%$ in M12. $\alpha$-Pinene was another component that characterized all the lemon fruit EOs and it constituted: $14.46 \%$ of M12, $8.88 \%$ of S3, $8.71 \%$ of G8, 7.73\% of G9, $7.29 \%$ of S4 and 7\% of S5. $\gamma$-Terpinene represented $6.75 \%$ in M12, 6.38\% in G8, 6.28\% in G9, $1.15 \%$ in $\mathrm{S} 5,0.39 \%$ in $\mathrm{S} 4$ and $<0.02 \%$ in $\mathrm{S} 3$.

The EOs of the INT fruits were characterized by a higher content of monoterpene hydrocarbons than those of ZB fruits. While the EOs from ZB fruits were characterized by a higher content of oxygenated monoterpenes, compared to those of INT fruits. Moreover, the EOs from ZB fruits collected in September $(\mathrm{S} 3, \mathrm{~S} 4)$ were those with the highest content of oxygenated monoterpenes. The fruits collected in September (S3, S4, S5) presented the highest content of Limonene compared to the others, and the lowest content of $\gamma$-Terpinene. The synthesis of some components of the EOs from ZB and INT lemon fruits were not only dependent on the cultivar but also on the harvest period.

A total of 117 compounds (Table 3_5) were identified in the six EOs from lemon leaves, 21 in S1, 16 in G6, 17 in M10, 22 in S2, 18 in G7 and 23 in M11. The total identified was $96.65 \%$ for $\mathrm{S} 1,98.42 \%$ for $\mathrm{G} 6,99.37 \%$ for M10, $95.45 \%$ for $\mathrm{S} 2,95.39 \%$ for G7 and $99.08 \%$ for M11. Oxygenated monoterpenes were the main fraction in all EOs except M10: $71 \%$ in $\mathrm{G} 7,73.49 \%$ in $\mathrm{S} 2,64.56 \%$ in $\mathrm{M} 11,59.83 \%$ in $\mathrm{G} 653.85 \%$ in $\mathrm{S} 1$ and $45.45 \%$ in $\mathrm{M} 10$. Monoterpene hydrocarbons were predominant in M10 53.92\% while in the other EOs were present in quantities of $42.8 \%$ in $\mathrm{S} 1,38.59 \%$ in G6, 32.9\% in M11, 23.05\% in G7 and $21.39 \%$ in S2. Sesquiterpene hydrocarbons and oxygenated sesquiterpenes were present in samples S2, G7 and M11 in small quantities. Limonene was the most abundant component in S1 (32.2\%), followed by geranial (24.12\%), neryl acetate (12.98\%), for $\beta$-Pinene (7.8\%) and geranyl acetate (5.17\%). The remaining compounds (16) were below 5\%. G6 was rich in Geranial (28.67\%) and Limonene (28.61\%), Neral (20.24\%) and $\beta$-Pinene (6.84\%). The rest of the compounds (12) were below 5\%. Limonene (39.54\%) was the most abundant component in M10, other abundant components were geranial (17.94\%), Neral (14.24\%) and $\beta$-Pinene $(8.86 \%)$, the other compounds (13) were inferior at $5 \%$. Geranial $(27.21 \%)$ was the more abundant component in S2, followed by Neral (17.16\%), Neryl acetate 
(16.93\%), Limonene (16.7\%) and Geranyl acetate (6.23\%); the rest of components (17) were below $5 \%$. G7 was composed of $27.1 \%$ of Geranial, $17.26 \%$ of Limonene, $16.91 \%$ of Neryl acetate, $16.17 \%$ of Neral and $5.99 \%$ of Geranyl acetate; the other compounds (13) were inferior at 5\%. Limonene (19.19\%) was the most abundant component in M11, followed by Nerol (15.64\%), Neryl acetate (15.15\%), Neral (9.56\%) and $\beta$-Pinene (8.79\%).

The remaining 17 compounds were below 5\%. In all EOs from ZB leaves, sesquiterpene hydrocarbons and oxygenated sesquiterpenes were missing. EOs from INT leaves were characterized by more components compared to EOs from ZB leaves.

EOs extracted from the samples collected in May (M10, M11) were characterized by a higher content of Limonene and $\beta$-Pinene and a lower content in oxygenated monoterpenes compared to other samples of EOs from leaves. From the obtained data, we can conclude that the composition of the EOs obtained was influenced by the cultivar and by the harvest period. The quantity of $\beta$-Pinene in all the May samples was greater compared to other samples. From the compositions and yields obtained, we enhanced the pruning waste of May, which could be used for the extraction of EOs. 


\begin{tabular}{|c|c|c|c|c|c|c|c|}
\hline \multirow[b]{2}{*}{ Compounds } & \multirow[b]{2}{*}{ RI } & \multicolumn{6}{|c|}{ Abundance \% } \\
\hline & & S3 & $\mathbf{S 4}$ & G8 & M12 & S5 & G9 \\
\hline Monoterpene Hydrocarbons & & 90.88 & 89.03 & 91.88 & 92.38 & 95.70 & 94.76 \\
\hline$\alpha$-Thujene & 930 & & & & & 0.16 & 0.17 \\
\hline$\alpha$-Pinene & 939 & 1.04 & 1.04 & 1.07 & 1.24 & 1.1 & 1.05 \\
\hline Sabinene & 976 & & 1 & 1.12 & 1.81 & 0.9 & 0.75 \\
\hline$\beta$-Pinene & 982 & 8.88 & 7.29 & 8.71 & 14.46 & 7 & 7.73 \\
\hline Myrcene & 991 & 1.04 & 1.01 & 1.31 & 1.10 & 1.21 & 1.38 \\
\hline o-Cymene & 1028 & 0.43 & & & & & \\
\hline Limonene & 1030 & 79.49 & 78.3 & 73.29 & 67.02 & 84.18 & 76.94 \\
\hline (E)- $\beta$-Ocimene & 1051 & & & & & & 0.16 \\
\hline$\gamma$-Terpinene & 1062 & $\mathrm{t}$ & 0.39 & 6.38 & 6.75 & 1.15 & 6.28 \\
\hline Terpinolene & 1087 & & & & & & 0.30 \\
\hline Oxygenated monoterpenes & & 6.96 & 9.47 & 5.66 & 5.85 & 4.03 & 3.51 \\
\hline (Z)-Linalool oxide & 1075 & $\mathrm{t}$ & & & & & \\
\hline (E)-linalool oxide & 1088 & $\mathrm{t}$ & & & & & \\
\hline Linalool & 1100 & 0.88 & 0.81 & 0.42 & 0.24 & 0.46 & 0.27 \\
\hline (E)-p-Mentha-2,8-dien-1-ol & 1121 & $\mathrm{t}$ & & & & & \\
\hline (Z)-Limonene oxide & 1132 & $\mathrm{t}$ & 0.3 & & & & \\
\hline (E)-Limonene oxide & 1139 & 0.44 & $\mathrm{t}$ & & & 0.19 & \\
\hline Camphor & 1144 & $\mathrm{t}$ & & & & & \\
\hline Citronellal & 1155 & $\mathrm{t}$ & $\mathrm{t}$ & & & & \\
\hline Terpinen-4-ol & 1182 & 0.48 & 0.59 & 0.6 & 0.46 & & \\
\hline$\alpha$-Terpineol & 1195 & 1.34 & 1.59 & 0.92 & 0.95 & 0.42 & 0.73 \\
\hline Nerol & 1226 & & & & & 1.04 & 0.99 \\
\hline Neral & 1240 & 1.03 & 2.3 & 0.67 & 1.05 & & 0.68 \\
\hline Carvone & 1241 & $\mathrm{t}$ & 0.34 & 1.76 & 1.04 & 0.55 & \\
\hline Geranial & 1270 & 1.34 & 3.01 & 0.89 & 1.34 & & \\
\hline Geranyl formate & 1305 & 0.36 & & & & 0.7 & \\
\hline Neryl acetate & 1360 & 0.85 & 0.53 & 0.31 & 0.42 & & \\
\hline Geranyl acetate & 1376 & 0.24 & & 0.09 & 0.35 & 0.48 & 0.55 \\
\hline Sesquiterpene Hydrocarbons & & $\mathbf{t}$ & $\mathbf{t}$ & 0.35 & 0.28 & 0.19 & 0.29 \\
\hline (E)- $\alpha$-Bergamotene & 1426 & $\mathrm{t}$ & & 0.12 & & 0.27 & 0.87 \\
\hline$\beta$-Bisabolene & 1498 & $\mathrm{t}$ & $\mathrm{t}$ & 0.23 & 0.28 & & 0.35 \\
\hline Oxygenated sesquiterpenes & & $\mathbf{t}$ & $\mathbf{t}$ & & & 0.27 & 0.52 \\
\hline Caryophyllene oxide & 1570 & $\mathrm{t}$ & $\mathrm{t}$ & & & & \\
\hline other & & $\mathbf{t}$ & $\mathbf{t}$ & & & & \\
\hline Nonanal & 1103 & $\mathrm{t}$ & $\mathrm{t}$ & & & & \\
\hline TOTAL IDENTIFIED & & 97.84 & 98.5 & 97.89 & 98.51 & 100 & 99.14 \\
\hline
\end{tabular}

Table 3_4. Composition of EOS extracted from $Z B$ and INT fruits from a productive citrus orchard during campaign 2018/2019. Compositional values lower than 0.02\% was denoted as traces $(t)$. 


\begin{tabular}{|c|c|c|c|c|c|c|c|}
\hline \multirow[b]{2}{*}{ Compound } & \multirow[b]{2}{*}{ RI } & \multicolumn{6}{|c|}{ Abundance \% } \\
\hline & & S1 & G6 & M10 & S2 & G7 & M11 \\
\hline Monoterpene Hydrocarbons & & 42.8 & 38.59 & 53.92 & 21.39 & 23.05 & 32.9 \\
\hline$\alpha$-Pinene & 939 & 0.3 & 0.23 & 0.45 & & & 0.27 \\
\hline Sabinene & 976 & 1.37 & 1.13 & 1.74 & 0.27 & & 1.61 \\
\hline$\beta$-Pinene & 982 & 7.8 & 6.84 & 8.86 & 3.46 & 4.6 & 8.79 \\
\hline 6-Methyl-5-hepten-2-one & 986 & 0.63 & 0.62 & 1.01 & 0.29 & 0.33 & 0.14 \\
\hline$\beta$-Myrcene & 991 & $\mathrm{t}$ & 0.38 & 0.87 & 0.22 & 0.37 & 0.63 \\
\hline$\delta$-3-Carene & 1010 & 0.5 & & 0.73 & & & \\
\hline Limonene & 1030 & 32.2 & 28.61 & 39.54 & 16.7 & 17.26 & 19.19 \\
\hline (E)- $\beta$-Ocimene & 1051 & $\mathrm{t}$ & 0.78 & 0.72 & 0.45 & 0.49 & 2.07 \\
\hline$\gamma$-Terpinene & 1062 & & & & & & 0.2 \\
\hline Oxygenated monoterpenes & & $\mathbf{5 3 . 8 5}$ & 59.83 & 45.45 & 73.49 & 71 & 64.56 \\
\hline Bergamal & 1056 & $\mathrm{t}$ & & & & & \\
\hline Linalool & 1100 & 2.36 & 1.53 & 1.21 & 1.84 & 0.12 & 1.91 \\
\hline (Z)-Limonene oxide & 1132 & $\mathrm{t}$ & & & & & \\
\hline (E)-Limonene oxide & 1139 & $\mathrm{t}$ & & & & & \\
\hline Citronellal & 1155 & 2.01 & 0.89 & 1.12 & 0.91 & 0.21 & 1.09 \\
\hline Terpinen-4-ol & 1182 & 0.86 & 1.19 & 0.79 & 1.05 & 1.08 & 0.8 \\
\hline$\alpha$-Terpineol & 1195 & 1.27 & 1.2 & 0.82 & 0.08 & 1.08 & 0.99 \\
\hline Nerol & 1226 & 4.1 & 0.03 & 1.48 & 1.98 & 1.68 & 15.64 \\
\hline Neral & 1240 & 0.98 & 20.24 & 14.24 & 17.16 & 16.17 & 9.56 \\
\hline Geranial & 1272 & 24.12 & 28.67 & 17.94 & 27.21 & 27.1 & 13.21 \\
\hline Geranyl formate & 1305 & & & & $\mathrm{t}$ & & \\
\hline Neryl acetate & 1360 & 12.98 & 3.41 & 4.67 & 16.93 & 16.91 & 15.15 \\
\hline Geranyl acetate & 1381 & 5.17 & 2.67 & 3.18 & 6.23 & 5.99 & 4.06 \\
\hline Ethyl geraniate & 1395 & & & & $\mathrm{t}$ & & 0.19 \\
\hline Geranyl propanoate & 1477 & & & & $\mathrm{t}$ & & \\
\hline Sesquiterpene Hydrocarbons & & & & & 0.05 & 0.33 & 1.06 \\
\hline (E)-Caryophyllene & 1420 & & & & 0.05 & 0.33 & 0.9 \\
\hline$\beta$-Bisabolene & 1498 & & & & & & 0.16 \\
\hline Oxygenated sesquiterpenes & & & & & 0.52 & 1.01 & 0.56 \\
\hline Caryophyllene oxide & 1570 & & & & 0.14 & 0.07 & 0.11 \\
\hline epi- $\alpha$-Bisabolol & & & & & & & 0.08 \\
\hline (E,Z)-Geranyl linalool & 1962 & & & & 0.15 & 0.32 & 0.37 \\
\hline$(\mathrm{Z}, \mathrm{E})$-Geranyl linalool & 2004 & & & & 0.23 & 0.62 & \\
\hline other & & $\mathbf{t}$ & & & & & \\
\hline n-Nonanal & 1103 & $\mathrm{t}$ & & & & & \\
\hline TOTAL IDENTIFIED & & 96.65 & 98.42 & 99.37 & 95.45 & 95.39 & 99.08 \\
\hline
\end{tabular}

Table 3_5. Composition of essential oils from ZB e INT leaves collected from a productive citrus orchard during campaign 2018/2019. Compositional values lower than 0.02\% was denoted as traces $(t)$. 


\subsubsection{GC/MS analysis of Industrial Hydrolates}

To identify the compounds of each extract a gas chromatography system, coupled with mass spectrometry, was employed. 158 compounds (Table 3_6) were identified in six extracts, three in hexane and three in ethyl acetate. The six extracts were obtained by the industrial hydrolates of Lemon, Orange and Tangerine. Within the components of each hydrolate, there were no differences between the two extractants solvents; the same compounds were identified in both hexane and ethyl acetate. In the industrial lemon hydrolate, 32 different components were identified, which corresponded to $98.80 \%$ of the extract in hexane (E) and $99.08 \%$ in ethyl acetate (E.A).

The compounds were divided into groups: monoterpene (88.01\% in E and 87.79\% in E.A.), oxygenated compound (8.25\% in $\mathrm{E}$ and $7.89 \%$ in E.A.), sesquiterpene hydrocarbons (1.67\% in $\mathrm{E}$ and $2.52 \%$ in E.A.) and oxygenated sesquiterpenes (0.87\% in $\mathrm{E}$ and $0.87 \%$ in E.A.). The main compound was Limonene (59\%) which, with $\beta$-Pinene and $\gamma$-Terpinene together, formed over $80 \%$ of the extract. All other compounds were less than $2.5 \%$. In the industrial hydrolate of Orange, 26 different components were identified corresponding to $99.49 \% \mathrm{E}$ and $99.84 \%$ in E.A. The compounds were divided into groups: monoterpene $(87.79 \%$ in $\mathrm{E}$ and $86.35 \%$ in E.A.), oxygenated compound (1.39\% in E and $1.44 \%$ in E.A.), sesquiterpene hydrocarbons (1.01\% in E and $1.21 \%$ in E.A.) and oxygenated sesquiterpenes (10.74\% in E and $11.14 \%$ in E.A.). The main compound was Limonene (81\%) which, with Citroptene $(10.70 \%)$, formed over $90 \%$ of the extract. Myrcene made up about 3\% in the extracts while, the remaining 23 components, were below $1 \%$.

In the Mandarin industrial hydrolate, 21 different components were identified, which corresponded to $99.81 \%$ of the $\mathrm{E}$ and $99.97 \%$ of the E.A.

The compounds were divided into groups: monoterpene (95.30\% in E and 95.47\% in E.A.), oxygenated compound (3.07\% in E and 3.14\% in E.A.), sesquiterpenes hydrocarbons $(0.61 \%$ in $\mathrm{E}$ and $0.62 \%$ in E.A.) and oxygenated sesquiterpenes (0.82\% in $\mathrm{E}$ and $0.75 \%$ in E.A.). The main compound was Limonene, about 65\%, which added to $\gamma$-Terpinene (20\%), formed more than $85 \%$ of the extract. Myrcene, $\alpha$-Pinene and $\beta$-Pinene, made up about $7 \%$ in the extracts while, the remaining 16 components, were below $1 \%$. 


\begin{tabular}{|c|c|c|c|c|c|c|c|}
\hline \multirow[b]{3}{*}{ Compound } & \multirow[b]{3}{*}{ IK } & \multicolumn{6}{|c|}{ Abundance \% } \\
\hline & & \multicolumn{2}{|c|}{$\mathbf{L I}$} & \multicolumn{2}{|c|}{ AI } & \multicolumn{2}{|c|}{ MI } \\
\hline & & $\mathbf{E}$ & E.A. & $\mathbf{E}$ & E.A. & $\mathbf{E}$ & E.A. \\
\hline Monoterpene & & 88.01 & 87.79 & 93.35 & 95.04 & 95.30 & 95.42 \\
\hline Tricyclene & 926 & 0.56 & 0.57 & & & & \\
\hline$\alpha$-Thujene & 931 & & & & & 1.09 & 1.14 \\
\hline$\alpha$-Pinene & 939 & 2.33 & 2.49 & 0.99 & 1.08 & 2.71 & 2.85 \\
\hline Camphene & 953 & 0.09 & 0.18 & & & & \\
\hline Sabinene & 976 & 0.42 & 0.40 & 0.54 & 0.58 & 0.27 & 0.27 \\
\hline$\beta$-Pinene & 980 & 10.90 & 11.17 & 0.05 & 0.04 & 1.87 & 1.93 \\
\hline Myrcene & 991 & 1.80 & 1.86 & 2.97 & 3.25 & 2.28 & 2.36 \\
\hline Dehydro Cineole & 994 & 0.19 & 0.22 & & & & \\
\hline$\alpha$-Phellandrene & 1004 & 0.15 & 0.21 & 0.47 & 0.69 & 0.29 & 0.30 \\
\hline$\alpha$-Terpinene & 1018 & 0.57 & 0.35 & & & 0.52 & 0.57 \\
\hline Limonene & 1031 & 59.04 & 58.66 & 81.12 & 80.29 & 65.37 & 65.16 \\
\hline Ecaliptol & 1034 & 0.04 & 0.10 & & & & \\
\hline (Z) $\beta$ Ocimene & 1040 & 0.16 & 0.20 & 0.05 & & & 0.05 \\
\hline$\gamma$-Terpinene & 1062 & 11.10 & 10.82 & 0.05 & 0.02 & 19.68 & 19.66 \\
\hline Terpinolene & 1088 & 0.65 & 0.55 & 0.11 & 0.09 & 1.21 & 1.12 \\
\hline Oxygenated compound & & 8.25 & 7.89 & 1.39 & 1.44 & $\mathbf{3 . 0 7}$ & 3.14 \\
\hline Linalool & 1098 & 0.47 & 0.40 & 0.68 & 0.67 & 0.33 & 0.31 \\
\hline Nonanal & 1098 & 0.12 & 0.10 & 0.05 & 0.07 & 0.06 & 0.08 \\
\hline Fenchol exo & 1112 & 0.05 & 0.04 & & & & \\
\hline Terpinen-4-ol & 1177 & 2.03 & 1.99 & 0.09 & 0.10 & 0.55 & 0.55 \\
\hline$\alpha$-Terpineol & 1189 & 1.70 & 1.76 & 0.18 & 0.18 & 0.69 & 0.72 \\
\hline Decanal & 1209 & & & 0.26 & 0.25 & 0.22 & 0.21 \\
\hline Nerol & 1228 & 0.16 & 0.18 & & & & \\
\hline Z-Citral & 1237 & & & 0.05 & 0.05 & & \\
\hline Neral & 1240 & 0.65 & 0.62 & 0.03 & 0.02 & & \\
\hline Geraniol & 1255 & 0.11 & 0.10 & & & & \\
\hline Geranial & 1270 & 1.17 & 0.97 & & & & \\
\hline Peryllaldheyde & 1271 & & & & & 0.08 & 0.08 \\
\hline Thymol & 1291 & & & & & 0.23 & 0.29 \\
\hline p-Menth-1-en-9-ol & 1291 & & 0.07 & & & & \\
\hline Citronellyn Acetate & 1354 & 0.13 & 0.12 & & & & \\
\hline Neryl acetate & 1365 & 0.97 & 0.91 & & & & \\
\hline Geranyl acetate & 1380 & 0.68 & 0.64 & & & & \\
\hline Dodecanal & 1392 & & & 0.05 & 0.09 & & \\
\hline Dimethyl anthranilate & 1402 & & & & & 0.91 & 0.88 \\
\hline Sesquiterpene Hydrocarbons & & 1.67 & 2.52 & 1.01 & 1.21 & 0.61 & 0.62 \\
\hline$\alpha$-Copaene & 1376 & & & 0.06 & & & \\
\hline$\beta$-Cubebene & 1390 & & & 0.09 & 0.09 & & \\
\hline t-Caryophyllene & 1417 & 0.25 & 0.37 & 0.05 & 0.06 & 0.17 & 0.17 \\
\hline$\beta$-Gurjunene & 1432 & & & 0.04 & 0.05 & & \\
\hline (Z)- $\alpha$-Bergamotene & 1434 & 0.39 & 0.70 & & & & \\
\hline ^-Gurjunene & 1473 & 0.13 & 0.17 & & & & \\
\hline
\end{tabular}




\begin{tabular}{cccccccc} 
(E)- $\alpha$-Bergamotene & 1485 & 0.90 & 1.28 & & & & \\
Valencene & 1490 & & & 0.63 & 0.81 & & \\
$\alpha-$ Selinene & 1494 & & & 0.08 & 0.13 & & \\
(E,E)- $\alpha$-Farnesene & 1508 & & & & & 0.44 & 0.45 \\
$\delta$-Cadinene & 1524 & & & 0.06 & 0.06 & & \\
Oxygenated sesquiterpenes & & $\mathbf{0 . 8 7}$ & $\mathbf{0 . 8 7}$ & $\mathbf{1 0 . 7 4}$ & $\mathbf{1 1 . 1 4}$ & $\mathbf{0 . 8 2}$ & $\mathbf{0 . 7 5}$ \\
$\alpha$-Bisabolol & 1666 & 0.26 & 0.08 & & & & \\
$\alpha$-Sinensal & 1752 & & & 0.04 & 0.04 & 0.82 & 0.75 \\
Citroptene & 1993 & 0.62 & 0.79 & 10.40 & 11.10 & & \\
Total identification & & $\mathbf{9 8 . 8 0}$ & $\mathbf{9 9 . 0 8}$ & $\mathbf{9 9 . 4 9}$ & $\mathbf{9 9 . 8 4}$ & $\mathbf{9 9 . 8 1}$ & $\mathbf{9 9 . 9 3}$ \\
\hline
\end{tabular}

Table 3_6. Percentage of the volatile components of industrial hydrolates from lemon (LI), orange (AI) and tangerine (MI). Extracted of two solvent hexane (E) and Ethyl Acetate (E_A), identified by GC/MS analysis.

\subsubsection{LC/MS Q-TOF analysis of Industrial Hydrolate by Citrus sinensis.}

Only the samples obtained from the extractions in ethyl acetate were dried and weighed to calculate the yield $(0.16 \% \mathrm{w} / \mathrm{v})$. Subsequently, they were solubilized in methanol and analyzed by LC/MS-Q-TOF technique.

The LC/MS-Q-TOF analysis of the Orange Industrial Hydrolate extracts identified several substances listed in Table 3_7.

Of the 19 compounds identified, the more abundant was citric acid in $48.2 \%$. Others compound was Bergapten in $14.12 \%$, L-ascorbic acid in $8.51 \%$, Acetyl maltose in $7.91 \%$, Digalacturonic acid in $6.69 \%$ and the others were below 3.5\%. Interesting substances present in the orange hydrolate were the Nobiletin (NOB) and 5,7,4'-Trihydroxy-8,3'dimethoxyflavanone: these compounds are classified as polymethoxyflavones (PMF). PMF is a type of flavonic compound with different methoxy groups, which have shown a wide range of physiological and pharmacological bioactivity. (Gao et al., 2018)

PMF is identified in seeds, leaves, juice, stems and peels, in particular, in flavedo and citrus peel. Citrus peels, such as orange peel or tangeretin, are generally considered by-products on the market but have been used in the traditional medicine to relieve stomach upset, cough, skin inflammation, muscle pain and ringworm infections, as well as, to lower the blood pressure, in some regions of the world (Li et al., 2009). Recently, intense pharmacological and mechanistic studies have been conducted, on citrus PMFs, to explore their therapeutic potential. To date, the bioactivity of citrus fruits PMFs included regulation of metabolic disturbance, anti-atherosclerosis, anti-inflammation, neuroprotection, anti-cancer, anti- 
microbial and anti-oxidation action. Anti-cardiovascular diseases, the anti-cancer and neuroprotection activities of PMF to citrus fruits have received considerable attention.

\begin{tabular}{cccc}
\hline RT & A.U. & \% & Compound \\
\hline $\mathbf{3 . 1 5}$ & 359999 & 0.20 & Nobiletin \\
$\mathbf{3 . 6 2}$ & 5898511 & 3.33 & Gluconic acid \\
$\mathbf{3 . 7 8}$ & 14000000 & 7.91 & Acetyl-maltose \\
$\mathbf{3 . 8 6}$ & 11844865 & 6.69 & Digalacturonic acid \\
$\mathbf{4 . 1 1}$ & 15060350 & 8.51 & L-ascorbic acid \\
$\mathbf{4 . 1 1}$ & 100000 & 0.06 & D-Galacturonate 1-phosphate \\
$\mathbf{4 . 2 8}$ & 5000000 & 2.82 & Mevalonate 5-diphosphate \\
$\mathbf{4 . 4 4}$ & 100000 & 0.06 & Citric acid \\
$\mathbf{4 . 5 3}$ & 85000000 & 48.02 & Bergapten \\
$\mathbf{5 . 5 3}$ & 25000000 & 14.12 & Caffeic acid 4-O-glucuronide \\
$\mathbf{1 9 . 1 5}$ & 1410351 & 0.80 & Nogalonic acid \\
$\mathbf{2 0 . 8 6}$ & 2000000 & 1.13 & O-Feruloylgalactarate \\
$\mathbf{2 1 . 6 9}$ & 100000 & 0.06 & Calyxin J \\
$\mathbf{2 9 . 9 0}$ & 600000 & 0.34 & Kaempferol 3-O-[2"-(4"'-acetyl-rhamnosyl)-6"-glucosyl] glucoside \\
$\mathbf{3 0 . 2 5}$ & 3000000 & 1.69 & Leucodelphinidin 3-[galactosyl-(1->4)-glucoside] \\
$\mathbf{3 0 . 3 8}$ & 5599675 & 3.16 & Nomilinic acid 17-glucoside \\
$\mathbf{3 2 . 4 6}$ & 719939 & 0.41 & Acacetin 7-Rhamnosyl-(1->6)[2"-acetylglucosyl-(1->2)glucoside] \\
$\mathbf{3 2 . 7 2}$ & 800000 & 0.45 & Patuletin 3-(4"-acetylrhamnoside)-7-(2"',4"'-diacetylrhamnoside) \\
$\mathbf{3 3 . 3 9}$ & 400000 & 0.23 &
\end{tabular}

Table 3_7. Percentage of different substances present in Orange Industrial Hydrolate extracts, identified by LC/MS-Q-TOF analysis.

NOB is one of the most ubiquitous flavones that can be isolated exclusively from the peel of citrus fruits. Besides Colorectal cancer, there is concurrently ongoing research looking into the effect of NOB on other types of cancers, such as breast cancer, ovarian cancer, gastric cancer, lung cancer, liver cancer and bone cancer. There are also recent studies attesting to the benefits of NOB in anti-neurodegeneration, anti-diabetes, anti-obesity, antimicrobial, anti-allergy and anti-inflammatory effects. Several articles support claims, indicating the role of NOB in reducing the risk of cardiovascular diseases and osteoporosis. Interestingly, this compound can be metabolised into several metabolites, which also show significant anti-cancer effects. There are several recent reviews on the bioactivities of these citrus PMF, as well as the potential chemopreventive abilities of these PMFs toward cancers in general (Goh et al., 2019).

L-ascorbic acid is the precursor of vitamin C. Vitamin C is an essential micronutrient, which plays an important role in numerous physiological processes in the human body. Unlike most mammals, humans cannot generate endogenous vitamin C. The biological efficacy of 
vitamin $\mathrm{C}$, depends on its redox capabilities and functions as a cofactor in many enzymatic reactions. In physiological concentrations, it also works as an antioxidant. It has also been shown to have a positive effect in patients with acute myeloid leukaemia, in association with decitabine and, the in vitro data show synergistic efficacy of both treatments. (Gorkom et al., 2019). Given the growing interest in the diet and bioactive compounds, that protect or treat various diseases, without undesirable effects, and given the very interesting composition of the hydrolate, the enhancement and intake of these products, could transform the citrus hydrolates from waste into a resource. 
4. Effect of controlled water stress of Citrus $\times$ clementina $\mathrm{cv}$. Clemenules and Citrus sinensis (L.) Osbeck cv. Sanguinelli 


\subsection{Introduction}

The effects of water stress on plant processes depend on different factors such as species and grade, and duration of stress (Bradford and Hshiao, 1982). The effects of water stress on yield depends on the phenological stage in which stress occurs. In many species, there are "critical" growth phases, in which the lack of water can lead to greater reductions in yield compared to other growth periods (Vaux and Pruit, 1983, Ginestar and Castle, 1996). For citrus fruits, the periods of flowering and fruiting are generally considered the most critical phases (Doorenbos and Kassam, 1979).

The production of secondary substances and metabolites can be supported by environmental factors, and water stress is considered one of the main ones that affect many aspects of plant physiology and biochemistry (Charles et al., 1994). In aromatic plants, drought can cause significant changes in the yield and compositions of some metabolites (Petropoulos et al., 2008). Biotic and abiotic environmental factors influence growth parameters, EO yield and components (Clark and Menary, 2008; Aziz and Hendawy, 2008).

Water stress due to drought affects multiple physiological parameters in citrus fruits, including a reduction in water potential and stomatal conductance (Gómez-Cadenas et al., 1996). Under severe water deprivation, the stomata close very quickly, stopping the flow of water almost completely in just two hours (Tudela and Primo Millo, 1992).

Continuous water stress conditions decrease plant growth and reduce $\mathrm{CO}_{2}$ assimilation (Brakke and Allen, 1995). In citrus trees, as in other plants, a period of drought, followed by a restoration of the hydration conditions favourable to growth, favours flowering (Lovatt $e t$ al., 1988; Southwick and Davenport, 1986). Citrus plants, subjected to severe water stress, can show leaf damage and even wilt without abscission (Tudela and Primo Millo, 1992). However, with rain and or irrigation, the water stress in the leaves is mitigated, recovering turgor and, shortly thereafter, some of them can detach from the tree (Gómez-Cadenas et al., 1996; Tudela and Primo Millo, 1992). The hormonal regulation of this response can be related to severe conditions of water stress, that promote the synthesis and accumulation of 1-aminocyclopropane-1-carboxylic acid (ACC, the metabolic precursor of ethylene) in the roots (Tudela and Primo Millo, 1992). The rehydration of the plants causes the transport of ACC towards the shoots, where it is oxidized to ethylene and, subsequently, favours the abscission of the leaves (Tudela and 1992). Also, abscisic acid (ABA) appears to be the intermediary between water stress conditions and ethylene production. Therefore, these plant growth regulators link the state of water to a plant survival response such as leaf abscission 
Gómez-Cadenas et al., 1996). Furthermore, water stress could influence monoterpenes synthesis (C10 compounds) from geranyl diphosphate (GPP), through the localized plastid pathway 2C-methyl-erythritol-4-phosphate (MEP) (Eisenreich et al., 1997), responsible for the diversity of terpenes structures involved in the composition of EOs (Bohlmann et al., 1998). This work aimed to evaluate the effect of water stress applied before the citrus plants bloom on the yield and composition of EOs from leaves and flowers. Also, the effect on fruit production was monitored. The stress was applied in February on Citrus $\times$ clementina cv. Clemenules and Citrus sinensis (L.) Osbeck cv. Sanguinelli plants. 


\subsection{Materials and methods}

\subsubsection{Plant material}

Sanguinelli and Clemenules plants three-years-old grew in pots under greenhouse were divided into two groups: one control, and others subjected to water stress. EOs from leaves of both groups were extracted in March when stressed plants reached a water potential of 3.500 pascals. The flowers were collected during the flowering period, in April 2018. Furthermore, until September, the number of flowers, size and number of fruits, number and type of shoots were monitored. Shoots were classified in: Multi-flowered leafless shoots, Single leafless flowered shoots, Vegetative shoots, Leafy mixed shoots, Terminal leafy flower shoots, Bud flower and Bud mixed (Agustì 2003).

\subsubsection{Measurement of the water potential of the trees}

The water potential measurements were made with the model psychrometric (HR33T Dew Point Microvolter). The HR-33T allows the determination of the water potential thanks to the coupling with the chamber (model C-52) and after appropriate calibration. After stress, all the plants were irrigated normally. Two leaves from each tree were picked and used immediately to determine the water potential.

\subsubsection{EOs extraction and characterization}

EOs were extracted from Sanguinelli and Clemenules in March 2018 and April 2018. Characterization and extraction of EOs was carried out following the methods previously listed (paragraph dedicated to EOs).

The EOs composition was identified through gas chromatography and gas chromatography coupled with mass spectrometry. 


\subsection{Result}

\subsubsection{Clemenules EOs}

In Clemenules EOs 116 compounds (Table 4_1) were identified in the four EOs: 38 in Clementine leaves of control plants (CLC), 31 in Clementine leaves of stressed plants (CLS), 23 in Clementine flower of control plants (CFC) and 24 in Clementine flower of stressed plants (CFS). The compounds identified accounted for $99.73 \%$ for CLC, $99.67 \%$ for CLS, $95.52 \%$ for CFC and $92.35 \%$ for CFS of the EO composition. monoterpene hydrocarbons were the more abundant, in percentage, in all EOs: $64.82 \%$ in CLC, $60.44 \%$ in CLS, $63.31 \%$ in CFC and 62.65 in CFS. Sabinene, the most abundant component in all Clementina EOs, was present in the following amount: $22.09 \%$ in CLC, $21.02 \%$ in CLS, $32.82 \%$ in CFC and $31.12 \%$ in CFS. Linalool, the second most abundant component in all Clementina EOs, was present in quantities of $17.14 \%$ in CLC, $17.27 \%$ in CLS, $20.71 \%$ in CFC and $17.02 \%$ in CFS. (Z)- $\beta$-Ocimene, the third more abundant component, was present in quantities of $16.64 \%$ in CLC, $15.56 \%$ in CLS, $11.08 \%$ in CFC and $16.24 \%$ in CFS.

The percentage of oxygenated monoterpenes in the EOs was: $28.91 \%$ in CLC, $30.51 \%$ in CLS, 26.93\% in CFC and 20.83 in CFS. Sesquiterpene hydrocarbons were present in the following amount: $5.1 \%$ in CLC, $4.97 \%$ in CLS, $0.63 \%$ in CFC and $0.13 \%$ in CFS.

Oxygenated sesquiterpenes were present in quantities of $0.9 \%$ in CLC, 3.75\% in CLS, 3.07\% in $\mathrm{CFC}$ and $2.3 \%$ in CFS.

\begin{tabular}{|c|c|c|c|c|c|}
\hline \multirow[b]{3}{*}{ Compound } & \multirow[b]{3}{*}{$\mathbf{R I}$} & \multicolumn{4}{|c|}{ Abundance \% } \\
\hline & & \multicolumn{2}{|c|}{ Clementine Leaves } & \multicolumn{2}{|c|}{ Clementine Flowers } \\
\hline & & $\begin{array}{c}\text { Control } \\
\text { (CLC) }\end{array}$ & $\begin{array}{l}\text { Stress } \\
\text { (CLS) }\end{array}$ & $\begin{array}{c}\text { Control } \\
\text { (CFC) }\end{array}$ & $\begin{array}{l}\text { Stress } \\
\text { (CFS) }\end{array}$ \\
\hline Monoterpenic Hydrocarbons & & 64.82 & 60.44 & 63.31 & 62.65 \\
\hline$\alpha$-Thujene & 931 & & & $\mathrm{t}$ & $\mathrm{t}$ \\
\hline$\alpha$-Pinene & 938 & 1.05 & 0.94 & 0.72 & 0.31 \\
\hline Sabinene & 978 & 22.09 & 21.02 & 32.82 & 31.12 \\
\hline$\beta$-Pinene & 980 & 1.25 & 1.17 & 1.36 & 0.82 \\
\hline$\beta$-Myrcene & 993 & 3.67 & 3.37 & 3.38 & 3.06 \\
\hline$\alpha$-Phellandrene & 1005 & $\mathrm{t}$ & $\mathrm{t}$ & & \\
\hline$\delta$-3-Carene & 1014 & 11.69 & 11.52 & 0.5 & 0.8 \\
\hline$\alpha$-Terpinene & 1019 & $\mathrm{t}$ & $\mathrm{t}$ & & \\
\hline$p$-Cymene & 1028 & $\mathrm{t}$ & $\mathrm{t}$ & 0.32 & \\
\hline Limonene & 1033 & 2.07 & 0.2 & 0.59 & 0.49 \\
\hline (Z)- $\beta$-Ocimene & 1037 & 16.64 & 15.56 & 11.8 & 16.24 \\
\hline (E)- $\beta$-Ocimene & 1054 & 4.9 & 5.16 & 9.6 & 9.5 \\
\hline$\gamma$-Terpinene & 1063 & 0.41 & 0.36 & 1.74 & 0.19 \\
\hline Terpinolene & 1088 & 1.05 & 1.14 & 0.48 & 0.12 \\
\hline Oxygenated Monoterpenes & & 28.91 & 30.51 & 26.93 & 20.83 \\
\hline Linalool & 1103 & 17.14 & 17.27 & 20.71 & 17.02 \\
\hline
\end{tabular}




\begin{tabular}{|c|c|c|c|c|c|}
\hline Citronellal & 1160 & 4.87 & 6.83 & & \\
\hline Terpinen-4-ol & 1181 & 3.99 & 3.48 & 4.43 & 2.82 \\
\hline$\alpha$-Terpineol & 1194 & 0.99 & 1.07 & 0.92 & 0.6 \\
\hline Citronellol & 1236 & 1.55 & 1.67 & & \\
\hline Neral & 1246 & 0.23 & $\mathrm{t}$ & & \\
\hline Geranial & 1276 & $\mathrm{t}$ & $\mathrm{t}$ & 0.13 & \\
\hline Methyl geranate & 1327 & 0.14 & 0.19 & & \\
\hline Citronellyl acetate & 1357 & $\mathrm{t}$ & $\mathrm{t}$ & & \\
\hline Neryl acetate & 1368 & $\mathrm{t}$ & $\mathrm{t}$ & 0.74 & 0.39 \\
\hline Sesquiterpenic Hydrocarbons & & 5.1 & 4.97 & 0.63 & 0.13 \\
\hline$\beta$-Elemene & 1395 & 4.01 & 4.4 & 0.48 & 0.08 \\
\hline$\beta$-Caryophyllene & 1420 & 0.87 & 0.57 & 0.15 & 0.05 \\
\hline$\alpha$-Humulene & 1454 & 0.22 & & & \\
\hline (E)- $\beta$-Farnesene & 1459 & $\mathrm{t}$ & $\mathrm{t}$ & & \\
\hline Germacrene D & 1481 & $\mathrm{t}$ & & & \\
\hline Byciclogermacrene & 1496 & $\mathrm{t}$ & & & \\
\hline Byciclogermacrene & 1496 & $\mathrm{t}$ & & & \\
\hline$(\mathrm{E}, \mathrm{E})-\alpha$-Farnesene & 1510 & $\mathrm{t}$ & & & \\
\hline$\beta$-Sesquiphellandrene & 1525 & $\mathrm{t}$ & & & \\
\hline Oxygenated Sesquiterpenes & & 0.9 & 3.75 & 3.07 & 2.3 \\
\hline (E)-Nerolidol & 1568 & $\mathrm{t}$ & $\mathrm{t}$ & & \\
\hline Caryophyllene oxide & 1582 & $\mathrm{t}$ & $\mathrm{t}$ & & \\
\hline Selin-11-en-4- $\alpha$-ol & 1660 & $\mathrm{t}$ & & & \\
\hline$\beta$-Sinensal & 1705 & 0.18 & 3.66 & 3.07 & 2.3 \\
\hline$\alpha$-Sinensal & 1760 & 0.72 & 0.09 & & \\
\hline Hydrocarbons & & 0 & 0 & 1.58 & 6.44 \\
\hline n-Heneicosane & 2074 & & & & 0.13 \\
\hline n-Docosane & 2174 & & & 1.11 & 3.6 \\
\hline n-Tricosane & 2323 & & & 0.47 & 2.54 \\
\hline Tetracosane & 2405 & & & & 0.17 \\
\hline Pentacosane & 2495 & & & & 1.22 \\
\hline TOTAL IDENTIFIED & & 99.73 & 99.67 & 95.52 & 92.35 \\
\hline
\end{tabular}

Table 4_1. Percentages of the Citrus $\times$ clementina cv. Clemenules essential oils components. Values lower than $0.04 \%$ in CLC, $0.05 \%$ in CLS, $0.09 \%$ in CFC and $0.06 \%$ was denoted as traces $(t)$.

\subsubsection{Sanguinelli EOs}

In EOs from leaves, 67 compounds (Table 4_2) were identified: 40 in Sanguinelli EOs from control leaves (SLC) and 27 in Sanguinelli leaves of stressed plants (SLS). The identified compounds accounted for $92.9 \%$ of the EO composition for SLC and $99.38 \%$ for SLS. Monoterpene hydrocarbons were present in both EOs, in quantities of $33.74 \%$ in SLC and $21.11 \%$ in SLS, Oxygenated monoterpenes represented $27.57 \%$ in SLC and $32.87 \%$ in SLS. Sesquiterpene hydrocarbons were present in quantities of $14.38 \%$ in SLC and $26.74 \%$ in SLS. Oxygenated sesquiterpene group accounted for $16.95 \%$ in SLC and $17.22 \%$ in SLS. 
SLC EO was mainly composed for $\beta$-Sinensal (10.7\%), (Z)- $\beta$-Ocimene (8.35\%), Sabinene (8.09\%), Citronellal (6.95\%), $\delta$-3-Carene (6.43\%), $\beta$-Elemene (5.92\%) and $\alpha$-Sinensal (5.76\%). The main compounds in SLS EO were Citronellol (15.66\%), Germacrene A (14.8\%), $\beta$-Elemene (11.07\%), $\beta$-Sinensal (8.31\%), Neral (8.1\%), $\alpha$-Sinensal $(7.56 \%)$ and $\delta$-3-Carene (7.54\%). The remaining 20 components were below 3.6\%.

\begin{tabular}{|c|c|c|c|}
\hline \multirow[b]{3}{*}{ Compound } & \multirow[b]{3}{*}{ RI } & \multicolumn{2}{|c|}{ Abundance \% } \\
\hline & & \multicolumn{2}{|c|}{ Sanguinelli Leaves } \\
\hline & & $\begin{array}{c}\text { Control } \\
\text { (SLC) }\end{array}$ & $\begin{array}{l}\text { Stress } \\
(\text { SLS }) \\
\end{array}$ \\
\hline Monoterpenic Hydrocarbons & & 33.74 & 21.11 \\
\hline$\alpha$-Pinene & 938 & 0.4 & 3.59 \\
\hline Sabinene & 977 & 8.09 & 0.85 \\
\hline$\beta$-Pinene & 981 & 0.63 & 0.09 \\
\hline Myrcene & 991 & 2.28 & 2.04 \\
\hline$\alpha$-Phellandrene & 1006 & 0.31 & $\mathrm{t}$ \\
\hline$\delta$-3-Carene & 1011 & 6.43 & 7.54 \\
\hline$\alpha$-Terpinene & 1020 & 0.32 & \\
\hline$p$-Cymene & 1026 & 0.39 & \\
\hline o-cymene & 1029 & 3.22 & 3.56 \\
\hline Limonene & 1037 & & \\
\hline (E)- $\beta$-Ocimene & 1039 & 0.38 & \\
\hline (Z)- $\beta$-Ocimene & 1051 & 8.35 & \\
\hline$\gamma$-Terpinene & 1062 & 0.92 & \\
\hline Terpinolene & 1088 & 2.02 & 3.44 \\
\hline Oxygenated Monoterpenes & & 27.57 & 32.87 \\
\hline Bergamal & 1057 & 0.13 & \\
\hline Linalool & 1101 & 4.26 & 1.39 \\
\hline Citronellal & 1156 & 6.95 & 1.9 \\
\hline Terpinen-4-ol & 1183 & 3.92 & 0.69 \\
\hline p-Cymen-8-ol & 1190 & $\mathrm{t}$ & \\
\hline$\alpha$-Terpineol & 1194 & 0.15 & 0.09 \\
\hline Decanal & 1207 & 0.28 & \\
\hline Citronellol & 1230 & 3.21 & 15.66 \\
\hline Neral & 1241 & 2.05 & 8.1 \\
\hline Geranial & 1274 & 3.33 & 3.02 \\
\hline methyl geraniate & 1326 & 0.45 & 0.88 \\
\hline methyl-Anthranilate & 1340 & & \\
\hline Citronellyl acetate & 1351 & 1.39 & \\
\hline Neryl acetate & 1360 & 0.75 & 1.14 \\
\hline Geranyl acetate & 1379 & 0.7 & \\
\hline Sesquiterpenic Hydrocarbons & & 14.38 & 26.74 \\
\hline$\beta$-Elemene & 1390 & 5.92 & 11.07 \\
\hline$\beta$-Caryophyllene & 1419 & 2.9 & \\
\hline
\end{tabular}




$\begin{array}{cccc}\alpha \text {-Humulene } & 1453 & 0.42 & 0.87 \\ \text { (E)- } \beta \text {-Farnesene } & 1456 & 1.42 & \\ \text { Germacrene D } & 1481 & 0.56 & \\ \text { Bicyclogermacrene } & 1496 & 0.39 & \\ \text { Germacrene A } & 1507 & 2.77 & 14.8 \\ \text { (E,E)- } \alpha \text {-Farnesene } & 1509 & & \text { t } \\ \text { Oxygenated Sesquiterpenes } & & 16.95 & 17.22 \\ \text { Caryophyllene oxide } & 1582 & 0.17 & \\ \text { 1-Hexadecene } & 1590 & 0.05 & \\ \beta \text {-Sinensal } & 1694 & 10.7 & 8.31 \\ \text { (2Z,6E)-Farnesol } & 1718 & 0.27 & 1.35 \\ \alpha-S i n e n s a l & 1758 & 5.76 & 7.56 \\ \text { Hydrocarbons } & & \mathbf{0 . 2 6} & \mathbf{1 . 4 4} \\ \text { Tetracosane } & 2400 & & 0.27 \\ \text { Hexacosane } & 2600 & & 0.58 \\ \text { Octacosane } & 2798 & & 0.59 \\ \text { Nonacosane } & 2899 & 0.26 & \end{array}$

TOTAL IDENTIFIED

$92.9 \quad 99.38$

Table 4_2. Percentage of Citrus sinensis (L.) Osbeck cv. Sanguinelli essential oils components. Values lower than $0.07 \%$ was denoted as traces $(t)$.

\subsubsection{Effects of water stress on shoots production}

Type of shoots of Clemenules trees is reported in Figure 4_1. The total number of shoots per tree was 208 in control and 214 in stress treatment. In control trees, the shoots consisted of 148 multi-flowered leafless shoots, 11 single leafless and 43 leafy mixed shoots. While the composition of total shoots in the stressed tree was 94 for multi-flowered leafless shoots, 20 for single leafless, 18 for vegetative shoots, 28 for leafy mixed shoots and 64 for terminal leafy flower shoots. Water stress treatment did not influence the total number of shoots and leafy mixed shoots. Moreover, water stress influenced negatively multiflowered leafless shoots and positively single leafless flowered number of shoots, compared to control. Only in the stressed tree were present the vegetative shoots and terminal leafy flower shoots. 


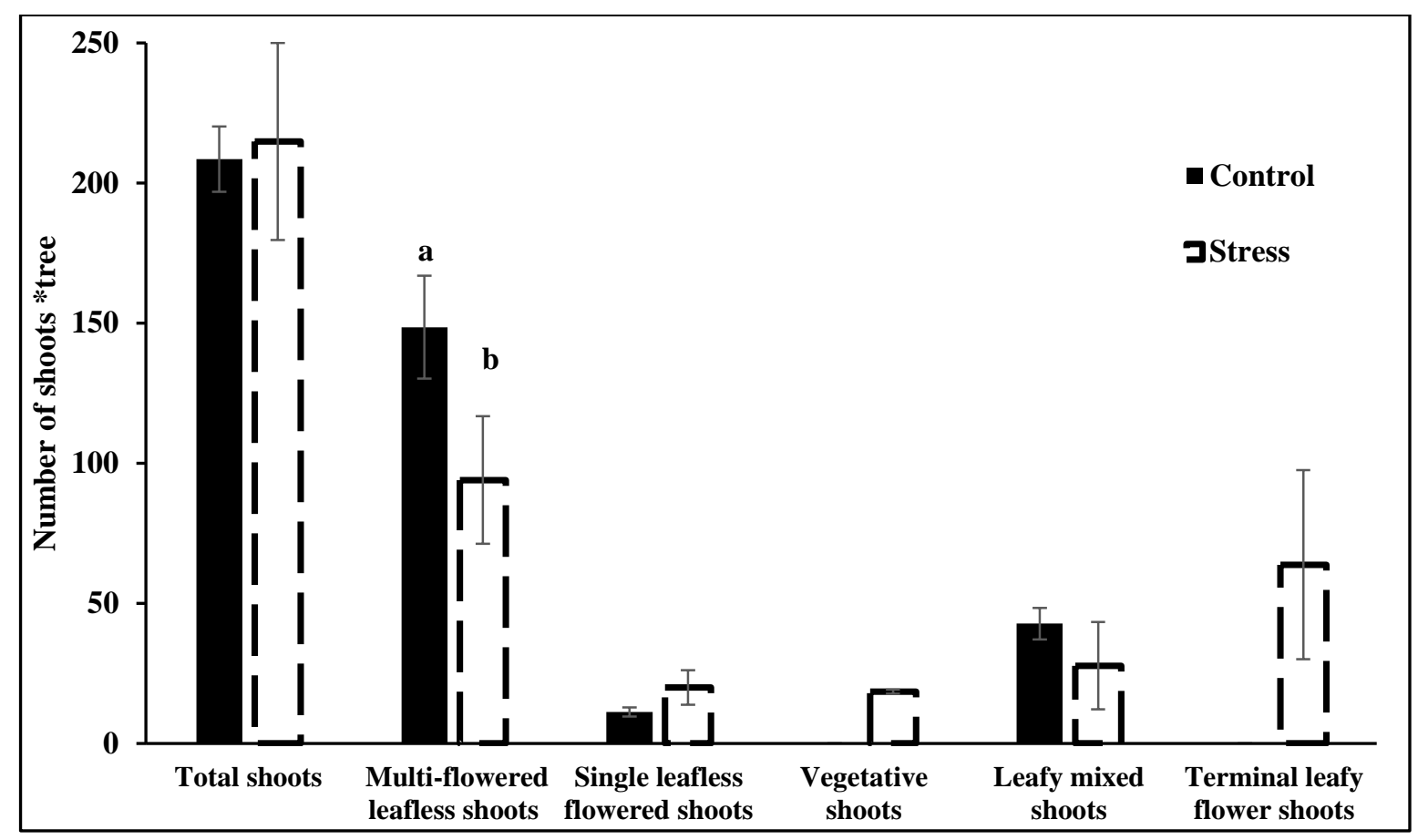

Figure 4_1. Effect of controlled water stress on Clemenules type of shoots. Different types of shoots present in plants are represented. The values are expressed as the average of the measurements made on four trees with their standard error. Different letters indicate significant differences $p(\leq 0.05)$.

Type of shoots of Sanguinelli trees is reported in Figure 4_2. The total number of shoots per tree was 108 in control and 88 in stress treatment. The total shoots consisted of 89 multiflowered leafless shoots and 38 leafy mixed shoots in control trees, while the composition of total shoots, in a stressed tree, was 88 multi-flowered leafless shoots and 28 leafy mixed shoots. The number of mixed buds, reported in Figure 4_3a, amounted to 6 for control and 5 for stressed trees. The number of flower buds, reported in Figure 4_3b, was 4 for control and 5 for stressed trees. Water stress treatment did not affect the total number of shoots, multi-flowered leafless shoots and leafy mixed shoots. However, the water stress favoured the differentiation of the flower buds and, negatively, influenced the differentiation of the mixed buds compared with control. 


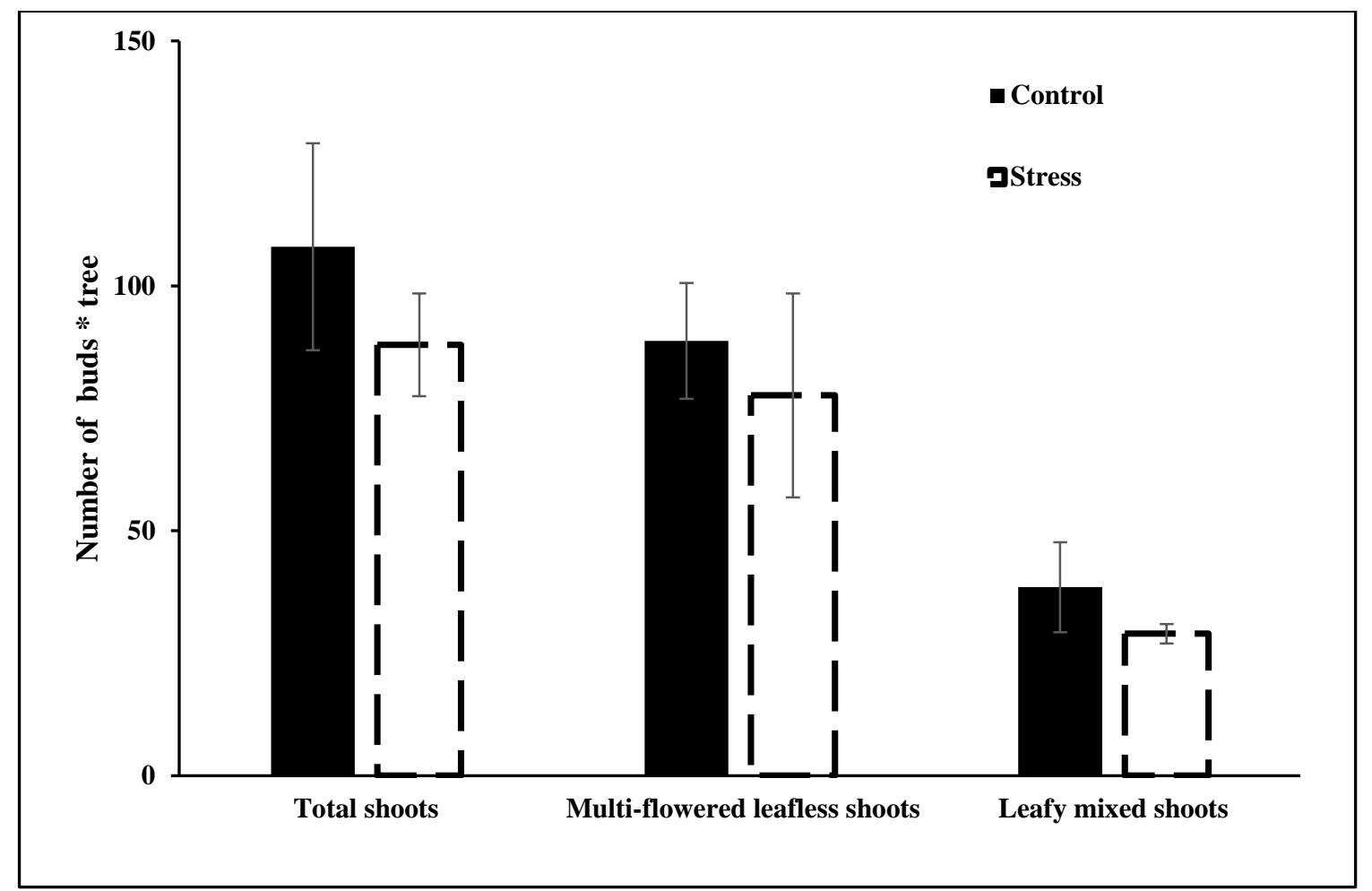

Figure 4_2. Effect of controlled water stress on Sanguinelli type of shoots. Different types of shoots present in trees are represented. The values are expressed as means of the measurements made on four trees \pm standard error. Different letters indicate significant differences $(p \leq 0.05)$.
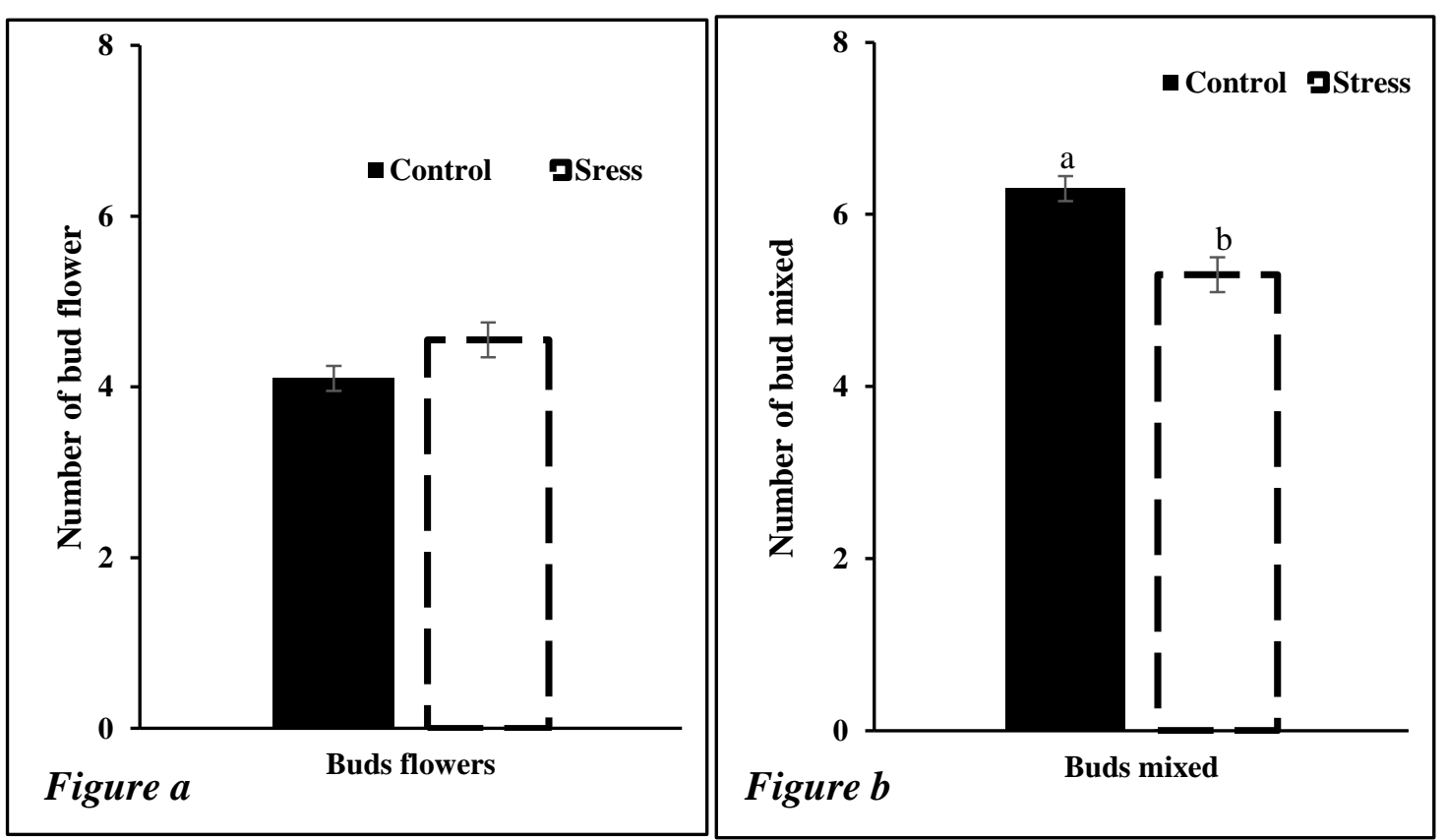

Figure 4_3. Effect of controlled water stress on Sanguinelli buds differentiation. Different types of buds present in plants are represented (a) buds flowers and (b) mixed buds. The values are expressed as the mean of the measurements made on four trees \pm standard error. Different letters indicate significant differences ( $p \leq 0.05$ ). 
The total number of fruits over the day in Clemenules per tree is reported in Figure 4_4. The initial number of attached fruit per tree was 344 in control and 398 in stress treatment. The fruits counted were monitored once a month. In September, which was the last month, the number of fruits per tree was 14 for control and 6 for stressed trees. Similarly, fruit diameters were measured from July onwards: the measurements are shown in Figure 4_5. At the starting point, corresponding to 10/07/2018, the average diameters in both treatments were $18 \mathrm{~mm}$. Also on $1^{\text {st }}$ August, the average diameters were in both treatments equal to $26 \mathrm{~mm}$ while in September they were $35 \mathrm{~mm}$ for control and $38 \mathrm{~mm}$ for stressed trees.

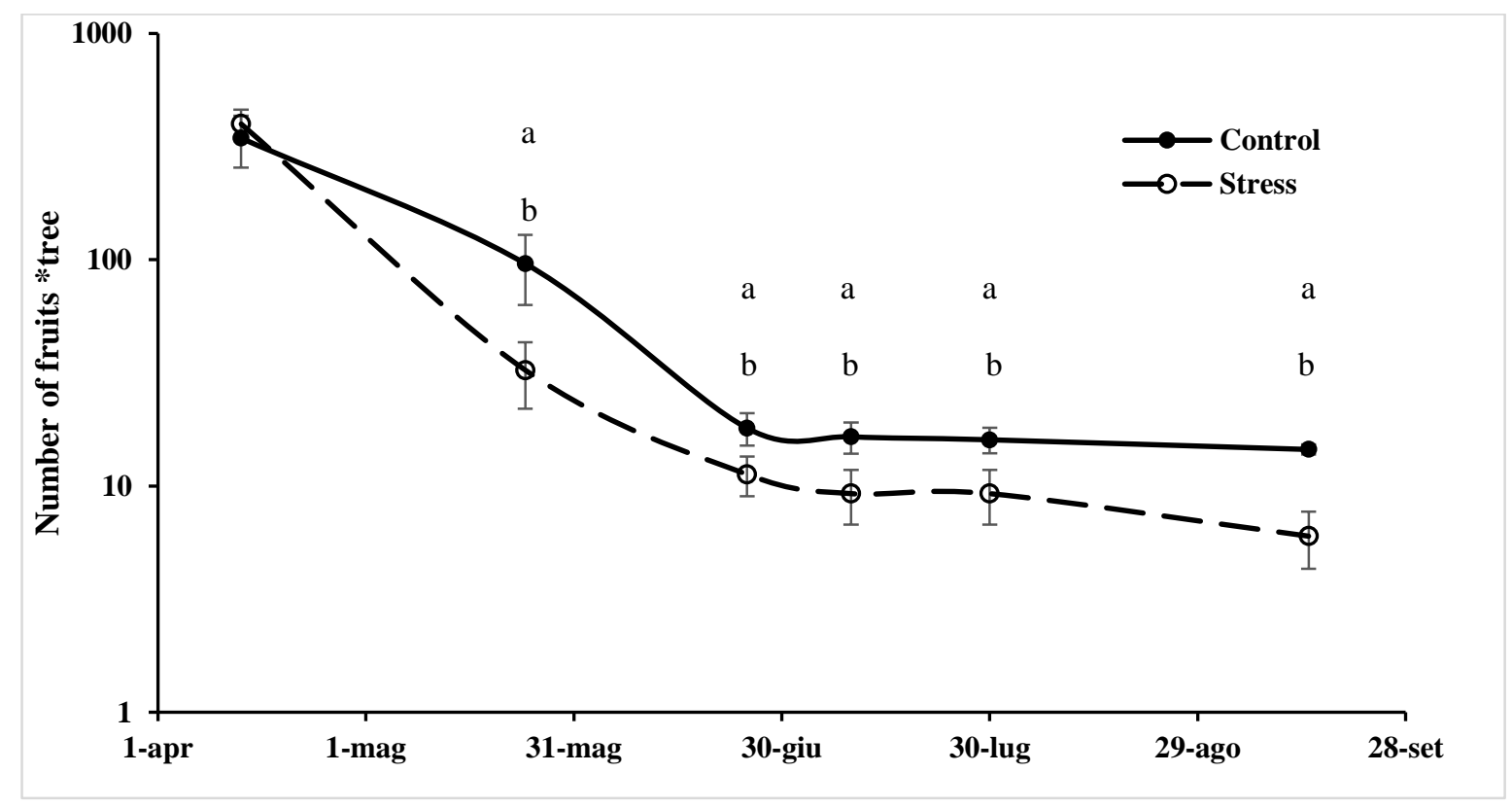

Figure 4_4. Effect of controlled water stress on Clemenules fruit number. Values are expressed as the mean of the measurements on four trees \pm standard error. Different letters indicate significant differences $(p \leq 0.05)$.

The trend of the total number of Sanguinelli fruits per tree is reported in Figure 4_6.

The initial number of attached fruits per tree was 182 in control and 264 in stress treatment. The fruits counted were monitored once a month. In September, which was the last month, the number of fruits per tree was 7 for control and 6 for stressed trees. Similarly, fruit diameters were measured from July onwards, and the measurements are shown in Figure 4_7. At the starting point, which corresponds to 10/07/2018, average diameters were $24 \mathrm{~mm}$ for control e $29 \mathrm{~mm}$ for stressed. In August were $29 \mathrm{~mm}$ for control and $35 \mathrm{~mm}$ in stressed, while in September was $41 \mathrm{~mm}$ for control and $48 \mathrm{~mm}$ for stressed trees. 


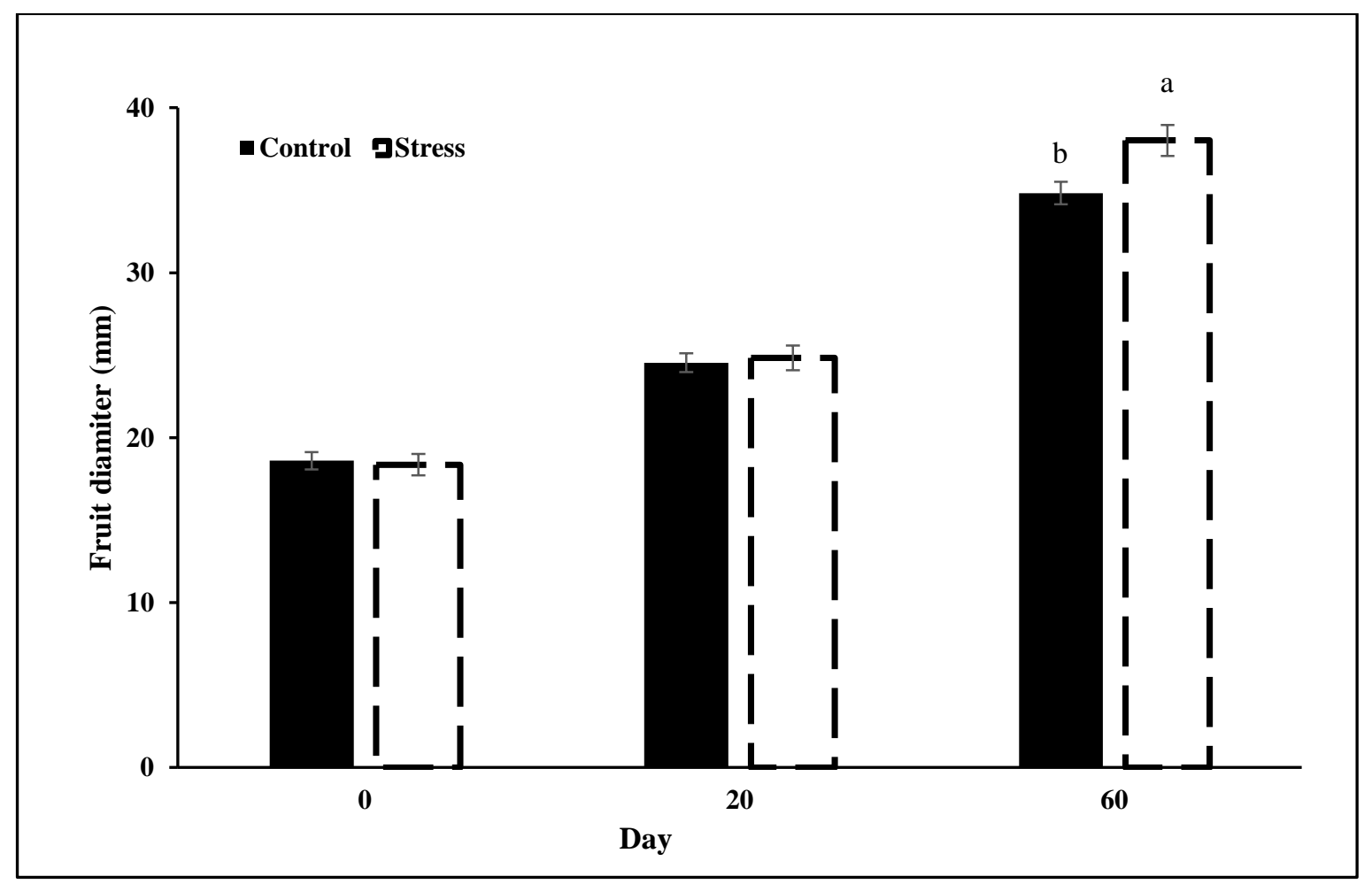

Figure 4_5. Effect of controlled water stress on Clemenules fruit diameter. Values are the means of the measurements made on four trees \pm standard error. Different letters indicate significant differences $(p<0.05)$.

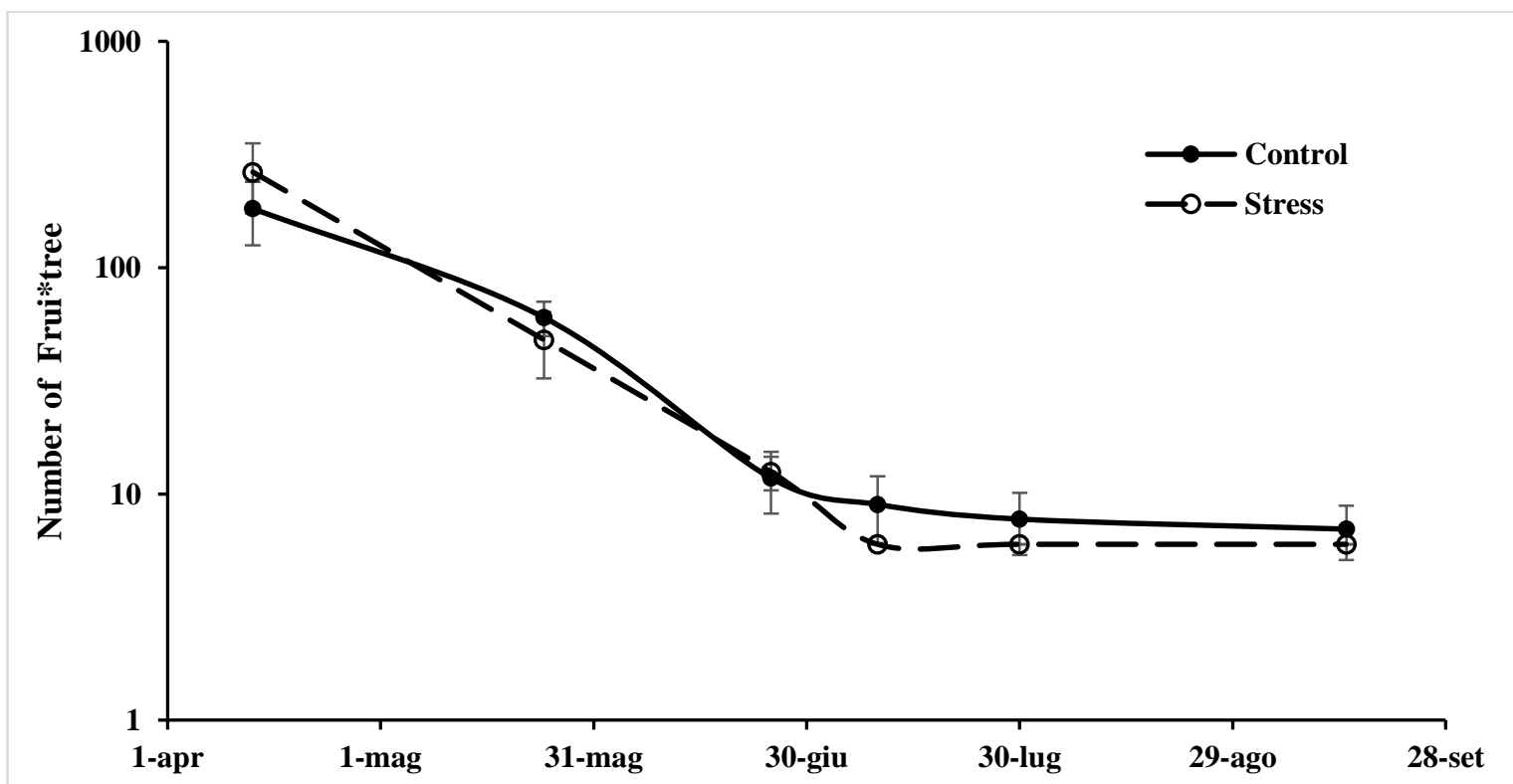

Figure 4_6. Effect of controlled water stress on Sanguinelli number of fruits. Values are expressed as the means of the measurements made on four trees \pm standard error. Different letters indicate significant differences ( $p \leq 0.05$ ). 


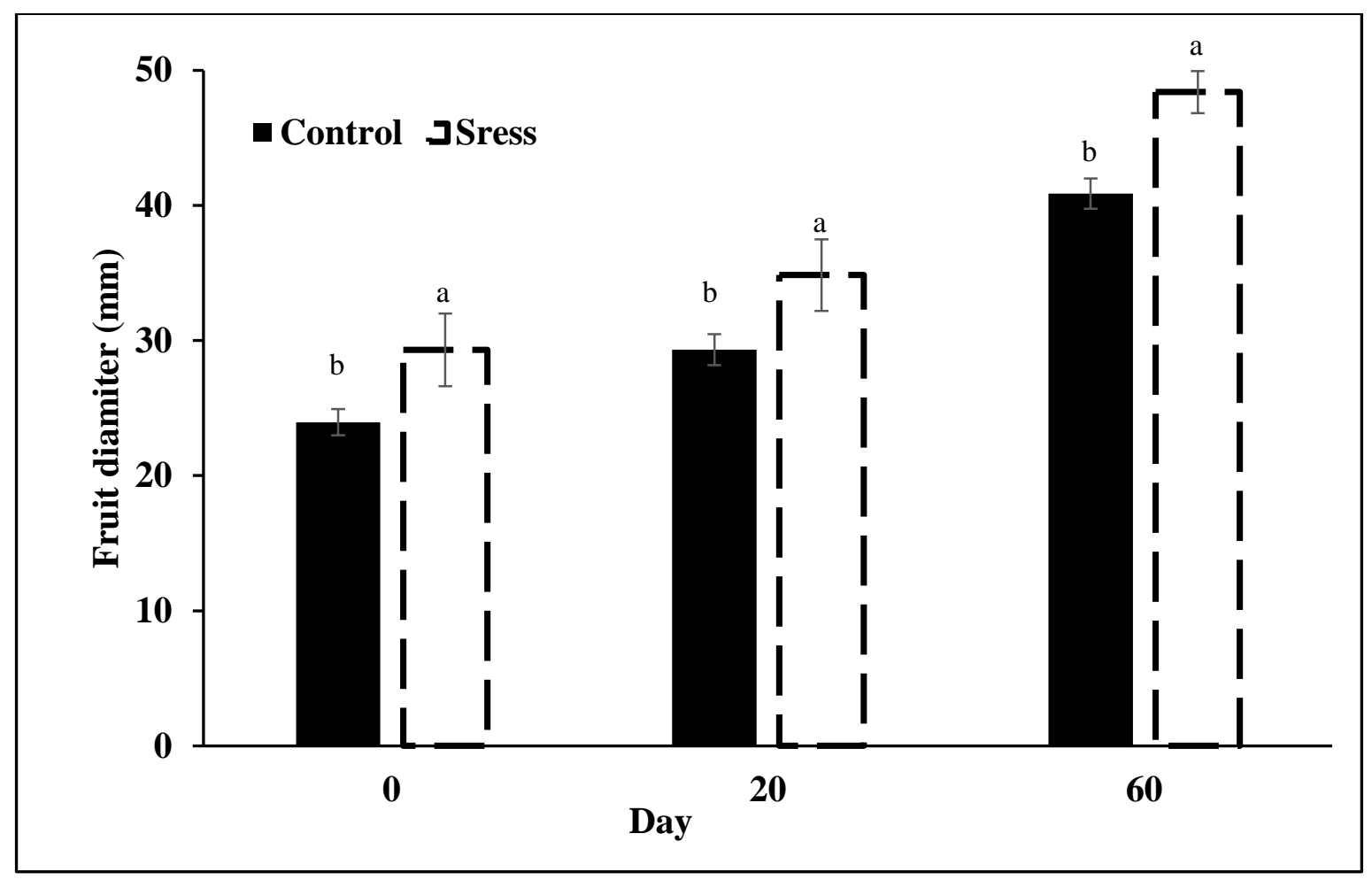

Figure 4_7. Effect of controlled water stress on Sanguinelli fruit diameter. Values are expressed as the mean of the measurements made on four trees \pm standard error. Different letters indicate significant differences $(p \leq 0.05)$. 


\subsection{Discussion}

In literature, there are no studies that apply, immediately after the vegetative recovery, water stress on Citrus species and, in particular, on Clemenules and Sanguinelli cultivar. The results are discussed in this chapter.

In all Clemenules EOs, there was a decrease in each monoterpene, except for (Z)- $\beta$ ocimene that, in CFS EO, increased. A decreasing trend of the monoterpene hydrocarbons has also been reported by Maatallah et al. (2016), which applied the water stress on plants of Laurus nobilis L. The stress increased the amount of oxygenated monoterpenes in the leaves EOs and, in particular, the Citronellall as such as the content in oxygenated sesquiterpenes.

In the CFS EO, the content in oxygenated monoterpenes was lower and, the abundance of all its components decreased. The content of oxygenated sesquiterpenes was also lower in CFS than in CFC. Furthermore, in CFS, there was a greater presence of other hydrocarbons. The application of water stress on Sanguinelli trees decreased, in the leaf EO, the content in monoterpene hydrocarbons. Within the previous group, the Sabinene content decreased and, the $\alpha$-Pinene content, increased. Stress was responsible, in EO SLS, for increasing in the number of oxygenated monoterpenes and, in particular, favoured the production of Citronellol. Stress, also, increased the quantity of sesquiterpene hydrocarbons in SLS, favouring by the synthesis of $\beta$-Elemene and Germacrene A. In the other two groups oxygenated sesquiterpenes and hydrocarbon of SLS EO, there were no important differences. Water stress, in Clemenules trees, influenced negatively multi-flowered leafless shoots and positively single leafless flowered number of shoots, as compared to control. Only in stressed trees, there were vegetative shoots and terminal leafy flower shoots. Clemenules trees stressed had few fruits, but on the other hand, their diameters were greater. Water stress treatment, in Sanguinelli, did not affect the total number of shoots, multiflowered leafless shoots and leafy mixed shoots. However, the water stress favoured the differentiation of the flower buds and negatively influenced the differentiation of the mixed buds, compared with control. Furthermore, the number of fruits had not been influenced, but the stress favoured a larger diameter of the fruits. A very concrete factor found in this study is that water stress increases the fruit diameter. This result will be certainly very attractive on the market and consumers. Another consideration is that the effects of stress were not immediate on citrus trees, but were evident after some time. 
5.Allelopathic effect of citrus essential oils on weed species 


\subsection{Introduction}

Weeds cause serious damage because they compete with the main crops for the intake of water and nutrients and cause large yield losses (Oerke 2006; Murphy et al., 2008) and represent a serious problem for world agriculture (Benvenuti et al., 2017).

The use of synthetic herbicides undoubtedly controls the weed but increases environmental pollution and is toxic to human health (Fagodia et al., 2017). Furthermore, in recent decades, the application of synthetic herbicides has been increasingly limited and the continuous use of them has led to the emergence of resistant weeds biotypes. The replacement of synthetic herbicides is necessary for the production of crops of good quality and respectful for the environment.

Research work on herbicides based on natural products has recently been increased due to the growing demand for its use in organic and conventional agriculture (Duke and Dayan, 2015; Gitsopoulos et al., 2017) and because they could be an environmentally friendly alternative to synthetic herbicides. Among the different natural plant products, volatile EO and its constituents have attracted a lot of attention because their phytotoxicity has shown strong activity against weeds (Duke et al., 2000). Furthermore, EOs are generally considered as safe chemicals (GRAS) (Isman, 2000; Tworkoski, 2002).

Different natural mechanisms of self-defence protect various plant species from the competitive effects of the vegetation present in the surrounding environment through some secondary metabolites that they produce which exert an allelopathic action (Weston and Duke, 2003). Allelopathy is defined as the effect of a plant (or a microorganism) on other plants (or microorganism) through the release of chemical substances (called allelochemicals) into the environment by leaching, exudation, volatilization (release of volatile compounds) or decomposition (El-Rokiek and El-Nagdi, 2011). Allelopathic substances influence the germination of seeds, the physiology of plants, the growth and survival of other plants.

Over the past two decades a large number of allelochemicals, from more than 20 families (phenolic compounds and other secondary metabolites), have been discovered in radical exudates, volatile compounds or decomposing tissues (Bais et al., 2006; Belz, 2007; Doré et $a l ., 2004)$. Consequently, the potential of allelochemicals released by plants to control weeds has been studied and suggested, and some experimental tests have confirmed their partial or total control (Belz, 2007; Caamal-Maldonado et al., 2001; de Albuquerque et al., 2011; Liebman and Davis, 2000 ). 
In this thesis, the EOs of lemon and orange were tested on weeds species. The weeds species were Amaranthus retroflexus (L., Echinochloa crus-galli L. P. Beauv, Portulaca oleracea L. and Avena fatua L. These species were chosen because they are important weeds in many crops not only in the Mediterranean area but also in the rest of the world, because of their cosmopolite distribution. 


\subsection{Materials and Methods}

\subsubsection{Plant material}

The EOs tested (AU, AI, LU, LI) have been described in the previous chapter. The weed seeds used for this assays (from A. retroflexus, E. crus-galli, P. oleracea and A. fatua) were purchased from Herbiseed (United Kingdom) in 2018, the seeds were collected in 2017.

\subsubsection{In vitro allelopathic activity test of essential oils}

The effect of orange and lemon EOs on seed germination and the growth of weed seedlings of (A. retroflexus, E. crus-galli, P. oleracea, A. fatua ) was assessed.

\section{-Petri preparation}

To perform this test, for the species $A$. retroflexus and $P$. oleracea, 20 seeds of each of the two species were placed in $9 \mathrm{~cm}$ diameter Petri dishes with 2 disks of $73 \mathrm{~g} / \mathrm{m}^{2}$ filter paper and $5 \mathrm{ml}$ of distilled water were added. For each treatment, five repetitions were performed. For E. crus-galli test, 10 seeds were used in each Petri dish, $6 \mathrm{ml}$ of distilled water were added and ten repetitions were performed. For A. fatua, 5 seeds were used in each petri dish, $6 \mathrm{ml}$ of distilled water were added, and ten repetitions were performed.

\section{-EO application}

For all species, the tested doses were prepared by adding the EO in volumes necessaries to obtain concentrations of 0 (CTR), 1(1), 2 (2), 4 (3), 8 (4) and 12 (5) $\mu \mathrm{L} / \mathrm{mL}$ respectively (number in () was dose index). After the addition of seeds and water to the Petri dish, the EO was placed in the centre of the inner part of two disks of $73 \mathrm{~g} / \mathrm{m} 2$ filter paper. Successively filter paper was situated on top of the seeds. All Petri dishes were sealed with Parafilm.

\section{- Germination chamber condition}

Petri dishes were placed in an EQUITEC brand germination-growth chamber (model EGCS 1501 3SHR) where they were incubated for 14 days.

The chamber conditions were adapted to the species tested, for E. crus-galli and P. oleracea seeds the chamber was set at $30.0 \pm 0.1^{\circ} \mathrm{C}$ for 16 hours of light and $20.0 \pm 0.1^{\circ} \mathrm{C}$ for 8 hours of darkness, while for A. retroflexus at $35.0 \pm 0.1^{\circ} \mathrm{C}$ for 16 hours of light and $22.0 \pm$ 
$0.1^{\circ} \mathrm{C}$ for 8 hours of darkness. The conditions for $A$. fatua were $23.0 \pm 0.1^{\circ} \mathrm{C}$ for 8 hours of light and $16.0 \pm 0.1^{\circ} \mathrm{C}$ for 16 hours of darkness.

\section{- Allelopathic activity monitoring}

To evaluate the allelopathic activity, photos were taken from all the Petri dishes 3, 5, 7, 10 and 14 days after treatments application. After making each photo, the plates were closed with Parafilm, without adding water or EO, and were again introduced into the germination chamber under the same conditions. The photos were processed with the software Digimizer, to count the seeds to obtain the germination percentages and to measure the seedlings, hypocotyls and root length.

\subsubsection{In vivo allelopathic activity test of essential oil}

This test was carried out in the greenhouses of the Universitat Politècnica de València. For each species, two different methods of application of the EO LI emulsified with Fitoil were tested. Fitoil, which was purchased from Xeda (Italy), is a biological commercial adjuvant that was utilized for preparing each emulsion at the dose of $0.5 \mathrm{~mL}$ for a liter of water.

In the first method, the emulsion was irrigated (I) directly in the soil of the pots. In the second method, the emulsion was sprayed (S) on the aerial part of the weeds using a manual sprayer from Hozelock (United Kingdom). Four doses for each method were tested: $12,18,24$ and $30 \mu \mathrm{L} / \mathrm{mL}$, to verify which method is the most adequate to maximize the herbicidal activity of the EO LI. Furthermore, each application method for each species involved the realization of two controls, one with only the application of water (CTR) and the other with water plus Fitoil (Fit). The controls with Fitoil were made to monitoring the effects it has on the weed species.

\section{-Pot preparation}

For each treatment, 10 polypropylene pots in with $8 \times 8 \mathrm{~cm}$ surface and $7 \mathrm{~cm}$ depth were used. A $73 \mathrm{~g} / \mathrm{m} 2$ filter paper, $8 \times 8 \mathrm{~cm}$ in size was placed at the base of each pot to prevent the perlite from leaking out. Above the filter paper, $7 \mathrm{~g}$ of perlite were placed which corresponded to about $2 \mathrm{~cm}$ high and subsequently above it was placed $220 \mathrm{~g}$ of dry soil corresponding to about $5 \mathrm{~cm}$ of soil. The soil was collected in an abandoned citrus orchard $\left(39^{\circ} 37^{\prime} 24.7^{\prime \prime} \mathrm{N}, 0^{\circ} 17^{\prime} 25.5^{\prime \prime} \mathrm{W}\right.$, Puzol, Valencia), non-treated with herbicides. 
The soil when was collected was finely chopped with the hoe, subsequently sieved with a $1 \mathrm{~cm}$ mesh sieve. The collected soil was stalked in the laboratory to dry it. Also, the water holding capacity (WHC) was determined by placing $50 \mathrm{~g}$ of dry soil in a funnel with wet filter paper to prevent the spillage of soil. After the funnel, very slow water was placed until percolation. The funnel was weighed before and after two hours of placing the water. For difference, the amount of water retained by $50 \mathrm{~g}$ of soil was obtained.

\section{- Plants preparation}

To obtain the weed species for the herbicidal tests (A. retroflexus, E. crus-galli, $P$. oleracea, A. fatua) 200 seeds of each species were placed on top of 2 sheets of filter paper saturated with water, in a plastic tray matte $30 * 40 \mathrm{~cm}$ and $5 \mathrm{~cm}$ high covered with aluminium foil for the first two days. The growth chamber and germination conditions were the same described for the in vitro activity tests. On the fifth day, the emerged seedlings were selected for uniformity in growth. One seedling was transplanted in each pot, the pots have been previously brought to the WHC. The pots with seedlings were left in the laboratory to rest for 24 hours and in the evening they were placed in the glass greenhouse. Before any treatment, the pots were grouped into ten to obtain homogeneous groups of plants. Ten replicates per each treatment were performed.

All treatment was applied when the plants reached the appropriate phenological stage. The $\mathrm{BBCH}$-scale was taken as a reference. The abbreviation derives from Biologische Bundesanstalt, Bundessortenamt and CHemical industry. For the monocotyledons species A. fatua and E. crus-galli, 13-14 BBCH was chosen corresponding to 2-3 true leaves, while for the dicotyledons $P$. oleracea and A. retroflexus was 4-5 true leaves, corresponding to 13$14 \mathrm{BBCH}$.

All pots in the same treatment were treated with $20 \mathrm{~mL}$ of emulsion or water, individually with the appropriate method and application dose.

\section{-Treatment preparation}

For each treatment, $200 \mathrm{~mL}$ of water emulsion (Fitoil and EO) were prepared. Preliminarily each dose of EO necessary to carry out the concentrations (12, 18, 24 and 30 $\mu \mathrm{L} / \mathrm{mL}$ ) was mixed with $100 \mu \mathrm{L}$ of Fitoil in a $50 \mathrm{~mL}$ falcon, subsequently, $20 \mathrm{~mL}$ of distilled water were added and the whole was stirred by vortex shaker for 2 minutes. Subsequently, this emulsion was brought to a volume of $200 \mathrm{~mL}$. The $250 \mathrm{~mL}$ beaker with 
the emulsion remained under stirring through a magnetic stirrer for the duration of the treatment. All the plants were treated in the greenhouse.

\section{-Greenhouse environmental conditions}

Once a week for the duration of the tests the pots were irrigated to bring the soil to the WHC. During the test, the greenhouse temperature and relative humidity data were recorded using a U23 Pro v2 external temperature data logger. The averages, maximum and minimum $\mathrm{T}^{\mathrm{a}}$ and H.R.for each treatment and species are shown in Table 5_S1.

\section{- Allelopathic activity in vivo measurement}

At the end of all tests, all plants of the four species were analyzed. The tests ended when was verified that the plants with serious or permanent damage had no vegetative restart. Each plant was recuperated by immersing the root system in water to remove the soil. Sequentially all plants were washed adequately to eliminate all soil residues and then dried with paper. Immediately for all plants, the fresh weight was recorded and digital images were taken to be processed after with the software Digimizer, to measure the length of the aerial parts and roots.

Also, the dry weight was obtained after being in a stove at $60^{\circ} \mathrm{C}$ until the plant reached a constant weight. The efficacy of each treatment was assessed for each plant, through assigning the value 100 if the plant was dead and 0 if it was alive.

\subsubsection{Statistical analysis}

Data were processed using the Statgraphics Centurion XVII statistical software. All data obtained were subjected to one-way analysis of variance (ANOVA) followed by Fisher's Least Significant Difference (LSD) test with 95\% probability level for the means differentiation.

The percentage data were previously transformed through the formula $y=\operatorname{arcosen} \sqrt{ }$ ( $\mathrm{x} / \mathrm{100}$ ), where $\mathrm{x}$ was the percentage obtained, to meet the required homoscedasticity requirements. 


\begin{tabular}{|c|c|c|c|c|c|c|c|c|c|c|}
\hline \multirow{2}{*}{ Species } & \multirow{2}{*}{ Method } & \multicolumn{3}{|c|}{ Date } & \multicolumn{3}{|c|}{$\mathrm{T}^{\mathrm{a}}\left({ }^{\circ} \mathrm{C}\right)$} & \multicolumn{3}{|c|}{ HR } \\
\hline & & Transplant & Treatment & Explant & med & $\max$ & $\min$ & med & $\max$ & $\min$ \\
\hline \multirow{2}{*}{ A. fatua } & I & $30 / 04 / 2018$ & $15 / 05 / 2018$ & $13 / 06 / 2018$ & 23.203 & 34.995 & 16.344 & 61.686 & 97.470 & 17.797 \\
\hline & S & 08/11/2018 & 26/11/2018 & $13 / 12 / 2018$ & 19.727 & 36.065 & 10.124 & 61.571 & 86.778 & 29.523 \\
\hline \multirow{2}{*}{ A. retroflexus } & I & 20/08/2018 & $30 / 08 / 2018$ & $11 / 09 / 2018$ & 27.411 & 38.032 & 22.034 & 70.832 & 87.959 & 42.813 \\
\hline & $\mathrm{S}$ & $20 / 08 / 2018$ & $30 / 08 / 2018$ & $11 / 09 / 2018$ & 27.411 & 36.700 & 22.585 & 70.832 & 88.883 & 38.863 \\
\hline \multirow{2}{*}{ P. oleracea } & I & 09/07/2018 & 03/08/2018 & $23 / 08 / 2018$ & 29.018 & 44.043 & 22.872 & 67.158 & 93.701 & 17.442 \\
\hline & S & $16 / 07 / 2018$ & 09/08/2018 & $30 / 08 / 2018$ & 28.787 & 39.488 & 23.136 & 68.769 & 89.211 & 35.006 \\
\hline \multirow{2}{*}{ E. crus-galli } & I & $13 / 07 / 2018$ & $24 / 07 / 2018$ & 02/08/2018 & 29.249 & 44.043 & 23.208 & 66.566 & 93.701 & 17.442 \\
\hline & $S$ & $20 / 08 / 2018$ & $30 / 08 / 2018$ & $11 / 09 / 2018$ & 27.411 & 36.700 & 22.585 & 70.832 & 88.883 & 38.863 \\
\hline
\end{tabular}

Table 5_3 S1. Transplant, treatment and explant dates are reported. Average, maximum and minimum temperature and HR in the greenhouse during, each experiment are reported. 


\subsection{Results}

\subsubsection{In-Vitro allelopathic activity}

Citrus EOs LI, LU, AI and AU described above were applied to the four weed species. Five doses numbered 1, 2, 3, 4 and 5 corresponding to 1, 2, 4, 8 and $12 \mu \mathrm{L} / \mathrm{mL}$ per dose plus control (CTR) were applied for each species.

The results obtained are discussed individually by species. For each species, the effects of germination and length of plant, stem and root are discussed.

\section{-Effects on Avena fatua.}

The effects of citrus EOs applied to A. fatua at different doses are reported in (Tables 5_1a, 5_1b, 5_2a and 5_2b). All EOs inhibited A. fatua germination (Table 5_1b).

\begin{tabular}{|c|c|c|}
\hline \multicolumn{3}{|c|}{ 5_1a. Hypocotyl length (cm) } \\
\hline LI1 & $9.12 \pm 1.00$ & $\mathrm{a}$ \\
\hline AU1 & $9.00 \pm 1.77$ & $\mathrm{a}$ \\
\hline LU2 & $8.80 \pm 0.46$ & $\mathrm{abc}$ \\
\hline CTR & $8.06 \pm 0.83$ & abc \\
\hline AI2 & $7.16 \pm 0.91$ & abcd \\
\hline LU1 & $6.94 \pm 2.09$ & abcd \\
\hline AU2 & $5.88 \pm 1.95$ & bcde \\
\hline LI2 & $5.70 \pm 1.05$ & bcde \\
\hline LI3 & $5.22 \pm 1.24$ & bcde \\
\hline AI1 & $4.94 \pm 0.86$ & de \\
\hline AU3 & $3.32 \pm 1.22$ & ef \\
\hline AI3 & $2.98 \pm 1.09$ & efg \\
\hline LI4 & $1.69 \pm 0.00$ & efg \\
\hline AI4 & $0.79 \pm 0.79$ & fg \\
\hline AU4 & $0.23 \pm 0.23$ & $\mathrm{~g}$ \\
\hline LU3 & $0.06 \pm 0.06$ & $\mathrm{~g}$ \\
\hline AU5 & $0.00 \pm 0.00$ & $\mathrm{~g}$ \\
\hline AI5 & $0.00 \pm 0.00$ & $\mathrm{~g}$ \\
\hline LI5 & $0.00 \pm 0.00$ & $\mathrm{~g}$ \\
\hline LU5 & $0.00 \pm 0.00$ & $\mathrm{~g}$ \\
\hline LU4 & $0.00 \pm 0.00$ & $\mathrm{~g}$ \\
\hline
\end{tabular}

\begin{tabular}{|l|r|l|l|}
\hline 5_1b. & Germination $(\%)$ \\
\hline CTR & $75.0 \pm 0.56$ & $\mathrm{a}$ \\
AI1 & $33.1 \pm 0.21$ & $\mathrm{~b}$ \\
LI1 & $29.0 \pm 0.23$ & $\mathrm{bc}$ \\
AU1 & $19.4 \pm 0.68$ & $\mathrm{bcd}$ \\
LI2 & $17.7 \pm 0.62$ & cd \\
AI2 & $9.8 \pm 0.92$ & de \\
LU1 & $8.6 \pm 0.70$ & de \\
AU3 & $6.2 \pm 0.75$ & ef \\
AU2 & $5.2 \pm 0.59$ & ef \\
LU2 & $5.2 \pm 0.59$ & ef \\
LI3 & $3.3 \pm 0.56$ & efg \\
AI3 & $1.3 \pm 0.60$ & fgh \\
AI4 & $0.8 \pm 0.38$ & fgh \\
AI5 & $0.2 \pm 0.21$ & gh \\
LI4 & $0.2 \pm 0.21$ & gh \\
AU4 & $0.0 \pm 0.00$ & h \\
AU5 & $0.0 \pm 0.00$ & h \\
LI5 & $0.0 \pm 0.00$ & h \\
LU3 & $0.0 \pm 0.00$ & h \\
LU4 & $0.0 \pm 0.00$ & h \\
LU5 & $0.0 \pm 0.00$ & h \\
\hline
\end{tabular}

Table 5_la and 5_1b. Effects of citrus EOs on A. fatua hypocotyl length (5_la) and germination (5_1b). Data are means \pm standard error of 10 replicates. Different letters in the same column indicate significant differences between the treatments 
The average germination of the control was $75 \%$, the least effect was manifested by AI1 with a reduction compared to the control of $42 \%$, while in LI5, AU4, AU5, LU3, LU4, LU5 no seeds had germinated on the fourteenth day (Table 5_1b).

All EOs influenced the biometric parameters of the plants (Tables 5_1a, 5_2a, 5_2b). The EOs reduced the seedlings length (Table 5_2a) and the root length (Table 5_2b). The length of the CTR seedlings was $17.49 \mathrm{~cm}$, while the plants grown in LU3 measured $0.17 \mathrm{~cm}$. CTR root length was $9.44 \mathrm{~cm}$ followed by AI1 $8.17 \mathrm{~cm}$ the smallest was LU3 $0.11 \mathrm{~cm}$ (Table $\left.5 \_2 b\right)$.

Strange results were obtained in the hypocotyl length (Table 5_1a) as some low doses of the tested EOs stimulated the growth of the hypocotyl. The hypocotyl length of the treatments was $9.12 \mathrm{~cm}$ in LI1, $9.00 \mathrm{~cm}$ in AU1, $8.80 \mathrm{~cm}$ in LU2, all greater than the CTR hypocotyl length, which was $8.06 \mathrm{~cm}$. The treatments with the shortest hypocotyls were LI5 and LU3.

\begin{tabular}{|c|c|c|}
\hline \multicolumn{3}{|c|}{ 5_2a. Seedling length $(\mathrm{cm})$} \\
\hline CTR & $17.49 \pm 0.99$ & $\mathrm{a}$ \\
\hline LI1 & $16.30 \pm 1.73$ & $a b$ \\
\hline LU2 & $14.32 \pm 1.22$ & abcd \\
\hline AI1 & $13.11 \pm 1.72$ & bc \\
\hline AU1 & $12.93 \pm 2.44$ & bcd \\
\hline AI2 & $12.13 \pm 1.20$ & $\mathrm{~cd}$ \\
\hline LU1 & $11.78 \pm 3.49$ & cde \\
\hline LI2 & $9.87 \pm 1.73$ & cdef \\
\hline AU2 & $8.95 \pm 2.44$ & defg \\
\hline LI3 & $7.59 \pm 1.34$ & efg \\
\hline AI3 & $5.72 \pm 1.49$ & fgh \\
\hline AU3 & $5.34 \pm 1.54$ & g \\
\hline LI4 & $3.73 \pm 0.00$ & fghi \\
\hline AI4 & $1.08 \pm 1.08$ & hi \\
\hline AU4 & $0.46 \pm 0.46$ & 1 \\
\hline LU3 & $0.17 \pm 0.17$ & $\mathrm{i}$ \\
\hline AU5 & $0.00 \pm 0.00$ & $\mathrm{i}$ \\
\hline AI5 & $0.00 \pm 0.00$ & 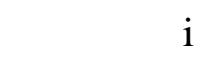 \\
\hline LI5 & $0.00 \pm 0.00$ & $\mathrm{i}$ \\
\hline LU4 & $0.00 \pm 0.00$ & 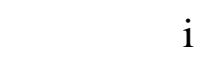 \\
\hline LU5 & $0.00 \pm 0.00$ & 1 \\
\hline
\end{tabular}

\begin{tabular}{|l|rrr|l|}
\hline 5_2b. & Root length $(\mathrm{cm})$ \\
\hline CTR & 9.44 & \pm & 0.51 & $\mathrm{a}$ \\
AI1 & 8.17 & \pm & 1.03 & $\mathrm{ab}$ \\
LI1 & 7.18 & \pm & 0.87 & $\mathrm{bc}$ \\
LU2 & 5.51 & \pm & 1.68 & cde \\
AI2 & 4.97 & \pm & 0.62 & $\mathrm{~d}$ \\
LU1 & 4.84 & \pm & 1.55 & de \\
LI2 & 4.17 & \pm & 0.70 & def \\
AU1 & 3.92 & \pm & 0.74 & def \\
AU2 & 3.07 & \pm & 0.50 & efg \\
AI3 & $2.73 \pm$ & 0.69 & efg \\
LI3 & $2.37 \pm$ & 0.20 & fg \\
LI4 & 2.04 & \pm & 0.00 & defghi \\
AU3 & 2.02 & \pm & 0.36 & gh \\
AI4 & 0.29 & \pm & 0.29 & hi \\
AU4 & 0.24 & \pm & 0.23 & i \\
LU3 & 0.11 & \pm & 0.11 & i \\
LU4 & 0.00 & \pm & 0.00 & i \\
AI5 & 0.00 & \pm & 0.00 & i \\
LI5 & 0.00 & \pm & 0.00 & i \\
LU5 & 0.00 & \pm & 0.00 & i \\
AU5 & $0.00 \pm$ & 0.00 & i \\
\hline
\end{tabular}

Table 5_2a and 5_2b. Effect of citrus EOs on A. fatua seedling length (5_2a) and root length $\left(5 \_2 b\right)$. Data are means \pm standard error of 10 replicates. Different letters in the same column indicate significant differences between the treatments. 


\section{-Effect on Amaranthus retroflexus}

Effects of citrus EOs applied at different doses are reported in (Tables 5_3a, 5_3b, 5_4a and 5_4b). All EOs treatments inhibited A. retroflexus germination (Table 5_3b) compared to CTR.

\begin{tabular}{|l|c|l|l|}
\hline 5_3a. & \multicolumn{3}{|l|}{ Hypocotyl length $(\mathrm{cm})$} \\
\hline AI2 & $2.92 \pm 0.14$ & $\mathrm{a}$ \\
AI3 & $2.83 \pm 0.18$ & $\mathrm{a}$ \\
AI1 & $2.71 \pm 0.11$ & $\mathrm{a}$ \\
AI4 & $2.28 \pm 0.34$ & $\mathrm{~b}$ \\
AU1 & $1.43 \pm 0.04$ & $\mathrm{c}$ \\
AU2 & $1.36 \pm 0.10$ & $\mathrm{~cd}$ \\
CTR & $1.28 \pm 0.05$ & $\mathrm{cde}$ \\
AI5 & $1.25 \pm 0.34$ & $\mathrm{cde}$ \\
LU1 & $1.23 \pm 0.02$ & $\mathrm{cde}$ \\
LU2 & $1.19 \pm 0.02$ & $\mathrm{cde}$ \\
LI2 & $1.18 \pm 0.05$ & $\mathrm{cde}$ \\
LI1 & $1.15 \pm 0.04$ & $\mathrm{de}$ \\
AU3 & $1.01 \pm 0.10$ & ef \\
AU4 & $0.80 \pm 0.05$ & fg \\
LU3 & $0.60 \pm 0.16$ & gh \\
LI3 & $0.55 \pm 0.07$ & gh \\
LU4 & $0.49 \pm 0.01$ & gh \\
AU5 & $0.41 \pm 0.02$ & h \\
LI4 & $0.00 \pm 0.00$ & & i \\
LI5 & $0.00 \pm 0.00$ & & i \\
LU5 & $0.00 \pm 0.00$ & i \\
\hline
\end{tabular}

\begin{tabular}{|l|r|l|}
\hline 5_3b. & \multicolumn{3}{|l|}{ Germination $(\%)$} \\
\hline CTR & $99.2 \pm 0.30$ & a \\
AU1 & $90.7 \pm 1.21$ & ab \\
AU2 & $89.2 \pm 1.94$ & bc \\
LI2 & $80.6 \pm 0.26$ & bcd \\
LU1 & $78.7 \pm 0.34$ & bcd \\
LI1 & $72.2 \pm 0.08$ & cde \\
AI1 & $71.4 \pm 0.24$ & cde \\
LU2 & $67.6 \pm 0.42$ & def \\
AI2 & $63.4 \pm 0.48$ & def \\
AU3 & $53.2 \pm 0.44$ & ef \\
AI3 & $45.1 \pm 1.78$ & fg \\
AU4 & $24.2 \pm 3.29$ & gh \\
LI3 & $13.8 \pm 0.89$ & hi \\
LU3 & $8.6 \pm 0.11$ & hij \\
AU5 & $8.2 \pm 1.41$ & hij \\
AI4 & $5.5 \pm 0.98$ & ijk \\
AI5 & $4.0 \pm 0.82$ & ijk \\
LU4 & $0.8 \pm 0.30$ & jk \\
LI4 & $0.0 \pm 0.00$ & $\mathrm{k}$ \\
LU5 & $0.0 \pm 0.00$ & $\mathrm{k}$ \\
LI5 & $0.0 \pm 0.00$ & $\mathrm{k}$ \\
\hline
\end{tabular}

Table 5_3a and 5_3b. Effects of citrus EOs on A. retroflexus hypocotyl length (5_3a) and germination (5_3b). Data are means \pm standard error of 10 replicates. Different letters in the same column indicate significant differences between the treatments

The average germination of CTR was $99.2 \%$, the minimum effect was manifested by AU2 with a reduction compared to the CTR of $10 \%$, while in LI5, LI4 and LU5 no seeds had germinated on the fourteenth day.

EOs influenced biometric parameters of the plants (Tables 5_3a, 5_4a, 5_4b).

AI1, AI2, AI3 treatments were stimulants of seedling length compared to CTR while the other treatments were inhibitory. The smaller plants had grown in the LU4 and AU5 treatments. All EOs doses inhibited the root length (Table 5_4b). 


\begin{tabular}{|c|c|c|}
\hline \multicolumn{3}{|c|}{ 5_4a. Seedling length $(\mathrm{cm})$} \\
\hline $\mathrm{AI} 2$ & $4.01 \pm 0.21$ & $\mathrm{a}$ \\
\hline AI3 & $3.97 \pm 0.24$ & $a b$ \\
\hline AI1 & $3.75 \pm 0.13$ & $a b c$ \\
\hline CTR & $3.50 \pm 0.14$ & bcd \\
\hline LI2 & $3.33 \pm 0.14$ & cde \\
\hline AU2 & $3.23 \pm 0.08$ & de \\
\hline AU1 & $3.19 \pm 0.08$ & de \\
\hline AI4 & $3.18 \pm 0.49$ & de \\
\hline LU2 & $3.11 \pm 0.08$ & de \\
\hline LI1 & $3.06 \pm 0.13$ & de \\
\hline AU3 & $2.91 \pm 0.25$ & $\mathrm{e}$ \\
\hline LU1 & $2.87 \pm 0.15$ & $\mathrm{e}$ \\
\hline AU4 & $2.33 \pm 0.10$ & $\mathrm{e}$ \\
\hline LI3 & $1.79 \pm 0.25$ & $\mathrm{e}$ \\
\hline LU3 & $1.73 \pm 0.30$ & $\mathrm{e}$ \\
\hline AI5 & $1.70 \pm 0.44$ & de \\
\hline LU4 & $1.38 \pm 0.08$ & e \\
\hline AU5 & $1.26 \pm 0.15$ & e \\
\hline LU5 & $0.00 \pm 0.00$ & \\
\hline LI4 & $0.00 \pm 0.00$ & \\
\hline LI5 & $0.00 \pm 0.00$ & 1 \\
\hline
\end{tabular}

\begin{tabular}{|c|c|c|}
\hline \multicolumn{3}{|c|}{ 5_4b. Root length $(\mathrm{cm})$} \\
\hline CTR & $2.22 \pm 0.09$ & $\mathrm{a}$ \\
\hline LI2 & $2.15 \pm 0.12$ & $a b$ \\
\hline LU2 & $1.92 \pm 0.07$ & $a b c$ \\
\hline AU3 & $1.91 \pm 0.16$ & $\mathrm{bc}$ \\
\hline LI1 & $1.91 \pm 0.16$ & bc \\
\hline AU2 & $1.87 \pm 0.16$ & $\mathrm{bc}$ \\
\hline AU1 & $1.77 \pm 0.07$ & $\mathrm{~cd}$ \\
\hline LU1 & $1.64 \pm 0.13$ & $\mathrm{~cd}$ \\
\hline AU4 & $1.53 \pm 0.07$ & de \\
\hline LI3 & $1.23 \pm 0.18$ & ef \\
\hline AI3 & $1.14 \pm 0.06$ & fg \\
\hline LU3 & $1.13 \pm 0.16$ & fg \\
\hline $\mathrm{AI} 2$ & $1.09 \pm 0.07$ & fg \\
\hline AI1 & $1.05 \pm 0.04$ & fg \\
\hline AI4 & $0.89 \pm 0.16$ & fg \\
\hline LU4 & $0.89 \pm 0.09$ & fgh \\
\hline AU5 & $0.85 \pm 0.13$ & gh \\
\hline AI5 & $0.44 \pm 0.10$ & $\mathrm{~h}$ \\
\hline LU5 & $0.00 \pm 0.00$ & $\mathrm{i}$ \\
\hline LI4 & $0.00 \pm 0.00$ & $\mathrm{i}$ \\
\hline LI5 & $0.00 \pm 0.00$ & $\mathrm{i}$ \\
\hline
\end{tabular}

Table 5_4a and 5_4b. Effect of citrus EOs on A. retroflexsus seedling length (5_4a) and root length (5_4b). Data are means \pm standard error of 10 replicates. Different letters in the same column indicate significant differences between the treatments.

\section{-Effect on Echinochloa crus-galli}

Effects of citrus EOs application on E. crus-galli at different doses are reported in Tables 5_5a, 5_5b, 5_6a and 5_6b). All EOs treatments inhibited E. crus-galli germination (Table 5_5b) and root length (Table 5_6b) compared to CTR. The average germination of the CTR was $96.5 \%$; AU1 and AI1 showed the minimum effect, with a reduction of $34 \%$ compared to the CTR, while in LI5 and LU5 no seeds had germinated on the fourteenth day (Table 5_5b). The root length in CTR was $3.44 \mathrm{~cm}$ in LI1 was decreasing by $0.22 \mathrm{~cm}$. While in AI4, the measurement was $0.84 \mathrm{~cm}$, which was the smallest in E. crus-galli. Seedling length is reported in Table 5a. LI 1 treatment with $8.53 \mathrm{~cm}$ was stimulatory compared to CTR, with $6.41 \mathrm{~cm}$, while all the other treatments reduced seedling length, being AU 4, with $2.00 \mathrm{~cm}$ the treatment with major inhibitory effect on seedling length. Hypocotyl length for seedlings of the different treatments is reported in (Table 5_5b) in decreasing order. Hypocotyl measured $5.32 \mathrm{~cm}$ in LI1, $4.76 \mathrm{~cm}$ in LI2, $3.40 \mathrm{~cm}$ in AI1, 3.40 in LI3, 3.27 in 
AU1, 3.27 in AU2 and 3.22 in LU1, all they were stimulatory of hypocotyl growth, although only LI1 and LI2 were significantly stimulant compared to CTR, which measured $2.97 \mathrm{~cm}$. The shorter hypocotyl was measured $0.73 \mathrm{~cm}$ in AU4.

\begin{tabular}{|c|c|c|}
\hline 5_5a. & Hypocotyl & ngth $(\mathrm{cm})$ \\
\hline LI1 & $5.32 \pm 0.34$ & $\mathrm{a}$ \\
\hline LI2 & $4.76 \pm 0.45$ & $a$ \\
\hline AI1 & $3.40 \pm 0.14$ & b \\
\hline LI3 & $3.40 \pm 0.35$ & $\mathrm{bc}$ \\
\hline AU1 & $3.27 \pm 0.17$ & bc \\
\hline AU2 & $3.27 \pm 0.16$ & bc \\
\hline LU1 & $3.22 \pm 0.16$ & $\mathrm{bc}$ \\
\hline CTR & $2.97 \pm 0.07$ & $\mathrm{bc}$ \\
\hline $\mathrm{AI} 2$ & $2.88 \pm 0.20$ & bcd \\
\hline LU2 & $2.83 \pm 0.24$ & bcde \\
\hline LI4 & $2.68 \pm 0.32$ & cde \\
\hline $\mathrm{AI} 3$ & $2.28 \pm 0.30$ & def \\
\hline AU3 & $2.18 \pm 0.23$ & ef \\
\hline LU3 & $1.83 \pm 0.20$ & $\mathrm{fg}$ \\
\hline AI5 & $1.75 \pm 0.33$ & fgh \\
\hline LU4 & $1.21 \pm 0.34$ & ghi \\
\hline AI4 & $1.16 \pm 0.17$ & hi \\
\hline AU5 & $1.04 \pm 0.39$ & ghi \\
\hline AU4 & $0.73 \pm 0.10$ & $\mathrm{ij}$ \\
\hline LI5 & $0.00 \pm 0.00$ & $\mathrm{k}$ \\
\hline LU5 & $0.00 \pm 0.00$ & $\mathrm{k}$ \\
\hline
\end{tabular}

\begin{tabular}{|c|c|c|}
\hline 5_5b. & Germination & $(\%)$ \\
\hline CTR & $96.5 \pm 0.42$ & $\mathrm{a}$ \\
\hline AU1 & $62.8 \pm 0.34$ & $\mathrm{~b}$ \\
\hline AI1 & $62.7 \pm 0.25$ & b \\
\hline LI1 & $58.7 \pm 0.30$ & bc \\
\hline AI2 & $58.0 \pm 0.40$ & bc \\
\hline LU1 & $51.2 \pm 0.28$ & $\mathrm{bc}$ \\
\hline AU2 & $45.9 \pm 0.23$ & $\mathrm{~cd}$ \\
\hline AI3 & $34.6 \pm 0.08$ & de \\
\hline LI2 & $31.2 \pm 0.17$ & def \\
\hline LU2 & $30.0 \pm 0.24$ & ef \\
\hline AI5 & $27.1 \pm 0.63$ & efg \\
\hline LI3 & $22.2 \pm 0.47$ & efgh \\
\hline AI4 & $18.9 \pm 0.17$ & fghi \\
\hline LU3 & $14.9 \pm 0.29$ & ghij \\
\hline AU3 & $13.5 \pm 0.48$ & hij \\
\hline AU4 & $8.1 \pm 0.63$ & ijk \\
\hline LI4 & $5.7 \pm 0.55$ & $\mathrm{jkl}$ \\
\hline AU5 & $2.4 \pm 0.43$ & $\mathrm{klm}$ \\
\hline LU4 & $0.9 \pm 0.24$ & $\operatorname{lm}$ \\
\hline LI5 & $0.0 \pm 0.00$ & $\mathrm{~m}$ \\
\hline LU5 & $0.0 \pm 0.00$ & $\mathrm{~m}$ \\
\hline
\end{tabular}

Table 5_5a and 5_5b. Effects of citrus EOs on E. crus-galli hypocotyl length (5_5a) and germination (5_5b). Data are means \pm standard error of 10 replicates. Different letters in the same column indicate significant differences between the treatments 


\begin{tabular}{|c|c|c|}
\hline \multicolumn{3}{|c|}{ 5_6a. Seedling length $(\mathrm{cm})$} \\
\hline LI1 & $8.53 \pm 0.57$ & $\mathrm{a}$ \\
\hline LI2 & $6.51 \pm 0.56$ & $\mathrm{~b}$ \\
\hline CTR & $6.41 \pm 0.11$ & b \\
\hline AI1 & $5.91 \pm 0.25$ & bc \\
\hline AU1 & $5.51 \pm 0.24$ & bcd \\
\hline LU1 & $5.19 \pm 0.26$ & cde \\
\hline AU2 & $5.10 \pm 0.25$ & cde \\
\hline $\mathrm{AI} 2$ & $4.94 \pm 0.30$ & cde \\
\hline LI 3 & $4.75 \pm 0.49$ & def \\
\hline LU2 & $4.65 \pm 0.41$ & def \\
\hline LU3 & $4.21 \pm 0.50$ & efg \\
\hline LI4 & $3.68 \pm 0.39$ & fgh \\
\hline $\mathrm{AI} 3$ & $3.63 \pm 0.45$ & fgh \\
\hline AU3 & $3.54 \pm 0.38$ & $\mathrm{gh}$ \\
\hline LU4 & $3.36 \pm 0.70$ & fgh \\
\hline AI5 & $2.74 \pm 0.47$ & hi \\
\hline AU5 & $2.60 \pm 0.71$ & hi \\
\hline AI4 & $2.00 \pm 0.28$ & $\mathrm{i}$ \\
\hline AU4 & $1.78 \pm 0.25$ & $\mathrm{i}$ \\
\hline LI5 & $0.00 \pm 0.00$ & $\mathrm{j}$ \\
\hline LU5 & $0.00 \pm 0.00$ & $\mathrm{j}$ \\
\hline
\end{tabular}

\begin{tabular}{|l|r|l|}
\hline 5_6b. & Root length $(\mathrm{cm})$ \\
\hline CTR & $3.44 \pm 0.07$ & $\mathrm{a}$ \\
LI1 & $3.22 \pm 0.23$ & $\mathrm{a}$ \\
AI1 & $2.51 \pm 0.14$ & $\mathrm{~b}$ \\
LU3 & $2.38 \pm 0.33$ & $\mathrm{bc}$ \\
AU1 & $2.24 \pm 0.07$ & $\mathrm{bcd}$ \\
LU4 & $2.15 \pm 0.42$ & bcde \\
AI2 & $2.06 \pm 0.12$ & cde \\
LU1 & $1.98 \pm 0.11$ & cde \\
AU2 & $1.83 \pm 0.12$ & def \\
LU2 & $1.81 \pm 0.21$ & defg \\
LI2 & $1.75 \pm 0.11$ & efgh \\
AU5 & $1.55 \pm 0.36$ & efghi \\
AU3 & $1.36 \pm 0.15$ & ghi \\
LI 3 & $1.36 \pm 0.17$ & fghi \\
AI3 & $1.34 \pm 0.16$ & hi \\
AU4 & $1.06 \pm 0.20$ & $\mathrm{ij}$ \\
LI4 & $1.00 \pm 0.11$ & $\mathrm{ij}$ \\
AI5 & $0.98 \pm 0.14$ & $\mathrm{ij}$ \\
AI4 & $0.84 \pm 0.13$ & $\mathrm{j}$ \\
LI5 & $0.00 \pm 0.00$ & $\mathrm{k}$ \\
LU5 & $0.00 \pm 0.00$ & $\mathrm{k}$ \\
\hline
\end{tabular}

Table 5_6a and 5_6b. Effect of citrus EOs on E. crus-galli seedling length (5_6a) and root length $\left(5 \_6 b\right)$. Data are means \pm standard error of 10 replicates. Different letters in the same column indicate significant differences between the treatments. 


\section{-Effect on Portulaca oleracea}

The effects of citrus EOs applied on P. oleracea at different doses are reported in Tables 5_7a , 5_7b, 5_8a and 5_8b. The average germination of the control was $87 \%$, in LU5, LI5 and AU5 no seeds had germinated on the fourteenth day. All EOs influenced the biometric parameters (Tables 5_7a, 5_8a and 5_8b) compared to CTR. AI3, AI2, AI1, AI4 treatments were stimulatory of the seedling length compared to CTR, but only AI3 and A12 effects were significant as compared with CTR; while AU2 seedling length was equal to CTR and the other treatments were inhibitors (Table 5_8a). The smaller seedlings were grown in LU3, AU4, LI4, and LU4. The treatments AI3, AI2, AI1, AI4, AU2 and AU1 were stimulatory of root length compared to CTR, however, only the three doses of AI (1,2 and 3) showed a significant effect. The rest of the treatments were inhibitory. AU4, LU3, LI4 and LU4 were the higher inhibitors of root length. AI3, AI2, LI1 and AI1 stimulated hypocotyl growth, but only AI3 and AI2 showed a significant effect comparing with CTR, while the rest of the treatments reduced the hypocotyl length. The smaller hypocotyls were in AU4, LI4 and LU4.

\begin{tabular}{|c|c|c|}
\hline \multicolumn{3}{|c|}{ 5_7a. Stem length $(\mathrm{cm})$} \\
\hline AI3 & $1.20 \pm 0.3$ & $\mathrm{a}$ \\
\hline $\mathrm{AI} 2$ & $1.14 \pm 0.1$ & $\mathrm{a}$ \\
\hline LI1 & $1.01 \pm 0.1$ & $a b$ \\
\hline AI1 & $0.92 \pm 0 .($ & $a b$ \\
\hline CTR & $0.81 \pm 0 .($ & bc \\
\hline AI4 & $0.81 \pm 0 .($ & bc \\
\hline LU1 & $0.61 \pm 0 .($ & $\mathrm{cd}$ \\
\hline AI5 & $0.58 \pm 0.1$ & $\mathrm{~cd}$ \\
\hline AU1 & $0.56 \pm 0.0$ & cde \\
\hline AU2 & $0.55 \pm 0.0$ & cde \\
\hline AU3 & $0.52 \pm 0.0$ & def \\
\hline LU2 & $0.47 \pm 0 .($ & defg \\
\hline $\mathrm{LI} 2$ & $0.41 \pm 0 .($ & defg \\
\hline LI3 & $0.29 \pm 0.1$ & efg \\
\hline LU3 & $0.27 \pm 0.1$ & fgh \\
\hline AU4 & $0.21 \pm 0 .($ & gh \\
\hline LI4 & $0.21 \pm 0 . c$ & fgh \\
\hline LU4 & $0.19 \pm 0 .($ & gh \\
\hline LU5 & $0.00 \pm 0 .($ & $\mathrm{h}$ \\
\hline AU5 & $0.00 \pm 0 .($ & $\mathrm{h}$ \\
\hline LI5 & $0.00 \pm 0 .($ & $\mathrm{h}$ \\
\hline
\end{tabular}

\begin{tabular}{|c|c|c|}
\hline \multicolumn{3}{|c|}{ 5_7b. Germination (\%) } \\
\hline AI3 & $90.5 \pm 0.16$ & $\mathrm{a}$ \\
\hline CTR & $87.0 \pm 0.04$ & $\mathrm{ab}$ \\
\hline AI4 & $83.6 \pm 0.24$ & $a b c$ \\
\hline $\mathrm{AI} 2$ & $80.9 \pm 0.67$ & $\mathrm{bc}$ \\
\hline LU2 & $75.6 \pm 0.22$ & $\mathrm{~cd}$ \\
\hline LU1 & $74.5 \pm 0.31$ & $\mathrm{~cd}$ \\
\hline LI1 & $73.8 \pm 0.42$ & cde \\
\hline LI2 & $72.8 \pm 0.33$ & cde \\
\hline AI5 & $66.7 \pm 0.35$ & de \\
\hline AI1 & $64.6 \pm 0.23$ & de \\
\hline LI3 & $61.6 \pm 0.25$ & ef \\
\hline AU1 & $50.5 \pm 1.21$ & fg \\
\hline LU3 & $47.5 \pm 1.29$ & $\mathrm{~g}$ \\
\hline AU3 & $45.5 \pm 0.44$ & $\mathrm{~g}$ \\
\hline AU4 & $30.0 \pm 3.29$ & $\mathrm{~h}$ \\
\hline LI4 & $26.8 \pm 0.06$ & $\mathrm{~h}$ \\
\hline AU2 & $19.7 \pm 1.94$ & $\mathrm{~h}$ \\
\hline LU4 & $2.9 \pm 0.59$ & $\mathrm{i}$ \\
\hline LU5 & $0.0 \pm 0.00$ & $\mathrm{j}$ \\
\hline LI5 & $0.0 \pm 0.00$ & $\mathrm{j}$ \\
\hline AU5 & $0.0 \pm 0.00$ & $\mathrm{j}$ \\
\hline
\end{tabular}

Table 5_7a and 5_7b. Effects of citrus EOs on P. oleracea hypocotyl length (5_7a) and germination $\left(5 \_7 b\right)$. Data are means \pm standard error of 10 replicates. Different letters in the same column indicate significant differences between the treatments. 


\begin{tabular}{|l|l|l|l|}
\hline 5_8a. & Seedling length $(\mathrm{cm})$ \\
\hline AI3 & $3.15 \pm 0.91$ & $\mathrm{a}$ \\
AI2 & $2.93 \pm 0.38$ & $\mathrm{ab}$ \\
AI1 & $2.39 \pm 0.11$ & $\mathrm{bc}$ \\
AI4 & $2.15 \pm 0.09$ & $\mathrm{~cd}$ \\
AU2 & $1.88 \pm 0.09$ & $\mathrm{cde}$ \\
CTR & $1.88 \pm 0.05$ & $\mathrm{cde}$ \\
AU1 & $1.73 \pm 0.08$ & de \\
LI1 & $1.64 \pm 0.06$ & def \\
AI5 & $1.60 \pm 0.15$ & def \\
LU1 & $1.50 \pm 0.08$ & def \\
LU2 & $1.26 \pm 0.07$ & efg \\
AU3 & $1.24 \pm 0.05$ & efg \\
LI2 & $1.07 \pm 0.13$ & fgh \\
LI3 & $0.62 \pm 0.05$ & ghi \\
LU3 & $0.51 \pm 0.03$ & hi \\
AU4 & $0.48 \pm 0.05$ & hi \\
LI4 & $0.42 \pm 0.07$ & hi \\
LU4 & $0.38 \pm 0.03$ & hi \\
AU5 & $0.00 \pm 0.00$ & i \\
LU5 & $0.00 \pm 0.00$ & i \\
LI5 & $0.00 \pm 0.00$ & i \\
\hline
\end{tabular}

\begin{tabular}{|l|r|l|}
\hline \multicolumn{3}{|l|}{ 5_8b. Root length $(\mathrm{cm})$} \\
\hline AI3 & $1.95 \pm 0.55$ & $\mathrm{a}$ \\
AI2 & $1.79 \pm 0.21$ & $\mathrm{ab}$ \\
AI1 & $1.47 \pm 0.07$ & $\mathrm{bc}$ \\
AI4 & $1.34 \pm 0.05$ & $\mathrm{~cd}$ \\
AU2 & $1.32 \pm 0.06$ & $\mathrm{~cd}$ \\
AU1 & $1.16 \pm 0.05$ & $\mathrm{cde}$ \\
CTR & $1.06 \pm 0.03$ & def \\
AI5 & $1.02 \pm 0.09$ & defg \\
LU1 & $0.89 \pm 0.11$ & efg \\
LU2 & $0.79 \pm 0.07$ & efg \\
AU3 & $0.72 \pm 0.03$ & fgh \\
LI2 & $0.66 \pm 0.11$ & ghi \\
LI1 & $0.63 \pm 0.07$ & ghij \\
LI3 & $0.33 \pm 0.03$ & hijk \\
AU4 & $0.26 \pm 0.03$ & ijk \\
LU3 & $0.25 \pm 0.02$ & jk \\
LI4 & $0.21 \pm 0.03$ & ijk \\
LU4 & $0.20 \pm 0.02$ & jk \\
LI5 & $0.00 \pm 0.00$ & $k$ \\
AU5 & $0.00 \pm 0.00$ & $k$ \\
LU5 & $0.00 \pm 0.00$ & $k$ \\
\hline
\end{tabular}

Table 5_8a and 5_8b. Effect of citrus EOs on P. oleracea seedling length (5_8a) and root length (5_8b). Data are means \pm standard error of 10 replicates. Different letters in the same column indicate significant differences between the treatments. 


\subsubsection{In-Vivo allelopathic activity of different LI treatment}

Given the good results obtained in vitro tests by the industrial EO of lemon (LI) and the ease of obtention and low costs, further tests were conducted in vivo on the same species and the highest dose tested in vitro was taken as the starting dose. Two application methods were used, spray (S) and irrigation (I).

\section{-Effect on A. fatua}

Effects of LI treatments applied to A. fatua with different doses and by both methods are reported in Tables 5_9a , 5_9b, 5_10a, 5_10b, 5_11a and 5_11b ). All doses above 12 $\mathrm{mL} / \mathrm{L}$ applied with the method (I) were influential on efficacy concerning method (S); the effect increased with increasing dose and was greater for LI 30 I (Table 5_9a). All treatments with a dose higher than $12 \mathrm{~mL} / \mathrm{L}$ negatively affected all the biometric variables measured: total length of the plant, root and aerial part length, although not all effects were significant. With method (I) the biometric parameters were always decreasing with increasing dose (Tables 5_9b, 5_9c and 5_9d). LI 30 I was the treatment that had the best negative effect on all the measured variables. LI $12 \mathrm{~S}$ favoured the growth of the A. fatua plant compared to CTR S, although no significantly (Table 5_9b). The LI 18 S and LI 12 S treatments increased the fresh weight compared to CTR S, however no significantly (Table 5_11a). All treatments applied by the method I greater than $12 \mathrm{~mL} / \mathrm{L}$ reduced the dry and fresh weight more than the equivalent treatments applied by $\mathrm{S}$. The phytotoxic effects increased with the dose (Tables 11a and 11b).

\begin{tabular}{|l|c|c|}
\hline 5_9a. & \multicolumn{3}{|c|}{ Efficacy } \\
\hline LI 30 I & $90 \pm 10$ & $\mathrm{a}$ \\
LI 24 I & $60 \pm 20$ & $\mathrm{~b}$ \\
LI 18 I & $60 \pm 20$ & $\mathrm{~b}$ \\
LI 30 S & $50 \pm 20$ & $\mathrm{bc}$ \\
LI 24 S & $30 \pm 20$ & $\mathrm{c}$ \\
FIT S & $0 \pm 0$ & $\mathrm{~d}$ \\
CTR S & $0 \pm 0$ & $\mathrm{~d}$ \\
CTR I & $0 \pm 0$ & $\mathrm{~d}$ \\
LI 12 S & $0 \pm 0$ & $\mathrm{~d}$ \\
LI 12 I & $0 \pm 0$ & $\mathrm{~d}$ \\
FIT I & $0 \pm 0$ & $\mathrm{~d}$ \\
LI 18 S & $0 \pm 0$ & $\mathrm{~d}$ \\
\hline
\end{tabular}

\begin{tabular}{|l|r|l|}
\hline 5_9 b. & Plant length $(\mathrm{cm})$ \\
\hline FIT I & $50,68 \pm 2,72$ & $\mathrm{a}$ \\
LI 12 S & $50,26 \pm 2,84$ & $\mathrm{a}$ \\
CTR S & $48,32 \pm 2,69$ & $\mathrm{a}$ \\
CTR I & $46,72 \pm 2,56$ & $\mathrm{a}$ \\
LI 12 I & $46,18 \pm 4,20$ & $\mathrm{a}$ \\
FIT S & $37,86 \pm 3,02$ & $\mathrm{ab}$ \\
LI 18 S & $30,15 \pm 5,20$ & $\mathrm{bc}$ \\
LI 24 S & $22,10 \pm 4,96$ & $\mathrm{bc}$ \\
LI 30 S & $19,39 \pm 6,57$ & $\mathrm{bc}$ \\
LI 18 I & $18,52 \pm 7,69$ & $\mathrm{bc}$ \\
LI 24 I & $16,38 \pm 6,75$ & $\mathrm{c}$ \\
LI 30 I & $3,19 \pm 3,19$ & $\mathrm{e}$ \\
\hline
\end{tabular}

Table 5_9a and 5_9b. Effect of different LI treatment on A. fatua. Efficacy (5_9a) and Plant length (5_9b). Results are means \pm standard error of ten replications. Different letters in the same column indicate significant differences. 


\begin{tabular}{|l|r|r|}
\hline 5_10a. & \multicolumn{3}{|c|}{ Root length $(\mathrm{cm})$} \\
\hline LI 12 S & $19,84 \pm 1,81$ & $\mathrm{a}$ \\
FIT I & $19,67 \pm 1,54$ & $\mathrm{a}$ \\
CTR S & $19,14 \pm 1,58$ & $\mathrm{a}$ \\
LI 12 I & $18,88 \pm 1,35$ & $\mathrm{a}$ \\
CTR I & $18,34 \pm 2,19$ & $\mathrm{a}$ \\
FIT S & $15,25 \pm 1,71$ & $\mathrm{ab}$ \\
LI 18 S & $11,66 \pm 2,14$ & $\mathrm{bc}$ \\
LI 30 S & $8,90 \pm 3,26$ & $\mathrm{c}$ \\
LI 24 S & $7,60 \pm 1,71$ & $\mathrm{c}$ \\
LI 18 I & $6,78 \pm 2,82$ & $\mathrm{~cd}$ \\
LI 24 I & $5,90 \pm 2,46$ & $\mathrm{~cd}$ \\
LI 30 I & $1,45 \pm 1,45$ & $\mathrm{e}$ \\
\hline
\end{tabular}

\begin{tabular}{|l|r|l|}
\hline 5_10b. Aerial part length $(\mathrm{cm})$ \\
\hline FIT I & $31,02 \pm 1,69$ & $\mathrm{a}$ \\
LI 12 S & $30,42 \pm 2,15$ & $\mathrm{a}$ \\
CTR S & $29,18 \pm 1,09$ & $\mathrm{a}$ \\
CTR I & $28,38 \pm 1,53$ & $\mathrm{a}$ \\
LI 12 I & $27,02 \pm 3,11$ & $\mathrm{a}$ \\
FIT S & $24,16 \pm 1,72$ & $\mathrm{ab}$ \\
LI 18 S & $18,48 \pm 3,14$ & $\mathrm{bc}$ \\
LI 24 S & $14,50 \pm 3,29$ & $\mathrm{c}$ \\
LI 18 I & $11,74 \pm 4,93$ & $\mathrm{c}$ \\
LI 30 S & $10,49 \pm 3,51$ & $\mathrm{c}$ \\
LI 24 I & $10,48 \pm 4,30$ & $\mathrm{c}$ \\
LI 30 I & $1,75 \pm 1,75$ & $\mathrm{~d}$ \\
\hline
\end{tabular}

Table 5_10a and 5_10b. Effect of different LI treatments on A. fatua root length (5_10a) and aerial part length (5_10b). Results are means \pm standard error of ten replications. Different letters in the same column indicate significant differences.

\begin{tabular}{|l|c|l|}
\hline 5_11 a. & \multicolumn{3}{|c|}{ Fresh weight $(\mathrm{g})$} \\
\hline LI 18 S & $2,09 \pm 0,34$ & $\mathrm{a}$ \\
LI 12 S & $1,94 \pm 0,29$ & $\mathrm{a}$ \\
FIT S & $1,79 \pm 0,20$ & $\mathrm{a}$ \\
FIT I & $1,55 \pm 0,14$ & $\mathrm{ab}$ \\
CTR I & $1,43 \pm 0,13$ & $\mathrm{ab}$ \\
CTR S & $1,42 \pm 0,25$ & $\mathrm{ab}$ \\
LI 12 I & $1,41 \pm 0,42$ & $\mathrm{ab}$ \\
LI 24 S & $0,93 \pm 0,21$ & $\mathrm{bc}$ \\
LI 30 S & $0,72 \pm 0,27$ & $\mathrm{~cd}$ \\
LI 18 I & $0,48 \pm 0,20$ & $\mathrm{~cd}$ \\
LI 24 I & $0,33 \pm 0,15$ & $\mathrm{~cd}$ \\
LI 30 I & $0,09 \pm 0,09$ & $\mathrm{~d}$ \\
\hline
\end{tabular}

\begin{tabular}{|l|l|l|}
\hline 5_11 b. & \multicolumn{2}{|l|}{ Dry weight $(\mathrm{g})$} \\
\hline LI 18 S & $0,231 \pm 0,026$ & $\mathrm{a}$ \\
CTR I & $0,220 \pm 0,020$ & $\mathrm{a}$ \\
FIT I & $0,219 \pm 0,020$ & $\mathrm{a}$ \\
CTR S & $0,217 \pm 0,025$ & $\mathrm{a}$ \\
FIT S & $0,211 \pm 0,021$ & $\mathrm{a}$ \\
LI 12 S & $0,184 \pm 0,020$ & $\mathrm{ab}$ \\
LI 12 I & $0,184 \pm 0,049$ & $\mathrm{ab}$ \\
LI 24 S & $0,124 \pm 0,029$ & $\mathrm{bc}$ \\
LI 30 S & $0,105 \pm 0,036$ & $\mathrm{c}$ \\
LI 18 I & $0,069 \pm 0,030$ & $\mathrm{~cd}$ \\
LI 24 I & $0,059 \pm 0,025$ & $\mathrm{~cd}$ \\
LI 30 I & $0,014 \pm 0,014$ & $\mathrm{~d}$ \\
\hline
\end{tabular}

Table 5_11 1 a and 5_11b. Effect of different LI treatment on A. fatua on fresh (5_11a) and dry weight (5_11b). Results are means \pm standard error of ten replications. Different letters in the same column indicate significant differences.

\section{-Effects of EOs on A. retroflexus}

Effects of LI treatments applied to A. retroflexus at different doses and by both methods are reported in Tables (5_12 a, 5_12b, 5_13a, 5_13b, 5_14a and 5_14b).

All doses applied with the method (S) were more effective to control this weed than the same doses applied with the method (I). The maximal efficacy (100, all plants dead) was achieved for LI 30 S treatment. (Table 5_12a). 
All treatments were inhibitors of the biometric variables measured such as total plant length, root and aerial part length (Tables 5_12b, 5_13a and 5_13b).

Measurements always decreased with increasing dose, but at dose parity, the treatments (S) showed greater inhibitory effects than treatments (I) (although not always this greater inhibitory effects were significant).

The same considerations can be applied to dry and fresh weight (Tables 5_14a and 5_14b).

\begin{tabular}{|l|r|l|}
\hline 5_12a. & \multicolumn{2}{|c|}{ Efficacy } \\
\hline LI 30 S & $100 \pm 0$ & $\mathrm{a}$ \\
LI 24 S & $90 \pm 10$ & $\mathrm{a}$ \\
LI 18 S & $90 \pm 10$ & $\mathrm{a}$ \\
LI 12 S & $60 \pm 20$ & $\mathrm{~b}$ \\
LI 30 I & $60 \pm 20$ & $\mathrm{~b}$ \\
LI 24 I & $50 \pm 20$ & $\mathrm{~b}$ \\
LI 18 I & $20 \pm 10$ & $\mathrm{c}$ \\
FIT S & $0 \pm 0$ & $\mathrm{c}$ \\
CTR S & $0 \pm 0$ & $\mathrm{c}$ \\
LI 12 I & $0 \pm 0$ & $\mathrm{c}$ \\
FIT I & $0 \pm 0$ & $\mathrm{c}$ \\
CTR I & $0 \pm 0$ & $\mathrm{c}$ \\
\hline
\end{tabular}

\begin{tabular}{|l|r|l|}
\hline 5_12 b. & \multicolumn{2}{|c|}{ Plant length $(\mathrm{cm})$} \\
\hline FIT S & $17,00 \pm 3,15$ & $\mathrm{a}$ \\
CTR S & $14,71 \pm 1,88$ & $\mathrm{a}$ \\
CTR I & $14,22 \pm 1,34$ & $\mathrm{a}$ \\
FIT I & $13,67 \pm 1,89$ & $\mathrm{ab}$ \\
LI 12 I & $9,32 \pm 0,37$ & $\mathrm{bc}$ \\
LI 18 I & $6,55 \pm 1,28$ & $\mathrm{~cd}$ \\
LI 24 I & $4,50 \pm 1,70$ & $\mathrm{de}$ \\
LI 12 S & $4,29 \pm 1,76$ & $\mathrm{de}$ \\
LI 30 I & $3,38 \pm 1,55$ & $\mathrm{de}$ \\
LI 18 S & $1,33 \pm 1,33$ & $\mathrm{e}$ \\
LI 24 S & $0,70 \pm 0,70$ & $\mathrm{e}$ \\
LI 30 S & $0,00 \pm 0,00$ & $\mathrm{e}$ \\
\hline
\end{tabular}

Table 5_12a and 5_12b. Effect of different LI treatment on A. retroflexus. Efficacy (5_12a) and Plant length (5_12b). Results are means \pm standard error of ten replications. Different letters in the same column indicate significant differences.

\begin{tabular}{|l|c|l|}
\hline 5_13a. & Root length $(\mathrm{cm})$ \\
\hline CTR S & $6,27 \pm 0,74$ & $\mathrm{a}$ \\
FIT I & $6,08 \pm 0,75$ & $\mathrm{ab}$ \\
FIT S & $5,71 \pm 0,80$ & $\mathrm{ab}$ \\
CTR I & $5,23 \pm 0,73$ & $\mathrm{ab}$ \\
LI 12 I & $4,39 \pm 0,25$ & $\mathrm{bc}$ \\
LI 18 I & $3,34 \pm 0,69$ & $\mathrm{~cd}$ \\
LI 24 I & $2,24 \pm 0,87$ & $\mathrm{~d}$ \\
LI 12 S & $2,10 \pm 0,86$ & $\mathrm{de}$ \\
LI 30 I & $1,70 \pm 0,73$ & def \\
LI 18 S & $0,34 \pm 0,34$ & ef \\
LI 24 S & $0,29 \pm 0,29$ & ef \\
LI 30 S & $0,00 \pm 0,00$ & $\mathrm{f}$ \\
\hline
\end{tabular}

\begin{tabular}{|l|r|l|}
\hline 5_13b. & Aerial part length $(\mathrm{cm})$ \\
\hline FIT S & $11,29 \pm 2,43$ & $\mathrm{a}$ \\
CTR I & $8,99 \pm 0,94$ & $\mathrm{ab}$ \\
CTR S & $8,44 \pm 1,32$ & $\mathrm{ab}$ \\
FIT I & $7,59 \pm 1,30$ & $\mathrm{bc}$ \\
LI 12 I & $4,94 \pm 0,30$ & $\mathrm{~cd}$ \\
LI 18 I & $3,21 \pm 0,67$ & $\mathrm{de}$ \\
LI 24 I & $2,26 \pm 0,83$ & def \\
LI 12 S & $2,20 \pm 0,91$ & def \\
LI 30 I & $1,68 \pm 0,84$ & ef \\
LI 18 S & $0,99 \pm 0,99$ & ef \\
LI 24 S & $0,41 \pm 0,41$ & ef \\
LI 30 S & $0,00 \pm 0,00$ & $\mathrm{f}$ \\
\hline
\end{tabular}

Table 5_13a and 5_13b. Effect of different LI treatments on A. retroflexus root length (5_13a) and aerial part length (5_13b). Results are means \pm standard error of ten replications. Different letters in the same column indicate significant differences. 


\begin{tabular}{|l|r|l|}
\hline 5_14 a. & Fresh weight $(\mathrm{g})$ \\
\hline FIT I & $0,44 \pm 0,06$ & $\mathrm{a}$ \\
FIT S & $0,43 \pm 0,08$ & $\mathrm{a}$ \\
CTR I & $0,39 \pm 0,08$ & $\mathrm{ab}$ \\
CTR S & $0,38 \pm 0,08$ & $\mathrm{ab}$ \\
LI 12 I & $0,27 \pm 0,03$ & $\mathrm{bc}$ \\
LI 18 I & $0,20 \pm 0,05$ & $\mathrm{~cd}$ \\
LI 12 S & $0,13 \pm 0,05$ & $\mathrm{cde}$ \\
LI 24 I & $0,12 \pm 0,04$ & $\mathrm{de}$ \\
LI 30 I & $0,08 \pm 0,03$ & $\mathrm{de}$ \\
LI 18 S & $0,03 \pm 0,03$ & $\mathrm{e}$ \\
LI 24 S & $0,01 \pm 0,01$ & $\mathrm{e}$ \\
LI 30 S & $0,00 \pm 0,00$ & $\mathrm{e}$ \\
\hline
\end{tabular}

\begin{tabular}{|l|r|l|}
\hline 5_14 b. & \multicolumn{1}{|l|}{ Dry weight $(\mathrm{g})$} & \\
\hline FIT I & $0,055 \pm 0,010$ & $\mathrm{a}$ \\
CTR S & $0,050 \pm 0,012$ & $\mathrm{a}$ \\
FIT S & $0,047 \pm 0,010$ & $\mathrm{a}$ \\
CTR I & $0,045 \pm 0,009$ & $\mathrm{ab}$ \\
LI 12 I & $0,027 \pm 0,003$ & $\mathrm{bc}$ \\
LI 18 I & $0,018 \pm 0,004$ & $\mathrm{~cd}$ \\
LI 12 S & $0,013 \pm 0,005$ & $\mathrm{~cd}$ \\
LI 24 I & $0,012 \pm 0,004$ & $\mathrm{~cd}$ \\
LI 30 I & $0,009 \pm 0,004$ & $\mathrm{~cd}$ \\
LI 18 S & $0,003 \pm 0,003$ & $\mathrm{~d}$ \\
LI 24 S & $0,002 \pm 0,002$ & $\mathrm{~d}$ \\
LI 30 S & $0,000 \pm 0,000$ & $\mathrm{~d}$ \\
\hline
\end{tabular}

Table 5_14a and 5_14b. Effect of different LI treatment on A. retroflexus on fresh (5_14a) and dry weight (5_14b). Results are means \pm standard error of ten replications. Different letters in the same column indicate significant differences.

\section{-Effect on Echinochloa crus-galli}

Effects of LI treatment applied to Echinochloa crus-galli at different doses and by both methods are reported in Tables (5_15a, 5_15b, 5_16a, 5_16b, 5_17a and 5_17b). Treatments applied by (S) were more effective than by (I) to control this weed (Table 5_15a). The efficacy increased with the dose, for (S) treatments and was maximal for LI $30 \mathrm{~S}$ treatment (Table 5_15a).

All treatments (S) showed stronger inhibitory effects on the variables measured such as total plant, root and aerial parts length (Tables 5_15b, 5_16a and 5_16b), fresh and dry weight (Tables 5_17a and 5_17b); compared to treatments (I). In (S) treatments, measures always decreased with increasing dose.

\begin{tabular}{|l|c|c|}
\hline 5_15a. & \multicolumn{2}{|c|}{ Efficacy } \\
\hline LI 30 S & $90 \pm 10$ & $\mathrm{a}$ \\
LI 24 S & $80 \pm 10$ & $\mathrm{ab}$ \\
LI 18 S & $70 \pm 20$ & $\mathrm{ab}$ \\
LI 30 I & $50 \pm 20$ & $\mathrm{bc}$ \\
LI 12 S & $40 \pm 20$ & $\mathrm{bc}$ \\
LI 18 I & $20 \pm 10$ & $\mathrm{~cd}$ \\
LI 12 I & $20 \pm 10$ & $\mathrm{~cd}$ \\
LI 24 I & $20 \pm 10$ & $\mathrm{~cd}$ \\
FIT S & $0 \pm 0$ & $\mathrm{~d}$ \\
CTR I & $0 \pm 0$ & $\mathrm{~d}$ \\
CTR S & $0 \pm 0$ & $\mathrm{~d}$ \\
FIT I & $0 \pm 0$ & $\mathrm{~d}$ \\
\hline
\end{tabular}

\begin{tabular}{|l|r|l|}
\hline 5_15 b. & Plant length $(\mathrm{cm})$ \\
\hline CTR I & $50,36 \pm 1,65$ & $\mathrm{a}$ \\
FIT I & $49,01 \pm 2,61$ & $\mathrm{a}$ \\
LI 24 I & $43,98 \pm 7,62$ & $\mathrm{a}$ \\
CTR S & $42,49 \pm 7,00$ & $\mathrm{a}$ \\
LI 12 I & $41,78 \pm 7,32$ & $\mathrm{a}$ \\
FIT S & $38,30 \pm 5,47$ & $\mathrm{ab}$ \\
LI 18 I & $37,96 \pm 7,23$ & $\mathrm{ab}$ \\
LI 30 I & $23,50 \pm 7,84$ & $\mathrm{bc}$ \\
LI 12 S & $9,64 \pm 4,11$ & $\mathrm{~cd}$ \\
LI 18 S & $5,42 \pm 2,70$ & $\mathrm{~d}$ \\
LI 24 S & $4,20 \pm 2,71$ & $\mathrm{~d}$ \\
LI 30 S & $2,56 \pm 2,43$ & $\mathrm{~d}$ \\
\hline
\end{tabular}


Table 5_15a and 5_15b. Effect of different LI treatment on E. crus-galli. Efficacy (5_15a) and Plant length (5_15b). Results are means \pm standard error of ten replications. Different letters in the same column indicate significant differences.

\begin{tabular}{|l|r|l|}
\hline 5_16a. & \multicolumn{2}{|c|}{ Root length $(\mathrm{cm})$} \\
\hline CTR I & $21,22 \pm 1,41$ & $\mathrm{a}$ \\
LI 24 I & $21,10 \pm 3,58$ & $\mathrm{a}$ \\
FIT I & $20,90 \pm 1,54$ & $\mathrm{a}$ \\
LI 12 I & $19,36 \pm 3,61$ & $\mathrm{a}$ \\
LI 18 I & $18,65 \pm 3,66$ & $\mathrm{ab}$ \\
CTR S & $15,92 \pm 3,86$ & $\mathrm{ab}$ \\
FIT S & $13,61 \pm 3,44$ & $\mathrm{ab}$ \\
LI 30 I & $11,07 \pm 3,71$ & $\mathrm{bc}$ \\
LI 12 S & $3,89 \pm 1,62$ & $\mathrm{~cd}$ \\
LI 18 S & $1,91 \pm 0,99$ & $\mathrm{~d}$ \\
LI 24 S & $1,81 \pm 1,14$ & $\mathrm{~d}$ \\
LI 30 S & $1,05 \pm 1,00$ & $\mathrm{~d}$ \\
\hline
\end{tabular}

\begin{tabular}{|l|r|l|}
\hline 5_16b. & \multicolumn{3}{|c|}{ Aerial parts length $(\mathrm{cm})$} \\
\hline CTR I & $29,14 \pm 1,10$ & $\mathrm{a}$ \\
FIT I & $28,10 \pm 1,49$ & $\mathrm{a}$ \\
CTR S & $26,57 \pm 3,68$ & $\mathrm{ab}$ \\
FIT S & $24,69 \pm 2,68$ & $\mathrm{ab}$ \\
LI 24 I & $22,88 \pm 4,15$ & $\mathrm{ab}$ \\
LI 12 I & $22,42 \pm 3,99$ & $\mathrm{ab}$ \\
LI 18 I & $19,31 \pm 3,68$ & $\mathrm{bc}$ \\
LI 30 I & $12,43 \pm 4,21$ & $\mathrm{~cd}$ \\
LI 12 S & $5,75 \pm 2,54$ & $\mathrm{de}$ \\
LI 18 S & $3,52 \pm 1,73$ & $\mathrm{e}$ \\
LI 24 S & $2,39 \pm 1,58$ & $\mathrm{e}$ \\
LI 30 S & $1,51 \pm 1,43$ & $\mathrm{e}$ \\
\hline
\end{tabular}

Table 5_16a 16b. Effect of different LI treatments on E. crus-galli root length (5_16a) and aerial part length (5_16b). Results are means \pm standard error of ten replications. Different letters in the same column indicate significant differences.

\begin{tabular}{|l|r|l|}
\hline 5_17 a. & Fresh weight $(\mathrm{g})$ \\
\hline CTR I & $1,21 \pm 0,13$ & $\mathrm{a}$ \\
CTR S & $1,03 \pm 0,30$ & $\mathrm{ab}$ \\
FIT I & $0,90 \pm 0,10$ & $\mathrm{abc}$ \\
FIT S & $0,74 \pm 0,22$ & $\mathrm{bcd}$ \\
LI 12 I & $0,67 \pm 0,14$ & $\mathrm{bcd}$ \\
LI 18 I & $0,62 \pm 0,15$ & bcd \\
LI 24 I & $0,50 \pm 0,24$ & cde \\
LI 30 I & $0,39 \pm 0,14$ & def \\
LI 12 S & $0,08 \pm 0,04$ & ef \\
LI 18 S & $0,04 \pm 0,02$ & $\mathrm{f}$ \\
LI 24 S & $0,03 \pm 0,02$ & $\mathrm{f}$ \\
LI 30 S & $0,02 \pm 0,02$ & $\mathrm{f}$ \\
\hline
\end{tabular}

\begin{tabular}{|l|l|l|}
\hline 5_17 b. & \multicolumn{1}{|l|}{ Dry weight $(\mathrm{g})$} & \\
\hline CTR I & $0,15 \pm 0,012$ & $\mathrm{a}$ \\
FIT I & $0,11 \pm 0,012$ & $\mathrm{ab}$ \\
LI 12 I & $0,09 \pm 0,020$ & $\mathrm{bc}$ \\
CTR S & $0,09 \pm 0,019$ & $\mathrm{bcd}$ \\
LI 18 I & $0,07 \pm 0,017$ & $\mathrm{bcd}$ \\
FIT S & $0,07 \pm 0,013$ & $\mathrm{bcd}$ \\
LI 24 I & $0,05 \pm 0,025$ & $\mathrm{~cd}$ \\
LI 30 I & $0,05 \pm 0,017$ & de \\
LI 12 S & $0,01 \pm 0,005$ & ef \\
LI 18 S & $0,01 \pm 0,003$ & ef \\
LI 24 S & $0,00 \pm 0,003$ & ef \\
LI 30 S & $0,00 \pm 0,003$ & f \\
\hline
\end{tabular}

Table 5_17a and 5_17b. Effect of different LI treatment on E. crus-galli on fresh (5_17a) and dry weight (5_17b). Results are means \pm standard error of ten replications. Different letters in the same column indicate significant differences. 


\section{-Effect on Portulaca oleracea}

Effect of LI treatment applied to Echinochloa crus-galli at different doses with both methods are reported in Tables (5_18 a, 5_18b, 5_19a, 5_19b, 5_20a and 5_20b).

Only treatments applied by (S) were capable to control this weed (Table 5_18a). Efficacy increased with the dose and was maximal for LI 30 S treatment (Table 5_18a).

Moreover, all treatments (I) and LI 12 (S) did not affect the measured variables such as length of plants, roots and aerial parts, fresh and dry weight, compared to controls. The other treatments $(\mathrm{S})$ were inhibitors of the measured variables and the effect was maximum for LI 30 I (Tables 5_18b, 5_19a, 5_19b, 5_20a, 5_20b).

\begin{tabular}{|l|c|c|}
\hline 5_18a. & \multicolumn{2}{|c|}{ Efficacy } \\
\hline LI 30 S & $80 \pm 10$ & $\mathrm{a}$ \\
LI 24 S & $50 \pm 20$ & $\mathrm{~b}$ \\
LI 18 S & $30 \pm 20$ & $\mathrm{~b}$ \\
LI 30 I & $0 \pm 0$ & $\mathrm{c}$ \\
CTR I & $0 \pm 0$ & $\mathrm{c}$ \\
LI 12 S & $0 \pm 0$ & $\mathrm{c}$ \\
CTR S & $0 \pm 0$ & $\mathrm{c}$ \\
FIT I & $0 \pm 0$ & $\mathrm{c}$ \\
LI 18 I & $0 \pm 0$ & $\mathrm{c}$ \\
FIT S & $0 \pm 0$ & $\mathrm{c}$ \\
LI 24 I & $0 \pm 0$ & $\mathrm{c}$ \\
LI 12 I & $0 \pm 0$ & $\mathrm{c}$ \\
\hline
\end{tabular}

\begin{tabular}{|l|r|l|}
\hline 5_18 b. & Plant length $(\mathrm{cm})$ \\
\hline FIT I & $21,15 \pm 1,52$ & $\mathrm{a}$ \\
FIT S & $20,93 \pm 0,72$ & $\mathrm{a}$ \\
CTR S & $19,73 \pm 1,30$ & $\mathrm{ab}$ \\
LI 12 I & $19,50 \pm 1,12$ & $\mathrm{ab}$ \\
CTR I & $18,65 \pm 1,17$ & $\mathrm{ab}$ \\
LI 30 I & $18,14 \pm 1,04$ & $\mathrm{ab}$ \\
LI 24 I & $17,58 \pm 1,52$ & $\mathrm{ab}$ \\
LI 18 I & $16,78 \pm 1,10$ & $\mathrm{~b}$ \\
LI 12 S & $12,45 \pm 1,39$ & $\mathrm{c}$ \\
LI 18 S & $5,85 \pm 1,70$ & $\mathrm{~d}$ \\
LI 24 S & $3,86 \pm 1,45$ & $\mathrm{de}$ \\
LI 30 S & $1,68 \pm 1,24$ & $\mathrm{e}$ \\
\hline
\end{tabular}

Table 5_18a and 5_18b. Effect of different LI treatment on P. oleracea. Efficacy (5_18a) and Plant length (5_18b). Results are means \pm standard error of ten replications. Different letters in the same column indicate significant differences.

\begin{tabular}{|l|c|l|}
\hline 5_19b. & Steam length $(\mathrm{cm})$ \\
\hline FIT I & $8,03 \pm 0,69$ & $\mathrm{a}$ \\
CTR I & $7,96 \pm 0,61$ & $\mathrm{a}$ \\
LI 12 I & $7,93 \pm 0,45$ & $\mathrm{a}$ \\
LI 24 I & $7,45 \pm 0,54$ & $\mathrm{ab}$ \\
LI 30 I & $6,87 \pm 0,31$ & $\mathrm{abc}$ \\
LI 18 I & $6,68 \pm 0,48$ & $\mathrm{abc}$ \\
FIT S & $6,34 \pm 0,36$ & $\mathrm{bc}$ \\
CTR S & $5,94 \pm 0,33$ & $\mathrm{~cd}$ \\
LI 12 S & $4,68 \pm 0,70$ & $\mathrm{~d}$ \\
LI 18 S & $1,97 \pm 0,52$ & $\mathrm{e}$ \\
LI 24 S & $1,42 \pm 0,50$ & $\mathrm{e}$ \\
LI 30 S & $0,63 \pm 0,42$ & $\mathrm{e}$ \\
\hline
\end{tabular}

\begin{tabular}{|l|r|l|}
\hline 5_19a. & \multicolumn{1}{|c|}{ Root length $(\mathrm{cm})$} \\
\hline FIT S & $14,59 \pm 0,62$ & $\mathrm{a}$ \\
CTR S & $13,78 \pm 1,09$ & $\mathrm{ab}$ \\
FIT I & $13,12 \pm 1,15$ & $\mathrm{abc}$ \\
LI 12 I & $11,57 \pm 1,03$ & $\mathrm{bcd}$ \\
LI 30 I & $11,27 \pm 1,13$ & $\mathrm{bcd}$ \\
CTR I & $10,69 \pm 0,98$ & $\mathrm{~cd}$ \\
LI 24 I & $10,13 \pm 1,20$ & $\mathrm{de}$ \\
LI 18 I & $10,10 \pm 0,95$ & $\mathrm{de}$ \\
LI 12 S & $7,78 \pm 0,91$ & $\mathrm{e}$ \\
LI 18 S & $3,88 \pm 1,22$ & $\mathrm{f}$ \\
LI 24 S & $2,44 \pm 1,00$ & $\mathrm{f}$ \\
LI 30 S & $1,05 \pm 0,83$ & $\mathrm{f}$ \\
\hline
\end{tabular}

Table 5_19a and 5_19b. Effect of different LI treatments on P. oleracea root length (5_19a) and aerial part length (5_19b). Results are means \pm standard error of ten replications. Different letters in the same column indicate significant differences. 


\begin{tabular}{|l|r|l|}
\hline 5_20 a. & Fresh weight $(\mathrm{g})$ \\
\hline CTR I & $1,58 \pm 0,17$ & $\mathrm{a}$ \\
FIT I & $1,48 \pm 0,19$ & $\mathrm{ab}$ \\
LI 12 I & $1,46 \pm 0,10$ & $\mathrm{ab}$ \\
LI 30 I & $1,40 \pm 0,12$ & $\mathrm{ab}$ \\
FIT S & $1,30 \pm 0,09$ & $\mathrm{ab}$ \\
LI 18 I & $1,29 \pm 0,13$ & $\mathrm{ab}$ \\
CTR S & $1,23 \pm 0,12$ & $\mathrm{~b}$ \\
LI 24 I & $1,14 \pm 0,16$ & $\mathrm{~b}$ \\
LI 12 S & $0,58 \pm 0,09$ & $\mathrm{c}$ \\
LI 18 S & $0,23 \pm 0,07$ & $\mathrm{~d}$ \\
LI 24 S & $0,19 \pm 0,07$ & $\mathrm{~d}$ \\
LI 30 S & $0,08 \pm 0,05$ & $\mathrm{~d}$ \\
\hline
\end{tabular}

\begin{tabular}{|l|l|l|}
\hline 5_20 b. & \multicolumn{1}{l|}{ Dry weight $(\mathrm{g})$} \\
\hline FIT I & $0,258 \pm 0,078$ & $\mathrm{a}$ \\
CTR I & $0,199 \pm 0,022$ & $\mathrm{ab}$ \\
FIT S & $0,175 \pm 0,016$ & $\mathrm{~b}$ \\
LI 12 I & $0,170 \pm 0,012$ & $\mathrm{~b}$ \\
LI 30 I & $0,157 \pm 0,018$ & $\mathrm{~b}$ \\
CTR S & $0,152 \pm 0,014$ & $\mathrm{~b}$ \\
LI 18 I & $0,141 \pm 0,015$ & $\mathrm{~b}$ \\
LI 24 I & $0,127 \pm 0,016$ & $\mathrm{~b}$ \\
LI 12 S & $0,064 \pm 0,011$ & $\mathrm{bc}$ \\
LI 18 S & $0,021 \pm 0,007$ & $\mathrm{~cd}$ \\
LI 24 S & $0,016 \pm 0,006$ & $\mathrm{~d}$ \\
LI 30 S & $0,006 \pm 0,004$ & $\mathrm{~d}$ \\
\hline
\end{tabular}

Table 5_20a and 5_20b. Effect of different LI treatment on P. oleracea on fresh (5_20a) and dry weight (5_20b). Results are means \pm standard error of ten replications. Different letters in the same column indicate significant differences. 


\subsection{Discussion}

EOs have always been used in the cosmetic, medicinal and food industries and are believed to be safe compounds for humans, animals and the environment. In the present study, the EOs of orange (Citrus sinensis) and lemon (Citrus limon) were tested for their allelopathic effects on A. retroflexus, P. oleracea, A. fatua and E. crus-galli. They were selected as target weeds, because are important weeds in the Mediterranean crops and also around the world because of their cosmopolite distribution. Moreover, they are reported in the international herbicide-resistant weed database (Heap, 2020) so it is necessary to find alternatives to synthetic herbicides to control them, even more considering an integrated weed management strategy.

\subsubsection{Experiment preliminary}

Preliminary to this study, a test was carried out in containers $(10 \times 25 \times 10 \mathrm{~cm})$ filled with $500 \mathrm{~g}$ of soil. The citrus EOs were applied both irrigated and sprayed at the dose 8 $\mathrm{mL} / \mathrm{L}$. Four replications were performed. After 30 days the soils were sampled and all the parameters concerning the microbial biomass were studied. From the results obtained (Table 5_22), it was concluded that the EOs did not make any effects compared to the controls. Misra and Pavlostathis (1996), Marmulla and Harder (2014) observed that monoterpenes were degraded very easily by soil microorganisms which was encouraging for the application of EOs in the soil.

\subsubsection{In vitro weed germination test}

Lemon EOs have shown strong herbicidal effects, in some species even at lower doses thus indicating that they have promising uses as natural herbicides source. The $12 \mathrm{ml} / \mathrm{L}$ EO lemon dose inhibited the germination of all species.

However, albeit to a lesser extent, appreciable efficacy has also been demonstrated by orange EOs in high doses. Furthermore, another interesting finding was the stimulatory activity of $\mathrm{AI}$ and in some cases also of LI at low doses. These results open the possibility of studying this treatment for their potential application as biostimulators on plants at lower doses than the used in our experiments and the studies must be carried out on crops instead that on weeds to know they specific response to them. 
The results obtained are confirmed by previous researches, which associated the powerful phytotoxic activity of EOs with a high amount of oxygenated monoterpenes (Astani et al., 2009; DeAlmeida et al., 2010; Ersilia et al., 2018).

Based on these results, further in vivo experiments were conducted to verify the herbicidal activity in greenhouse conditions, using only EO LI, which is a low-cost product easily available from the citrus industries.

\subsubsection{Possible chemical compounds of citrus EOs with allelopathic activity.}

EOs and their components are suitable for the management of weeds and pests (Mehmet et al, 2016). Due to the high number of components in the chemical composition, it is not easy to establish those responsible for the biological activity. However, in according with Dayan and Duke, 2010 and Benvenuti et al, 2017 the richness in Limonene of citrus EO seems to be closely linked to the excellent performance of Orange EO. Since in this EOs the content of Limonene was much higher than that of Lemon. In the case of lemon EO, it is not only a single component responsible for its inhibitory activity, but the interaction of all the compounds.

The phytotoxicity of Limonene has also been observed in Amaranthus viridis (Vaid et al, 2011).This monoterpene can be obtained from a large number of aromatic species (Vaid et al., 2010). Barney et al. (2005) observed a reduction in root and shoot length in Limonenetreated Lepidium sativum seedlings; Alsaadawi et al. (1985) found growth inhibition in Amaranthus retroflexus treated with Limonene isolated from leaves of Citrus aurantium. Limonene has been also demonstrated to reduce germination, radicle length, seedling dry weight, chlorophyll content and respiratory activity in Amaranthus viridis (Vaid et al., 2011). It is also known that Limonene stimulates basal respiration of isolated mitochondria from Zea mays roots and inhibits the coupled respiration; causing loosening of respiratory control (Abrahim et al., 2000). This could explain the stimulatory effects of the low dose of Orange EO.

Probably, the simultaneous presence in lemon of different oxygenated monoterpenes increases its toxicity, as it has already been discovered that they have a marked inhibitory activity in the germination of weeds (Angelini et al., 2003); this could explain the greater phytotoxic effect of the EOs of lemon compared with the others citrus EOs studied.

The results confirmed the role of monoterpenes, which have already been found to be elicitors of germination inhibition (Martino et al, 2010). Monoterpenes can influence energy 
metabolism (Singh et al., 2002b) and consequently the plant's allelopathic performance (Duke, 2003).

Perhaps the hydrocarbons of monoterpenes also play a crucial role, however, oxygenated monoterpenes are more effective than monoterpenes hydrocarbons as inhibitors of germination (Vaughn and Spencer 1993, Benvenuti et al, 2017).

Monoterpenes are mainly volatile constituents of plants EOs. Several monoterpenes have been studied individually, in pairs or mixtures, as potential bioherbicides.

Thanks to their oily nature, these compounds are lipophilic. This feature can favour the expansion of cell membranes by EOs and their destruction through increased fluidity or inhibition of membrane enzymes. This type of membrane rupture caused by the phytotoxicity of monoterpenes could be responsible for the herbicide effect and lead to cell death (Mutlu et al., 2011, Grana et al., 2012).

The possible role of monoterpenes as weed germination inhibitors is also supported by previous studies that have reported the oxygenated monoterpene artemisia ketone as the main responsible for the inhibitory effect of Eriocephalus africanus EO against several weeds (Verdeguer et al., 2009).

In the studies of El Sawi et al., (2019), it can be seen that EOs from Citrus reticulata peels had a greater inhibitory effect at a lower concentration than the other EOs from citrus fruits tested. The EOs tested had a very similar composition, the only compound that differed was $\gamma$-Terpinene, that in C. reticulata $\mathrm{EO}$ was in concentration 10 times higher than in the others. This could be associated with the best effect found with $C$. reticulata EO. Even in this thesis, the tested lemon EOs contained $\gamma$-terpinene 10 times higher in concentration than the orange EOs.

Another component known for its allelopathic activity is $\alpha$-pinene. It is known that EOs with a high content of $\alpha$-Pinene can inhibit the germination of the seeds of Amaranthus hybridus and Portulaca oleracea, and the germination and growth of the roots of Amaranthus viridis, Cassia occidentalis, Zea mays, Pisum sativum, Cicer arietinum and Triticum aestivum (Singh et al, 2006, Verdeguer et al., 2009).

Corn seedlings treated with $\alpha$-Pinene showed changes in mitochondrial respiration, with the inhibited activity of the electron transport chain; and increased levels of malondialdehyde, an indicator of oxidative stress(Abrahim et al., 2003, Scrivanti et al., 2003).

$\beta$-Pinene has been found to inhibit the length of the root and sprout in Lepidium sativum and Artemisia vulgaris. It also reduced root lengthening in Digitaria sanguinalis (Barney et al., 2005) and Brassica campestris (Nishida et al., 2005). Furthermore, $\alpha$-Pinene from the leaves 
of Citrus aurantium inhibited the growth of Amaranthus retroflexus (Alsaadawi et al.,1985). Pinene has also been found to reduce the chlorophyll content of Oryza sativa coleoptiles, cellular respiration, the enzyme activity of proteases and $\alpha$-amylases and the length of roots and coleoptiles. In parallel activities, peroxidase and polyphenol oxidase increased in a dosedependent manner as a defence mechanism (Chowhan et al., 2011).

Citral has been reported as a strong microtubule disrupter in Arabidopsis thaliana, showing time and dose-dependent effect (Chaimovitsh et al., 2010). Besides, mitotic microtubules were found to be more affected than cortical ones (Chaimovitsh et al., 2012). Other experiments also showed that Citral inhibited germination and root growth in A. thaliana. Citral appears to be a potent mitotic inhibitor and cell wall disrupter in root meristems (Grana et al., 2012).

\subsubsection{In vivo $L I$ treatment}

This study is the first to test in vivo the phytotoxic potential of LI EO to control the weeds A. fatua, A. retroflexus, E. crus-galli, P. oleracea.

The herbicidal activity of the EOs tested, depended on the method of application, the dose tested, and the weed species on which they were applied. Except for A.fatua the application (S) has always given stronger phytotoxic results at the same dose compared to the application (I). This result in A. fatua could be because the EO irrigated in the soil was more efficiently adsorbed by the root system of this species which was highly developed compared to other species and as previously mentioned, the citral could be responsible for the radical development inhibition (Grana et al., 2012). The lesser effect of the treatments (I) could be due to the difficulty for the weed species to take the EO, to the volatilization of the EO and to the degradation of the EO by the soil microorganisms.

Another hypothesis could be because A. fatua is a plant with a C3 photosynthetic system and it has a different leaf system than other weeds with the $\mathrm{C} 4$ photosynthetic system (Reddy et al., 2000). In fact, in the leaves of the C4 species, there are different photosynthetic cells (Voet et al.,, 1995), which could be damaged by monoterpenes and therefore lead to the death of the plant. Furthermore, it is known that mono- and sesquiterpenes influence the physiological processes of weeds, such as photosynthesis, the synthesis of chlorophyll and cell destruction, which may involve the accumulation of lipid globules in the cytoplasm or the reduction of organelles (such as mitochondria or nuclei) (Grosso et al., 2010, Grana et al., 2012). Furthermore, it has been reported that monoterpenes such as Citronellol, Citronellal and Linalool, which are the components present in LI EO, influencing the 
synthesis of chlorophyll and reducing its content (Romagni et al., 2000; Singh et al., 2002 a and $b$ ).

Although it is not possible to determine which is the most active chemical, phytotoxicity can probably be attributed, as mentioned above, to monoterpenes, whose in vitro toxicity has been previously reported (Brown et al., 1987).

The effectivity of LI $30 \mathrm{~S}$ always was high, in fact in A. retroflexus was 100, this means that all the plants died, while it was 90 in E. crus-galli and 80 in P. oleacea and 50 in A. fatua even if the results are different the mechanism of action seems to be similar. The lower doses in some cases led to the death of the plants while in others reduced the various measured parameters or had no effect.

Observing the dynamic of toxicity, by spraying the LI30 solution on a weed healthy plant (Figure 1ERB a) after one hour there was the browning of the tissues (figure 5_1) and the subsequent whitening after 24 hours (figure 5_2). Describing the toxic effect of LI $30 \mathrm{~S}$ in the first 24 hours, this caused a rapid alteration of the water state of the plant and a collapse of the architecture (figure 5_2).

Subsequently, most of the plants become even drier, stopping their vegetative activity. The remaining plants on the fourth day after treatment resumed vegetative activity by issuing new leaves. The whitening of the leaf tissues (figure 5_2) indicates the destruction of the chlorophyll molecules and, probably, of the chloroplasts integrity (Benvenuti et al., 2017). Although the physiological mechanism of toxicity of EOs is still unclear, they have been found to inhibit mitochondrial respiration (Abrahim et al., 2003). The EOs have also been able to damage the integrity of the membrane, alter the plant water status and cause oxidative stress (Araniti et al., 2017) further influencing pH homeostasis and inorganic ion balance (Lambert et al., 2001). The dynamic described above is in accordance with Benvenuti et al. (2017). LI 30 I on A. fatua had the same dynamics described above but the action times were longer. The architecture's settlement and collapse took place one day after the treatment while the total whitening of the plant took place after seven days (figure 5_2 d) from the treatment with subsequent death or vegetative restart in the case of a single plant. 


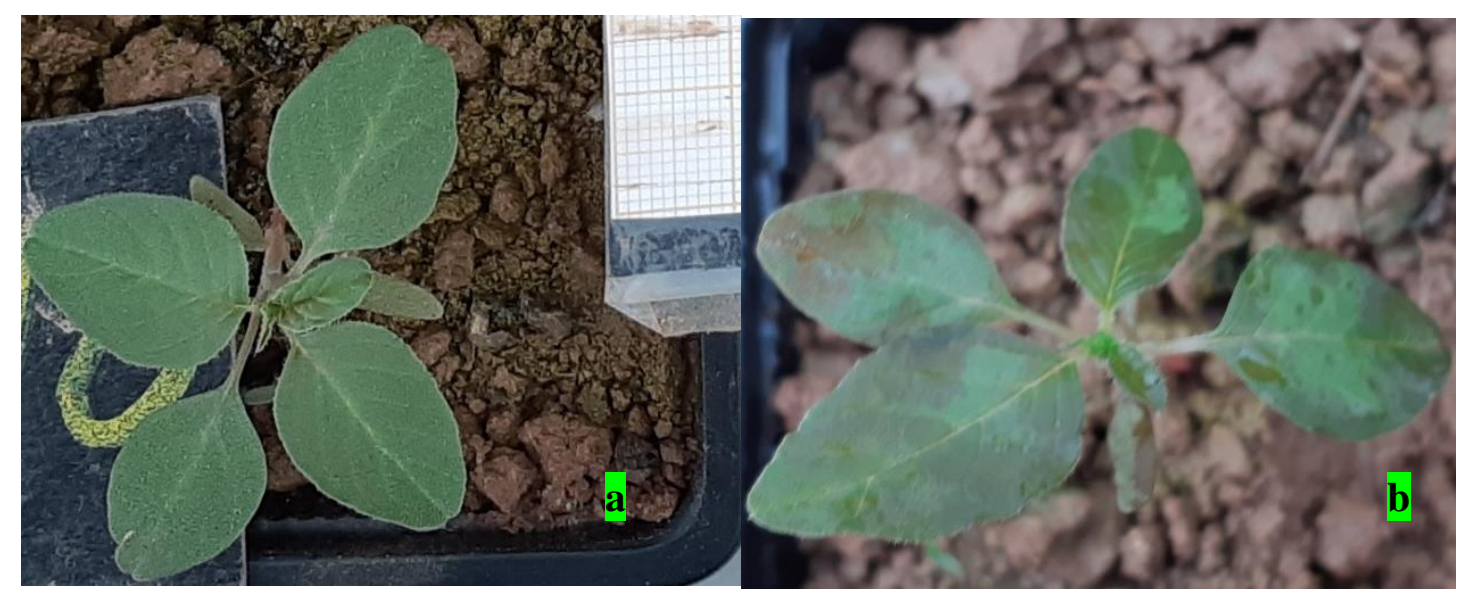

Figure 5_1. A. retroflexus plantlet (a) before treatment and (b) one hour after treatment.

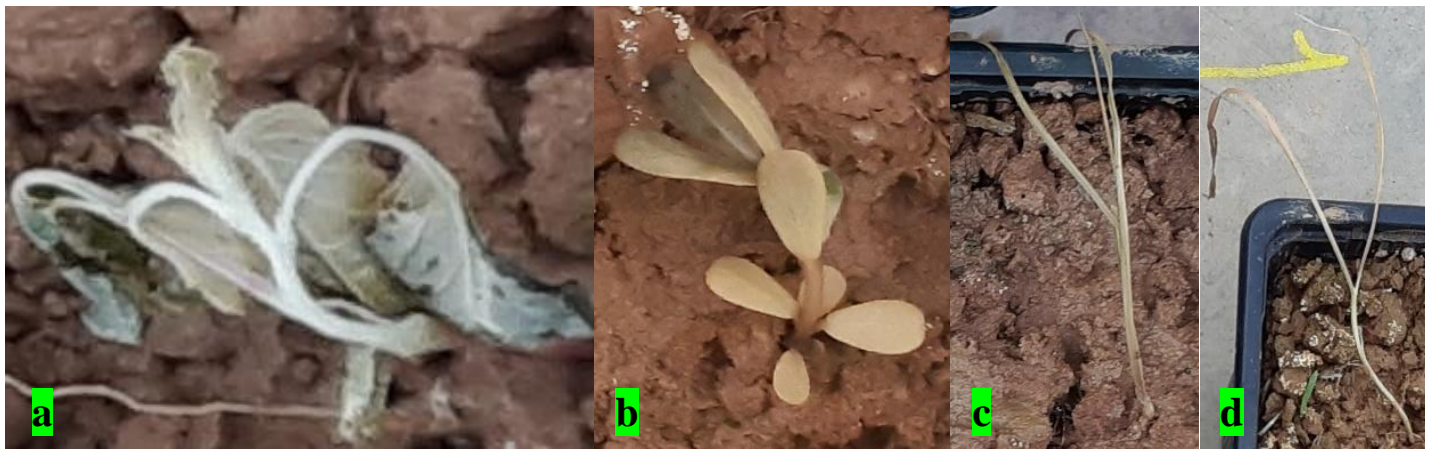

Figure 5_2. Whitening of the leaf tissues 24 hours after treatment in (a), A.retroflexus (b) $P$. oleracea, (c) E. crus-galli and (d) one week after treatment application in A. fatua. 


\subsection{Conclusion}

The results obtained confirmed the hypothesis that EOs extracted from lemon peels with an industrial method could be used as bioherbicide. Certainly, is a product easily available on the market in high quantities with low costs what is an important advantage concerning other EOs that have high costs or which costs are not known (Azirak and Karaman, 2008; Benvenuti et al., 2017).

In our case, further studies should be done on other weeds and in crops focused on finding the optimum doses, method of application and phenological stage to maximize herbicidal effects in weeds and minimize phytotoxic effects in crops, for practical use in field conditions.

The allelopathic properties found in the studied lemon EO represent a good basis for the development of herbicides of natural origin biodegradable and eco-friendly. 
6 Wastewaters from citrus processing industry as natural biostimulants for soil microbial community 


\subsection{Introduction}

According to the database of the United Nations Food and Agriculture Organization, the world's citrus fruit production destined for processing in 2016 was of 23,538.9 thousand tons (FAO, 2017). The top ten countries yearly processing citrus fruits are Brazil, United States, Mexico, Argentina, China, Spain, South Africa, Italy, Costa Rica and Turkey (FAO, 2017). During the processing, large amounts of drinking water for washing fruits and equipments, to extract Es and juices, and for other secondary operations are required (Thevendiraraj et al., 2003). Italian small-medium factories processing 60,000 Mg of citrus fruits per year are estimated to use about $0.8 \mathrm{~m} 3$ of drinking water per ton of fruits (Eurofood, Messina, Sicily, Italy; personal communication). Indeed, water consumption per weight unit of processed fruit depends on the adopted technology; Tamburino et al. (2007) reported the use of $1 \mathrm{~m}^{3}$ of water per ton of processed fruits without peel drying and by waterrecirculation systems, whereas Corsino et al. (2018) observed that a citrus factory processing $25 \mathrm{Mg} \mathrm{h}-1$ of lemons produced about $17 \mathrm{~m}^{3}$ of wastewater per ton of processed fruits.

Citrus fruit processing wastewaters (CWWs) are rich in organic matter, show a low $\mathrm{pH}$ and could hold essential oils in trace. They also contain a little bit of nitrogen, phosphorus and traces of some microelements (Zema et al., 2012). Up to nowadays, CWWs have been addressed to sewage treatment before being disposed of, with a negative economic impact for the company budget. Moreover, the reliability of the depuration, the efficiency and the sustainability of the activated sludge plants, commonly used for processing CWWs, are negatively conditioned by their high acidity, scarcity of nutrients and essential oils content (Corsino et al., 2018; Lane, 1983). Furthermore, the activated sludge depuration process of CWWs requires a high energy input (Cheng, et al 2012).

Since CWWs derive from the use of drinking water and edible fruits, it could be of interest, especially for the sustainability of the industrial process, their reuse in agriculture for irrigation, either as they are or diluted with conventional water (Bastida et al., 2018). Such a thought becomes even more reasonable because CWWs hold a significant amount of both dissolved organic matter and nutrients (Corsino et al., 2018), thus being potentially able to reduce the input of inorganic fertilizers and increase soil organic matter. Moreover, due to the drastic decrease of water resources during last decades, and their further reduction as a consequence of the incoming climate change (OECD, 2017), resorting to unconventional water resources for irrigation, contextually to sustainable agriculture, it is becoming a must. However, before using CWWs for crop irrigation, their impact on soil properties and, in particular, on soil microorganisms have to be assessed. Being the latter the drivers of soil 
nutrient cycling, whatever practice that will positively or negatively affect them, in turn, it will have an impact on soil fertility and crop productivity.

The addition of exogenous organic substrates to agricultural soils is a widely used practice to improve soil aggregation and to increase soil organic matter, $\mathrm{N}$ and $\mathrm{P}$ availability (Melero et al., 2007; Badalucco et al., 2010; Laudicina et al., 2011; Becerra-Castro et al., 2015). Moreover, in arid and semiarid environments, the reuse of wastewater in agriculture to supply water to plant and organic matter to soil (Adrover et al., 2012; Ma et al., 2015; Pezzolla et al., 2015) is very welcome due to the scarcity of water for irrigation (OECD, 2017) and the continuous decline of soil organic matter (Laudicina et al., 2011, 2012a). Also, biochemical soil properties are deeply impacted by the addition of organic substrates through wastewaters (Meli et al., 2003). Many studies have reported an increase of labile carbon pools and microbial respiration following the addition of pig slurry (Rochette et al., 2000), olive mill wastewaters (Piotrowska et al., 2006), secondary-treated municipal wastewater (Adrover et al., 2012), pig slurry-derived digestate (Pezzolla et al., 2015) and untreated textile wastewater (Roohi et al., 2016). It is also true that other studies have found a negative effect of wastewater on microbial biomass and activity (Kayikcioglu, 2012; Charlton et al., 2016). Such negative effects have been generally ascribed to heavy metals or phenolic compounds held in wastewaters. Other important effects of the addition of wastewaters to soil are those on the main microbial groups (Blagodatskaya and Kuzyakov, 2008; Ma et al., 2015; Pezzolla et al., 2015) since, for example, shifts of the fungi to bacteria and of the grampositive to the gram-negative bacteria may indicate changes in $\mathrm{C}$ sequestration and availability (Fanin et al., 2019; Jastrow et al., 2007; Laudicina et al., 2012b; Waring et al., 2013).

Up to nowadays, to our best knowledge, no studies are available about the effect of CWWs on soil microbial biomass and activity, and the main microbial groups. If from one hand positive feedback could be expected since the significant amount of organic substrates held within CWWs, on the other hand also a negative impact could be hypothesized as they can hold some essential oils, which have been proved to have some inhibitory effects on soil microorganisms (Settanni et al., 2012; Palazzolo et al., 2013).

Based on the above considerations, the aim of this study carried out at laboratory scale, was to evaluate the effects of CWWs on soil stable and labile $\mathrm{C}$ pools, microbial biomass $\mathrm{C}$ and $\mathrm{N}$, microbial respiration, and on the relative abundance of main microbial groups. The CWWs used were those coming from the lemon, orange and tangerine processing industry; they held different amounts of $\mathrm{C}$ and were added to soil as they are or diluted with water. 
The hypotheses tested were: i) CWWs increase both stable and labile soil $\mathrm{C}$ pools but also stimulate microbial activity; ii) such increase and stimulation are proportional to the amount of $\mathrm{C}$ added by CWWs, iii) the easily available $\mathrm{C}$ held within added CWWs affected the bacteria to fungi ratio due to their different $\mathrm{C}$ use efficiency. To test these hypotheses, total and extractable organic $\mathrm{C}$, and microbial biomass $\mathrm{C}$ were determined as indicators of stable and labile $\mathrm{C}$ carbon, respectively, while microbial respiration as an indicator of microbial activity (Laudicina et al., 2012b). Phospholipid fatty acids were assessed to follow changes of the main microbial groups (Frostegård et al., 2011). Some simple indexes were calculated from the ratio of biochemical parameters or specific PLFAs as indicators of soil $\mathrm{C}$ sequestration (ratio between bacteria/fungi; Jastrow et al., 2007; Waring et al., 2013), C use efficiency and metabolic stress (the ratio between microbial respiration and microbial biomass $\mathrm{C}$, i.e. the metabolic quotient, and between microbial biomass $\mathrm{C}$ and total organic C, i.e. the microbial quotient; Anderson, 2003; Schloter et al., 2003; Wardle and Ghani, 2018), nutrient availability (ratio between gram-positive and gram-negative bacteria (Fanin et al., 2019) and microbial community stress (ratio between monounsaturated and saturated fatty acids, and between cyclopropanoic and precursors fatty acids; Kaur et al., 2005).

Results of this study could have two important relapses: from one hand, if CWWs improve soil chemical and biochemical properties, they could be used to maintain or improve the soil organic matter, and hence soil fertility, in semiarid and arid environments, where citrus cultivation is largely diffused (ecological relapse); on the other hand, the citrus processing industry could make a profit by selling or simply giving away the CWWs to farms (economic relapse), instead of paying for their disposal.

\subsection{Materials and methods}

\subsubsection{Citrus wastewaters}

Citrus wastewaters (CWWs) were obtained from three citrus species: Citrus sinensis (L.) Osbeck (Orange), Citrus limon (L.) Osbeck (Lemon) and Citrus reticulata Blanco (Tangerine). The CWWs, obtained by cold pressing of citrus peels, were provided by a local industry (EuroFood, Messina, Italy). Briefly, citrus fruits were washed, grated by many small knives, and finally half-cut and squeezed to extract the juice. After this step, the remaining pulp was addressed to the cold press to extract essential oils. During the latter step, also a consistent amount of water was used to wash out the essential oils ( $\sim .1 \mathrm{~m}^{3} \mathrm{Mg}-1$ of pulp); 
the suspension was then addressed to a centrifuge that separated the two phases: essential oils and CWWs.

\subsubsection{Experimental set-up}

The experiment was carried out at laboratory scale. The topsoil $(0-15 \mathrm{~cm})$ of an olive orchard was used. The main characteristics of the soil were: clay $16 \%$, sand $65 \%, \mathrm{pH}$ in water 7.0, electrical conductivity (1:5, w/v) $0.1 \mathrm{dS} \mathrm{m}^{-1}$, total organic carbon $15.5 \mathrm{~g} \mathrm{~kg}^{-1}$, total nitrogen $1.2 \mathrm{~g} \mathrm{~kg}^{-1}$, no total carbonates. After sampling, the soil was air dried and sieved at $<2 \mathrm{~mm}$. Later, $450 \mathrm{~g}$ of soil were placed in 1L plastic bottles and moistened up to $50 \%$ of the water holding capacity (WHC) by applying CWWs or water only (control, CTR). The CWWs were applied at three different doses to reach $1 / 3,2 / 3$ and $3 / 3$ of the $50 \%$ of soil WHC (Table 6_S1). Respectively, 35, 70 and $105 \mathrm{~mL}$ of each CWWs were singly added to $450 \mathrm{~g}$ of air-dried soil. Distilled water was added to the control soil up to $50 \%$ of its WHC and, when necessary, to CWWs treatments to complement the $50 \%$ of WHC. Soils were then incubated in the dark at constant temperature $\left(23.0 \pm 0.5^{\circ} \mathrm{C}\right)$, and their humidity weekly adjusted up to $50 \%$ of WHC by replenishing the lost water. Four replicates per treatment were run for a total of 40 samples ( 3 CWWs x 3 doses $x 4$ replicates plus 4 controls). At the same time, $20 \mathrm{~g}$ of soil from each of the above 40 soil samples were similarly incubated in $200 \mathrm{~mL}$ glass jars), sealed with rubber stoppers holding silicon septa to monitor the emission of $\mathrm{CO} 2$ as a measure of the microbial respiration.

\subsubsection{Soil analyses}

Soils incubated in the plastic bottles $(450 \mathrm{~g})$ were analyzed at 7, 28 and 56 incubation days. Soil reaction was determined by using a potentiometric glass electrode in 1:2.5 (w/v) soil/distilled water suspension. Total organic carbon (TOC) was determined by the WalkleyBlack wet oxidation method (Nelson and Sommers, 1996), whereas total N (TN) by the Kjeldahl digestion method (Mulvaney, 1996). Microbial biomass C (MBC) was determined by the fumigation-extraction method (Vance et al., 1987); it corresponded to the difference between organic $\mathrm{C}$ extracted by $0.5 \mathrm{M} \mathrm{K}_{2} \mathrm{SO}_{4}$ from fumigated and not fumigated samples, multiplied by 2.64. The concentration of $\mathrm{K}_{2} \mathrm{SO}_{4}$-extractable $\mathrm{C}$ from not fumigated soil was used as a proxy of organic C available to microorganisms (Laudicina et al., 2013). Microbial biomass $\mathrm{N}$ was calculated multiplying by 5 the difference between the ninhydrin-reactive $\mathrm{N}$ 
determined on $0.5 \mathrm{M} \mathrm{K}_{2} \mathrm{SO}_{4}$ extracts from fumigated and not fumigated soil (Joergensen and Brookes, 1990).

Phospholipid fatty acids (PLFAs) were extracted and analyzed according to the modified Bligh and Dyer's method (Wu et al., 2009). The nonadecanoic acid methyl ester was used as the internal standard for FAMEs quantification. Peaks were identified by comparison with retention times of known standards (Supelco BAME mix 47080-U; Supelco 37 Component FAME mix 47885-U). Fatty acids (FAs) with less than 14 or more than 19 carbon atoms were neglected as originating from non-microbial sources. The FAs i15:0, a15:0, 15:0, i16:0,

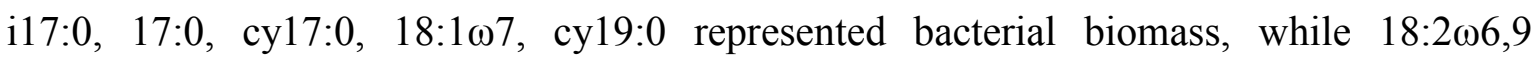
corresponded to fungal biomass (Frostegård and Bååth, 1996). The FAs i15:0, a15:0, i16:0,

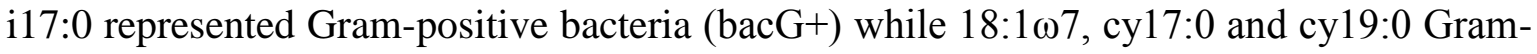
negative bacteria (bacG-) (Zelles, 1997).

The $\mathrm{CO}_{2}$ accumulated during the incubation in the headspace of the glass jars was determined by a gas chromatograph (Thermo Trace GC 90, fitted with a thermal conductivity detector, a Poropak Q column and using He as the carrier) after 1, 3, 7, 10, 17, 23, 31, 44, 59 days. At each $\mathrm{CO}_{2}$ determination, jars were ventilated with fresh air for 30 min and then sealed again, after possible replenishment of lost soil moisture by distilled water. The $\mathrm{C}$ mineralization rate, expressed as $\mathrm{mg} \mathrm{CO}_{2}-\mathrm{C} \mathrm{kg}^{-1}$ dry soil day ${ }^{-1}$, was fitted to the following first-order decay function (Riffaldi et al., 1996):

Mineralized $\mathrm{C}=\mathrm{C} 0 \mathrm{e}^{-\mathrm{kt}}$

where $\mathrm{C} 0$ is the biologically available $\mathrm{C}$ at time zero (i.e. the intercept value), $\mathrm{k}$ is the decay rate constant, and $\mathrm{t}$ is the incubation day. The total $\mathrm{CO}_{2}-\mathrm{C}$ mineralized over 59 days of incubation was calculated by the linear interpolation of two neighbouring rates and the integration over time:

Total C mineralized $=\sum_{n}^{i} \llbracket\left[\left(\mathrm{r}_{\mathrm{i}}+\mathrm{r}_{(\mathrm{i}+1)}\right) * \mathrm{~d} / 2+\cdots+\left(\mathrm{r}_{(\mathrm{n}-1)+} \mathrm{r}_{\mathrm{n}}\right) * \mathrm{~d} / 2\right] \rrbracket$

where $\mathrm{i}$ is the date of the first measurement of $\mathrm{CO} 2-\mathrm{C}$ rate, $\mathrm{n}$ is the last day of measurement of $\mathrm{CO}_{2}-\mathrm{C}$ rate, $\mathrm{r}$ is the $\mathrm{CO}_{2}-\mathrm{C}$ rate expressed as $\mathrm{mg} \mathrm{CO}_{2}-\mathrm{C} \mathrm{kg}^{-1}$ dry soil day ${ }^{-1}$, and $\mathrm{d}$ is the number of days between the two consecutive $\mathrm{CO}_{2}$ rate measurements.

\subsubsection{Statistical analyses}

Reported data were expressed on the oven-dry $\left(105^{\circ} \mathrm{C}\right)$ soil weight basis. Except for C mineralization, data were subjected to two-way ANOVA, within each citrus type, with CWWs dose and incubation day as main factors. Fisher $(F)$ values were used to individuate 
the relative importance of each factor in affecting a given soil parameter. Post-hoc tests (Tukey at $\mathrm{P} \leq 0.05$ ) were carried out among incubation days within the same CWWs dose, and among CWWs doses at the same incubation day. Moreover, the Tukey test was also used to compare the control with all the CWWs doses at the same incubation day. $\mathrm{C}$ mineralization data $(\mathrm{C} 0, \mathrm{k}$ and $\mathrm{C} 0 \mathrm{k})$ were subjected to one-way ANOVA with only $\mathrm{CWWs}$ dose as factor and Tukey test was carried out to assess significant differences at $\mathrm{P} \leq 0.05$ among doses and also the control. 


\subsection{Results}

\subsubsection{Chemical composition of CWWs}

The three CWWs had the same density but quite different chemical properties (Table 6_1). Orange citrus wastewater (OWW) had more than twice total $\mathrm{C}$ and $\mathrm{N}$ compared to the other two CWWs, but the lowest content of ashes. The C/N ratio of CWWs ranged from 8.9 to 16.3 , being the lowest in lemon wastewater (LWW) and the highest in tangerine wastewater (TWW). Both total carbohydrates and soluble monosaccharides were the highest in OWW, intermediate in TWW and the lowest in LWW. The reaction of CWWs was acidic, ranging from $\mathrm{pH} 2.4$ in $\mathrm{LWW}$ to about $\mathrm{pH} 3.0$ in the other two CWWs.

\subsubsection{Effect of CWWs on soil total organic carbon and pH}

Total organic $\mathrm{C}$ determined after one day since the addition of CWWs increased, for each treatment, by about the amount of $\mathrm{C}$ held within the added CWWs (Table 6_S2). Then, at day 7, TOC decreased from 3 to $31 \%$ compared to day 1, with the decrease rate following the order OWW $>$ TWW $>$ LWW and, as expected, the higher the CWWs dose the higher the decrease. TOC continued decreasing up to day 56 when, except for soils added with LWW and OWW at the highest dose, reached values comparable to those of the control.

The addition of CWWs lowered soil pH during the first 3 days of incubation, reaching about 4.0 with the highest doses of LWW and OWW, and 5.5 with TWW (Figure 6_1); then, at day 7, soil $\mathrm{pH}$ came back comparable to the control $\mathrm{pH}$, except for OWW at the highest dose for which the recovery occurred at day 21 .

\subsubsection{Effects of LWW on biochemical soil properties and main microbial groups}

Extractable C, MBC and MBN were mainly affected by incubation day (highest F values), whereas cumulative CO2 by the applied LWW dose (Table 6_2). At day 7, extractable $\mathrm{C}$ showed higher values in LWW treated soil compared to the control (from 36 to $370 \%$ ) and its increase was proportional to the applied dose (Figure 6_2). After day 7, extractable $\mathrm{C}$ remarkably decreased towards values of the control, with small differences among doses at both 28 and 56 days, suggesting that most of the organic C held in LWW had been assimilated already after 28 days of incubation. Similarly, at day 7, MBC increased, proportionally to LWW dose, from 99 to 206\% (Figure 6_2). At day 28, MBC was still higher in treated soils than in the control but with small differences among doses whereas, at day 56, it was higher with the largest dose only. Also MBN, at day 7 was proportionally 
enhanced by the applied dose of LWW but at days 28 and 56 this effect was less pronounced (Figure 6_2). Regardless of dose, the microbial quotient (MBC/TOC) decreased with incubation time (Table 6_3) while at day 7 it proportionally increased with LWW dose; however, this stimulating effect disappeared later throughout the incubation.

Carbon mineralization rate was significantly stimulated by the addition of LWW up to day 22; then, no further difference was observed among control and treatments, thus suggesting the exhaustion of $\mathrm{C}$ substrates added by LWW (Figure 6_3). The biologically available $\mathrm{C}$ at time zero (C0), as expected, was the lowest with the $1 / 3$ dose, although it did not proportionally increase with the two highest doses, which did not differ between them (Figure 6_3). Consequently, both the decay rate constant (k) and the C0k product, i.e. the initial potential rate of C mineralized (Riffaldi et al., 1996), were inversely related to the LWW dose (Figure 6_3).

The metabolic quotient, at day 7, compared to the control, was more than twice with the $1 / 3$ dose whereas nearly 7 and 5 times, respectively, higher with the 2/3 and $3 / 3$ doses (Table $\left.6 \_3\right)$. At day 28 and 56, only the $2 / 3$ dose was able to slightly increase the qCO2, compared to the control.

Generally, both the dose and incubation time affected the main microbial groups (Table 6_4). At all tested doses, LWW increased, compared to the control, all monitored main microbial groups (Table 6_5). However, during the incubation, regardless of LWW dose, the general trend for all bacteria groups was that they were larger at 7 and 56 days, while smaller at day 28. On the contrary, fungi generally at the same day increased with LWW dose but at the same LWW dose decreased with incubation day (Table 6_4). Based on above trends, also the bacG+/bacG- and fungi/bacteria ratios generally increased and never decreased, compared to control, and were affected by both incubation time and LWW dose, with the first ratio much more affected by the first factor and the second ratio equally affected by both factors (Table 6_4).

\subsubsection{Effects of OWW on biochemical soil properties and main microbial groups}

Except for extractable $\mathrm{C}$, which was mainly affected by incubation time (highest $\mathrm{F}$ values), biochemical properties did so by the applied dose of OWW (Table 6_2). At day 7, OWW strongly increased extractable C, proportionally to the applied dose, from 394 to 1404 mg C kg${ }^{-1}$ compared to the control (Figure 6_4). Then, regardless of dose, at day 28 extractable $\mathrm{C}$ fell by about $75 \%$ and even more at 56 days, with only negligible differences compared to the control. MBC was always stimulated by OWW at any dose, compared to 
the control, but proportionally at 28 days only (Figure 6_4). On the contrary, MBN increased linearly with the dose, at any incubation day, with small temporal differences within each dose (Figure 6_4). The microbial quotient was generally increased by OWW compared to the control. It decreased during the incubation with $1 / 3$ dose whereas increased with the two highest doses (Table 6_3). On average, the microbial quotient increased proportionally with the OWW dose (Table 6_3).

Carbon mineralization rate and, consequently, cumulated $\mathrm{CO} 2$, proportionally increased with OWW dose (Figures 6_4 and 6_5). Notably, after 31 days the rate with the two lowest doses was the same, while that with the highest dose was still the highest one (Figure 6_5). Also, C0 proportionally increased with the dose (Figure 6_5). However, the decay rate constant did not significantly change by increasing the dose, but the initial potential rate of $\mathrm{C}$ mineralized was the highest with the highest dose (Figure 6_5). The metabolic quotient, compared to the control, always increased after OWW addition (Table 6_3); moreover, regardless of incubation, it was generally directly related to the OWW dose, whereas at any dose it decreased with incubation day.

The abundance of microbial groups, compared to the control, nearly always increased after OWW addition and was affected, at the same extent, by both OWW dose and incubation day, but in opposite sense; generally, their abundance increased with the OWW dose while decreased with incubation day (Table 6_4). Notably, the ratio bacG+/bacG- did not change at the lowest dose, throughout incubation, while increased at the two highest doses. Moreover, the added OWW at any incubation day favoured more fungi than bacteria as the fungi/bacteria ratio increased proportionally to the applied dose (Table 6_4).

\subsubsection{Effects of TWW on biochemical soil properties and main microbial groups}

MBC, MBN and cumulative CO2 were mainly affected by TWW dose, whereas incubation day affected more the extractable C (Table 6_2). Indeed, at day 7, extractable C was increased, proportionally to the two highest applied dose, compared to the control (Figure 6_6); then, throughout incubation, no significant differences emerged among doses and the control except for $1 / 3$ dose at day 28 , when it was lower than in the control. Within each dose, extractable $\mathrm{C}$ decreased with incubation day from $43 \%$ for $1 / 3$ dose to $83 \%$ for the 3/3 dose (Figure 6_6). At days 7 and 28, the lowest and intermediate doses of TWW increased MBC compared to the control, although between 7 and 28 days MBC markedly decreased. Notably, at 56 days, the effects of applied TWW at any dose disappeared since MBC practically did not change compared to control. Moreover, with the intermediate TWW 
dose, MBC decreased with incubation day (Figure 6_6). During the whole incubation, MBN was higher than the control with the two highest TWW doses only and, it was the highest at day 56 with any treatment (Figure 6_6).

The MBC/TOC ratio was generally increased by the two lowest doses, within which it decreased with incubation day, whereas the $3 / 3$ dose increased it only at day 28 compared to the control (Table 6_4).

Carbon mineralization rate was stimulated by TWW proportionally to the applied dose only up to day 18 (Figure 6_7). As a consequence, also the cumulative $\mathrm{CO}_{2}$ increased with increasing TWW doses and incubation day (Figure 6_6). The biologically available C (C0) was the highest in TWW treated soils and increased with increasing dose whereas, on the contrary, the decay rate constant and the product $\mathrm{C} 0 \mathrm{k}$ decreased but they were always higher than in the control (Figure 6_7). The metabolic quotient increased with the dose on day 7, then drastically decreased with no clear trend among applied doses, although remaining higher than in the control (Table 6_3).

All monitored microbial groups at any TWW dose and incubation day were higher than in the control, except for few cases at day 56 when were equal or lower. Moreover, at a given incubation day, they increased with the TWW dose whereas, at a given dose, they decreased with incubation day (Table 6_4). The fungi/bacteria ratio at 7 and 28 days of incubation was higher than in the control, whereas at day 56 no significant yet occurred. Remarkably, regardless of dose, the fungi/bacteria ratio was the highest at 28 days. The bact/bac- ratio at day 56 with any TWW dose was lower than the control, whereas within each dose there was no clear trend with time (Table 6_4). 


\subsection{Discussion}

The addition of CWWs caused a decrease in soil $\mathrm{pH}$, although transient, and an increase of stable and labile carbon pools, as well as stimulated carbon mineralization. Such an effect depended on incubation day and CWWs dose, with few exceptions, so confirming our first two hypotheses. Regardless of CWW type, immediately after their addition, soil $\mathrm{pH}$ decreased from 2 to 3 units likely due to the acidic reaction of the CWWs. However, after 7 days, soils recovered their initial $\mathrm{pH}$ values, thus suggesting a good buffer capacity mainly ascribable to its inorganic and organic colloidal components, given that carbonates were absent (Weil and Brady, 2017).

The increase of TOC, as well as of extractable $\mathrm{C}$, at the beginning of the incubation and proportionally to CWW dose, was expected since they held organic C.

As CWWs held different amounts of $\mathrm{C}$ and since pre-fixed volumes of each CWW were added, the increase of extractable $\mathrm{C}$ at day 7 was proportional to $\mathrm{C}$ added by CWWs and, consequently, regardless of CWWs dose, it followed the order OWW $>$ LWW $\geq$ TWW. Such an increase, however, was quite ephemeral for all TWW and LWW doses, and also for OWW at $1 / 3$ dose since, at day 28 , both TOC and extractable $\mathrm{C}$ were comparable to the control. Similar findings have been already reported by Di Bene et al. (2013) and Gamba et al. (2005) following the addition of olive mill wastewaters and have been ascribed to the rapid mineralization of added organic matter (Di Serio et al., 2008; Mechri et al., 2007). Our results agreed with such previous studies since an intensification of the $\mathrm{C}$ mineralization was registered following the addition of CWWs, due to the concomitant stimulation of the microbial biomass. However, when OWW was applied at the two highest doses the increase of TOC and extractable C was not so ephemeral since, at the end of the incubation, both $\mathrm{C}$ pools were still higher than in the control.

The great reduction of extractable $\mathrm{C}$ at day 28 , compared to day 7 , suggested that $\mathrm{C}$ supplied by CWWs was easily either immobilized or respired by soil microorganisms (Laudicina $e t$ al., 2010). Indeed, both MBC and C mineralization at the beginning of the incubation were greatly enhanced following the addition of CWWs. Such results agreed with Adrover et al. (2012) and Chen et al. (2008) who suggested that the positive effects of treated wastewater irrigation on soil microbial biomass and activity can be attributed to the addition of easily decomposable organic matter and nutrients. In general, the addition of organic substrates enhances microbial respiration, because they are potential energetic sources consumed through the oxidative metabolism of the heterotrophic soil microbiota (Bhattacharyya et al., 
2001). The small, or even the null, reduction of extractable $C$ from day 28 to day 56 was indicative of the exhaustion of available organic $\mathrm{C}$ for microbial utilization.

The increase of MBC depended on both type of CWWs and dose. About the type of CWWs, the greatest $\mathrm{MBC}$ increase was according to the highest $\mathrm{C}$ content in wastewaters, i.e. to OWW. The higher the dose the greater the increase, at least at 7 incubation days and except for tangerine, it was consistent with previous findings by Roohi et al. (2016), Armenta et al. (2012), and Mojiri (2011) who added to soil untreated textile wastewaters, municipal wastewaters and sewage sludge, respectively. Such MBC increase resulted, for all tested CWWs, in higher values of MBC/TOC ratio, thereby suggesting that some carbon available from added CWWs was incorporated by microorganisms for growth (Anderson and Domsch, 1989) dose. Similarly, Piotrowska et al. (2006) and Plaza et al. (2007) found that $\mathrm{MBC} / \mathrm{TOC}$ ratio increased during the first 14 days following the application of olive mill wastewater and pig slurry, respectively. The increase of $\mathrm{MBC}$ inversely related to the two highest TWW doses might be due to the presence of residual essential oil, or some specific components held in TWW that, when added at greater doses, was able to counteract the benefit of the C addition (Settanni et al., 2012).

The MBC decrease observed from day 7 to day 28 agreed with previous findings (e.g. Rochette et al., 2000; Roohi et al., 2016) and can be attributed to the exhaustion of labile C substrates which were scarce to maintain the initial microbial growth rate for a longer period (Plaza et al., 2007). Also, some microorganisms likely died due to the residual essential oil held in CWWs (Settanni et al., 2012; Palazzolo et al., 2013). However, the higher values of MBC up to day 56, compared to the control, with OWW at any dose, while with LWW and TWW only at the highest dose, put in evidence a specific ability of such CWWs in stimulating soil microorganisms and providing $\mathrm{C}$ for microbial growth.

Whether from one hand supplied C by CWWs was immobilized by microorganisms, on the other hand, it stimulated the microbial activity. Both measured cumulated $\mathrm{CO}_{2}$ and estimated initial biological available $\mathrm{C}(\mathrm{C} 0)$ increased in soil treated with $\mathrm{CWW}$. As for MBC, the stimulation of microbial activity depended on both the type and dose of applied CWWs. The only exception was with LWW, for which both the daily respiration rate and total emitted $\mathrm{CO}_{2}$ did not increase between the doses $2 / 3$ and $3 / 3$ throughout the whole incubation, probably because the higher the dose the greater the quantity of essential oil held within added LWW and inhibiting microbial activity. The increase of $\mathrm{CO}_{2}$ following the addition of CWWs is to be ascribed to the supply of easily degradable organic substrates determining a trigger-effect on soil microorganisms, i.e. the rapid assimilation of easily degradable 
organic substrates by r-strategist bacteria (De Nobili et al., 2001; Moore-Kucera and Dick et al., 2008; Pezzolla et al., 2015). Such a hypothesis was confirmed by the consistent increase of bacteria as assessed by PLFAs biomarkers.

The increase of microbial respiration itself, however, is not indicative of either a positive or negative impact of CWWs addition on soil microbial community. On the other hand, when microbial respiration rate is combined with microbial biomass $\mathrm{C}$ into a simple indicator, i.e. the $\mathrm{qCO}_{2}$, may provide information about stress or disturbance of soil microbial community and, hence, on its metabolic efficiency (Anderson, 2003; Wardle and Ghani, 2018). The increase of $\mathrm{qCO}_{2}$ may occur for several reasons: new input of fresh organic substrates, microbial response to adverse conditions, a predominance of the zymogen microflora ( $r$ strategists) over the autochthonous one (K-strategists), or alteration of the bacteria/fungi ratio since they have different carbon use strategies (Dilly and Munch, 1998). Here the huge increase of the $\mathrm{qCO}_{2}$ at day 7 can be ascribed to the high amount of extractable $\mathrm{C}$ supplied by $\mathrm{CWWs}$ which determined a flush of $\mathrm{CO} 2$ and, at the same time, the stimulation of the zymogenous (r-strategist) over the autochthonous (K-strategists) microorganisms, with the former characterized by a higher energy consumption at a lower efficiency than the latter (Bradley and Fyles, 1995). Fierer et al. (2007) reported that the addition of easily degradable organic substrates stimulates the growth of some copiotrophic bacteria, which are usually included within the group of r-strategists. Finally, also the addition of CWWs could have stressed soil microorganisms due to the essential oils held within or even to osmotic stress caused by the high amount of soluble $\mathrm{C}$, especially at the highest dose. All those causes likely surmounted that the increase of the fungi/bacteria ratio should have caused a decrease of the $\mathrm{qCO}_{2}$ due to the higher $\mathrm{C}$ use efficiency of fungi compared to bacteria (Soares and Rousk, 2019).

The kinetics of carbon mineralization following the addition of organic substrates has been generally described by interpolating $\mathrm{CO}_{2}$ emission data with different models. In this study, among the different models tested, the best fit was obtained with the first-order exponential decay model (Riffaldi et al., 1996). Such finding suggested that the added C consisted of a single pool of organic substrates mainly with a similar degree of decomposability (Bernal $e t$ al., 1998).

The increase of $\mathrm{C} 0$ proportionally to CWWs dose is reasonable since the higher the dose of CWWs the more the $\mathrm{C}$ held within. On the other hand, the turnover rate constant $(\mathrm{k})$ decreased by increasing the amount of added LWW and TWW but did not change for OWW. Similarly, the product C0k was inversely related to the dose for LWW and TWW, while 
directly related to OWW. The above trends of $\mathrm{k}$ and $\mathrm{C} 0 \mathrm{k}$ may be explained by two possible reasons, not necessarily mutually exclusive: 1) the quality of organic substrates (palatability) within OWW was higher than LWW and TWW; 2) likely, LWW and TWW held higher amounts of inhibiting compounds (essential oil) compared to OWW.

The increase of bacteria and fungi in soil added with CWWs compared to the control during the whole incubation is consistent with the supply of easily assimilable organic substrates that favoured their growth (Paul, 2015). However, fungi were more favoured than bacteria since the fungi/bacteria ratio was higher in treated soils than in the control. Such an increase was probably even emphasized by the acidic reaction of added CWWs that lowered soil $\mathrm{pH}$. Indeed, it is well known that fungi generally grow in acidic environments better than bacteria (Paul, 2015). This shift of the microbial groups if maintained over the time in field application of CWWs may have important relapses from an ecological point of view as soil richer in fungi may contribute to sequester more $\mathrm{C}$ in soil (Malik et al., 2016; Waring et al., 2013). Also, the bacterial community was affected by CWWs, although less than fungi. More precisely, the addition of LWW at 3/3 dose and OWW at 2/3 and 3/3 doses increased more the gram-positive bacteria than the gram-negative ones. Such results are in contrast with what reported by Fanin et al. (2019) who found gram-negative bacteria more associated with simple C compounds. However, on the other hand, Bastida et al. (2008) reported that, in soil amended with compost and sludge, the preferential development of the Gram+ bacteria may be interpreted as a shift from chemolithotrophic microbial communities, many of them Gram- (Schlegel, 1992), towards a more heterotrophic community by increasing available C (Tscherko et al., 2004). Such an aspect, however, is worthy of further investigations. 


\subsection{Conclusions}

This study provides preliminary results regarding the effect of lemon, orange and tangerine processing wastewaters on stable and labile soil $\mathrm{C}$ pools, microbial biomass and activity and on the main microbial groups. Generally, CWWs increased both C pools but at the lowest application dose (1/3 and 2/3 of the $50 \%$ of soil water holding capacity) such an increase was ephemeral; on the contrary, when LWW and OWW were applied at the highest dose (3/3 of the $50 \%$ of soil water holding capacity) the increase was more lasting. Besides to be depending on the dose, such effects depended on CWWS type, being the higher the amount of $\mathrm{C}$ held the more effective. Precisely, the CWWs showed the efficiency orange $>$ lemon $\geq$ tangerine.

Following the application of CWWs, microbial respiration was greatly stimulated, with the consequent increase of the metabolic quotient which suggested the incoming of stress conditions; however, also under stress, soil microorganisms were able to use organic $\mathrm{C}$ for their growth as evidenced by the increase of the microbial quotient. Concerning the main microbial groups, they were all stimulated by CWWs, but fungi were favoured more than bacteria, especially during the first days after the addition of CWWs, probably due to the resulting, although transient, soil acidification. Overall, our findings provided evidence that CWWs may play some role within sustainable agriculture since, when added to a sandy-clay soil, they increased total and labile $\mathrm{C}$ pools and stimulated soil microbial activity, so improving the soil quality and fertility. 


\begin{tabular}{lccccccccc}
\hline Wastewater & Density & Total C & Total N Total C/N Ashes Total soluble & \multicolumn{2}{c}{ Total } & \multicolumn{2}{c}{ Total } & pH \\
& & & & & & & Monosaccharides & Carbohydrates & Fibers \\
& $\mathrm{g} \mathrm{cm}^{-3}$ & $\%$ & $\%$ & & $\%$ & $\%$ & $\%$ & $\%$ & \\
\hline LWWs & 1.01 & $2.5 \mathrm{~b}$ & $0.28 \mathrm{~b}$ & $8.9 \mathrm{c}$ & $2.6 \mathrm{a}$ & $1.1 \mathrm{c}$ & $1.4 \mathrm{c}$ & $0.9 \mathrm{~b}$ & $2.4 \mathrm{~b}$ \\
OWWs & 1.04 & $6.9 \mathrm{a}$ & $0.54 \mathrm{a}$ & $12.8 \mathrm{~b}$ & $1.4 \mathrm{~b}$ & $3.1 \mathrm{a}$ & $3.6 \mathrm{a}$ & $1.1 \mathrm{a}$ & $3.1 \mathrm{a}$ \\
TWWs & 1.01 & $2.7 \mathrm{~b}$ & $0.16 \mathrm{~b}$ & $16.9 \mathrm{a}$ & $2.2 \mathrm{a}$ & $2.0 \mathrm{~b}$ & $2.9 \mathrm{~b}$ & $0.3 \mathrm{c}$ & $2.9 \mathrm{ab}$ \\
\hline
\end{tabular}

Table 6_1. Main chemical properties of lemon, orange and tangerine wastewaters ( $L W W$, $O W W$ and $T W W$, respectively) supplied to soil at three different doses (1/3, 2/3 and 3/3 of the $50 \%$ of soil water holding capacity). Different letters indicate significant differences among $C W W$ s at $P \leq 0.05$

\begin{tabular}{|c|c|c|c|}
\hline $\begin{array}{l}\text { Treatment / } \\
\text { Parameters }\end{array}$ & Dose & Day & Dose x Day \\
\hline \multicolumn{4}{|l|}{ LWW } \\
\hline Extractable C & $260 * * *$ & $684 * * *$ & $150 * * *$ \\
\hline Microbial biomass $\mathrm{C}$ & $178 * * *$ & $266 * * *$ & $51 * *$ \\
\hline Microbial biomass $\mathrm{N}$ & $33 * *$ & $44 * *$ & NS \\
\hline Cumulative $\mathrm{CO}_{2}$ & $215^{* * *}$ & $33 *$ & NS \\
\hline \multicolumn{4}{|l|}{ OWW } \\
\hline Extractable C & $926 * * *$ & $2906 * * *$ & $520 * * *$ \\
\hline Microbial biomass $\mathrm{C}$ & $285 * * *$ & $23 *$ & $16^{*}$ \\
\hline Microbial biomass $\mathrm{N}$ & $124 * * *$ & $30 *$ & NS \\
\hline Cumulative $\mathrm{CO}_{2}$ & $1751 * * *$ & $543 * * *$ & $85^{* *}$ \\
\hline \multicolumn{4}{|l|}{ TWW } \\
\hline Extractable C & $180 * * *$ & $466 * * *$ & $155 * * *$ \\
\hline Microbial biomass $\mathrm{C}$ & $130 * * *$ & $94 * * *$ & $66 * *$ \\
\hline Microbial biomass $\mathrm{N}$ & $85^{* *}$ & $64 * *$ & NS \\
\hline Cumulative $\mathrm{CO}_{2}$ & $5538 * * *$ & $749 * * *$ & $95 * * *$ \\
\hline
\end{tabular}

Table 6_2. F values obtained following two-way ANOVA performed on soil parameters determined 7, 28 and 56 days after the addition of lemon, orange and tangerine wastewaters (LWW, OWW and TWW, respectively) at three different doses $(1 / 3,2 / 3$ and $3 / 3$ of the $50 \%$ of soil water holding capacity). *, $\mathrm{P} \leq 0.05 ; * *, \mathrm{P} \leq 0.01 ; * * *, \mathrm{P} \leq 0.001$; NS, not significant. 


\begin{tabular}{|c|c|c|c|c|}
\hline Treatment & Dose & Day & $\begin{array}{l}\mathrm{qCO}_{2} \\
\mathrm{mg} \mathrm{CO}_{2}-\mathrm{C} \mathrm{g}^{-1} \mathrm{MBC} \mathrm{h}^{-1}\end{array}$ & $\begin{array}{l}\mathrm{MBC} / \mathrm{TOC} \\
\%\end{array}$ \\
\hline \multirow[t]{3}{*}{ CTR } & & 7 & $3.5 \mathrm{a}$ & $1.5 \mathrm{~b}$ \\
\hline & & 28 & $1.9 \mathrm{~b}$ & $0.7 \mathrm{c}$ \\
\hline & & 56 & $0.9 \mathrm{c}$ & $2.1 \mathrm{a}$ \\
\hline \multirow[t]{9}{*}{ LWW } & $1 / 3$ & 7 & 7.9 $\mathrm{Ba}$ & $2.7 \mathrm{Ba}$ \\
\hline & $1 / 3$ & 28 & $1.9 \mathrm{Cb}$ & $2.2 \mathrm{Ab}$ \\
\hline & $1 / 3$ & 56 & $1.0 \mathrm{Bc}$ & $2.1 \mathrm{Bb}$ \\
\hline & $2 / 3$ & 7 & $23.5 \mathrm{Aa}$ & $3.3 \mathrm{Aa}$ \\
\hline & $2 / 3$ & 28 & $5.4 \mathrm{Ab}$ & $1.6 \mathrm{Bb}$ \\
\hline & $2 / 3$ & 56 & $2.3 \mathrm{Ac}$ & $1.6 \mathrm{Cb}$ \\
\hline & $3 / 3$ & 7 & 18.2 Аа & $3.3 \mathrm{Aa}$ \\
\hline & $3 / 3$ & 28 & $2.9 \mathrm{Bb}$ & $1.6 \mathrm{Bc}$ \\
\hline & $3 / 3$ & 56 & $1.6 \mathrm{ABc}$ & 2.6 $\mathrm{Ab}$ \\
\hline Dose & & & $103 * * *$ & $91 * * *$ \\
\hline Day & & & $396 * * *$ & $163 * * *$ \\
\hline Dose x Day & & & $84 * * *$ & $31 * *$ \\
\hline \multirow[t]{9}{*}{ OWW } & $1 / 3$ & 7 & 26.5 $\mathrm{Ba}$ & $3.1 \mathrm{Aa}$ \\
\hline & $1 / 3$ & 28 & 4.7 $\mathrm{Bb}$ & $2.2 \mathrm{Bb}$ \\
\hline & $1 / 3$ & 56 & $2.0 \mathrm{Bc}$ & $2.5 \mathrm{Bb}$ \\
\hline & $2 / 3$ & 7 & 37.9 Аа & $2.0 \mathrm{Cc}$ \\
\hline & $2 / 3$ & 28 & $5.6 \mathrm{Bb}$ & $3.1 \mathrm{Aa}$ \\
\hline & $2 / 3$ & 56 & 3.0 Bc & $2.6 \mathrm{Bb}$ \\
\hline & $3 / 3$ & 7 & $29.2 \mathrm{Ba}$ & $2.5 \mathrm{Bc}$ \\
\hline & $3 / 3$ & 28 & $8.3 \mathrm{Ab}$ & 3.3 $\mathrm{Ab}$ \\
\hline & $3 / 3$ & 56 & 4.6 Ac & 3.9 Аа \\
\hline Dose & & & $263 * * *$ & $148 * * *$ \\
\hline Day & & & $1362 * * *$ & $54 * *$ \\
\hline Dose x Day & & & $141 * * *$ & $13 * *$ \\
\hline \multirow[t]{7}{*}{ TWW } & $1 / 3$ & 7 & $8.8 \mathrm{Ca}$ & 3.0 Aa \\
\hline & $1 / 3$ & 28 & $2.7 \mathrm{ABb}$ & $1.7 \mathrm{Bb}$ \\
\hline & $1 / 3$ & 56 & $1.8 \mathrm{Bc}$ & $1.9 \mathrm{ABb}$ \\
\hline & $2 / 3$ & 7 & 17.0 Ba & 3.2 Aa \\
\hline & $2 / 3$ & 28 & $2.2 \mathrm{Bb}$ & $2.5 \mathrm{Ab}$ \\
\hline & $2 / 3$ & 56 & $2.3 \mathrm{ABb}$ & $1.7 \mathrm{Bc}$ \\
\hline & $3 / 3$ & 7 & 43.7 $\mathrm{Aa}$ & $1.6 \mathrm{Bb}$ \\
\hline
\end{tabular}




\begin{tabular}{lllll} 
& $3 / 3$ & 28 & $\mathbf{3 . 1} \mathrm{Ab}$ & $\mathbf{2 . 4} \mathrm{Aa}$ \\
& $3 / 3$ & 56 & $\mathbf{2 . 8} \mathrm{Ab}$ & $2.1 \mathrm{Aa}$ \\
Dose & & & $351 * * *$ & $48 * * *$ \\
Day & & & $1003 * * *$ & $31 * *$ \\
Dose x Day & & $290 * * *$ & $45 * * *$ \\
\hline
\end{tabular}

Table 6_3. Metabolic and microbial quotients determined 7, 28 and 56 days after the addition of lemon, orange and tangerine wastewaters ( $L W W, O W W$ and $T W W$, respectively) at three different doses (1/3, 2/3 and 3/3 of the 50\% of soil water holding capacity). $F$ values, reported in italic, were derived from two-way ANOVA (Dose $x$ Day). ** and *** indicate significant results at $P \leq 0.01$ and $P \leq 0.001 ; N S$, not significant. Control is soil moistened up to $50 \%$ of its water holding capacity by adding distilled water. Different lower case letters indicate significant differences $(P \leq 0.05)$ among sampling days within the same dose. Different upper case letters indicate significant differences $(P \leq 0.05)$ among doses at the same sampling day. Numbers in bold indicate significant differences $(P \leq 0.05)$ relative to the control at the same incubation day. 


\begin{tabular}{|c|c|c|c|c|c|c|c|c|}
\hline Treatment & Dose & Day & Bacteria & Fungi & bacG+ & bacG- & bacG+/bacG- & Fungi/Bacteria \\
\hline \multirow[t]{3}{*}{ Control } & & 7 & $114 \mathrm{~b}$ & $19 \mathrm{bc}$ & $48 \mathrm{~b}$ & $58 \mathrm{a}$ & $0.8 \mathrm{~b}$ & $0.2 \mathrm{a}$ \\
\hline & & 28 & $73 \mathrm{c}$ & $13 \mathrm{c}$ & $32 \mathrm{c}$ & $36 \mathrm{~b}$ & $0.9 \mathrm{~b}$ & $0.2 \mathrm{a}$ \\
\hline & & 56 & $169 \mathrm{a}$ & $19 \mathrm{ab}$ & $93 \mathrm{a}$ & $63 \mathrm{a}$ & $1.5 \mathrm{a}$ & $0.1 \mathrm{a}$ \\
\hline \multirow[t]{9}{*}{ LWWs } & $1 / 3$ & 7 & $181 \mathrm{Bb}$ & $55 \mathrm{Cb}$ & $77 \mathrm{Bb}$ & $95 \mathrm{Ba}$ & $0.8 \mathrm{Bb}$ & $0.3 \mathrm{Cb}$ \\
\hline & $1 / 3$ & 28 & $130 \mathrm{Bc}$ & $86 \mathrm{Ca}$ & $62 \mathrm{Bc}$ & $61 \mathrm{Bb}$ & $1.0 \mathrm{Ab}$ & $0.7 \mathrm{Ca}$ \\
\hline & $1 / 3$ & 56 & $263 \mathrm{Aa}$ & $32 \mathrm{Bc}$ & $139 \mathrm{Aa}$ & 96 Аа & $1.4 \mathrm{Aa}$ & $0.1 \mathrm{Bc}$ \\
\hline & $2 / 3$ & 7 & $191 \mathrm{Bb}$ & $129 \mathrm{Ba}$ & $92 \mathrm{Bb}$ & $88 \mathrm{Ba}$ & $0.9 \mathrm{Bb}$ & $0.6 \mathrm{Bb}$ \\
\hline & $2 / 3$ & 28 & $132 \mathrm{Bc}$ & $129 \mathrm{Ba}$ & $66 \mathrm{Bb}$ & $60 \mathrm{Bb}$ & $1.1 \mathrm{Ab}$ & $0.9 \mathrm{Ba}$ \\
\hline & $2 / 3$ & 56 & 254 Аa & $45 \mathrm{Bb}$ & $136 \mathrm{Aa}$ & $93 \mathrm{Aa}$ & $1.5 \mathrm{Aa}$ & $0.2 \mathrm{ABc}$ \\
\hline & $3 / 3$ & 7 & 332 Аа & 340 Aa & $180 \mathrm{Aa}$ & $131 \mathrm{Aa}$ & $1.4 \mathrm{Aa}$ & 1.0 Ab \\
\hline & $3 / 3$ & 28 & $180 \mathrm{Ac}$ & $220 \mathrm{Ab}$ & $91 \mathrm{Ac}$ & $79 \mathrm{Ac}$ & $1.2 \mathrm{Ab}$ & $1.3 \mathrm{Aa}$ \\
\hline & $3 / 3$ & 56 & $249 \mathrm{Ab}$ & $107 \mathrm{Ac}$ & $120 \mathrm{Ab}$ & $94 \mathrm{Ab}$ & $1.4 \mathrm{Aa}$ & $0.4 \mathrm{Ac}$ \\
\hline Dose & & & $77 * * *$ & $509 * * *$ & $58 * *$ & $58 * *$ & $11 *$ & $342 * * *$ \\
\hline Day & & & $100 * * *$ & $165 * * *$ & $76^{* * * *}$ & $61 * *$ & $78 * * *$ & $322 * * *$ \\
\hline Dose x Day & & & $13 *$ & $65 * *$ & $17 *$ & $5 *$ & $8 *$ & $37 * *$ \\
\hline \multirow[t]{9}{*}{ OWWs } & $1 / 3$ & 7 & $328 \mathrm{Ba}$ & $240 \mathrm{Ca}$ & $140 \mathrm{Ba}$ & $174 \mathrm{Ba}$ & $0.8 \mathrm{Bb}$ & $0.7 \mathrm{Bb}$ \\
\hline & $1 / 3$ & 28 & $173 \mathrm{Cb}$ & $191 \mathrm{Cb}$ & $81 \mathrm{Cb}$ & $82 \mathrm{Bb}$ & $1.0 \mathrm{Bb}$ & 1.1 Ba \\
\hline & $1 / 3$ & 56 & $179 \mathrm{Bb}$ & $74 \mathrm{Cc}$ & $90 \mathrm{Bb}$ & $61 \mathrm{Ac}$ & $1.5 \mathrm{Ba}$ & $0.4 \mathrm{Bc}$ \\
\hline & $2 / 3$ & 7 & 511 Аа & $497 \mathrm{Ba}$ & $272 \mathrm{Aa}$ & 220 Aa & $1.2 \mathrm{Ab}$ & 1.0 ABb \\
\hline & $2 / 3$ & 28 & $268 \mathrm{Bb}$ & $370 \mathrm{Bb}$ & $142 \mathrm{Bb}$ & $116 \mathrm{Ab}$ & $1.2 \mathrm{ABb}$ & $1.3 \mathrm{ABa}$ \\
\hline & $2 / 3$ & 56 & $223 \mathrm{ABb}$ & $139 \mathrm{Bb}$ & $120 \mathrm{Ab}$ & $72 \mathrm{Ac}$ & 1.7 $\mathrm{ABa}$ & $0.7 \mathrm{ABc}$ \\
\hline & $3 / 3$ & 7 & 510 Aa & $756 \mathrm{Aa}$ & $275 \mathrm{Aa}$ & $215 \mathrm{Aa}$ & $1.3 \mathrm{Ab}$ & $1.5 \mathrm{Aa}$ \\
\hline & $3 / 3$ & 28 & $317 \mathrm{Ab}$ & $529 \mathrm{Ab}$ & $179 \mathrm{Ab}$ & $124 \mathrm{Ab}$ & $1.4 \mathrm{Ab}$ & 1.6 Aa \\
\hline & $3 / 3$ & 56 & 229 Ac & $210 \mathrm{Ac}$ & $136 \mathrm{Ac}$ & $69 \mathrm{Ac}$ & 1.9 Aa & $0.9 \mathrm{Ab}$ \\
\hline Dose & & & $355 * * *$ & $1033 * * *$ & $399 * * *$ & $135 * * *$ & $22 *$ & $492 * * *$ \\
\hline Day & & & $355 * * *$ & $579 * * *$ & $234 * * *$ & $320 * * *$ & $60 * *$ & $169 * * *$ \\
\hline Dose x Day & & & $67 * *$ & $113 * * *$ & $67 * *$ & $39 * *$ & $N S$ & $18 *$ \\
\hline \multirow[t]{9}{*}{ TWWs } & $1 / 3$ & 7 & $177 \mathrm{Ca}$ & $107 \mathrm{Ca}$ & $79 \mathrm{Ca}$ & $89 \mathrm{Ca}$ & $0.9 \mathrm{Ba}$ & $0.6 \mathrm{Ca}$ \\
\hline & $1 / 3$ & 28 & $153 \mathrm{Cb}$ & $100 \mathrm{Ca}$ & $67 \mathrm{Cb}$ & $76 \mathrm{Cb}$ & $0.9 \mathrm{Aa}$ & $0.7 \mathrm{Ca}$ \\
\hline & $1 / 3$ & 56 & $131 \mathrm{Bc}$ & $26 \mathrm{Cb}$ & $65 \mathrm{Bb}$ & $56 \mathrm{Bc}$ & 1.1 Aa & $0.2 \mathrm{Bb}$ \\
\hline & $2 / 3$ & 7 & $244 \mathrm{Ba}$ & $185 \mathrm{Ba}$ & $117 \mathrm{Ba}$ & $114 \mathrm{Ba}$ & $1.0 \mathrm{ABab}$ & 0.8 Bb \\
\hline & $2 / 3$ & 28 & $196 \mathrm{Bb}$ & $212 \mathrm{Ba}$ & $88 \mathrm{Bb}$ & $93 \mathrm{Bb}$ & $0.9 \mathrm{Ab}$ & 1.1 Ba \\
\hline & $2 / 3$ & 56 & $147 \mathrm{ABc}$ & $38 \mathrm{Bb}$ & $76 \mathrm{ABc}$ & $58 \mathrm{ABc}$ & 1.2 Aa & $0.3 \mathrm{Ac}$ \\
\hline & $3 / 3$ & 7 & 383 Aа & $413 \mathrm{Aa}$ & $186 \mathrm{Aa}$ & $165 \mathrm{Aa}$ & $1.1 \mathrm{Aa}$ & $1.1 \mathrm{Ab}$ \\
\hline & $3 / 3$ & 28 & $273 \mathrm{Ab}$ & $375 \mathrm{Ab}$ & $119 \mathrm{Ab}$ & $139 \mathrm{Ab}$ & $0.9 \mathrm{Ab}$ & $1.4 \mathrm{Aa}$ \\
\hline & $3 / 3$ & 56 & $177 \mathrm{Ac}$ & $53 \mathrm{Ac}$ & $85 \mathrm{Ac}$ & $72 \mathrm{Ac}$ & $1.1 \mathrm{Aa}$ & $0.3 \mathrm{Ac}$ \\
\hline
\end{tabular}




\begin{tabular}{lrrrrrc} 
Dose & $183 * * *$ & $549 * * *$ & $159 * * *$ & $241 * * *$ & $4 *$ & $175 * * *$ \\
Day & $77 * * *$ & $396 * * *$ & $61 * *$ & $165 * * *$ & $82 * * *$ & $207 * * *$ \\
Dose $x$ Day & $43 * *$ & $106 * * *$ & $51 * *$ & $46 * *$ & $12 *$ & $29 *$ \\
\hline
\end{tabular}

Table 6_4. Main microbial groups (nmol FAs $g^{-1}$ dry soil) determined 7, 28 and 56 days after the addition of lemon, orange and tangerine wastewaters ( $L W W, O W W$ and TWW, respectively) at three different doses $(1 / 3,2 / 3$ and $3 / 3$ of the $50 \%$ of soil water holding capacity). F values, reported in italic, were derived from two-way ANOVA (Dose x Day). *, $* *$ and $* * *$ indicate significant results at $P \leq 0.05, P \leq 0.01$ and $P \leq 0.001 ; N S$, not significant. Control is soil moistened up to 50\% of its water holding capacity by adding distilled water. Different lower case letters indicate significant differences $(P \leq 0.05)$ among sampling days within the same dose. Different upper case letters indicate significant differences $(P \leq 0.05)$ among doses at the same sampling day. Numbers in bold indicate significant differences $(P \leq 0.05)$ compared with the control at the same sampling day. 


\begin{tabular}{lcccc}
\hline Treatment & $\begin{array}{l}\text { WWs } \\
\mathrm{mL} \mathrm{kg}^{-1}\end{array}$ & $\begin{array}{l}\mathrm{H}_{2} \mathrm{O} \\
\mathrm{mL} \mathrm{kg}^{-1}\end{array}$ & $\begin{array}{c}\text { Total C added } \\
\mathrm{g} \mathrm{kg}^{-1}\end{array}$ & $\begin{array}{l}\text { Total N added } \\
\mathrm{g} \mathrm{kg}^{-1}\end{array}$ \\
\hline CTR & 0.0 & 235.0 & 0.0 & 0.0 \\
LWW 1/3 & 78.3 & 156.7 & 2.0 & 0.22 \\
LWW 2/3 & 156.7 & 78.3 & 3.9 & 0.43 \\
LWW 3/3 & 235.0 & 0.0 & 5.9 & 0.66 \\
OWW 1/3 & 78.3 & 156.7 & 5.4 & 0.42 \\
OWW 2/3 & 156.7 & 78.3 & 10.8 & 0.85 \\
OWW 3/3 & 235.0 & 0.0 & 16.2 & 1.27 \\
TWW 1/3 & 78.3 & 156.7 & 2.1 & 0.12 \\
TWW 2/3 & 156.7 & 78.3 & 4.2 & 0.25 \\
TWW 3/3 & 235.0 & 0.0 & 6.3 & 0.38 \\
\hline
\end{tabular}

Table 6_S1. Volumes of lemon, orange and tangerine wastewaters ( $L W W, O W W$ and TWW, respectively) and distilled water $\left(\mathrm{H}_{2} \mathrm{O}\right)$, and grams of total $\mathrm{C}$ and $\mathrm{N}$ added per $\mathrm{kg}$ of dry soil.

\begin{tabular}{|c|c|c|c|c|}
\hline Day & 1 & 7 & 28 & 56 \\
\hline \multicolumn{5}{|l|}{ Treatment } \\
\hline CTR & 15.5 & 15.5 & 15.3 & 15.1 \\
\hline LWW $1 / 3$ & 17.6 Bc & 16.9 $\mathrm{Ab}$ & $16.3 \mathrm{Ab}$ & $15.3 \mathrm{Ab}$ \\
\hline LWW 2/3 & $18.8 \mathrm{Cb}$ & 18.2 Aa & 16.9 Aab & $16.1 \mathrm{Ab}$ \\
\hline LWW 3/3 & $21.9 \mathrm{Ba}$ & $19.6 \mathrm{Ba}$ & $17.5 \mathrm{Ba}$ & 17.3 Aa \\
\hline OWW 1/3 & $20.5 \mathrm{Ac}$ & $17.5 \mathrm{Ab}$ & $16.5 \mathrm{Ab}$ & $15.5 \mathrm{Ab}$ \\
\hline OWW $2 / 3$ & 29.2 $\mathrm{Ab}$ & $20.5 \mathrm{Aa}$ & 17.6 $\mathrm{Ab}$ & $16.1 \mathrm{Ab}$ \\
\hline OWW 3/3 & $33.6 \mathrm{Aa}$ & 23.0 Аa & $19.8 \mathrm{Aa}$ & 18.8 $\mathrm{Aa}$ \\
\hline TWW $1 / 3$ & 18.4 $\mathrm{ABc}$ & 17.5 Аа & 16.1 Aa & 15.7 Aa \\
\hline TWW 2/3 & $20.7 \mathrm{Bb}$ & 18.0 Aa & 16.5 Aa & 15.7 Aa \\
\hline TWW 3/3 & $22.8 \mathrm{Ba}$ & $18.8 \mathrm{Ba}$ & 16.9 $\mathrm{Ba}$ & $15.9 \mathrm{Ba}$ \\
\hline
\end{tabular}

Table 6_S2. Total organic carbon (TOC; $\mathrm{g} \mathrm{kg}^{-1}$ ) determined 1, 7, 28 and 56 days after the addition of lemon, orange and tangerine wastewaters ( $L W W, O W W$ and $T W W$, respectively) at three different doses (1/3, 2/3 and 3/3 of the 50\% of soil water holding capacity). Control is soil moistened up to $50 \%$ of its water holding capacity by adding distilled water. Different lower case letters indicate significant differences $(P \leq 0.05)$ among sampling days within the same dose. Different upper case letters indicate significant differences $(P \leq 0.05)$ among doses at the same sampling day. Numbers in bold indicate significant differences $(P \leq 0.05)$ compared with the control at the same sampling day. 

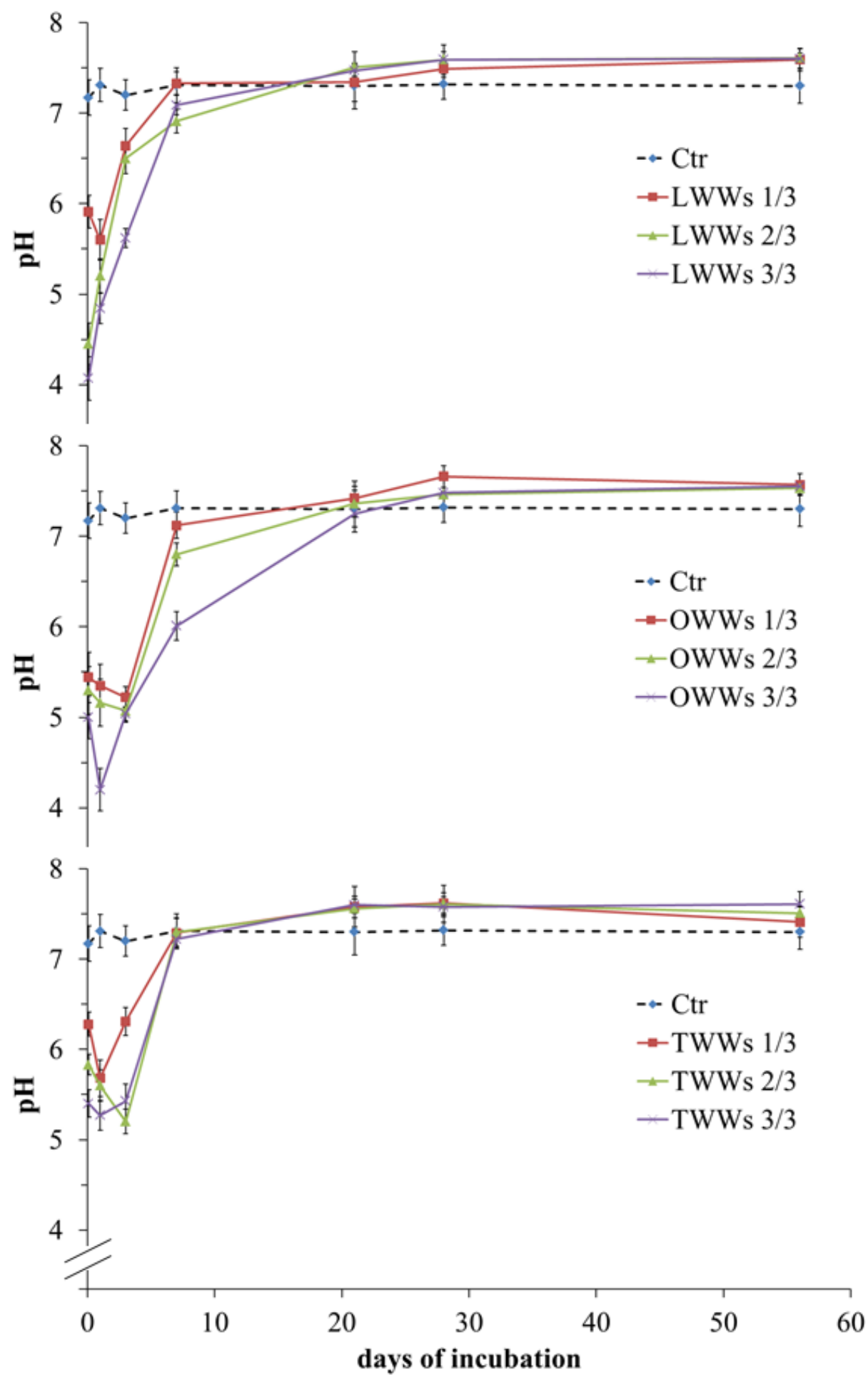

Figure 6_1. Soil reaction determined after 2 hours, and 1, 3, 7, 21, 28, 56 days since the addition of lemon, orange and tangerine wastewaters ( $L W W, O W W$ and $T W W$, respectively) at three different doses (1/3, 2/3 and 3/3 of the 50\% of soil water holding capacity). Control (CTR) is soil moistened up to 50\% of its water holding capacity by adding distilled water. Reported results are means of four replicates and bars indicate the standard deviations. 

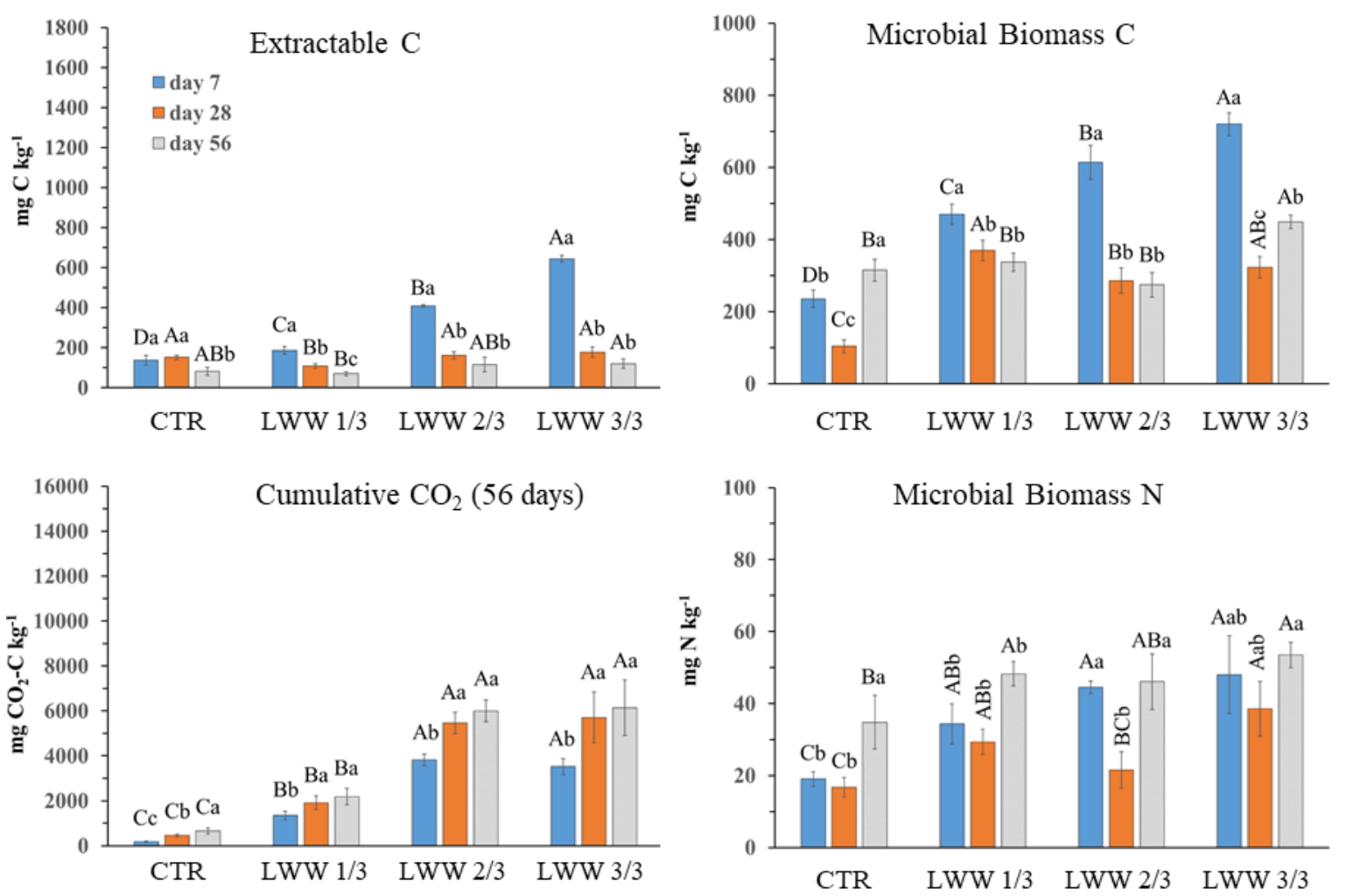

Figure 6_2. Biochemical soil variables determined after 7, 28 and 56 days since the addition of lemon wastewaters (LWW) at three different doses (1/3, 2/3 and 3/3 of the 50\% of soil water holding capacity). Control (CTR) is soil moistened up to 50\% of its water holding capacity by adding distilled water. Reported results are means of four replicates and bars indicate the standard deviations. Different lower case letters indicate significant differences $(P \leq 0.05)$ among incubation days within the same dose. Different upper case letters indicate significant differences $(P \leq 0.05)$ among doses at the same incubation day. 


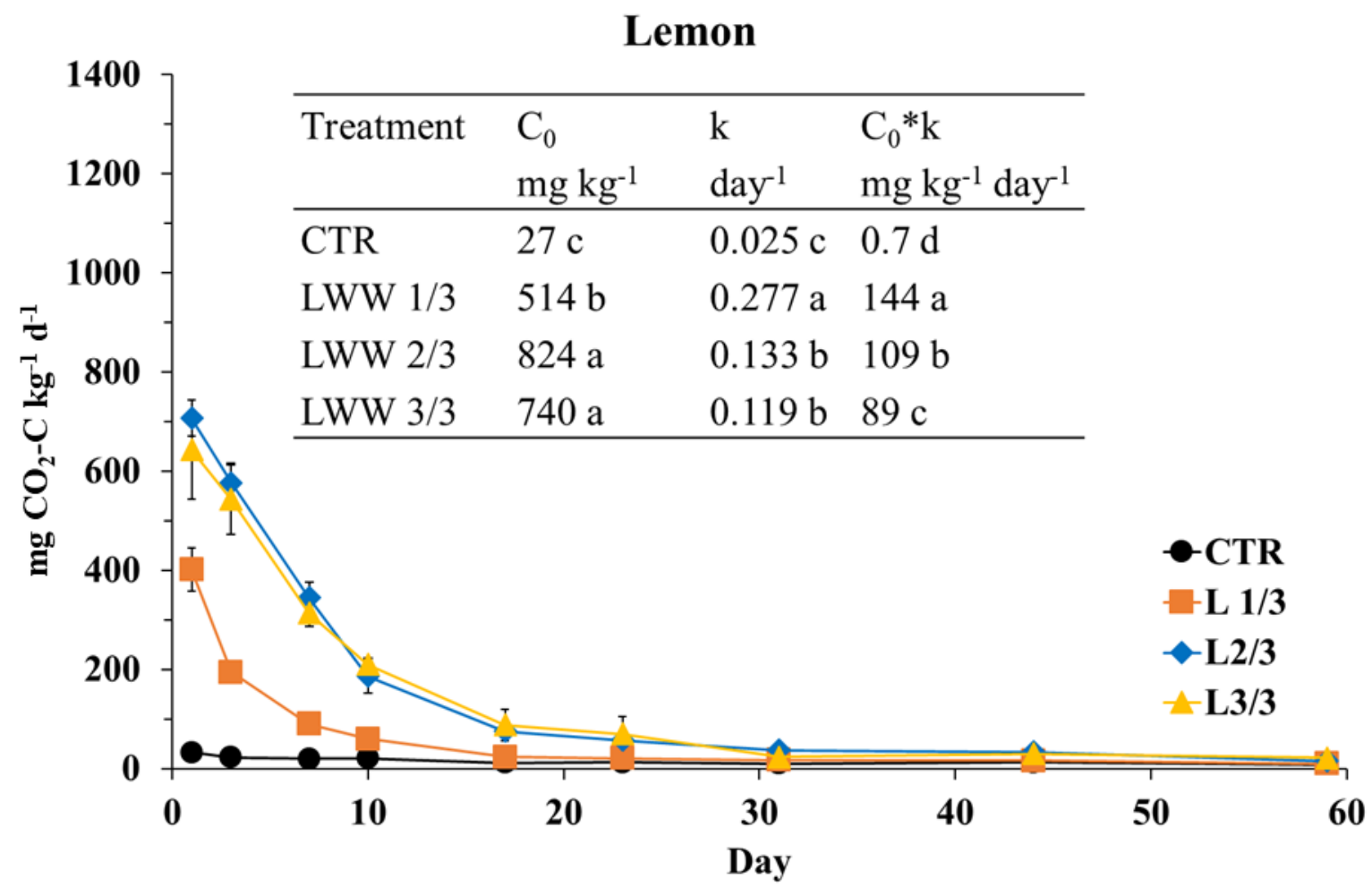

Figure 6_3. Microbial respiration rate and parameters $(C 0$, biological available $C ; k$, turnover constant rate; $C_{0} k$, initial potential rate of $C$ mineralization) derived from the exponential first-order decay function (Mineralized $C=C_{0} e^{-k t}$ ) determined on soil moistened up to $50 \%$ of its water holding capacity with lemon wastewaters $(L W W)$ at three different doses (1/3, 2/3 and 3/3 of the 50\% of soil water holding capacity). Control (CTR) is soil moistened up to $50 \%$ of its water holding capacity by adding distilled water. Reported results are means of four replicates and bars indicate the standard deviations. Along a column, lower case letters indicate significant differences among doses. 

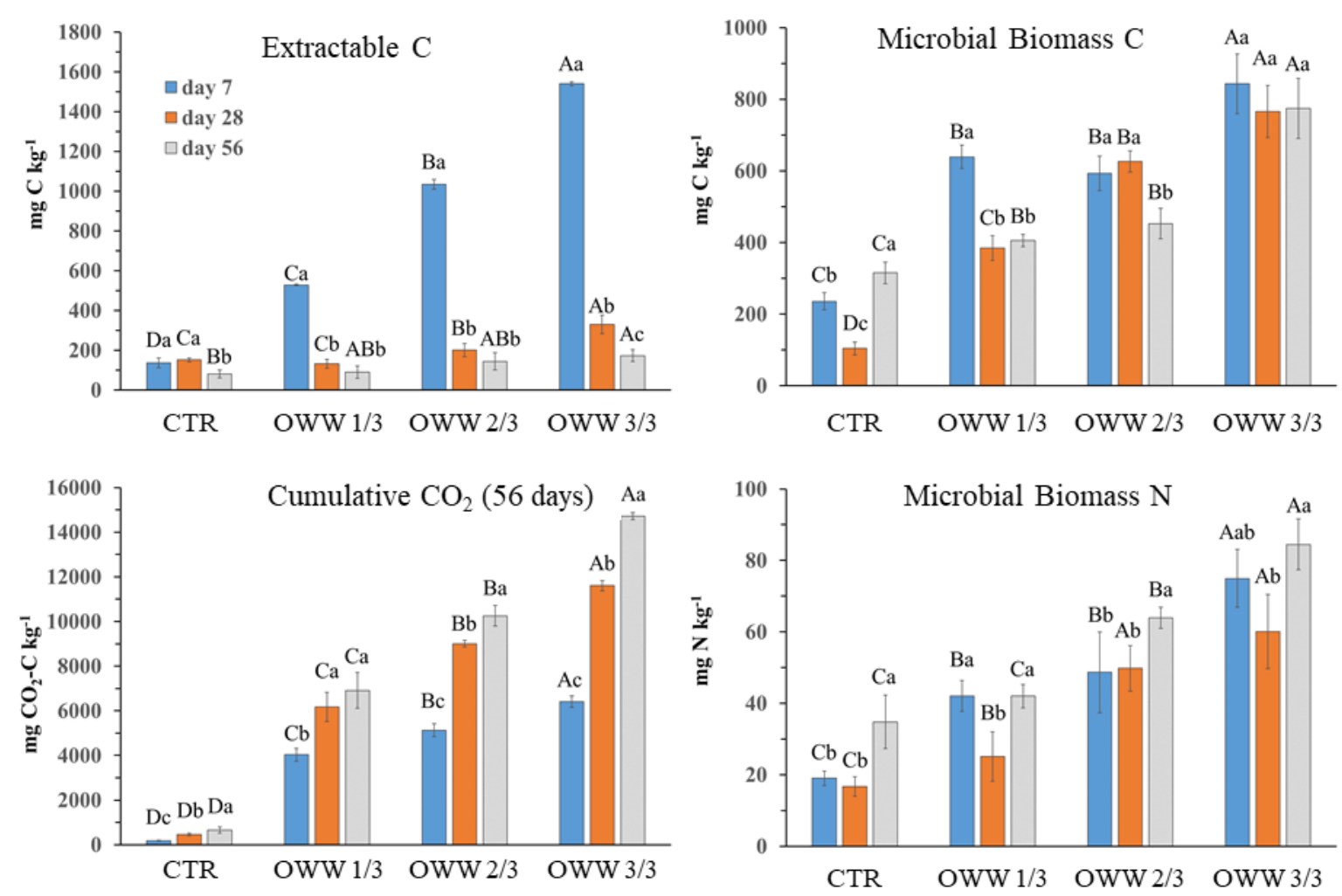

Figure 6_4. Biochemical soil variables determined after 7, 28 and 56 days since the addition of orange wastewaters $(O W W)$ at three different doses (1/3, 2/3 and 3/3 of the 50\% of soil water holding capacity). Control (CTR) is soil moistened up to 50\% of its water holding capacity by adding distilled water. Reported results are means of four replicates and bars indicate the standard deviations. Different lower case letters indicate significant differences $(P \leq 0.05)$ among incubation days within the same dose. Different upper case letters indicate significant differences $(P \leq 0.05)$ among doses at the same incubation day. 


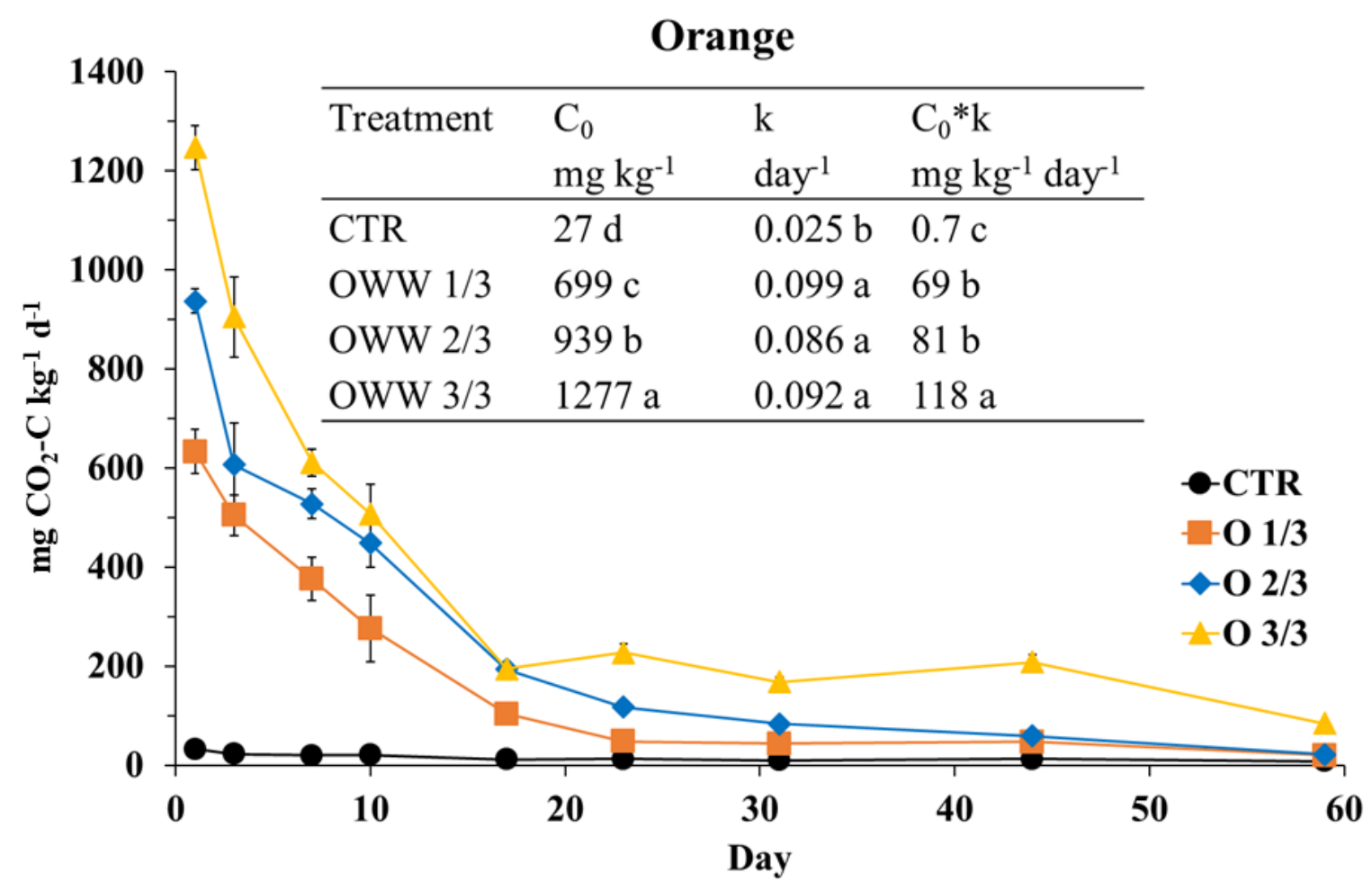

Figure 6_5. Microbial respiration rate and parameters $\left(C_{0}\right.$, biological available $C ; k$, turnover constant rate; $C_{0} k$, initial potential rate of $C$ mineralization) derived from the exponential first-order decay function (Mineralized $C=C_{0} e^{-k t}$ ) determined on soil moistened up to $50 \%$ of its water holding capacity with orange wastewaters $(O W W)$ at three different doses (1/3, 2/3 and 3/3 of the 50\% of soil water holding capacity). Control (CTR) is soil moistened up to $50 \%$ of its water holding capacity by adding distilled water. Reported results are means of four replicates and bars indicate the standard deviations. Along a column, lower case letters indicate significant differences among doses. 

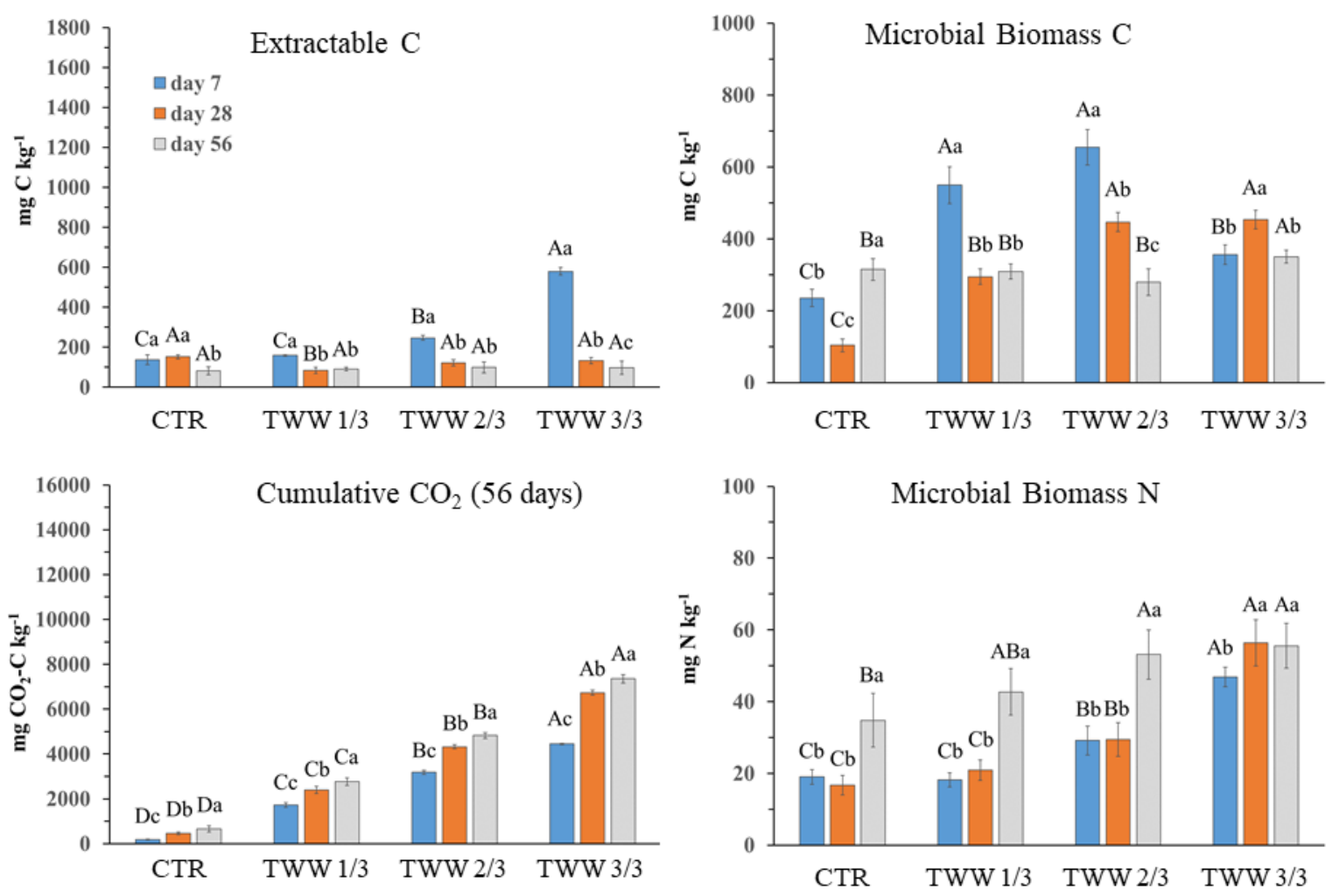

Figure 6_6. Biochemical soil variables determined after 7, 28 and 56 days since the addition of tangerine wastewaters (TWW) at three different doses (1/3, 2/3 and 3/3 of the 50\% of soil water holding capacity). Control (CTR) is soil moistened up to 50\% of its water holding capacity by adding distilled water. Reported results are means of four replicates and bars indicate the standard deviations. Different lower case letters indicate significant differences $(P \leq 0.05)$ among incubation days within the same dose. Different upper case letters indicate significant differences $(P \leq 0.05)$ among doses at the same incubation day. 


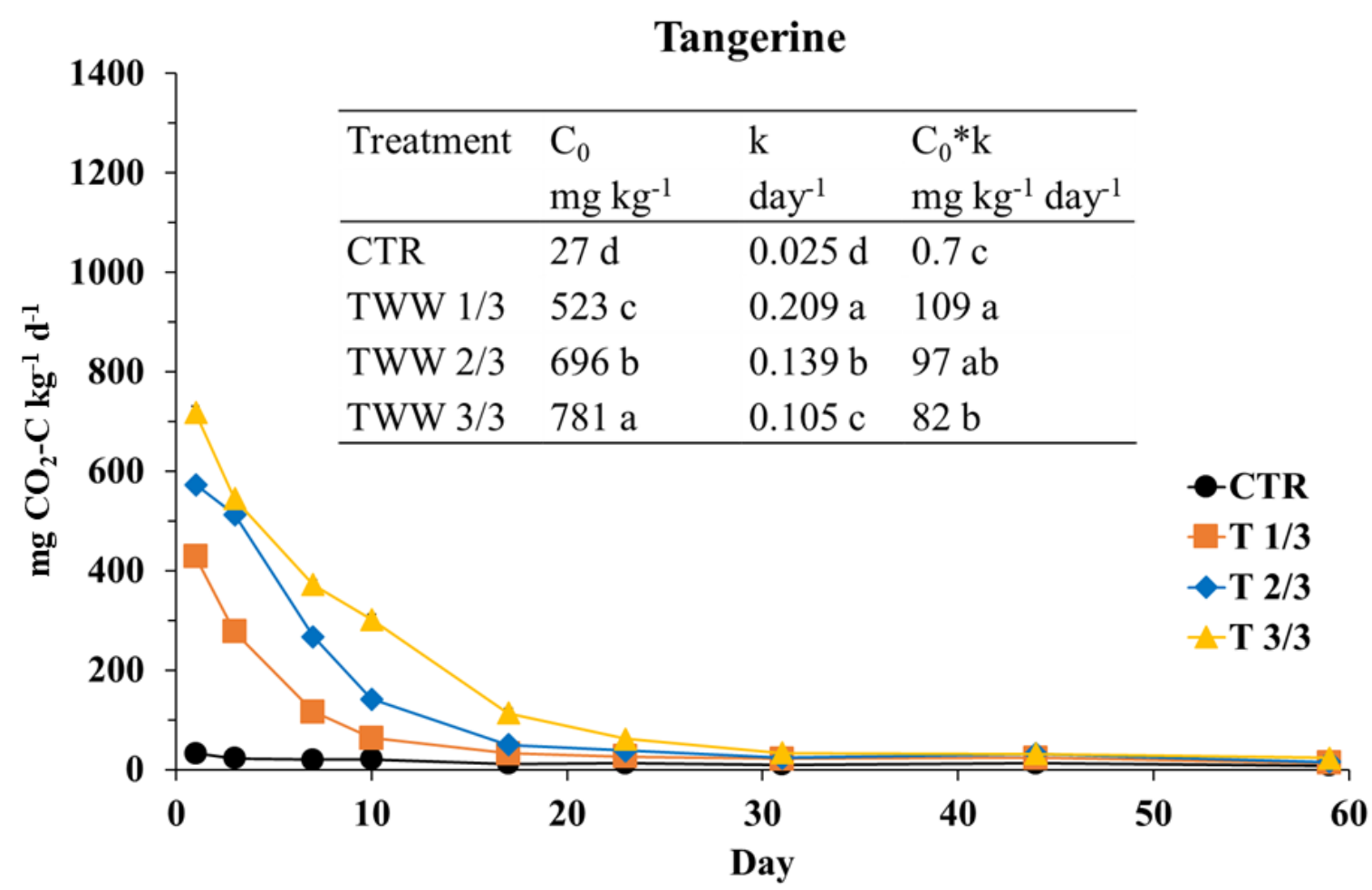

Figure 6_7. Microbial respiration rate and parameters $\left(C_{0}\right.$, biological available $C ; k$, turnover constant rate; $C_{0} k$, initial potential rate of $C$ mineralization) derived from the exponential first-order decay function (Mineralized $C=C_{0} e^{-k t}$ ) determined on soil moistened up to $50 \%$ of its water holding capacity with tangerine wastewaters $(T W W)$ at three different doses (1/3, 2/3 and 3/3 of the 50\% of soil water holding capacity). Control (CTR) is soil moistened up to $50 \%$ of its water holding capacity by adding distilled water. Reported results are means of four replicates and bars indicate the standard deviations. Along a column, lower case letters indicate significant differences among doses. 
7 Geochemical traceability applied to lemon production. 


\section{.1 Introduction}

Citrus is one of the world's important fruit crops, with global availability and popularity contributing to human diets.

In the last years, food traceability has become a topic of great importance concerning safety and quality and now typicality characteristics, are a relevant aspect of the food market. Today, the agro-food geographical origin is essentially guaranteed by labelling and administrative documentation, without any tools or analytical controls.

The increasing importance is given from legislators and consumers to the provenance of agrifood products purchased and/or eaten, in last years motivated several types of research to the identification of the geographical origin of agrifood products.

The development of innovative methods for the control of the authenticity of food products is a top priority in Europe when discussing food safety and typicality.

The application of modern analytical techniques for fast, effective and high performance reporting concerning investigated samples, if properly applied, to verify the authenticity of the product, represents a valuable tool for the legal authorities assigned to perform control functions.

For this reason, it is important to know one or more chemistry relationships between the soil and the agricultural products that, therefore, could be important tools for quality food evaluation.

Many chemical tracers and analytical techniques were tested to verify the origin of foods (Luykx and Van Ruth, 2008; Peres et al., 2007; Papetti et al., 2012; Baroni et al., 2015; Drivelos and Georgiou, 2012; Durante et al., 2016; Gonzalvez et al., 2009; Marchionni et al., 2016; Reid et al., 2006; Zhao et al., 2013, Amenta et al., 2016.).

One of the most important groups of chemical tracers is that of metals. Several studies have shown that trace metals, particularly REEs, can act as geochemical markers (Brown et al., 1990; Liang et al., 2008).

IUPAC organization has defineed rare earth elements (REEs) as the fifteen lanthanides, scandium (Sc) and yttrium (Y). REEs share similar chemical properties arising from their $4 \mathrm{f}$ electronic configuration. (Henderson, 1984).

Despite their name, these elements are not particularly rare and can be found in well measurable concentrations in the crust of Earth. REEs concentrations in soils vary according to parent material properties, mainly depend on geological processes and chemical conditions under which a rock was formed, history and weathering state of the soil itself and, for this reason, REEs have recognized as very useful tracers (Laveuf and Cornu, 2009). 
Concentrations of REEs in plants are usually very low compared to their total concentrations in soils. A further advantage of REEs is that they do not play a specific role in the metabolism of plants and are, therefore, taken up indiscriminately from the soil by the plant, with no fractionation of the original distribution and in roots have generally higher concentrations than in shoots. Uptake is positively correlated, though often weakly, with soil acidity and easily soluble concentrations of the elements, but rarely well related to their total concentrations in the soil. However, for any trace elements (REEs) there is little information about their distribution, biological role in the natural system and use in the traceability of foodstuffs (Cao et al. 2000; Tyler, 2004).

These characteristics allow them REEs to represent probably the best geochemical tracer of processes involving the occurrence of an interface between media with different chemicalphysical characteristics. This aspect makes REE the best choice to investigate processes occurring to trace elements during their migration from soil to plant and its fruits (Censi et al., 2014).

Having regard to the recent studies carried out on grapevine - soil system to evaluate the REEs the distribution (Censi et al.2014, Pisciotta et al.2017)

This research aims to observe whether the fruits of various cultivars of citrus cultivated on the same soil and their products (fruit and juice) reproduce the same distribution of REEs The two Lemon PGIs, a typical area from Sicily, have been taken and their production areas have been analyzed as such in three other areas where limonicolture is very advanced. Another production area, the Campania region, has also been considered.

Because of the concentration of REEs present, $\mathrm{nmol} / \mathrm{kg}$ level or less in citrus juice, a highly sensitive technique must be used to produce valid data. We employed the inductively coupled plasma-mass spectrometry (ICP-MS) instrument, a multi-elemental technique with high sensitivity, accuracy, and precision. 


\subsection{Materials and methods}

\subsubsection{Chemicals}

Concentrated nitric acid (65\%) and hydrogen peroxide (30\%) of ultrapure grade, purchased from Baker (Milano, Italy) and DTPA (purity > 99\%) from Sigma-Aldrich (Milano, Italy) were used.

Ultrapure water $18.2 \mathrm{M} \Omega \mathrm{cm}$, produced with an EASYpureII (Thermo, Italy), was used for all standard solutions and sample preparations. Y, lanthanoids, Rh and Re standard solutions $\left(1000 \pm 5 \mu \mathrm{g} \mathrm{mL}^{-1}\right)$ were purchased from BDH, Merck and CPI International (Milan, Italy). Polypropylene and polystyrene vials used respectively for sample storage and analysis, were kept in $1 \%$ nitric acid then rinsed with ultrapure water when needed.

\subsubsection{Plant material and sampling}

The sampling was done in the year 2017/2018. Lemon fruits (Citrus limon Osbeck(L.)) of ten different varieties grafted onto a unique rootstock (Citrus $\times$ aurantium L.) were sampled. The trees are grown on volcanic soil in two experimental farms, located at the "Acireale" region (latitude 37 37' 23 N, longitude 15 09' $51 \mathrm{E}$ and $205 \mathrm{~m}$ a.s.l., in Sicily, Italy) and "Portici" region (latitude $40^{\circ} 81^{\prime} 55 \mathrm{~N}$, longitude $14^{\circ} 34^{\prime} 75 \mathrm{E}$ and $75 \mathrm{~m}$ a.s.l., in Campania, Italy). The cultivar selected were: Akragas, Erice, Selinunte, Segesta, Continella, Femminello Siracusano, Femminello Dosaco, Kamarina, Sfusato, Ovale di Sorrento, Interdonato. Furthermore, the samples had been collected in various fields of lemon falling in the provinces of Messina (ME) from PGI Interdonato, PGI Siracusa (RG), Trapani (TP) and Palermo (PA). A sample of $2 \mathrm{~kg}$ of fruit was collected at technological ripeness from each plant of three for every cultivar. As well as, three soil samples (about $2 \mathrm{~kg}$ ), in the field corresponding to lemon sampling, were collected and, to reduce any surface contamination, from a depth of 10-30 cm.

\subsubsection{Sample preparation}

The soil samples dried in an oven at $105^{\circ} \mathrm{C}$, successively were gently crushed, sieved (Ø $0.2 \mathrm{~mm}$ ) and homogenized. Aliquots of $\simeq 0.500 \mathrm{~g}$ (DW) were digested using $3 \mathrm{ml}$ of $\mathrm{HNO}_{3}$ and $2 \mathrm{ml} \mathrm{H}_{2} \mathrm{O}_{2}$ in a microwave system as in the USEPA 200.7 method.

The fresh juice was extracted using an electric fruit squeezer. Fruit and juice were dried in an oven at $105^{\circ} \mathrm{C}$ and homogenized. 
To aliquots of juice and fruit $\simeq 0.500 \mathrm{~g}$ (DW), in open vessels, $3 \mathrm{ml}$ of $\mathrm{HNO}_{3}$ were added in two steps, to avoid the accidentally tumultuous formation of gas with leaks of the sample. After about $15 \mathrm{~min}$, the vessels were closed and digested adding $2 \mathrm{ml} \mathrm{of} \mathrm{H}_{2} \mathrm{O}_{2}$, in a microwave system (Mars 5 Xpress, CEM, Milano, Italy). The solutions obtained after digestion were transferred to a graduated polypropylene test tube and diluted with ultrapure water to $13.0 \mathrm{~mL}$. Each analytical sequence included a procedural blank (ultrapure water treated as the other samples).

\subsubsection{ICP-MS analyses}

An ICP-MS instrument (Agilent Technologies 7500ce Series Spectrometer) was used and all instrumental parameters were optimized for the analyses of all the investigated trace elements. Each solution was measured three times and ICP-MS analyses were carried out with a classical external calibration approach, from 2.5 to $10,000 \mathrm{pg} \mathrm{mL}^{-1}$ for each investigated element, using ${ }^{103} \mathrm{Rh}$ and ${ }^{187} \mathrm{Re}\left(1000 \mathrm{pg} \mathrm{mL}{ }^{-1}\right)$ as an internal standard to compensate for any signal instability. The isotopes used to quantification were as follows: ${ }^{139} \mathrm{La},{ }^{140} \mathrm{Ce},{ }^{141} \mathrm{Pr},{ }^{146} \mathrm{Nd},{ }^{147} \mathrm{Sm},{ }^{151} \mathrm{Eu},{ }^{158} \mathrm{Gd},{ }^{159} \mathrm{~Tb}{ }^{163} \mathrm{Dy},{ }^{89} \mathrm{Y},{ }^{165} \mathrm{Ho},{ }^{167} \mathrm{Er},{ }^{169} \mathrm{Tm},{ }^{172} \mathrm{Yb}$,

${ }^{175} \mathrm{Lu}$. Instrument and measurement parameters were: forward power, $1550 \mathrm{~W}$; nebulizer gas flow, 1.00 $\mathrm{L} \mathrm{min}^{-1}$; auxiliary gas flow, $0.80 \mathrm{~L} \mathrm{~min}^{-1}$; plasma gas flow, $15 \mathrm{~L} \mathrm{~min}^{-1}$, three replicates for a total acquisition time of $180 \mathrm{~s}$. Interferences were evaluated as follows: $\mathrm{CeO}^{+} / \mathrm{Ce}^{+}$and $\mathrm{Ce}^{2+} / \mathrm{Ce}^{+}$ratios $<1 \%$. In particular, for a better determination of ${ }^{151} \mathrm{Eu}$, we have carefully tuned the mass spectrometer with a solution containing $1.0 \mu \mathrm{gmL}^{-1}$ of $\mathrm{Ba}$ in $\mathrm{HNO}_{3}$ following and optimising both ratio ${ }^{135} \mathrm{Ba}^{16} \mathrm{O}^{+} /{ }^{135} \mathrm{Ba}^{+}$and ${ }^{134} \mathrm{Ba}^{17} \mathrm{O}^{+} /{ }^{134} \mathrm{Ba}^{+}$the higher amount of which was below $0.5 \%$. Successively we have determined, in our real samples solutions for ICP-MS measurements, the amount of barium to better control on ${ }^{135} \mathrm{Ba}^{16} \mathrm{O}^{+} /{ }^{135} \mathrm{Ba}^{+}$and a more accurate determination of Eu. A stability test was performed before each analysis session by monitoring ${ }^{7} \mathrm{Li},{ }^{59} \mathrm{Co},{ }^{89} \mathrm{Y},{ }^{140} \mathrm{Ce}$ and ${ }^{205} \mathrm{Tl}$ masses and verifying a precision better than $2 \%$. The instrumental precision was better than $2 \%$ for REE elements, while the overall uncertainty (involving both sample preparation and instrumental analysis), which calculation based on three replicates, was better than 5\%.

To evaluate the performance and recovery of the overall lemons samples treatments, the INCT-OBTL-5 Oriental Basma Tobacco Leaves certified standard material (tobacco leaves with certified and known REE composition) was analysed (Samczynski et al., 2012). The trueness of method was evaluated comparing obtained results by acid digestion, as above reported for the lemon samples, with certified values. The recovery percent and its 
standard deviation were also estimated for the elements listed as information values in analysis certificate (data not shown). Recovery values of the certified elements ( $\mathrm{La}, \mathrm{Ce}, \mathrm{Nd}$, $\mathrm{Sm}, \mathrm{Eu}, \mathrm{Tb}, \mathrm{Er}, \mathrm{Yb}$ ), ranged between $96 \%$ and $103 \%$, while for the elements of the series listed as informative values, from 97 to $111 \%$. Only Lu showed a low but still acceptable recovery of $85 \%$. The CRM 2711a Montana Soil II (NIST) was made up of moderately contaminated soil with a certified and known chemical composition also for REE total content. To verify the quality of pseudo-total REE content of our samples, the CRM was exclusively subjected to oxidant mixture, $\mathrm{HNO}_{3}: \mathrm{H}_{2} \mathrm{O}_{2}$ as in the USEPA 200.7 method. Five independent aliquots of CRM were carefully weighed $(0.250 \mathrm{~g})$, treated with $6 \mathrm{~mL}$ of the $\mathrm{HNO}_{3}: \mathrm{H}_{2} \mathrm{O}_{2}(2: 1 \mathrm{v} / \mathrm{v})$ mixture and subjected to microwave digestion. Because no REE value, though indicative, was reported as pseudo-total, we have considered our REE results acceptable, considering that the recovery results obtained for selected metals $(\mathrm{Co}, \mathrm{Cu}, \mathrm{Mn}$. $\mathrm{Zn}, \mathrm{V}, \mathrm{Cr}$ ), ranging from 89 to $98 \%$ of reported values and that the relative standard deviation of the five replicates for the REE amounts was lower than $10 \%$.

\subsubsection{Data representation}

The software packages, Microsoft Office EXCEL 2013(Copyright (C) Microsoft 2014), were used to produce any figures. The concentrations of each element have been normalized. Soil REE concentration was normalized by Upper Continental Crust (UCC) and fruits end juices were normalized by soil to which they belonged. For any group, standard error and average were calculated. Ratios of heavy REE (HREE, from La to Gd) vs light REE ( from Tb to Lu plus Y) were represented. 


\subsection{Discussion}

\subsubsection{REE concentration in soil, fruit and juice}

The soil, fruit and juice extracts had been processed as listed above and, the extracts, were analyzed by ICP-MS technique. The results obtained were reported in Table 7_1 for soils, Table 7_2 for fruits and Table 7_3 for juices and expressed in $\mathrm{nmol}^{*} \mathrm{Kg}^{-1}$.

The element most contained in the soil of Catania was the Ce followed in order by $\mathrm{La}, \mathrm{Nd}$, Y, Pr, Sm, Gd, Dy, Eu, Er, Yb, Tb, Ho, Tm and Lu. Besides, in the fruit and juice, the greater concentration of REE was present in the samples of Catania, while the lowest, in those of Messina. The REE concentration of the Naples samples was after Catania. This, probably, was due to a greater bioavailability of elements in that soil compared to other soils and highly favoured by the acidic $\mathrm{pH}$. In the Catania fruit samples, the most concentrated element was La followed in order by Ce, Y, Nd, Pr, Gd, Sm, Eu, Dy, Er, Yb, Tb, Ho, Tm and Lu. Besides, the other samples of fruit followed a similar order. In the juices of Catania, the most concentrated element was the Ce followed in order by La, Y, Nd, Pr, Gd, Sm, Dy, Eu, Er, $\mathrm{Yb}, \mathrm{Tb}, \mathrm{Ho}, \mathrm{Tm}$ and Lu.

It can be seen that the heavier elements $\mathrm{Er}, \mathrm{Yb}, \mathrm{Tb}, \mathrm{Ho}, \mathrm{Tm}$ and $\mathrm{Lu}$ do not change position, but follow the course of the soil, probably, because the plant does not differentiate them and they are absorbed indiscriminately (Brioschi et al. 2013).

\subsubsection{Effect of REE absorption by cultivar}

The fields of Acireale and Naples had previously been studied. These two fields had been taken because there were 10 identical lemon cultivars inside them. As was evident from the results, the cultivar effect was cancelled, and the trend depends, exclusively, on the type of soil and bioavailability of the elements.

\subsubsection{Soil}

For analyzing the soil sample of the citrus field, the ICP-MS technique was employed. The relation of $\sum[\mathrm{HREE}]_{\mathrm{UCC}} v s \sum[\mathrm{LREE}]_{\mathrm{UCC}}$ for all soils of the citrus field were reported in Figure 7_1, where three main groupings can be evidenced. A link between these soils was the pristine rocks from which they were formed. In fact, concerning the synthetic geological map of the Sicilian Region (Tables E.3_1 /6; E.3_2 / 6; E.3_3; /6E.3_4/6; available by http://www.osservatorioacque.it/?cmd=articleandid=75), the rocks, that gave 
rise to the soils in our study, were classified as marly rocks (PA, RG and TP), metamorphic rocks (ME) and volcanic rocks (CT).

The NA soil was also volcanic, but with other mineralogy. Even if they were both volcanic, soils of the two areas show significant differences, in particular, the REE concentration is higher in the Acireale soils. According to Brioschi et al., (2013), the REE concentrations in soils was primarily controlled by the pedogenetic parameters working in the transfer from bedrock to the soil, rather than by the absolute REE concentrations in the bedrock.

To study the transfer of REE from soil to lemon fruit, we chose to determine the quantities of REE as pseudo-total fractions and not their total content, to evaluate the content of REE in all phases released from the ground, avoiding those blocked in silicates. It is important to remember that the distributions of concentrations, rather than single absolute concentration values, must be taken into account (Henderson, 1984; Laveuf and Cornu, 2009). In geochemistry studies, REE concentrations were usually normalized concerning different geochemical references. For this reason, in our study, we chose the Upper Continental Crust (UCC) as a reference (Wedepohl, 1995). As reported in the introduction, to reduce any problems from relatively low concentrations of $\mathrm{Yb}$ and $\mathrm{Lu}$, we have considered the $\left(\sum \mathrm{HREE} / \sum \mathrm{LREE}\right)_{\mathrm{UCC}}$ ratio and not the $(\mathrm{Yb} / \mathrm{La})_{\mathrm{UCC}}$ or $(\mathrm{Lu} / \mathrm{La})_{\text {UCC }}$ ones. Figure 7_1 shows $\sum[\text { HREE }]_{\text {UCC }}$ vs $\sum[$ LREE] UCC relation for all soil samples. The linearity of samples enhances the homogeneity of REE distribution. The normalized patterns (Figure7_2) as it is known, represent a soil sample fingerprint, able to estimate and evidence similarities or differences between different soils (Censi et al., 2014).

The considerable spatial uniformity of the studied area, confirming the hypothesis of the "similar soil" in the REE distribution, is confirmed by the values of the standard error.

The pseudo-total soil fractions show a flat REE distribution along with the series with a progressive slight decrease, from $\mathrm{Gd}$ until Lu, without any significant anomaly. 


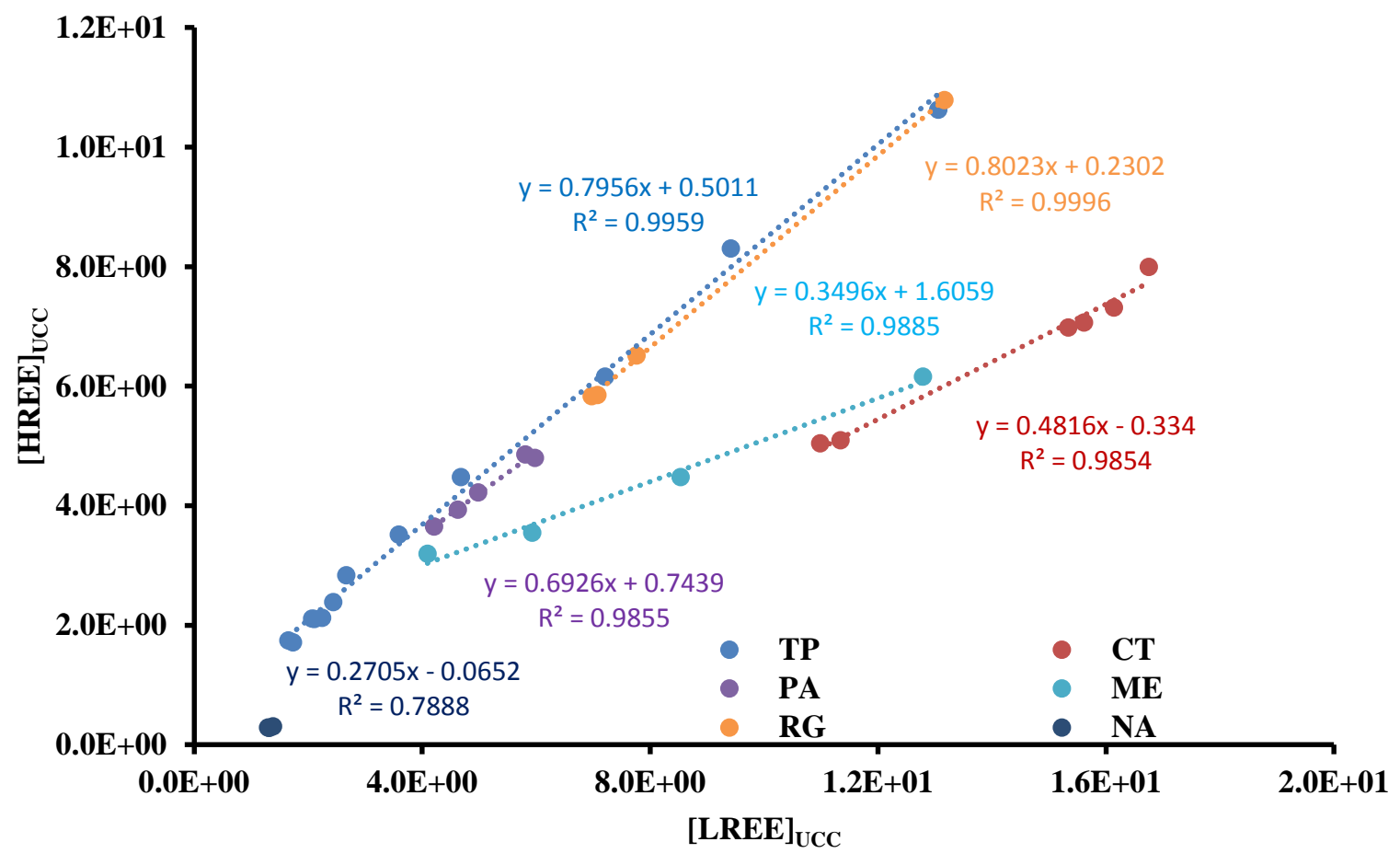

Figure 7_ 1. $\sum[H R E E]_{U C C}$ vs $\sum[L R E E]_{U C C}$ relations for all soils of citrus field.

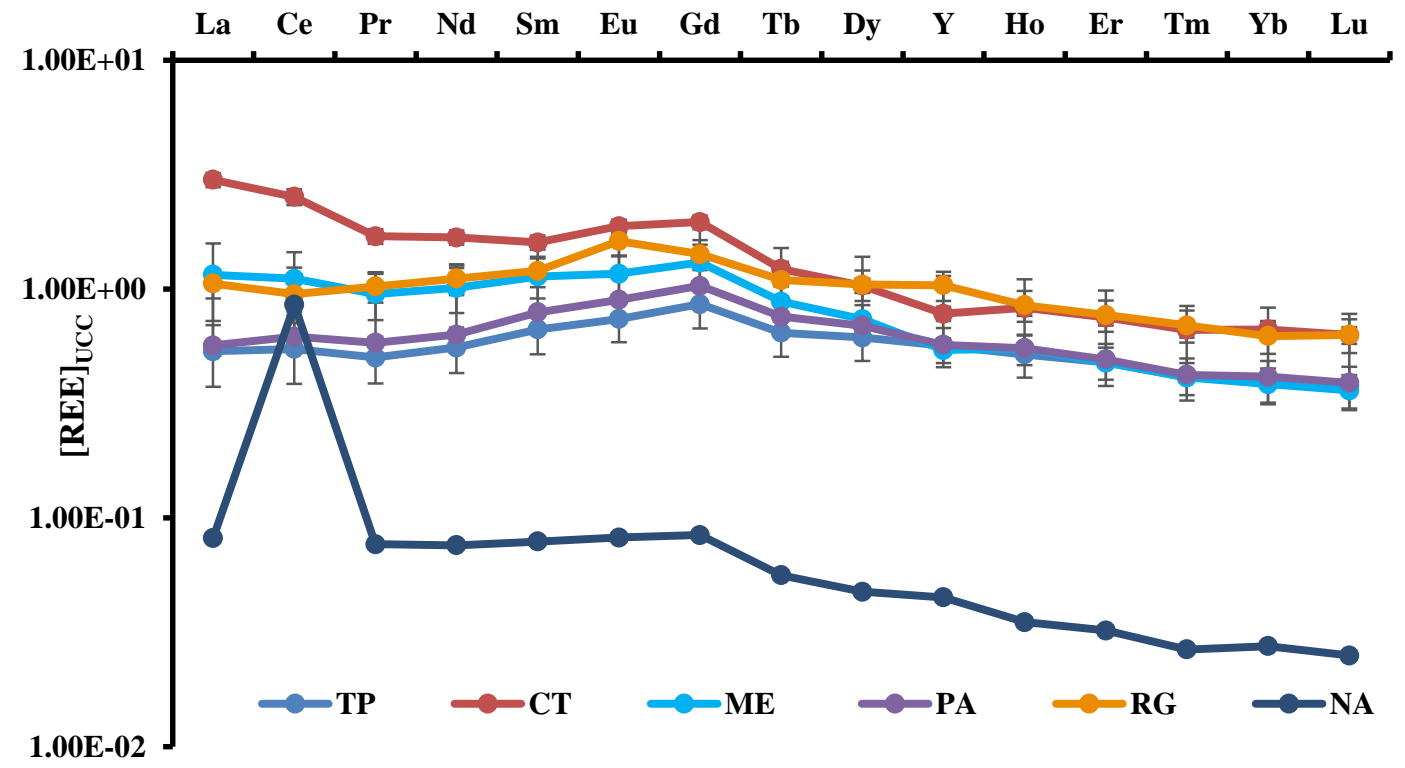

Figure 7_2. UCC-normalized REE patterns of soil sample of citrus field. 


\subsubsection{Fruit and juice}

The REE concentration found in the different extracts of Lemon fruit, compared with soil data, were very small. However, this result was predictable and consistent, comparing our data with ones obtained by fruits of other species. (Vystavna et all. 2015, Pisciotta et all. 2017 ,). In other studies, we had seen that such data was influenced by rainfall. This statement was not valid in our case because lemon was an irrigated crop. This was because the rain affects the amount of circulation water, which allows dissolving different amounts of REE that could be available for the roots. (Pisciotta et all. 2017).

The relation for all lemon fruit samples, $\Sigma[\text { HREE }]_{\text {UCC }}$ vs $\Sigma[\text { LREE }]_{\text {UCC, }}$, is represented in Figure 7_3, while the same relation, but for the juices, is in Figure 7_5.

The result obtained was interesting: we found high $\mathrm{R} 2$ values, grouping the samples for the origin area. Fruits and juices have shown two different correlations: within each grouping of samples, for an area of origin, they showed the same correlation. The concept the relationship was linked to the type of soil, was strengthened by the evidence that both the Naples and Catania specimens, with a good interpolation, had similar angular coefficients, even if the two groups were well-differentiated. Differently, both in the juices and in the fruits of TP and PA, the angular coefficients are very similar. Very interesting, also inside the lemon samples, the angular coefficient differentiates the groups.

In Figures 7_4 and 7_6, the normalized REE patterns were reported. The mean values of the different origin area were reported with the standard error. Juices presented significant differences compared to fruit concentration. The identical behaviour of every cultivar in the uptake of REE was confirmed from strong similarities of all REE distributions, without any significant fractionation.

A positive anomaly of Eu was present in our study that is very frequent in plant REE absorption. This element was preferentially mobilized from soil to lemon, probably, because of its similitude with $\mathrm{Ca}$ and relating to a potential implication in biological processes (Yang and Sachs, 1989; Liang et al., 2008; Brioschi et al., 2013.). 


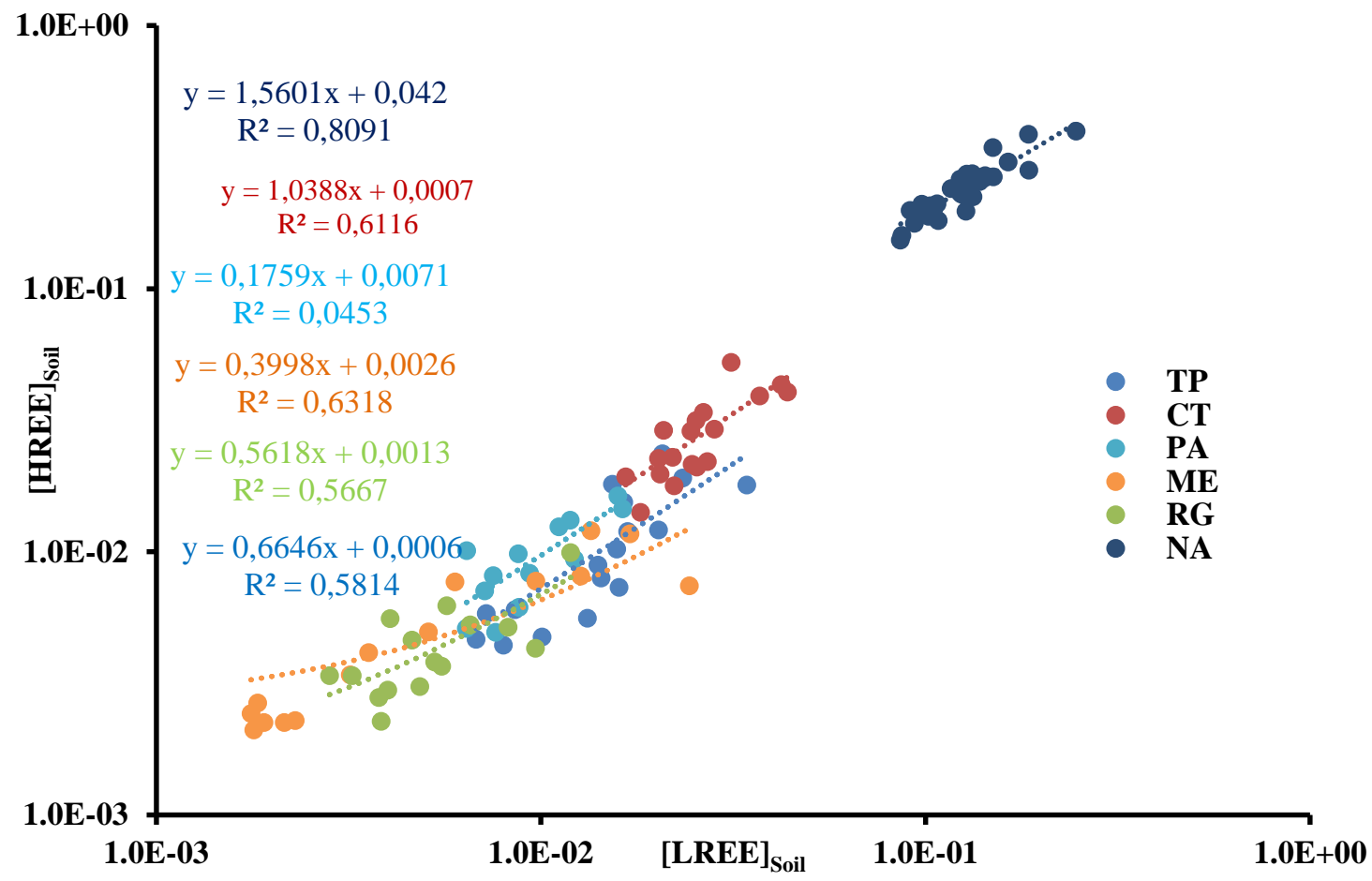

Figure 7_3. $\sum[H R E E]_{U C C}$ vs $\sum[L R E E]_{U C C}$ relations for lemon fruit grouped for origin area.

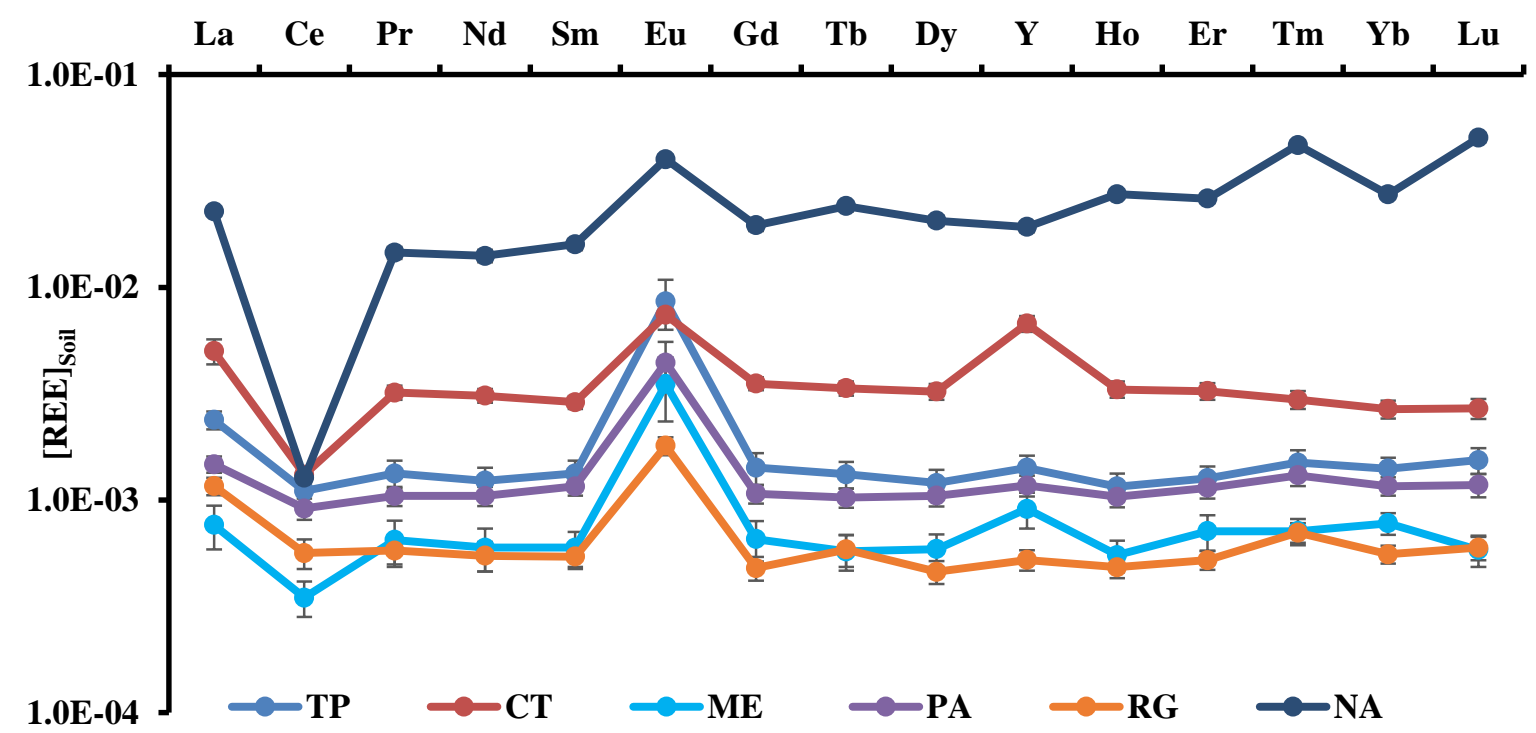

Figure 7_4. Soil-normalized REE patterns of fruit sample of different origin area. 


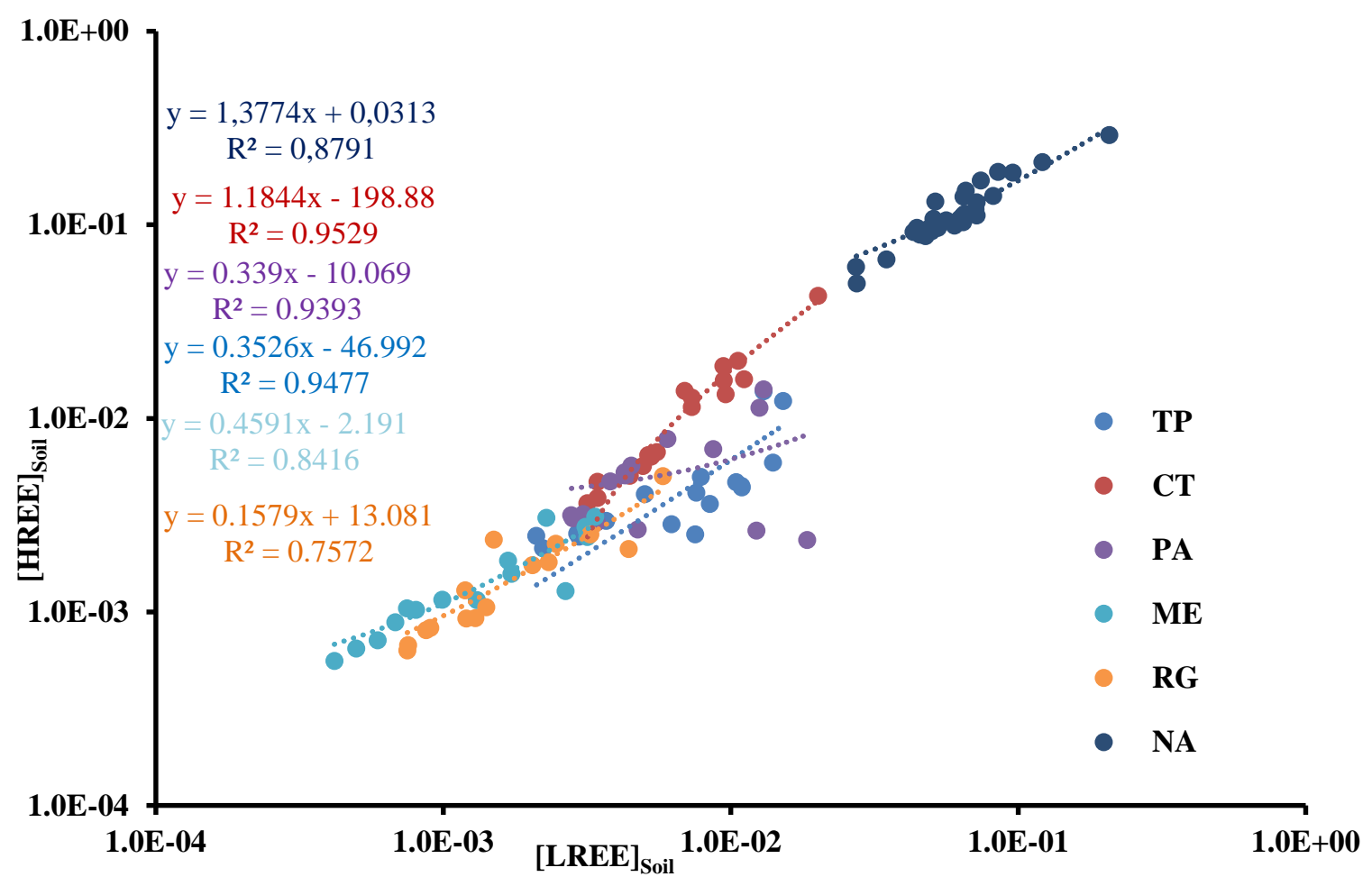

Figure 7_5. $\sum[H R E E]_{U C C} v s \sum[L R E E]_{U C C}$ relations for lemon juice grouped for origin area.

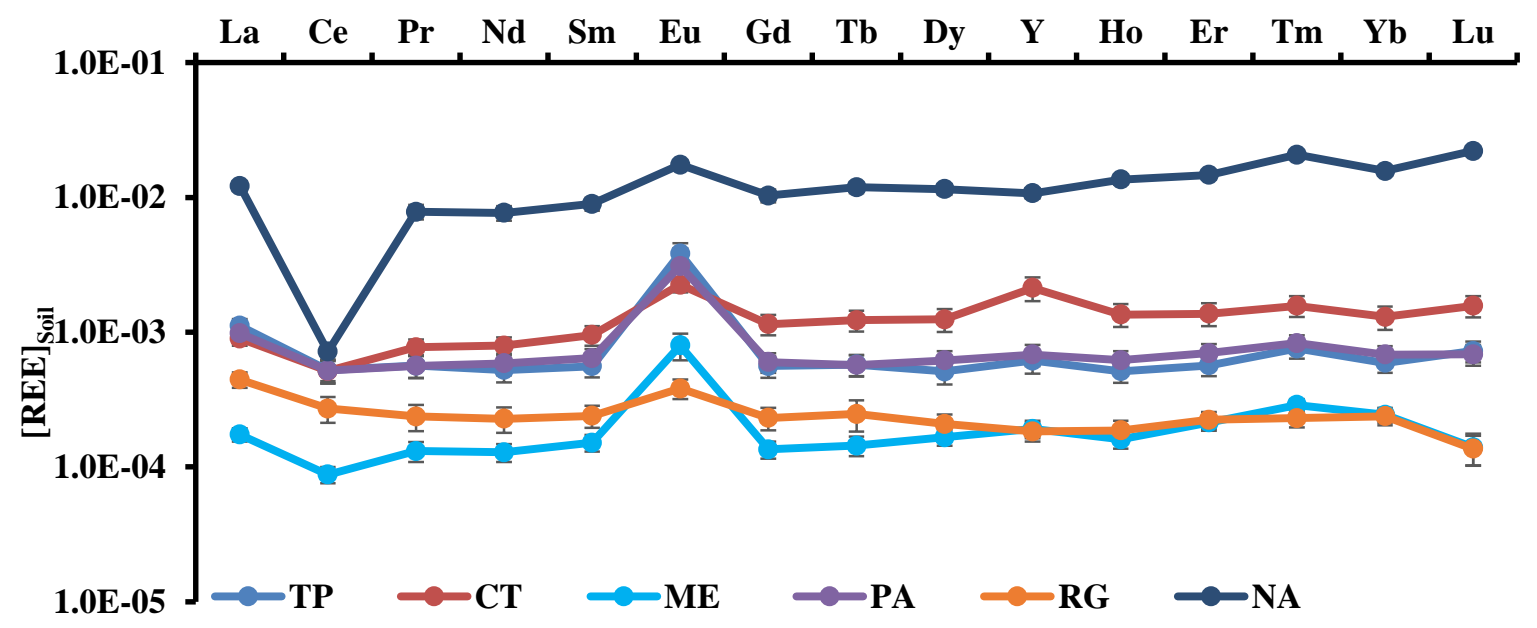

Figure 7_6. Soil-normalized REE patterns of juice sample of different origin area 


\subsection{Conclusion}

The obtained results evidence that the fruits of different cultivars, grown on soil with a similar REE pattern, have the same REE distribution. The lemon fruit REE pattern normalization, to the quantity of the own soil, it is essential to study and, eventually, recognize an effective relationship soil-lemon fruit. Therefore, the REE pattern could be used as a tool to connect soil and lemons, with the aim of a possible geographical characterization. 


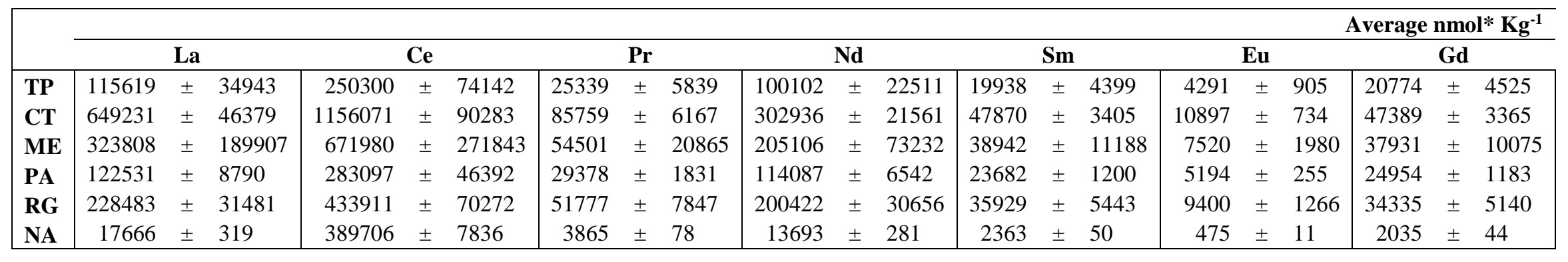

\begin{tabular}{|c|c|c|c|c|c|c|c|c|c|c|c|c|c|c|c|c|c|c|c|c|c|c|c|}
\hline \multicolumn{3}{|c|}{$\mathbf{T b}$} & \multicolumn{3}{|c|}{ Dy } & \multicolumn{3}{|c|}{$\mathbf{Y}$} & \multicolumn{3}{|c|}{ Ho } & \multicolumn{3}{|c|}{ Er } & \multicolumn{3}{|c|}{ Tm } & \multicolumn{3}{|c|}{$\mathbf{Y b}$} & \multicolumn{3}{|c|}{ Lu } \\
\hline 2597 & \pm & 556 & 13227 & \pm & 2769 & 140158 & \pm & 27335 & 2513 & \pm & 524 & 6565 & \pm & 1375 & 805 & \pm & 168 & 5079 & \pm & 1093 & 688 & \pm & 147 \\
\hline 4936 & \pm & 364 & 22322 & \pm & 1644 & 193292 & \pm & 13793 & 4012 & \pm & 308 & 10336 & \pm & 794 & 1298 & \pm & 100 & 8472 & \pm & 687 & 1152 & \pm & 96 \\
\hline 4139 & \pm & 977 & 18339 & \pm & 4209 & 142023 & \pm & 35916 & 3061 & \pm & 763 & 7394 & \pm & 2120 & 867 & \pm & 282 & 5297 & \pm & 1760 & 681 & \pm & 234 \\
\hline 3050 & \pm & 146 & 14928 & \pm & 740 & 141366 & \pm & 7808 & 2681 & \pm & 139 & 6774 & \pm & 400 & 825 & \pm & 53 & 5272 & \pm & 348 & 712 & \pm & 49 \\
\hline 4412 & \pm & 675 & 22524 & \pm & 3418 & 257314 & \pm & 37644 & 4124 & \pm & 629 & 10599 & \pm & 1647 & 1357 & \pm & 216 & 7927 & \pm & 1310 & 1155 & \pm & 194 \\
\hline 226 & \pm & 5 & 1026 & \pm & 31 & 11129 & \pm & 319 & 170 & \pm & 4 & 443 & \pm & 14 & 52 & \pm & 2 & 350 & \pm & 10 & 46 & \pm & 1 \\
\hline
\end{tabular}

Table 7_1. Average amounts in nanomoles* $\mathrm{Kg}^{-1}$ and standard error of Ree in citrus fields soil samples regrouped for same Geographic area. 


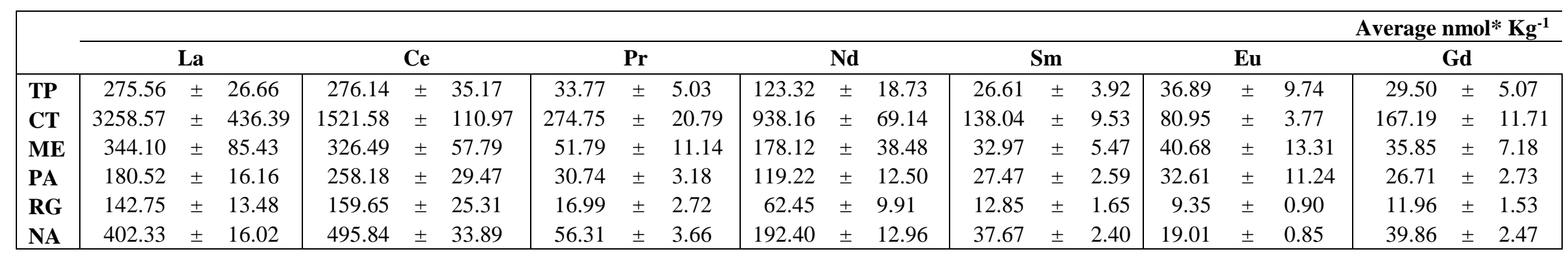

\begin{tabular}{|c|c|c|c|c|c|c|c|c|c|c|c|c|c|c|c|c|c|c|c|c|c|c|c|}
\hline \multicolumn{3}{|c|}{$\mathbf{T b}$} & \multicolumn{3}{|c|}{ Dy } & \multicolumn{3}{|c|}{$\mathbf{Y}$} & \multicolumn{3}{|c|}{ Ho } & \multicolumn{3}{|c|}{$\mathbf{E r}$} & \multicolumn{3}{|c|}{ Tm } & \multicolumn{3}{|c|}{$\mathbf{Y b}$} & \multicolumn{3}{|c|}{ Lu } \\
\hline 3.44 & \pm & 0.50 & 15.90 & \pm & 2.42 & 198.54 & \pm & 28.09 & 2.90 & \pm & 0.44 & 8.32 & \pm & 1.12 & 1.21 & \pm & 0.17 & 7.13 & \pm & 0.90 & 1.06 & \pm & 0.15 \\
\hline 16.55 & \pm & 1.26 & 72.24 & \pm & 6.04 & 1306.25 & \pm & 110.55 & 13.30 & \pm & 1.17 & 33.62 & \pm & 2.98 & 3.84 & \pm & 0.37 & 22.66 & \pm & 2.16 & 3.11 & \pm & 0.33 \\
\hline 3.39 & \pm & 0.55 & 15.00 & \pm & 2.35 & 180.83 & \pm & 32.74 & 2.37 & \pm & 0.33 & 7.19 & \pm & 1.41 & 0.84 & \pm & 0.09 & 5.36 & \pm & 0.49 & 0.57 & \pm & 0.07 \\
\hline 3.13 & \pm & 0.32 & 15.63 & \pm & 1.71 & 165.49 & \pm & 18.77 & 2.78 & \pm & 0.31 & 7.74 & \pm & 0.84 & 1.08 & \pm & 0.12 & 6.13 & \pm & 0.60 & 0.84 & \pm & 0.11 \\
\hline 1.78 & \pm & 0.30 & 6.87 & \pm & 0.86 & 73.95 & \pm & 8.11 & 1.29 & \pm & 0.15 & 3.54 & \pm & 0.36 & 0.58 & \pm & 0.06 & 2.93 & \pm & 0.28 & 0.43 & \pm & 0.05 \\
\hline 5.45 & \pm & 0.30 & 21.14 & \pm & 1.19 & 214.15 & \pm & 11.98 & 4.66 & \pm & 0.21 & 11.59 & \pm & 0.53 & 2.43 & \pm & 0.12 & 9.57 & \pm & 0.43 & 2.32 & \pm & 0.11 \\
\hline
\end{tabular}

Table 7_2. Average amounts in nanomoles* $\mathrm{Kg}^{-1}$ and standard error of Ree in citrus fruit samples regrouped for same Geographic area. 


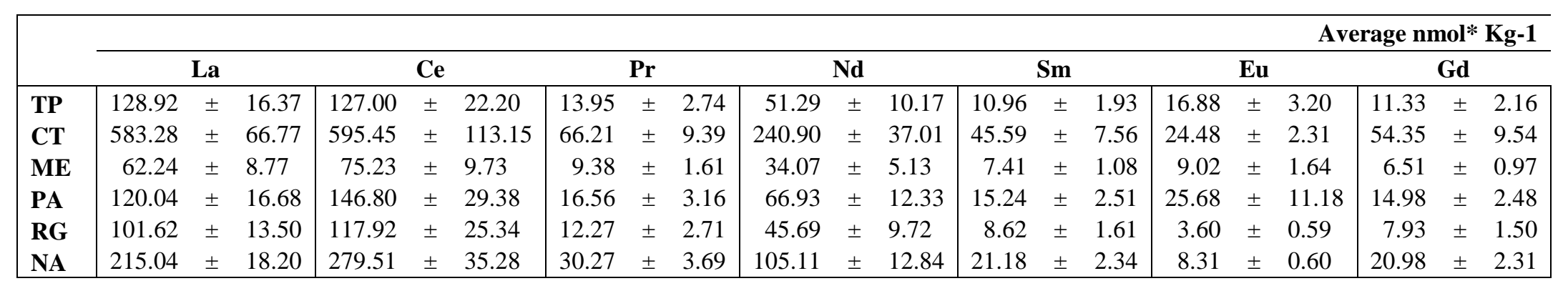

\begin{tabular}{|c|c|c|c|c|c|c|c|c|c|c|c|c|c|c|c|c|c|c|c|c|c|c|c|}
\hline \multicolumn{3}{|c|}{$\mathbf{T b}$} & \multicolumn{3}{|c|}{ Dy } & \multicolumn{3}{|c|}{$\mathbf{Y}$} & \multicolumn{3}{|c|}{ Ho } & \multicolumn{3}{|c|}{$\mathbf{E r}$} & \multicolumn{3}{|c|}{ Tm } & \multicolumn{3}{|c|}{$\mathbf{Y b}$} & \multicolumn{3}{|c|}{ Lu } \\
\hline 1.45 & \pm & 0.27 & 6.62 & \pm & 1.33 & 83.47 & \pm & 16.92 & 1.26 & \pm & 0.23 & 3.63 & \pm & 0.63 & 0.59 & \pm & 0.10 & 2.93 & \pm & 0.47 & 0.48 & \pm & 0.09 \\
\hline 6.06 & \pm & 1.06 & 27.79 & \pm & 5.36 & 412.31 & \pm & 82.38 & 5.43 & \pm & 1.04 & 14.19 & \pm & 2.75 & 2.04 & \pm & 0.36 & 11.00 & \pm & 2.17 & 1.81 & \pm & 0.33 \\
\hline 1.74 & \pm & 0.31 & 9.22 & \pm & 1.60 & 96.40 & \pm & 17.38 & 1.66 & \pm & 0.28 & 4.75 & \pm & 0.78 & 0.68 & \pm & 0.10 & 3.60 & \pm & 0.55 & 0.49 & \pm & 0.09 \\
\hline 1.09 & \pm & 0.29 & 4.70 & \pm & 0.83 & 47.20 & \pm & 7.62 & 0.77 & \pm & 0.14 & 2.37 & \pm & 0.35 & 0.31 & \pm & 0.05 & 1.88 & \pm & 0.27 & 0.16 & \pm & 0.04 \\
\hline 2.69 & \pm & 0.26 & 11.84 & \pm & 1.10 & 119.40 & \pm & 10.52 & 2.31 & \pm & 0.18 & 6.51 & \pm & 0.47 & 1.08 & \pm & 0.07 & 5.50 & \pm & 0.39 & 1.01 & \pm & 0.06 \\
\hline
\end{tabular}

Table 7_3. Average amounts in nanomoles* $\mathrm{Kg}^{-1}$ and standard error of Ree in citrus juice samples regrouped for same Geographic area. 
8. Conclusions 
In this thesis, the common objectives in agreement with the citrus industry "EuroFood" and the research project "PON industrial P.h.D - a.a. 2016/2017" have been addressed.

Different Citrus EOs have been characterized in this study and it has been seen that the oils produced by the pruning waste of May could be used for the extraction of EO with high yields. Also, nutraceutical and pharmacological substances have been found in the orange industrial hydrolate.

Industrial lemon EO has had good preliminary results as a herbicide activity. The allelopathic properties, found in the studied lemon EO, represent a good basis for the development of herbicides of natural origin, biodegradable and eco-friendly.

Thanks to the application of water stress after the winter vegetative restart, a very concrete factor found is that water stress increases the diameter of the fruit. This result will certainly be very interesting on the market and consumers. Another consideration is that the effects of stress were not immediate on citrus trees, but were evident after some time.

This study provides preliminary results regarding the effect of lemon, orange and tangerine hydrolates on stable and labile soil $\mathrm{C}$ pools, microbial biomass and activity and on the main microbial groups. Overall, our findings provided evidence that CWWs may play some role within sustainable agriculture since, when added to a soil, they so improving the soil quality and fertility.

The application of EO as a microbial and antifungal activity has not been reported because preliminary screening showed that they had no significant effects. Also, the industrial lemon and tangerine EOs have been used for the production of "first salt" flavoured cheese from sheep's milk. A panellists' survey showed that the one with the addition of lemon EO and the one with the mandarin EO were highly appreciated. EO LI was used for the production of ice cream (figure 8_1) and won the prize shown in figure 8_2.

The object of traceability was achieved; the REE model could be used as a tool to connect soil and lemons, for a possible geographical characterization and a direct link with the production territory or soil.

In this thesis, in collaboration with the citrus industry "EuroFood" and thanks to the research project "PON industrial PhD - ay 2016/2017". Interesting results have been 
obtained that could give a boost to the Sicilian citrus sector; in particular to the lemon one thanks to the enhancement of some waste and by-products but above all by linking the products to the territories of origin.

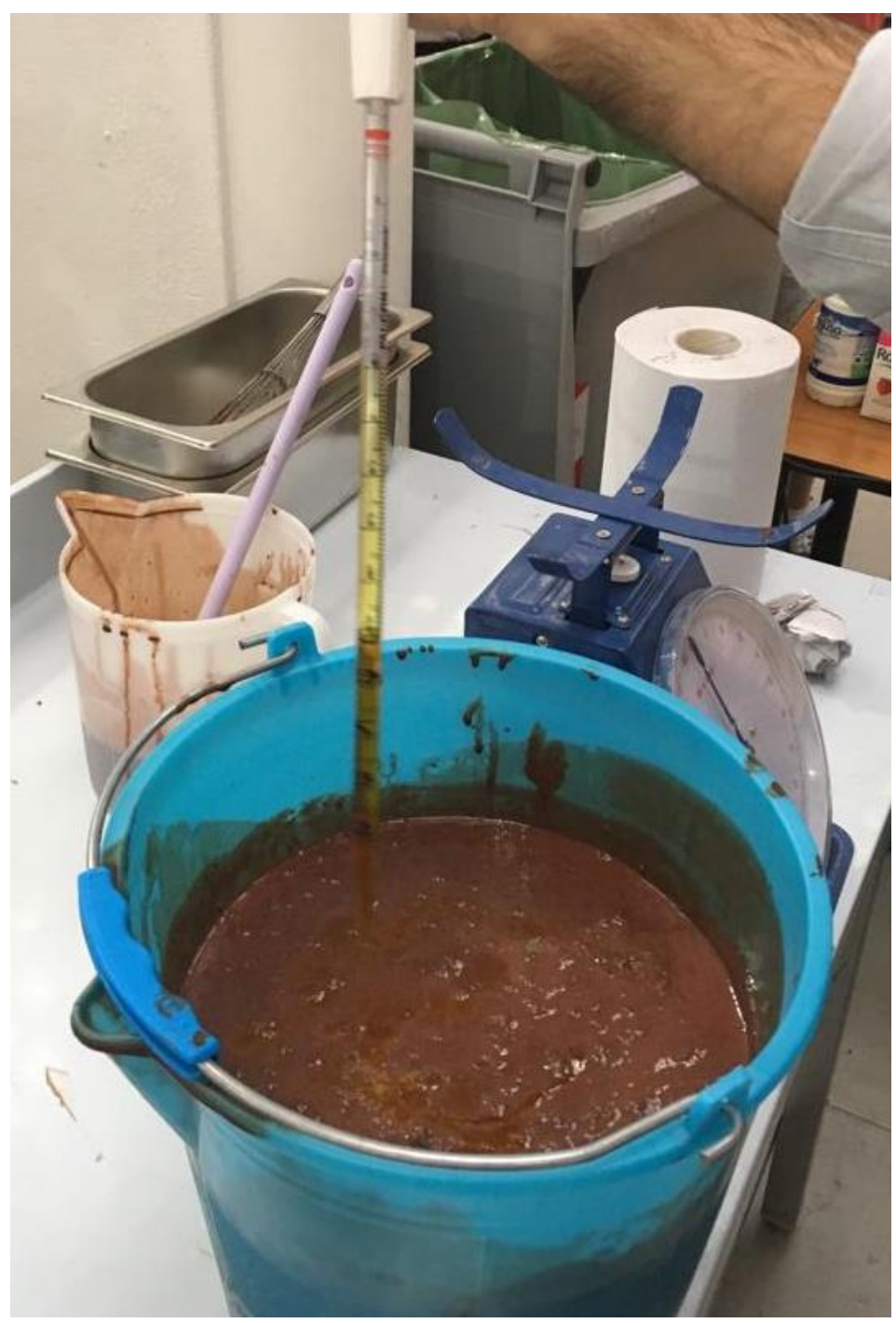

Figure 8_1 Preparation of ice-cream made with chocolate, Pantelleria capers and lemon Essential Oils. 


\section{PSherbeth: \\ CONCORSO INTERNAZIONALE

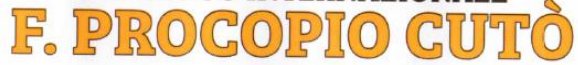

INNOVAZIONE:

STAL - CORSO DI LAUREA IN SCIENZE E TECNOLOGIE AGROALIMENTARI

Per l'apporto scientifico e il prezioso lavoro di ricerca con-

dotto con l'utilizzo di materie prime di assoluta qualità e

nella valorizzazione delle eccellenze del territorio applicato al comparto della gelateria artigianale.

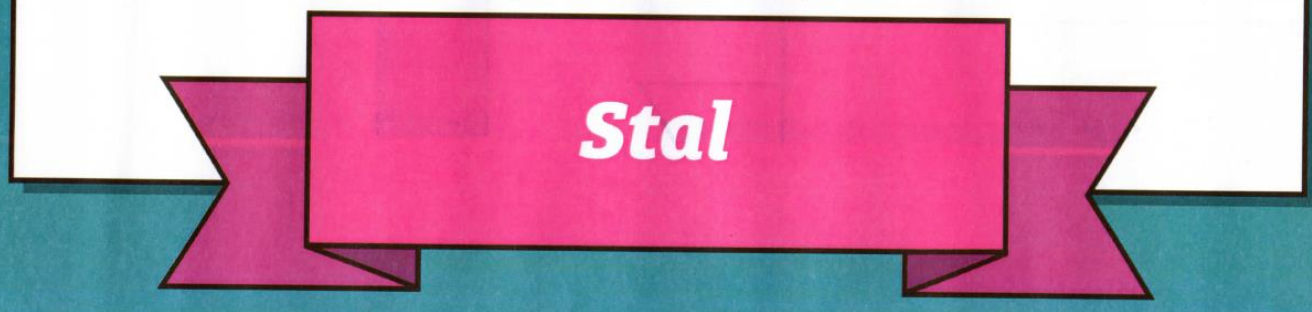

\section{Settembre • 01 Ottobre 2017}

Figure 8_2. Innovation award won at the Sherbeth Festival 2017 
9. References 
Abrahim, D., Braguini, W.L., Kelmer-Bracht, A.M., Ishiilwamoto, E.L. 2000. Effects of four monoterpenes on germination, primary root growth, and mitochondrial respiration of maize. Journal of chemical ecology 26, 611-624.

Abrahim, D., Francischini, A. C., Pergo, E. M., Kelmer-Bracht, A. M., Ishii-Iwamoto, E. L. 2003. Effects of $\alpha$-pinene on the mitochondrial respiration of maize seedlings. Plant Physiology and Biochemistry 41, 985-991.

Adrover, M., Farrus, E., Moyà, G., Vadell, J., 2012. Chemical properties and biological activity in soils of Mallorca following twenty years of treated wastewater irrigation. Journal of Environmental Management 95, 5188-5192

Agustì-Fonfria, M. 2003. Citricultura.. 2.ed. Barcelona: Mundi-Prensa.

de Albuquerque, M.B., dos Santos, R.C., Lima, L.M., Melo, P.D., Nogueira, R., da Camara, C.A.G., Ramos, A.D., 2011. Allelopathy, an alternative tool to improve cropping systems. A review. Agronomy for Sustainable Development 31, 379-395

Alsaadawi, I.S., Arif, M.B., Alrubeaa, A.J. 1985. Allelopathic effects of Citrus aurantium L. II. Isolation, characterization, and biological activities of phytotoxins. Journal of chemical ecology 11, 1527-1534.

Amenta M., Ballistreri G., Fabroni S., Romeo F.V., Spina A., Rapisarda P. 2015. Qualitative and nutraceutical aspects of lemon fruits grown on the mountainsides of the Mount Etna: a first step for a protected designation of origin or protected geographical indication application of the brand name "Limone dell'Etna" Food Research International, 74, 250-259

Amenta, M., Fabroni, S., Costa, C., Rapisarda, P. 2016. Traceability of 'Limone di Siracusa PGI'by a multidisciplinary analytical and chemometric approach. Food chemistry, 211, 734-740.Salazar M., Pisano P., 1 González Sierra M., Furlan R. 2018. NMR and multivariate data analysis to assess traceability of argentine citrus, Microchemical Journal 141, 264-270.

Anderson, J.P.E., and Domsch, K.H., 1989. Ratios of microbial biomass carbon to total carbon in arable soils. Soil biology and biochemistry 21, 471-479

Anderson, T.H., 2003. Microbial eco-physiological indicators to assess soil quality. Agriculture, Ecosystems and Environment 98, 285-293. 
Angelini, L.G., Carpanese, G., Cioni, P.L., Morell, I., Macchia, M., Flamini, G., 2003. Essentialoils from Mediterranean Lamiaceae as weed germination inhibitors. Journal of Agricultural and Food Chemistry 51, 6158-6164.

Anitei S. 2007. Where did citrus fruits originate from Softpedia. Available from: http://news.softpedia.com/news/Where-Did-Citrus-Fruits-Originate-From67365.shtml. Accessed 2011 June.

Armenta, R., Vaca, R., Lugo, J., Aguila, P.D., 2012. Microbiological and biochemical properties of an agricultural Mexican soil amended with sewage sludge. Revista Brasileira de Ciência do Solo 36, 1646-1655.

Araniti, F., Sánchez-Moreiras, A. M., Graña, E., Reigosa, M. J., Abenavoli, M. R. 2017. Terpenoid trans-caryophyllene inhibits weed germination and induces plant water status alteration and oxidative damage in adult Arabidopsis. Plant Biology, 19, 7989.

Astani, A., Reichling, J., Schnitzler, P., 2009. Comparative study on the antiviral activityof selected monoterpenes derived from essential oils. Phytotherapy Research: An International Journal Devoted to Pharmacological and Toxicological Evaluation of Natural Product Derivatives 24, 673-679.

Azirak, S., and Karaman, S. 2008. Allelopathic effect of some essential oils and components on germination of weed species. Acta Agriculturae Scandinavica Section B-Soil and Plant Science, 58, 88-92.

Aziz, E. E., and Hendawy, S. F. 2008. Effect of Soil Type and Irrigation Intervals on Plant Growth, Essential Oil and Constituents of Thymus vulgaris Plant. American Eurasian Journal Agricolture Environment Science 4,443-450.

Badalucco, L., Rao, M., Colombo, C., Palumbo, G., Laudicina, V.A., Gianfreda, L., 2010. Reversing agriculture from intensive to sustainable improves soil quality in a semiarid South Italian soil. Biology and Fertility of Soils 46, 481-489

Bais HP, Weir TL, Perry LG, Gilroy S, Vivanco JM 2006. The role of root exudates in rhizosphere interactions with plants and other organisms. Annu Rev Plant Biol 57, 233-266. 
Barney, J.N., Hay, A.G., Weston, L.A. 2005. Isolation and characterization of allelopathic volatiles from mugwort (Artemisia vulgaris). Journal of chemical ecology 31, 247265.

Baroni, M. V., Podio, N. S., Badini, R. G., Inga, M., Ostera, H. A., Cagnoni, M., ... and Wunderlin, D. A. 2015. Linking soil, water, and honey composition to assess the geographical origin of Argentinean honey by multielemental and isotopic analyses. Journal of Agriculture and Food Chemistry 63, 4638-4645.

Bartholomew E.T., and Sinclair W.B. 1951. The Lemon Fruit: its composition, physiology, and products. - sidalc.net SIDALC.

Bastida, F., Kandeler, E., Moreno, J. L., Ros, M., García, C., Hernández, T.2008. Application of fresh and composted organic wastes modifies structure, size and activity of soil microbial community under semiarid climate. Applied Soil Ecology 40, 318-329.

Bastida, F., Torres, I. F., Abadía, J., Romero-Trigueros, C., Ruiz-Navarro, A., Alarcón, J. J., ... and Nicolás, E. 2018. Comparing the impacts of drip irrigation by freshwater and reclaimed wastewater on the soil microbial community of two citrus species. Agricultural Water Management 203, 53-62.

Baydar, H., and Göktürk Baydar, N. 2005. The effects of harvest date fermentation duration and Tween 20 treatment on essential oil content and composition of industrial oil rose (Rosa damascena Mill.). Industrial crops and products 21,251-255.

Baydar, H., Erbaş, S., Kineci, S., Kazaz, S. 2007. Yağ gülü (Rosa damascena Mill.) damıtma suyuna katılan tween-20'nin taze ve fermente olmuş çiçeklerin gül yağı verimi ve kalitesi üzerine etkisi. SDÜ Ziraat Fakültesi Dergisi 2, 15-20.

Becerra-Castro, C., Lopes, A. R., Vaz-Moreira, I., Silva, E. F., Manaia, C. M., Nunes, O. C. 2015. Wastewater reuse in irrigation: A microbiological perspective on implications in soil fertility and human and environmental health. Environment international $75,117-135$.

Bellakhdar J.1997. La Pharmacope'e marocaine traditionnelle. Casablanca, Maroc: Editions Le Fennec. 
Belz R.G. 2007. Allelopathy in crop/weed interactions e an update. Pest Management Science: formerly Pesticide Science 63, 308-326.

Benvenuti, S., Cioni, P., Flamini, G., Pardossi, A.J.W.R., 2017. Weeds for weed control: Asteraceae essential oils as natural herbicides. Weed research 57, 342-353.

Bernal, M.P., Sanchez-Monedero, M.A., Paredes, C., Roig, A., 1998. Carbon mineralization from organic wastes at different composting stages during their incubation with soil. Agriculture, Ecosystems and Environment 69, 175-189

Bhattacharyya, P., Pal, R., Chakraborty, A., Chakrabarti, K., 2001. Microbial biomass and activity in lateritic soil amended with municipal solid waste compost. Journal of Agronomy and Crop Science 187, 207-211.

Blagodatskaya, E., and Kuzyakov, Y., 2008. Mechanisms of real and apparent priming effects and their dependence on soil microbial biomass and community structure: critical review. Biology and Fertility of Soils 45, 115-131.

Bohlmann, J., Meyer-Gauen, G., Croteau, R. 1998. Plant terpenoid synthases: molecular biology and phylogenetic analysis. Proceedings of the National Academy of Sciences 95, 4126-4133.

Bradford, K. J., and Hsiao, T. C. (1982). Physiological responses to moderate water stress. In Physiological plant ecology II (pp. 263-324). Springer, Berlin, Heidelberg.

Bradley RL and Fyles JW (1995). A kinetic parameter describing soil available carbon and relationship to rate increase in C mineralization. Soil Biol. Biochem. 27, 167172.

Brioschi, L., Steinmann, M., Lucot, E., Pierret, M. C., Stille, P., Prunier, J., Badot, P. M. 2013. Transfer of rare earth elements (REE) from natural soil to plant systems: implications for the environmental availability of anthropogenic REE. Plant and soil, $366,143-163$.

Brown, J. T., Hegarty, P. K., Charlwood, B. V. 1987. The toxicity of monoterpenes to plant cell cultures. Plant Science 48, 195-201.

Brown, P. H., Rathjen, A. H., Graham, R. D., Tribe, D. E. 1990. Em Handbook on the Physics and Chemistry of Rare Earths. Elsevier, Amsterdam, 13, 423-453. 
Carson, C.F., and Riley, T.V. 2003. Non-antibiotic therapies for infectiousdiseases. Communicable diseases intelligence quarterly report 27, 143-146.

Caamal-Maldonado, J.A., Jimenez-Osornio, J.J., Torres-Barragan, A., Anaya, A.L. 2001.The use of allelopathic legume cover and mulch species for weed control in cropping systems. Agronomy journal 93, 27-36.

Cao, X., Chen, Y., Gu, Z., and Wang, X. 2000. Determination of trace rare earth elements in plant and soil samples by inductively coupled plasma-mass spectrometry. International Journal of Environmental Analytical Chemistry 76, 295-309.

Censi, P., Saiano, F., Pisciotta, A., Tuzzolino, N. 2014. Geochemical behaviour of rare earths in Vitis vinifera grafted onto different rootstocks and growing on several soils. Science of the total environment 473, 597-608.

Charles, O., Joly, R., Simon, J.E., 1994. Effect of osmotic stress on the essential oil content and composition of peppermint. Phytochemistry 29, 2837-2840.

Chaimovitsh, D., Abu-Abied, M., Belausov, E., Rubin, B., Dudai, N., Sadot, E. 2010. Microtubules are an intracellular target of the plant terpene citral. Plant J. 61, 399408.

Chaimovitsh, D., Rogovoy, O., Altshuler, O., Belausov, E., Abu-Abied, M., Rubin, B., Dudai, N. 2012. The relative effect of citral on mitotic microtubules in wheat roots and BY2 cells. Plant biology, 14, 354-364.

Charlton, A., Sakrabani, R., Tyrrel, S., Casado, M. R., McGrath, S. P., Crooks, B., ... and Campbell, C. D. 2016. Long-term impact of sewage sludge application on soil microbial biomass: An evaluation using meta-analysis. Environmental Pollution 219, 1021-1035.

Chen, W., Wu, L., Frankenberger, W.T., Chang, A.C., 2008. Soil enzyme activities of long-term reclaimed wastewater-irrigated soils. J. Environ. Qual. 37, S36-S42

Cheng, K.Y., Ho, G., Cord-Ruwisch, R., 2012. Energy-efficient treatment of organic wastewater streams using a rotatable bioelectrochemical contactor (RBEC). Bioresourse Technology 126, 431-436. 
Chowhan, N., Singh, H.P., Batish, D.R., Kohli, R.K. 2011. Phytotoxic effects of $\beta$-pinene on early growth and associated biochemical changes in rice. Acta Phys. Plant. 33, 2369-2376.

Clark RJ, and Menary RC .2008. Environmental Effects on Peppermint (Mentha piperita L.). II. Effects of Temperature on Photosynthesis, Photorespiration and Dark Respiration in Peppermint with Reference to Oil Composition. Aust. J. Plant Physiol., 7(6): 693-697.

Corsino, S.F., Di Trapani, D., Torregrossa, M., Viviani, G., 2018. Aerobic granular sludge treating high strength citrus wastewater: Analysis of $\mathrm{pH}$ and organic loading rate effect on kinetics, performance and stability. Journal of Environmental Management214, 23-35

Dayan F.E. and Duke S.O. 2010 Natural products for weed management in organic farming in the USA. Outlooks on Pest Management 21, 156-160

De Nobili, M., Contin, M., Mondini, C., Brookes, P.C., 2001. Soil microbial biomass is triggered into activity by trace amounts of substrate. Soil Biology and Biochemistry 33, 1163-1170.

Di Bene, C., Pellegrino, E., Debolini, M., Silvestri, N., Bonari, E., 2013. Short- and longterm effects of olive mill wastewater land spreading on soil chemical and biological properties. Soil Biology and Biochemistry 56, 21-30.

Di Serio, M.G., Lanza, B., Mucciarella, M.R., Russi, F., Iannucci, E., Marfisi, P., Madeo, A., 2008. Effects of olive mill wastewater spreading on the physicochemical and microbiological characteristics of soil. International Biodeterioration and Biodegradation 62, 403-407.

Dilly, O., and Munch, J.C., 1998. Ratios between estimates of microbial biomass content and microbial activity in soils. Biology and Fertility of Soils 27, 374-379.

Doorenbos, J. and Kassam, A. H. 1979. Yield response to water. FAD Irrigation and Drainage Paper No. 33, 81-7.

Doré, T., Sène, M., Pellissier, F., Gallet, C. 2004. An agronomic view of allelopathic phenomena. Cahiers Agricultures, 13, 249-256. 
Drivelos, S. A., and Georgiou, C. A. 2012. Multi-element and multi-isotope ratio analysis to determine the geographical origin of foods in the European Union. Trends in Analytical Chemistry 40, 38-51.

Dugo, G., and Mondello, L. 2010. Citrus Oils: Composition, Advanced Analytical Techniques, Contaminants, and Biological Activity. Boca Raton: CRC Press.

Duke, S.O., Dayan, F.E., Romagni, J.G., Rimando, A.M., 2000. Natural products as sources of herbicides: current status and future trends. Weed research 40, 99-111.

Duke., S.O. 2003. Ecophysiological aspects of allelopathy. Planta 217, 529-539.

Duke, S.O., and Dayan, F.E.J.D., Products, S.O.C.P., 2015. Discovery of new herbicide modes of action with natural phytotoxins.

Durante, C., Bertacchini, L., Bontempo, L., Camin, F., Manzini, D., Lambertini, P., ... and Paolini, M. 2016. From soil to grape and wine: Variation of light and heavy elements isotope ratios. Food chemistry 210, 648-659.

Eisenreich, W., Sagner, S., Zenk, M. H., Bacher, A. 1997. Monoterpenoid essential oils are not of mevalonoid origin. Tetrahedron Letters, 38, 3889-3892.

El-Rokiek, K., and El-Nagdi, W. 2011. Dual effects of leaf extracts of Eucalyptus citriodora on controlling purslane and root-knot nematode in sunflower. Journal of plant protection research, 51, 121.

El Sawi, S. A., Ibrahim, M. E., El-Rokiek, K. G., El-Din, S. A. S. 2019. Allelopathic potential of essential oils isolated from peels of three citrus species. Annals of Agricultural Sciences, 64, 89-94.

Ersilia, A., Sumalan, R.M., Danciu, C., Obistioiu, D., Negrea, M., Poiana, M., Rus, C.,Radulov, I., Pop, G., Dehelean, C. 2018. Synergistic antifungal, allelopathic and antiproliferative potential of Salvia officinalis L., Thymus vulgaris L. essential oils. Molocules. 23, 1-15.

European Pharmacopoeia 1975. Vol. 3, Maisonneuve S. A., Sainte-Ruffine.

Fagodia, S.K., Singh, H.P., Batish, D.R., Kohli, R.K. 2017. Phytotoxicity and cytotoxicity of Citrus aurantiifolia essential oil and its major constituents: Limonene and citral. Industrial crops and products 108, 708-715. 
Fanin, N., Kardol, P., Farrell, M., Nilsson, M.C., Gundale, M.J., Wardle, D.A., 2019. The ratio of gram-positive to gram-negative bacterial PLFAs markers as an indicator of carbon availability in organic soils. Soil biology and biochemistry 128, 111-114.

FAO, Food and Agricultural Organization of the United Nations. 1967. The state of food and agriculture. Rome, Italy.

FAO, Food and Agricultural Organization of the United Nations. 2017. Citrus Fruit - Fresh and Processed Statistical Bulletin 2016. Rome, Italy.

Ferhat M.A., Meklati B.Y., Chemat F. 2007. Comparison of different isolation methods of essential oil from Citrus fruits: Cold pressing, hydrodistillation and microwave 'dry' distillation. Flavour and Fragrance Journal, 22, 494-504.

Fierer, N., Bradford, M.A., Jackson, R.B., 2007. Toward an ecological classification of soil bacteria. Ecology 88, 1354-1364.

Frostegård, A., and Bååth, E., 1996. The use of phospholipid fatty acid analysis to estimate bacterial and fungal biomass in soil. Biology and Fertility of soils 22, 59-65

Frostegård, A., Tunlid, A., Bååth, E., 2011. Use and misuse of PLFA measurements in soils. Soil biology and biochemistry 43, 1621-1625

Gamba, C., Piovanell, C., Papini, R., Pezzarossa, B., Ceccarini, L., Bonari, E., 2005. Soil microbial characteristics and mineral nitrogen availability as affected by olive oil waste water applied to cultivated soil. Communications in soil science and plant analysis 36, 937-950.

Gao, Z., Gao, W., Zeng, S. L., Li, P., and Liu, E. H. (2018). Chemical structures, bioactivities and molecular mechanisms of citrus polymethoxyflavones. Journal of Functional Foods, 40, 498-509.

Giacomo AD, and Mincione B 1994. Gli olii essenziali agrumari in Italia. Laruffa, Reggio, Calabria, 202

Ginestar, C., and Castel, J. R. 1996. Responses of young clementine citrus trees to water stress during different phenological periods. Journal of Horticultural Science 71, 551559.

Gitsopoulos, T.K., Kadoglidou, K., Damalas, C.A. 2017. Miscellaneous cropping systems. In: Korres, N.E., Burgos, N.R., Duke, S.O. (Eds.), WEED CONTROL, 
Gmitter, F., and Hu, X. 1990. The possible role of Yunnan province, China, in the origin of contemporary Citrus species (Rutaceae). Economic Botany 44, 267-277.

Goh, J. X. H., Tan, L. T. H., Goh, J. K., Chan, K. G., Pusparajah, P., Lee, L. H., Goh, B. H. 2019. Nobiletin and derivatives: Functional compounds from citrus fruit peel for colon cancer chemoprevention. Cancers, 11, 867.Gómez-Cadenas, A., Tadeo, F. R., Talon, M., Primo-Millo, E. 1996. Leaf abscission induced by ethylene in water stressed intact seedlings of Cleopatra mandarin requires previous abscisic acid accumulation in roots. Plant Physiology 112, 401-408.

Gonzalvez, A., Armenta, S., de la Guardia, M. (2009). Trace-element composition and stable-isotope ratio for discrimination of foods with protected designation of origin. Trends in Analytical Chemistry 28, 1295-1311.

van Gorkom, G. N., Lookermans, E. L., Van Elssen, C. H., Bos, G. M. 2019. The effect of vitamin $\mathrm{C}$ (ascorbic acid) in the treatment of patients with cancer: a systematic review. Nutrients, 11, 977.

Grana, E., Díaz-Tielas, C., M Sanchez-Moreiras, A., J Reigosa, M. 2012. Mode of action of monoterpenes in plant-plant interactions. Current Bioactive Compounds, 8, 8089.Sustainability, Hazards and Risks in Cropping Systems Worldwide. CRC Press, New Yark, 580-597.

Grosso, C., Coelho, J. A., Urieta, J. S., Palavra, A. M., Barroso, J. G. 2010. Herbicidal activity of volatiles from coriander, winter savory, cotton lavender, and thyme isolated by hydrodistillation and supercritical fluid extraction. Journal of agricultural and food chemistry, 58, 11007-11013.

Guenther, E. 1948. The Essential Oils; D. Van Nostrand: New York,

Heap, I. 2020, March 2. The international herbicide-resistant weed database. Corvallis, OR: International Survey of Herbicide-Resistant Weeds. Online. www.weedscience.org

Henderson, P. 1984. Rare earth element geochemistry. Developments in geochemistry (vol. 2). Amsterdam: Elsevier.

Hmamouchi M. 1999. Les plantes me'dicinales et aromatiques marocaines. Maroc: Imprimerie de $\mathrm{Fe}^{\prime}$ dala Mohammedia. 
http://www.osservatorioacque.it/?cmd=articleandid=75. Synthetic geological map of the sicily region by "Sicilian Region Department of Energy and Public Utilities", section "Water Observatory".

Inouye S, Takahashi M, Abe S. 2009. Inhibitory activity of hydrosols, herbal teas and related essential oils against filament formation and the growth of Candida albicans. Nippon Ishinkin Gakkai Zasshi 50, 243-251,

Isman, M. B. 2000. Plant essential oils for pest and disease management. Crop protection 19, 603-608.

Jastrow, J.D., Amonette, J.E., Bailey, V.L., 2007. Mechanisms controlling soil carbon turnover and their potential application for enhancing carbon sequestration. Climatic Change 80, 5-23.

Jeannot V., Chahboun J., Russell D., Baret P. 2005. Quantification and determination of chemical composition of the essential oil extracted from natural orange blossom water (Citrus aurantium L. ssp. aurantium) International Journal of Aromatherapy 15 , 9497.

Joergensen, R.G., and Brookes, P.C., 1990. Ninhydrin-reactive nitrogen measurements of microbial biomass in $0.5 \mathrm{~m} \mathrm{~K} 2 \mathrm{SO} 4$ soil extracts. Soil biology and biochemistry 22, 1023-1027

Kaur, A., Chaudhary, A., Kaur, A., Choudhary, R., Kaushik, R., 2005. Phospholipid fatty acid - A bioindicator of environment monitoring and assessment in soil ecosystem. Current Science 89, 1103-1112.

Kayikcioglu, H.H., 2012. Short-term effects of irrigation with treated domestic wastewater on microbiological activity of a Vertic xerofluvent soil under Mediterranean conditions. Journal of Environmental Management102, 108-114

Koksal N, Saribas R, Kafkas E, Aslancan H, Sadighazadi S. 2015. Determination of volatile compounds of the first rose oil and the first rose water by hs-spme $/ \mathrm{gc} / \mathrm{ms}$ techniques. African Journal of Traditional, Complementary and Alternative Medicines 12, 145-50. 
Lambert, R. J. W., Skandamis, P. N., Coote, P. J., Nychas, G. J. 2001. A study of the minimum inhibitory concentration and mode of action of oregano essential oil, thymol and carvacrol. Journal of applied microbiology, 91, 453-462.

Lane, A.G., 1983. Removal of peel oil from citrus peel press liquors before anaerobic digestion, Environmental Technology 4, 65-72.

Laudicina, V.A., Badalucco, L., Palazzolo, E., 2011. Effects of compost input and tillage intensity on soil microbial biomass and activity under Mediterranean conditions. Biology and Fertility of Soils 47, 63-70.

Laudicina, V.A., Barbera, V., Gristina, L., Badalucco, L., 2012a. Management practices to preserve soil organic matter in semiarid Mediterranean environment. In Björklund, P.A., Mello, F.V. (Eds.), Soil Organic Matter: Ecology, Environmental Impact and Management. Nova Science Publishers Inc., UK, 39-61.

Laudicina, V.A., Dennis, P.G., Palazzolo, E., Badalucco, L., 2012b. Key biochemical attributes to assess soil ecosystem sustainability, in: Malik, A., Grohmann, E. (Eds.), Environmental Protection Strategies for Sustainable Development. Springer Netherlands, Dordrecht, 193-227.

Laudicina, V.A., Palazzolo, E., Badalucco, L., 2013. Natural organic compounds in soil solution: potential role as soil quality indicators. Current Organic Chemistry 17, 2991-2997.

Laveuf, C., and Cornu, S. 2009. A review on the potentiality of rare earth elements to trace pedogenetic processes. Geoderma 154, 1-12.

Li, S., Pan, M. H., Lo, C. Y., Tan, D., Wang, Y., Shahidi, F., Ho, C. T. 2009. Chemistry and health effects of polymethoxyflavones and hydroxylated polymethoxyflavones. Journal of Functional Foods, 1, 2-12.

Liang, T., Shiming, D., Wenchong, S., Chong, Z., Zhang, C., Haitao, L. 2008. A review of fractionations of rare earth elements in plants. Journal of Rare Earths 26, 7-15.

Liebman, M., and Davis, A.S. 2000. Integration of soil, crop and weed management in lowexternal-input farming systems. Weed Research 40, 27-47. 
Lin C.C., Yang C.H., Wu P.S., Kwan C.C., Chenl Y.S. 2011 Antimicrobial, antityrosinase and antioxidant activities of aqueous aromatic extracts from forty-eight selected herbs. Journal of Medicinal Plants Research 5, 6203-6209.

Lovatt, C. J., Zheng, Y., Hake, K. D. 1988. Demonstration of a change in nitrogen metabolism influencing flower initiation in Citrus. Israel Journal of Botany 37, 181188.

Luykx, D. M. A. M., and Van Ruth, S. M., 2008. An overview of analytical methods for determining the geographical origin of food products. Food Chemistry 107, 897-911.

Ma, X., Liu, M., Li, Z., 2015. Changes in microbial properties and community composition in acid soils receiving wastewater from concentrated animal farming. Applied Soil Ecology 90, 11-17

Maatallah, S., Nasri, N., Hajlaoui, H., Albouchi, A., Elaissi, A. 2016. Evaluation changing of essential oil of laurel (Laurus nobilis L.) under water deficit stress conditions. Industrial Crops and Products, 91, 170-178.

Malik, A.A., Chowdhury, S., Schlager, V., Oliver, A., Puissant, J., Vazquez, P.G., Jehmlich, N., von Bergen, M., Griffiths, R.I., Gleixner, G., 2016. Soil fungal:bacterial ratios are linked to altered carbon cycling. Frontiers in microbiology, 7, 1247

Marchionni, S., Buccianti, A., Bollati, A., Braschi, E., Cifelli, F., Molin, P., ... and Conticelli, S. 2016. Conservation of $87 \mathrm{Sr} / 86 \mathrm{Sr}$ isotopic ratios during the winemaking processes of 'Red'wines to validate their use as geographic tracer. Food chemistry, 190, 777-785.

Marmulla, R., and Harder, J. 2014. Microbial monoterpene transformations - a review. Frontiers in microbiology, 5, 346.

Martino, L.D., Mancini E., De Almeida, L.F.R., Feo V.D. 2010. The antigerminative activity of twenty-seven monoterpenes. Molecules 15, 6630-6637.

Mehmet, A., Mavi, K., Uremis, I., 2016. Bio-herbicidal effects of oregano and rosemary essential oils on germination and seedling growth of bread wheat cultivars and weed. Romanian Biotechnology Letters. 21, 11149-11159. 
Mechri, B., Echbili, A., Issaoui, M., Braham, M., Elhadj, S.B., Hammami, M., 2007. Short term effects in soil microbial community following agronomic application of olive mill wastewaters. Applied Soil Ecology 36, 216-223.

Melero, S., Madejón, E., Ruiz, J. C., Herencia, J. F.2007. Chemical and biochemical properties of a clay soil under dryland agriculture system as affected by organic fertilization. European Journal of Agronomy 26, 327-334.

Meli S.M., Badalucco L., English L. C., Hopkins D. W. 2003. Respiratory responses of soil micro-organisms to simple and complex organic substrates. Biology and Fertility of Soils 37, 96-101.

Misra, G., and Pavlostathis, S. G. 1997. Biodegradation kinetics of monoterpenes in liquid and soil-slurry systems. Applied Microbiology and Biotechnology, 47, 572-577.

Mojiri, A., 2011. Effects of municipal wastewater on physical and chemical properties of saline soil. J. Biol. Environ. Sci. 5, 71-76

Moore-Kucera, J., and Dick, R.P., 2008. Application of 13C-labelled litter and root materials for in situ decomposition studies using phospholipid fatty acids. Soil Biology and Biochemistry 40, 2485-2493

Mostafavi, A., and Afzali, D. 2009. Chemical composition of the essential oils of Rosa damascene from two different locations in Iran. Chem. Nat. Compd., 45, 110-113.

Mulvaney, R.L., 1996. Nitrogen-Inorganic forms. In: Sparks DL (Ed), Methods of Soil Analysis. Chemical Methods. Part 3, pp.1123-1184. SSSA Book Series No. 5. Soil Science Society of America and American Society of Agronomy. Madison, WI, USA

Murphy, K. M., Dawson, J. C., Jones, S. S. 2008. Relationship among phenotypic growth traits, yield and weed suppression in spring wheat landraces and modern cultivars. Field Crops Research, 105, 107-115.

Mutlu, S., Atici, Ö., Esim, N., Mete, E. 2011. Essential oils of catmint (Nepeta meyeri Benth.) induce oxidative stress in early seedlings of various weed species. Acta Physiologiae Plantarum, 33, 943-951.

Navarro, A. R., Lopez, Z. O., Maldonado, M. C. 2008. A pilot plant for the treatment of lemon industry wastewater. Clean Technologies and Environmental Policy 10, 371375. 
Nagy S., and Attaway J.A. 1980. Citrus nutrition and quality. Washington , D.C. : American Chemical Society.

Nelson, D.W., and Sommers, L.E., 1996. Total carbon, organic carbon, and organic matter. In: Sparks, D.L. (Ed.), Methods of Soil Analysis. Part 3, Chemical Methods. SSSA Book Series No 5. SSSA and ASA, Madison, WI, . 961-1010.

Nishida, N., Tamotsu, S., Nagata, N., Saito, C., Sakai, A. 2005. Allelopathic effects of volatile monoterpenoids produced by Salvia leucophylla: inhibition of cell proliferation and DNA synthesis in the root apical meristem of Brassica campestris seedlings. Journal of chemical ecology 31, 1187-1203.

OECD, 2017. Water Risk Hotspots for Agriculture, OECD Studies on Water, OECD Publishing, Paris.

Oerke, E. C. 2006. Crop losses to pests. The Journal of Agricultural Science 144, 31-43.

Palazzolo, E., Laudicina, V., Germana, M. 2013. Current and potential use of citrus essential oils. Current Organic Chemistry 17, 3042- 3049.

Papetti, P., Costa, C., Antonucci, F., Figorilli, S., Solaini, S., Menesatti, P., 2012. A RFID web-based info tracing system for the artisanal Italian cheese quality traceability. Food Control 27, 234-241.

Paul, E.A., 2015. Soil Microbiology, Ecology and Biochemistry, 4th ed. Academic Press, Oxford, UK. 598.

Peres, B., Barlet, N., Loiseau, G., Montet, D., 2007. Review of the current methods of analytical traceability allowing determination of the origin of foodstuffs. Food Control 18, 228-235.

Petropoulos, S.A., Akoumianakis, C.A., Passam, H.C., 2008. The effect of nitrogenfertilization on plant growth and the nitrate content of leaves and roots of parsley in the mediterranean region. Scientia horticulturae118, 255-259.

Pezzolla, D., Marconi, G., Turchetti, B., Zadra, C., Agnelli, A., Veronesi, F., ... and Gigliotti, G. 2015. Influence of exogenous organic matter on prokaryotic and eukaryotic microbiota in an agricultural soil. A multidisciplinary approach. Soil Biology and Biochemistry 82, 9-20. 
Piotrowska, A., Iamarino, G., Rao, M.A., Gianfreda, L., 2006. Short-term effects of olive mill waste water (OMW) on chemical and biochemical properties of a semiarid Mediterranean soil. Soil Biology and Biochemistry 38, 600-610.

Pisciotta, A., Tutone, L., Saiano, F. 2017. Distribution of YLOID in soil-grapevine system (Vitis vinifera L.) as tool for geographical characterization of agro-food products. A two years case study on different grafting combinations. Food chemistry 221, 12141220.

Plaza, C., Garcia-Gil, J.C., Polo, A., 2007. Microbial activity in pig slurry-amended soils under aerobic incubation. Biodegradation 18, 159-165.

Ranganna S., Govindarajan V.S., Ramana K.V.R. 1983. Citrus fruits-varieties, chemistry, technology, and quality evaluation. Part II. Chemistry, technology, and quality evaluation. A. Chemistry. Critical Reviews in Food Science and Nutrition 18, 313-86.

Ramana K.V.R., Govindarajan V.S., Ranganna S. 1981. Citrus fruits-varieties, chemistry, technology, and quality evaluation. Part I: Varieties, production, handling, and storage. Critical Reviews in Food Science and Nutrition 15, 353-431.

Reddy, K. R., Hodges, H. F., Kimball, B. A. 2000. Crop ecosystem responses to climatic change: Cotton. Climate change and global crop productivity. CABI Publishing, Wallingford, UK, 161-187.

Reid, L. M., O’Donnell, C. P., Downey, G. 2006. Recent technological advances forthe determination of food authenticity. Trends in Food Science and Technology 17, 344353.

Riffaldi, R., Saviozzi, A., Levi-Menzi, R., 1996. Carbon mineralization kinetics as influenced by soil properties. Biology and Fertility of Soils 22, 293-298.

Rochette, P., Angers, D.A., Cote, D., 2000. Soil carbon and nitrogen dynamics following application of pig slurry for the 19th consecutive year: I. carbon dioxide fluxes and microbial biomass carbon. Soil Science Society of American Journal 64, 1389-1395

Romagni J. G., Allen S. N., Dayan F.E. 2000. Allelopathic effectsof volatile cineoles on two weedy plant species. Journal of Chemical Ecology 26, 303-313. 
Roohi, M., Riaz, M., Arif, M.S., Shahzad, S.M., Yasmeen, T., Riaz, M.A., Tahir, S., Mahmood, K., 2016. Varied effects of untreated textile wastewater onto soil carbon mineralization and associated biochemical properties of a dryland agricultural soil. Journal of Environmental Management 183, 530-540.

Samczyński, Z., Dybczyński, R. S., Polkowska-Motrenko, H., Chajduk, E., Pyszynska, M., Danko, B., ... and Kalbarczyk, P. (2012). Two new reference materials based on tobacco leaves: certification for over a dozen of toxic and essential elements. The Scientific World Journal, 2012.

Schlegel, H.G., 1992. General Microbiology. Cambridge University Press, Cambridge, UK, 673.

Schloter, M., Dilly, O., Munch, J.C., 2003. Indicators for evaluating soil quality. Agriculture, Ecosystems and Environment 98, 255-262.

Scora, R.W. 1975. On the history and origin of Citrus. Bulletin of the Torrey Botanical Club , 369-375.

Scrivanti, L. R., Zunino, M. P., Zygadlo, J. A. 2003. Tagetes minuta and Schinus areira essential oils as allelopathic agents. Biochemical systematics and ecology, 31, 563572.

Settanni, L., Palazzolo, E., Guarrasi, V., Aleo, A., Mammina, C., Moschetti, G., Germanà, M.A., 2012. Inhibition of foodborne pathogen bacteria by essential oils extracted from citrus fruits cultivated in Sicily. Food Control. 26. 326-330

Sinclair, W. B. 1961. “The Orange.” University of California, Division of Agricultural Sciences, Berkeley .

Singh H.P., Batish D.R., Kohli R.K.. 2002a. Allelopathic effectsof two volatile monoterpenes against bill-goat weed (Ageratum conyzoides L.). Crop Protection 21, $347-350$.

Singh H.P., Batish D.R., Kaur S., Ramezani H., Kohli R. K. 2002b. Comparative phytotoxicity of four monoterpenes against Cassia occidentalis. Annals of Applied Biology 141, 111-116. 
Singh, H.P., Batish, D.R., Kaur, S., Kohli, R.K., Arora, K. 2006. Phytotoxicity of the volatile monoterpene citronellal against some weeds. Zeitschrift für Naturforschung C, 61, 334-340.

Soares, M., and Rousk, J., 2019. Microbial growth and carbon use efficiency in soil: Links to fungal-bacterial dominance, SOC-quality and stoichiometry. Soil Biology and Biochemistry 131, 195-205.

Southwick, S. M., and Davenport, T. L. 1986. Characterization of water stress and low temperature effects on flower induction in citrus. Plant physiology 81, 26-29.

Tamburino, V., Zema, D.A., Zimbone, S.M., 2007. Depuration Processes of Citrus Wastewater. In Proceedings of the 3rd International Symposium of CIGR Section VI 'Food and Agricultural Products, Naples, Italy, 24-26 September 2007.

Thevendiraraj, S., Klemel', J., Paz, D., Aso, G., Cardenas, G.J., 2003. Water and wastewater minimisation study of a citrus plant. Resources, Conservation and Recycling 37, 227-250.

Tscherko, D., Hammesfahr, U., Marx, M.C., Kandeler, E., 2004. Shifts in rizosphere microbial communities and enzyme activity of Poa alpine across an alpine chronosequence. Soil Biol. Biochem. 36, 1685-1698.

Tudela, D., and Primo-Millo, E. 1992. 1-Aminocyclopropane-1-carboxylic acid transported from roots to shoots promotes leaf abscission in Cleopatra mandarin (Citrus reshni Hort. ex Tan.) seedlings rehydrated after water stress. Plant Physiology 100, 131-137.

Tyler, G., 2004. Rare earth elements in soil and plant systems: A review. Plant Soil 267, 191-206Tworkoski, T., 2002. Herbicide effects of essential oils. Weed Science. 50, $425-431$.

Vacante, V., and Calabrese, F. (Eds.). 2009.Citrus: trattato di agrumicoltura. Edagricole.

Vaid, S., Batish, D.R., Singh, H.P., Kohli, R.K. 2010. Phytotoxic effect of eugenol towards two weedy species. The Bioscan 5, 339-341.

Vaid, S., Batish,D.R., Singh, H.P.,Kohli, R.K. 2011. Phytotoxicity of Limonene against Amaranthus viridis. The Bioscan 6, 163-165. 
Vance, E.D., Brookes, P.C., Jenkinson, D.S., 1987. An extraction method for measuring soil microbial biomass C. Soil biology and biochemistry 19, 703-707

Vaughn, S.F., and Spencer, G.F. 1993. Volatile monoterpenes as potential parent structures for new herbicides. Weed Science, 41, 114-119.

Vaux, H. J., JR. and Pruitt, W. O. 1983. Crop-water production functions. Advances in Irrigation 2, 61-99.

Verdeguer, M., Blázquez, M.A., Boira, H. 2009. Phytotoxic effects of Lantana camara, Eucalyptus camaldulensis and Eriocephalus africanus essential oils in weeds of Mediterranean summer crops. Biochemical Systematics and Ecology, 37, 362-369.

Voet, D., Voet, J. G., Campbell, P.N. 1995. Biochemistry (2nd edn). Trends in Biochemical Sciences 20, 330.

Vystavna, Y., Rätsep, R., Klymenko, N., Drozd, O., Pidlisnyuk, V., and Klymenko, M. 2015. Comparison of soil-to-root transfer and translocation coefficients of trace elements in vines of Chardonnay and Muscat white grown in the same vineyard. Scientia Horticulturae 192, 89-96.

Wardle, D.A., and Ghani, A., 2018. A tale of two theories, a chronosequence and a bioindicator of soil quality. Soil biology and biochemistry 121, A3-A7

Waring, B.G., Averill, C., Hawkes, C.V., 2013. Differences in fungal and bacterial physiology alter soil carbon and nitrogen cycling: insights from meta-analysis and theoretical models. Ecology Letters 16, 887-894.

Webber, H.J. 1967. History and development of the Citrus industry. In The Citrus Industry (eds. Reuther, W. et al.) Chap. 1, 1-39 (University of California Press)

Wedepohl, K. H. 1995. The composition of the continental crust. Geochimica et Cosmochimica Acta 59, 1217-1232.

Weil, R., and Brady, N., 2017. The Nature and Properties of Soils. 15th edition. Pearson International, US.

Weston, L.A., and Duke, S.O. 2003. Weed and crop allelopathy. Critical Reviews in Plant Sciences 22, 367-389. 
Wu, Y., Ding, N., Wang, G., Xu, J., Wu, J., Brookes, P.C., 2009. Effects of different soil weights, storage times and extraction methods on soil phospholipid fatty acid analyses. Geoderma 150, 171-178.

Yang, X. C., and Sachs, F. 1989. Block of stretch-activated ion channels in Xenopus oocytes by gadolinium and calcium ions. Science, 243(4894), 1068-1071.

Zelles, L., 1997. Phospholipid fatty acid profiles in selected members of soil microbial communities. Chemosphere 35, 275-294.

Zema, D.A., Andiloro, S., Bombino, G., Tamburino, V., Sidari, R., Caridi, A. 2012. Depuration in aerated ponds of citrus processing wastewater with a high concentration of essential oils. Environmental technology (United Kingdom) 33, $1255-1260$.

Zhao, Y., Zhang, B., Chen, G., Chen, A., Yang, S., Ye, Z. 2013. Tracing the geographic origin of beef in china on the basis of the combination of stable isotopes and multielement analysis. Journal of Agriculture and Food Chemistry 61, 7055-7060. 